\title{
Uneasy Relationship: The Dilemma of Liberal State and New Citizens
}

\author{
By \\ Raffi Markarian
}

A Thesis Submitted to the School of Graduate Studies

In Partial Fulfillment of the Requirements

For the Degree

Doctor of Philosophy

Carleton University

(C) by Raffi Markarian, March 2010 


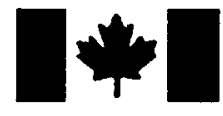

\author{
Library and Archives \\ Canada \\ Published Heritage \\ Branch \\ 395 Wellington Street \\ Ottawa ON K1A ON4 \\ Canada
}

Bibliothèque et

Archives Canada

Direction du

Patrimoine de l'édition

395, rue Wellington

Ottawa ON K1A ON4

Canada
Your file Votre reférence
ISBN: 978-0-494-67868-8
Our file Notre reférence
ISBN: $978-0-494-67868-8$
NOTICE:

The author has granted a nonexclusive license allowing Library and Archives Canada to reproduce, publish, archive, preserve, conserve, communicate to the public by telecommunication or on the Internet, loan, distribute and sell theses worldwide, for commercial or noncommercial purposes, in microform, paper, electronic and/or any other formats.

The author retains copyright ownership and moral rights in this thesis. Neither the thesis nor substantial extracts from it may be printed or otherwise reproduced without the author's permission.
AVIS:

L'auteur a accordé une licence non exclusive permettant à la Bibliothèque et Archives Canada de reproduire, publier, archiver, sauvegarder, conserver, transmettre au public par télécommunication ou par l'Internet, prêter, distribuer et vendre des thèses partout dans le monde, à des fins commerciales ou autres, sur support microforme, papier, électronique et/ou autres formats.

L'auteur conserve la propriété du droit d'auteur et des droits moraux qui protège cette thèse. $\mathrm{Ni}$ la thèse ni des extraits substantiels de celle-ci ne doivent être imprimés ou autrement reproduits sans son autorisation.
In compliance with the Canadian Privacy Act some supporting forms may have been removed from this thesis.

While these forms may be included in the document page count, their removal does not represent any loss of content from the thesis.
Conformément à la loi canadienne sur la protection de la vie privée, quelques formulaires secondaires ont été enlevés de cette thèse.

Bien que ces formulaires aient inclus dans la pagination, il n'y aura aucun contenu manquant. 


\title{
Uneasy Relationship: The Dilemma of the Liberal State and New Citizens
}

\begin{abstract}
This dissertation addresses one of the most compelling challenges facing liberal democracies today, namely integrating new citizens. For the past 150 years different generations of newcomers have integrated successfully into Western democratic systems. Today however, there are growing signs that this historic successful integration is not happening as smoothly as before. While the principles of liberal democratic systems encourage full integration of diverse communities in their societies, the empirical studies consistently and persistently show an increasing portion of new immigrants remaining socially, politically, and economically marginalized from the main stream society. By focusing on the case of Canada, this dissertation focuses on recent changes in the structure and behaviour of different players, the state, the new immigrants and civil society. The protagonists of the story narrated here therefore are: the new citizens and the dilemma they face; the liberal state and its transformation in the face of globalization; and the civil society, both as the scene for the playing out of the interaction between the first two, as well as the guardian of social and political cohesion. These changes have resulted in a more complicated and difficult relationship between them, subsequently making the integration of newcomers more difficult than before.
\end{abstract}

While others trace the integration of newcomers in Western societies mainly through economic, social and cultural analysis, the main focus here is on the relationship and the dynamic interactions among the main players. Robust and dynamic interactions among them give rise to stronger social cohesion, political stability and stronger sense of 
self-worth and substantial citizenship. The big claim of this dissertation is that the recent changes in the definition, features and objectives of the main stakeholders of the immigration process may lie at the heart of the problematic of integrating new citizens in the liberal democratic systems. I present a detailed quantitative and qualitative analysis of these changes in order to explain the problem, and offer a multi-dimensional reading of "Multiculturalism" as a practical measure to soften the process of integration. Instead of treating multiculturalism as a policy, one should see it as a way of thinking and doing. Such approach would generate three interconnected principles of commitment, recognition and inclusion, and in turn, help main players reach out to the other side and develop a long lasting relationship; one that helps state and society enjoy stronger cohesion and the newcomers a stronger sense of belonging. 


\section{Acknowledgements}

It is a pleasure to thank the many people who made this thesis possible.

I would like to gratefully and sincerely thank Prof. Farhang Rajaee for his guidance, understanding, patience, and most importantly, his friendship. Without his constant guidance and paramount mentorship, I could not have finished my Ph.D. He was always there to meet and talk about my ideas, to proofread and mark up my papers and chapters, and to ask me good questions to help me think through my problems. I consider it my fortune to be his friend, and to have worked with him.

I am also grateful to the members of my committee for taking the time to guide me through my dissertation. I would like express my appreciation to Prof. Tom Darby and Prof. Peter Swan for their insightful remarks and support. I would also like to acknowledge the members of the evaluation committee, Prof. Douglas Mogach and Prof. Warren Thorngate for their valuable guidance, and frank, critical comments.

This work has benefited from various researchers. Special mention goes to the Metropolis project, whose publications served as the starting point for this thesis.

I would also like to thank Angela Arnet Connidis for proof reading the text and providing editorial comments.

Finally, I would like to thank my family. My wife, Anahid, has been the bedrock upon which the past fifteen years of my life have been built. My always positive and joyful children, Vana and Annie, have been a powerful source of inspiration and energy. I thank my parents, Khoodan and Nazik (Haygoui), for their faith in me and allowing me to be as ambitious as I wanted. 


\section{Table of Contents}

Abstract ii

Acknowledgments iv

Table of contents $\quad \mathrm{V}$

$\begin{array}{lr}\text { Introduction } & 1-22\end{array}$

Chapter one: Theoretical Context 23-63

Citizenship Dimensions and Their Evolution; 29

Chapter Two: Problems $\quad$ 64-125

The Problematic of Immigrant's Economic Integration; 66

The Problematic of Immigrant's Political Integration; 90

The Problematic of Immigrant's Social Integration; 107

Chapter Three: Characteristics of the New Immigrant

Historical Patterns and Policies; 127

Immigrant's Destination; 144

Demographic Characteristics of the New Immigrant; 153

$\begin{array}{ll}\text { Education; } & 160\end{array}$

Religion; 163

Language; 166

Chapter Four: Transformation of the Liberal State 178-207

Welfare State \& Workfare State; 178

The Great Transformation; 189

Chapter Five: Shrinking Civil Society 208-238

The Idea of Social Capital; $\quad 219$

Immigrants Social Capital; 228

$\begin{array}{lr}\text { Conclusion } & 239-259\end{array}$

$\begin{array}{lr}\text { Bibliography } & \text { 260-297 }\end{array}$ 


\section{Uneasy Relationship: The Dilemma of Liberal State and New Citizens}

\section{Introduction:}

With virtually one in five $(19.8 \%)$ of its total population foreign-born in 2006 , Canada has one of the largest proportions of foreign-born citizenry in the world. In comparison to other Western liberal states, $12.9 \%$ of the population in the United States is foreign -born, $12.4 \%$ in Sweden, $9.7 \%$ in the United Kingdom, and $8.1 \%$ in France, with only Australia boasting a larger concentration (23.8\%) (OECD 2007, 330). The 2006 Canadian census revealed that between 2001 and 2006, Canada's foreign-born population increased by $13.6 \%$. This was four times higher than the growth rate of $3.3 \%$ for the Canadian-born population during the same period (Statistics Canada 2007a). With over 150 years of experience with large scale immigration, Canada and other major immigrant receiving countries in the West, such as United States and Australia, pride themselves in their historical success of integrating foreign born immigrants. In the last 150 years, different generations of new comers have integrated successfully into the existing political system, just as they have integrated economically and socially, and have contributed enormously to the political, economic, and cultural development of their adopted new country.

Today, however, there are growing signs that this historic prototype of successful integration of new comers in Western societies is at risk. While the principles of Western democratic systems encourage the full integration of diverse communities in their societies, the empirical studies consistently and persistently show an increasing portion of 
new immigrants remain socially, politically, and economically marginalized from the main stream society. For example, a recent study by the Institute for Research on Public Policy (IRPP) discloses that newly arrived visible-minority ${ }^{1}$ immigrants are slower to integrate into Canadian society than their white, European counterparts. They are less likely to identify themselves as "Canadian" and report more incidents of discrimination (Reitz and Banerjee 2007, 490). The 2002 Ethnic Diversity Survey (EDS) by Statistics Canada found that children of visible-minority immigrants exhibit a more profound sense of exclusion than their parents. These newcomers and their offspring identify themselves less as Canadians, trust their fellow citizens less, and are less likely to vote in comparison to the white immigrants from Europe.

A broad review of literature focusing on this issue reveals that, while there is a massive literature on the issues related to demographic and economic drivers of immigration and the integration of immigrants, little has been done to study the interaction of these two compelling factors in political science. Research on immigrant related issues in other disciplines often fails to present a thorough analysis of all the players and their role in the success or failure of the integration process of immigrants. Particularly, they fail to specify why the outcome of immigrants' integration process varies over time, in different spaces and for different immigrant groups.

In these studies, the common way to analyze the success of an immigrant's integration is measured by the economic and social outcomes of the process. My focus, however, is mainly on the process itself. I argue that political factors namely the

\footnotetext{
${ }^{1}$ The employment equity act uses "Visible Minority" to refer to a non-Caucasian in race or nonwhite in colour. Under the Act, an Aboriginal person is not considered a Visible Minority. (Source: http://www.statcan.ca/english/concepts/definitions/vis-minorit.htm)
} 
deliberate decision of the main players to get involved or refrain from the integration process, primarily affects the outcome of the immigrant's integration process. Instead of concentrating on social and economic factors, I address the role of major political factors, especially the key players and their relationships in this process. The main claim of this dissertation is that the recent changes in the definition, features and objectives of the main stakeholders of immigration process may lie at the heart of the problematic of integrating new citizens in the liberal democratic systems. By the main stakeholders, I mean: the new citizens, the state, and civil society where the interaction between the first two finds expression. The heroes of the story narrated here, therefore are: (1) the new citizens and the dilemma they face; (2) the liberal state and its transformation in the face of globalization, and (3) civil society, both as the scene for the playing out of interaction between the first two, as well as the guardian of social and political cohesion.

The main goal of this dissertation is to explain how recent changes in the structure and behaviour pertaining to these players have resulted in more complicated and difficult relationship between them, subsequently making the integration of newcomers more challenging and difficult than before.

\section{Approach and Method}

In terms of method, the researcher will use the latest lines of inquiry that are being pursued in regard to both theoretical and empirical analysis of the liberal state and the new citizen interaction.

The first line of research involves an overview of relevant theoretical approaches. Since a large part of research on immigration related issues has been done in disciplines 
other than political science, my approach is multi-disciplinary so I can engage thinkers outside of the discipline of political science. In addition to the review of immigration related arguments in other disciplines, such as economics, sociology and psychology, in different parts of my study I draw upon different theoretical schools of thought including liberalism (John Rawls); communitarian (Taylor \& Carens); cosmopolitan (Nussbaum and Held); republican (Michael Sandel); and liberal culturalism (Barry and Kymlicka). In my review of these theories, I will show why the integration process of the new immigrants has not been fully addressed by these theorists.

To examine these theories and present my arguments, I engage in a second line of research, which is empirical. There are two aspects to this. The first is to assemble relevant data sets on the integration of immigrants in Western democracies, particularly Canada. Several of the principle academics have done extensive research in this area and have gained considerable experience in undertaking both cross-country and single country data collection. In addition to the findings of latest censuses, I employ the results of a data from Statistics Canada's Ethnic Diversity Survey (EDS) and Longitudinal Survey of Immigrants to Canada (LSIC). These surveys, conducted in 2002 and 2003, are the best source of information on the integration of minorities yet produced in Canada. Their large sample permits analysis of specific minority groups and of the emerging Canadian-born generation of minorities. Linked to this is the empirical analysis of the data sets. In addition to the analysis of the above mentioned quantitative data sets, the research involves detailed qualitative analysis of historical events. Traditionally, one of the criticisms of quantitative research was its "snapshot" character, making it less effective for studying the dynamics of social change. Accordingly, in this research, the 
interest in prediction and in statistical association of variables at a single point in time was contrasted with the attention to process and "historical causality" in qualitative research.

\section{Organization of Chapters}

The changing nature of international immigration to North America and Western Europe has caused a dilemma for liberal states expressed in the following question: How to accommodate, incorporate and socialize the new citizens? Historically, migration to and from these countries was mainly internal, i.e. among the same cultural, religious and ethnic groups. A variety of factors, such as the breakdown of the colonial system and the intensified need for labour, led to gradual changes in immigration patterns and, in turn, policies that opened the way for the arrival of the so called 'visible minorities'. To focus on our case study here, the shift toward non-European sources of immigrants to Canada after the late 1960 s was marked by all censuses after 1971 . Immigrants arriving before 1970 were overwhelmingly from Europe or the United States. Of those arriving in the 1960 s or before, only 10.2 percent were racial or visible minorities (based on 2001 Census data). However, this figure rose dramatically to 51.8 percent for 1970 s arrivals, 65.4 percent for 1980 s arrivals and nearly 75 percent for 1990 s arrivals. As a result, as noted before, racial or visible minorities have grown from constituting less than 1 percent of the population in 1971 to 16 percent in 2006. According to 2006 census data, the number of visible minorities skyrocketed by 27 percent between 2001 and 2006, more than five times the previous increase of 5.4 per cent. The sharp growth in the visible minority population was largely due to the fact that more than three-quarters of new 
immigrants to Canada since 2001 were visible minorities. A recent Statistics Canada study has projected that by 2017 racial minorities will make up 20 percent of the Canadian population, when the country turns 150 years old.

The increasing diversity of migrants' ethnic backgrounds and of the migration channels used, often require governments of host countries to strike a delicate balance between two pressing realities. At one level, the economic and labour needs arising from global economy push liberal governments to open their doors to more immigrants. At another level, social, cultural, and political imperatives of the society for cohesion and social order press for attention to the integration of new comers and some degree of restrictions on international immigration. In general, the interaction between these two compelling factors has resulted in a combination of policies and programs aimed at both controlling and encouraging international immigration and, at the same time, facilitating the integration of new comers into the main current of society. However, in spite of these governmental policies and programs, as well as other attempts by non-governmental organizations, the latest findings indicate not progress, but regression in the integration of new immigrants in Western democracies.

This dissertation addresses three sets of questions. First, what main challenges do liberal states face in accommodating new citizens? Second, why is the integration of new immigrants in Western democracies getting more complicated and difficult daily? And, in the face of crisis over existing policies of integration, what policy alternative is there for the liberal states to pursue? In a way, these questions form the main parts of the dissertation. Five main chapters address these questions. 


\section{Chapter 1: Theoretical Context: citizenship dimensions and their evolution}

By critically reviewing the relevant theoretical approaches, I will contextualize my theoretical approach in chapter one. I start by a critical review of neo-classical and neoinstitutionalist approaches, which dominate immigration studies in economics and sociology. By critically analyzing these two approaches, I illustrate how both these approaches fail to explain why the outcome of the interaction between the three main players of immigration process (Liberal state, new citizen and public sphere) varies over time, in different spaces, in different states, and for different migrant groups. While both approaches measure the success of liberal states in integrating new comers through the assessment of economic and social factors, I argue that political factors are of primary importance, and shift the focus to the nature and behavior of the three main political players.

A cursory glance at immigration related studies in political theory shows that this issue has been addressed through a focus on ethno-cultural diversity, minority rights, cultural pluralism and its implications for citizenship and national identity in the liberal systems. Therefore, since most political philosophers draw on theories of citizenship to discuss ethno-cultural diversity and immigration related issues, I critically analyze the evolution of these theories in last couple of centuries. My main goal will be to give a compressed review of the debates so far, and explain what is missing in these debates with regard to immigrants' integration. All the way through, I will explain how major schools of thought, including classic liberalism, cosmopolitan, communitarian and cultural pluralist, fall short of explaining the problematic of immigrants' integration in the liberal system. 
I make three main arguments, which have not been addressed appropriately in these debates. First, that citizenship should be conceptualized as a dynamic process between the individual immigrant and the state, as well as one of between market and employment relations, neighborhoods, communities and households. Second, the legal status of citizenship does not automatically resolve the question of identity, belonging, and tolerance. And finally, substantial citizenship can be achieved only by the active exercise of rights and participation of immigrants in different aspects of social life. Along the way of my review of citizenship theories, I contend that the successful integration process is influenced by three distinct views, or conceptions held by newcomers. I will refer to these views as a conception of society, a conception of justice, and a conception of role.

The relation between these views may be outlined as follows: In his day to day interaction with state and non-state organizations, as well as other members of society, the new immigrant develops a conception of society and the rules of membership. Based on his/her expectations on the one hand and the outcome of these interactions on the other, immigrants conceptualize these rules and society as just or unjust. This perception of justice, then affects the immigrant's perception of his/her role in the society. Obviously, if society is perceived as just and welcoming there is a much higher possibility of active participation. Otherwise, a negative perception of society will result in a passive membership, at best, or a rebellious attitude, at worse. I believe a good understanding of these conceptions will open the way to understanding how new immigrants define themselves and their belonging to a given new society. This in turn will help us determine why the outcome of the interaction between new immigrants, 
state, and civil society varies over time, in different spaces, among different countries, and for different migrant groups.

\section{Chapter 2: The Problem and It's Significance}

Chapter two concentrates on the issues at the heart of the problem in the relationship between new immigrants and the state. The dilemma of liberal states and new citizens has multiple dimensions. Here the research concentrates on three issues: (1) widening gaps in political participation of new comers compared to the general public, (2) increasing inequality in earnings and economic well-being of the new citizens, and (3) increase in social exclusions based on ethnicity or religion.

The latest surveys and studies show an increasing gap in the political participation of new comers and the main society. The finding of these studies reveal that in comparison to the general public, new comers are less active in a range of political engagement, from voting and electoral politics to community involvement. The available evidence also shows that first and second generation immigrants, particularly among visible minorities, are under-represented in almost all levels of government in liberal democracies. The relative lack of visible minorities in representative bodies is no doubt due to their more recent arrival in a country like Canada. However, visible minorities appear to face more difficulties than previous groups of immigrants when seeking political nomination. In general, regardless of some progress in closing the gap between newcomers' proportion of population and their representation on different levels of government, they still do not carry the political weight they should in light of current demographic trends. The issue of the political representation of these groups is just as 
important for the democratic system as a whole as it is for new citizens themselves. Keeping in mind David Held's definition of democracy ${ }^{2}$ and considering the sharply increasing proportion of new comers to the population of western democracies, the successful political incorporation of new comers becomes more critical to the health of these democracies than before. Obviously, since ethno-cultural differences are wider and interconnections are weaker between new comers and native citizens, insuring democratic process of power sharing is vital to avoid future crisis in liberal democracies.

On the question of economic outcomes, despite attempts by liberal states to ensure the economic success of immigrants, recent studies show substantial deterioration of relative earnings of new citizens in the last 20 years. It appears new citizens, even highly educated ones, often have trouble reaching the average living standards of the society. Noting the significant implications of this problematic on issues such as earnings inequality, poverty dynamics and social cohesion, analyzing the convergence of earnings of immigrants towards those of Canadian-born has been a popular research objective over the last few decades. In Canada, using latest surveys and census results, a series of studies reveal that, overall, the earnings gap between recent immigrants and the Canadian-born population more than doubled between 1980 and 2000 . Interestingly, during the same period, the education and skill levels of new citizens have grown higher than Canadianborn citizens and the gap between these two groups has been widening.

On third question of social cohesion and inclusion, current evidence suggests that liberal state strategies of social inclusion are losing steam and more and more new

\footnotetext{
2 "Democracy presupposes a non-coercive political process in and through which people can pursue and negotiate the terms of their interconnection, interdependence and difference" (Held and McGrew 2007, 242).
} 
citizens face exclusion based on ethnicity and religion. Citing the rise in the number of ethnic enclaves in the margins of major Western cities, as well as emergence of phenomenon like Islamophobia and xenophobic populist right wing parties in Western Europe, a number of commentators have written of the growth of a "culture of mistrust" between new comers and the general public in contemporary Western societies. In a recent interview published in The Globe \& Mail, Allan Gregg, the chairman of the Strategic Council who has written about geographic concentrations of immigrants claimed that "In Canada, we may live in a multicultural society, but the evidence suggests that fewer and fewer of us are living in multicultural neighbourhoods." He added, "We spend so much time congratulating ourselves on tolerance and diversity that we have allowed it to slide into self-segregated communities, isolated along ethnic lines" (Cited in Jimenez 2007).

\section{Causes of the dilemma}

New citizens, to put it bluntly, can be divided into two groups. The first group follows the steps of earlier generations and gradually integrate into social, cultural, and political fabric of Canada, while, the second group seems to be a free rider rather than an active contributor. This second group is only concerned with the benefits of immigration such as access to welfare programs, better schooling for their children, better health system, passport and so on. When it comes to pay their share to secure these systems and to be an active member of the society, the second group is missing in action. In short, they take the rights of citizenship without paying any attention to the responsibilities of citizenship. The review of literature shows that so far there is no theoretical explanation 
for such differences in behaviour. By introducing the three conceptions of society, justice, and the role, my goal in this dissertation is to shed some light on the causes behind this differentiation.

\section{Chapter 3: Characteristics of the New Immigrant}

The empirical and theoretical study of the causes of the dilemma starts by a thorough review of changing patterns of international immigration and new citizens in the third chapter. The focus of this chapter is on the changing patterns of international immigration, where I will outline the latest studies on the origin, destination and distribution of international immigrants. The main focus of the third chapter is on the characteristics of the new citizen, where the available quantitative and qualitative information on demographic, socio-economic, cultural and political characteristics of new comers is analyzed. The goal of this chapter is first to elaborate on the changing patterns of international immigration and its impact on the characteristics of new citizens, and second to critically analyze the shortcomings of neo-classical and neo-institutional theoretical approaches in explaining these patterns.

As stated before, compared with earlier immigrants, who came mostly from JudeoChristian Europe, many new immigrants to North America and Western Europe come from Asia and Africa where traditional religions include Islam, Hinduism, and Buddhism. Just as the ethnic origins and religion of immigrants have changed, so too has their sexual and age distribution. For example, the latest figures provided by Statistics Canada show that the predominance of men among adult immigrants declined as family migration grew and women came to represent slightly over half of immigrants. As well, the majority of 
the immigrants who arrived in Canada during the 1990s were of working age between 25 to 64 years old. They tended to fall into younger working age brackets than the total population because most people migrate when they are young. According to a study in $2001,46 \%$ of the immigrants who arrived in the 1990 s were aged 25 to 44 , compared to $31 \%$ of the total population (Statistics Canada 2003g, 8).

In addition to these changing patterns in the origin and demographics of new comers, the inflow of immigrants increasingly concentrate in large urban areas. Unlike the first half of the $20^{\text {th }}$ century, when most immigrants settled in agricultural and rural areas, in the last few decades a vast majority of migrants settled in large metropolitan areas, especially Toronto, Montreal, and Vancouver. For instance, according to Statistics Canada, in 1981, about $58 \%$ of immigrants who had come to Canada during the previous 10 years lived in the three largest urban centres: Toronto, Vancouver, and Montreal. By 2001 , this proportion had increased to $74 \%$. This had made immigration and multiculturalism a metropolitan phenomenon, rather than a national Canadian issue. On the other hand, international immigrants have become the largest component of national population growth and a major factor in social change in many western countries. According to Statistics Canada, approximately two-thirds of Canada's population growth was due to migratory increase in the last ten years. Although the share of immigration in population growth is lower in the United States and Europe, they still account for about $40 \%$ of population growth in these countries (Statistics Canada 2007, 1).

With this sharply increasing proportion of new comers in the population of Western democracies, the successful political, cultural, social, and economic incorporation of immigrants is critical to the health of these democracies. As noted before, the available 
evidence shows that generally new comers are not politically active and engage less in a range of activities from voting and electoral politics to community activities. The available evidence also shows that first and second generation immigrants, particularly visible minorities, are under-represented in almost all levels of government in liberal democracies. This chapter examines several factors related to new comers' political incorporation that have been ignored so far. I add various immigrant-related variables to a model that controls for individual resources, social incorporation, institutional barriers and contexts of political mobilization. One of the main added variables is the relationship between the country of origin and political behaviour of new citizens. According to a set of studies on this issue, since the vast majority of new comers now arrive from countries with little democratic experience, in general, they are less likely to express opinion and are more sceptical about citizen competence. Moreover, many do not believe that government would listen to them even if they were to speak out (Bilodeau 2004). Overall, the immigrant-related variables introduced in our analysis add significantly to the existing theoretical knowledge on political participation of new comers.

The examination of new comers' characteristics in this study is not limited to their political engagement only. It also includes analysis of economic, cultural, and social features defining the new comers. The economic integration of new comers and their socio-economic well-being is an issue that has been a popular research subject over the last few decades. These studies address key questions like: How well new comers adapt to the host countries' labour market? What are the main barriers to their employment? Do they suffer from persistent disadvantages? What are the major difference between the average earnings of new comers and the majority? Does the earning gap between these 
new comers and the majority widen or narrow over time? Despite attempts by liberal states to ensure the economic success of new immigrants, the latest research findings show a substantial deterioration of relative earnings of new citizens in the last 20 years. According to these studies since late 1980s, many industrial nations including Canada have been subjected to an unexpected surge of poverty known as 'new poverty.' The findings indicate that immigrants in Canada are consistently overrepresented among the new poor; that their poverty rates are particularly high in larger cities, which have larger concentrations of immigrants; and that among immigrants, the poverty rates are higher for visible minorities, who are mostly recent immigrants. One particularly surprising finding was that the second-generation immigrants, who were expected to outperform their parents, had higher poverty rates than their parents.

This deterioration of new comers' earnings is surprising in light of the fact that the large majority of new immigrants have higher skills and education than their native counterparts. This trends will be analyzed in the next chapter under the title of 'Transformation of Liberal State', but suffice it to say here that, due to the restructuring of global capitalism, and in order to maintain competitive advantage and in the worldwide competition for the best brains, Western liberal states have started instituting annual immigration quotas in the last few decades. According to these quotas, the minority of qualified migrants are classified as 'wanted' or 'welcome' migrants and the rest of them, such as refugees, have been perceived as a competitive disadvantage. For example, in Canada since 1990s, economic immigrants with skills and credentials that are in demand have been the target of immigration policies and consequently the share of this group has increased significantly among total new comers. However, the limited ability 
of the Canadian labour market to absorb a large number of highly skilled immigrants, as well as problems regarding transferability of skill sets of these new comers, have resulted to increasing numbers of unemployed or underpaid immigrants in the last few years.

In addition to a critical review of theoretical approaches to economic integration of new comers, a series of analytical models are developed to shed some light on the possible reasons behind these trends. I utilize available data from Statistics Canada and other reliable sources to analyze the three sets of potential contributors, namely the new citizen (Human capital), the environment (Labour market), and the state (Policies and programs). I am especially interested in the effects of market dynamics on immigrants' conception of justice and role. I argue that current market dynamics operate negatively in influencing the development of what I call a pessimistic conception of justice among immigrants. By falling short to provide an equal opportunity for employment and promotion in job markets for a significant portion of new immigrants, the market perpetuates a form of inferiorized notion of membership among those who are kept away from employment chances. This inferiorized notion ultimately shapes a negative conception of justice and then role in society.

Research in socio-cultural characteristics of new comers has been another popular subject in immigration studies during the last couple of decades. According to a number of these studies, new immigrants, because of ethno-religious and cultural differences, do not follow the trajectories of the earlier ones in their socio-cultural integration. Latest research on political and socio- cultural conduct of new comers in Canada reveals that the offspring of visible minority immigrants integrate at a slower rate than the children of white immigrants. They are less likely to identify as "Canadian" and report more 
incidents of discrimination. Generally, these studies conclude that even though a large proportion of newcomers still blend willingly into Canadian society, the signs of visible minority immigrant's cultural marginalization are disturbingly on the rise.

\section{Chapter 4: Transformation of the Liberal State}

The main focus of the fourth chapter is on the transformation of the liberal state in the last few decades. The rise of global economy combined with local pressures has subverted the Canadian political system to function differently, delivering different outcomes, in spite of the superficial continuity of its forms. In addition to global pressures, recent economic and social changes, such as the significant decrease in the growth of productivity, a shift to service employment, aging populations, and changing household formations, have had a great impact on the structure and functions of the liberal state.

The goal of this chapter is to elaborate both on the transformation of the liberal state and on the social, political, and economic consequences of this transformation. A critical review of these changes will help us better understand the negative effects of the demise of welfare systems on the integration of new citizens in liberal democracies. In the first section of this chapter, I review the reform of political institutions and their functions and programs in the face of systemic processes of globalization and domestic transformations. By focusing on Philip G. Cerny's (1997) account of the "competition state" and Bob Jessop's (1993) account of the "Schumpeterian post-national workfare regime", I explain how heavily focusing on the reproduction of economic relations led to less attention on other elements of the relationship between the liberal state and its 
citizens. While the state-citizen relationship is closely bound up with economic relations, it also includes non-economic, more purely political and cultural aspects. I argue that not only the narrow focus on the economic relationship between the liberal state and new citizens did damage other elements of this relationship, it also failed to produce the desired economic outcomes.

One of the main outcomes of the transformation of the liberal state was the adjustment of social and cultural policies on the basis of new frameworks characterized by the domination of neo-liberal economic policies and conservative budget practices. The desire to limit government expenditures and redefine the social and cultural role of the state has resulted in the re-alignment of social programs with economic needs. The end result was huge cuts in health care, old age insurance, housing, vocational training and social and cultural programs, including programs targeted at facilitating the new citizen's integration into society. Even though the Canadian government still insists on the ideal of multiculturalism, in reality the neo-liberal ideas of fiscal responsibility, smaller government and individual self-reliance overshadows the idea of a "caring, sharing and tolerant" multicultural Canada that requires a strong welfare state and greater levels of state involvement in all areas of life.

In this chapter I will review another end result of the transformation of the liberal state: the changing of immigration policies. To reduce the dependency of new comers on social and cultural benefits, most liberal states changed their immigration policies. In view of the fact that new comers with higher skill levels were less dependent on welfare programs, almost all western governments changed their admission policies and made it more difficult for unskilled immigrants to cross their borders. They also changed their 
policies regarding the assignment of legal rights to new comers. Given that 'right to have rights ${ }^{3}$ only makes sense for people who already enjoy membership of a political community, the divergence of these rights in the liberal state had major impacts on the integration of new comers in the society. On the other hand, as noted before in the last few decades and in search for competitive advantages and lower welfare expenses, migration policies have been changed significantly. The effects of these changes on the relationship of the liberal state and its new comers shape the heart of my discussions in this chapter.

\section{Chapter 5: Shrinking Civil society}

In addition to the analysis of the transformation on both sides of the relationship between the liberal state and the new citizen, this study includes a separate chapter to review the public sphere and the mediating institutions that lie between the liberal state and a new comer as an individual. According to a number of scholars, atomization of individuals as well as the loosing ground of civil society and mediating institutions in the last few decades pushed the dilemma of liberal state and new citizens to deeper levels. Mediating institutions such as civic organizations, unions, churches, etc, not only serve as a medium for restoring trust between the individual and the state, they are also a reliable source of social cohesion between different social and cultural groups, including immigrants and the indigenous population. As well, these civic bodies play a significant role in enabling citizens, especially new comers, who have little experience of democracy

\footnotetext{
${ }^{3}$ I borrow this phrase from Hannah Arendt $(1951,267)$.
} 
and freedom to choose, to learn democratic principles, and play an active role in the arena of democracy.

The starting point of my analysis in the fifth chapter is the changing patterns of societal and political behaviours in Western democracies. The first section of this chapter is a broad review of critical works of Robert Putnam (2000) and other scholars like David Riesman (2001), who claim that civic culture in liberal democracies has been diminished dramatically in the second half of twentieth century. The social atomization and the destruction of social interactions following the imposition of neoliberal economic models and lifestyles are the focus of this chapter. The objective is to elaborate on the impacts these trends had on the socio-political integration of new comers. Putnam's argument on the collapse of overlapping social networks and their role on the creation of trust among the members of large social groups is one of the main points to be analyzed in relation to the subject of this dissertation. By focusing on the role of social networks in the creation of social capital, I push Putnam's idea of social capital further. I argue that the development of trust networks among new comers and the general public, which has always been a difficult task, has become more complicated over time. Nowadays, as individuals are more detached from their social networks, it is harder to create the social capital needed in a multicultural society. A number of recent studies conclude that the outcome of the disappearance of social networks, which play a significant role in development of social cohesion among different social and cultural groups, has been the reduced social integration of newcomers.

After reviewing the changing pattern of civic culture in general, I specifically consider new citizens and their social networks. Here, I mainly concentrate on ethnic 
networks and organizations and on what Putnam calls the bonding and bridging function of these institutions. My main point is that key social centres such as churches, sport clubs, and neighbourhood associations that historically played a bridging role between the Canadian-born and immigrants are loosing their importance and no longer play an influential role in the integration process of immigrants. I argue that as a consequence of numerous barriers, particularly lack of socio-economic resources, cultural differences and language, recent immigrants are only involved in social networks and cultural organizations that bond them to their ethnic counterparts and their cultural backgrounds, not with civic organizations that can play a bridging role in connecting them with wider society. I will also argue that since these types of organizations are more homogeneous than heterogeneous, participation in them not only does not lead to more connection to wider society, but quite the opposite, turns immigrants away from playing an active role in the wider society.

\section{Chapter 6: Conclusion}

Based on the arguments of the previous three chapters, it is safe to say that the large-scale migration of visible minorities, as well as the transformation of the state and civil society in last 30 years have reshaped the dynamic of the interaction immigrants have with state and members of host societies. At the very least, it appears that formal citizenship can no longer be seen as some end-point of an integration process, but a starting point. From this basis, it is evident that state, civil society and immigrants themselves should work together to reformulate these relationship to ensure that all main players feel satisfied with the dynamics and outcomes of immigrant's integration process. 
In 1971, the federal government announced its policy of multiculturalism. By recognizing the reality of increasing diversity, this policy challenged all Canadians to accept cultural pluralism. However, multiculturalism itself has been criticized on both theoretical and empirical grounds. Accordingly, my task in the concluding chapter will be twofold: First, to study the theoretical grounds of multiculturalism; and second to empirically analyze the success or failure of these policies.

Based on the findings of this dissertation, my goal is to explain why multiculturalism does not fully address the complex problem of new comers' integration in Canadian society. This chapter however is more than simply a theoretical criticism of multiculturalism. It includes an empirical review of multiculturalism as a policy of accommodation, where I will address the following questions: Is multiculturalism an appropriate solution to this problematic? Is multiculturalism relevant anymore? And, can or should multiculturalism policies be pushed further? These criticisms, as well as arguments by those who still believe in the success of multiculturalism, will be reviewed in this chapter. Finally, the last part of this chapter deals with possible alternative policies. 


\section{Chapter I: Theoretical Context}

The modern Western state has had difficulty in the face of the increasing diversity of migrants while preserving order and sovereignty. Considering the global competition for skilled labour, as well as the low fertility rate in most western societies, the state is under pressure from economic establishments to secure the needed manpower for sustainable economic development. One solution has been to open the door to the flow of foreign labour from a wide range of countries. Nowadays, in most capitalist systems the state encourages international labour migration and minimizes limitations on labour movement and flexibility. At the same time, a hasty process of immigration may have a compromising impact on state security. To sustain its own sovereignty the state is obliged to encourage, promote and uphold political unity and reduce the socio-cultural conflicts by fostering integration of the new immigrants.

Canada does not escape the dilemma between these two compelling factors, and since Canada is, and has always been, a country of immigration, any study in this issue has a great value and importance. A comprehensive review of literature on this issue reveals that, while there is an enormous body of literature on the issues related to demographic and economic drivers of immigration, on the one hand, and integration of immigrants on the other, little has been done to study the interaction of these two compelling factors in political science. The literature on immigrant related issues in other disciplines often fails to present a thorough analysis of all the players and their role in the success or failure of immigration policies. Particularly, they fail to specify why the outcome of interaction between these players varies over time, in different spaces, between different states and for different migrant groups. 
Generally speaking, neo-classical and neo-institutionalist approaches, which dominate the literature on immigration related issues in sociology and economics, are mainly interested in two overlapping themes; the question of why migration policies fail and the complex problems the liberal states faces with growing ethnic and religious diversity in the population. While these two matters are often treated together, in principle they address separate and distinct issues. The first addresses public policy on immigration and the gap between policy objectives and outcomes. It generally seeks to explain why states fail to achieve the goals of their migration policies. The second is concerned with explaining the consequences of immigration and factors linked to social cohesion, citizenship and relationship between the new comer and the liberal state, which is the main subject of study in this dissertation.

The main shortcomings of these two schools are their failure to explain why the outcome of the interaction between three main players (the liberal state, the new citizen and the public sphere) varies over time, in different spaces, in different states, and for different migrant groups. This failure somehow is a result of their narrow theoretical perspective. For example, for the neo-classical writers like Freeman and Hill (2006), the relationship between major players is essentially determined by the relative power weighing of organized interests in a given society. Neoclassical political economy models embrace a form of methodological individualism that attempts to reduce explanation to a series of propositions and deductions about the behaviour of individuals. It implies commitment to a view of human agency as following universal, and thus predictable, patterns of behaviour. The oversimplifying and economic focused nature of this theory has been the object of sustained critiques by neo-institutionalists, such as Jopke (1999) 
and Hollifield (2000). Overall, they reject the possibility of reducing an explanation of the dilemma of new comers' integration to individual agency. Instead, they stress the key role of institutions and beliefs in forming people's behaviour. For them, any explanation of social facts should include an analysis of institutions and how they influence human behaviour. Even though the institutionalist approach is wider than neo-classical method, they still fall short of explaining the problematic of the liberal state and new citizens. Principally, both these approaches come up short in explaining the mixed outcome of the integration process for different individual immigrants.

As an alternative to and, instead of a study of social and economic factors, in this dissertation I address the impact of the changing role of each player, as well as the dynamic of their interaction. The main claim of this dissertation is that the recent changes in the definition, features and objectives of the main stakeholders of the immigration process may lie at the heart of the problematic of integrating new citizens in the liberal democratic systems. By main stakeholders, I mean: the new citizen, the state and civil society where the interaction between the first two finds expression. The main goal of this dissertation is to explain how recent changes in the structure and behaviour of different players have resulted in more complicated and difficult relationships between them, subsequently making the integration of new comers more difficult than ever.

As noted before, while there is a substantial body of research on immigration in economics and sociology, somewhat less attention has been devoted to this crucial issue in political theory. So far, immigration related issues in political theory have been studied in conjunction with issues related to ethno-cultural diversity, minority rights, cultural pluralism and their implications for citizenship and national identity in the liberal 
systems. In fact, in the last twenty years, a number of recent political events and trends throughout the world resulted in an upsurge of interest among political philosophers about the rights of ethno-cultural groups and their citizenship within Western democracies. The resurgence of ethnic backlashes in Eastern Europe, the ongoing threat of separation within several Western democracies, such as Quebec in Canada, Scotland in Britain, Flanders in Belgium, and Basque and Catalonia in Spain, as well as the reappearance and political mobilization of indigenous peoples are a few examples that point to the importance of ethnicity and citizenship rights of minorities. Moreover, the terrorist attacks in United States, Britain, Spain and Netherland, as well as riots in France, Australia and Britain and the nativist backlash against immigrants and refugees in many Western countries awoke an intense interest on the question of cultural pluralism and citizenship in liberal systems.

So far, most political philosophers draw on the theories of citizenship to discuss immigration related issues. My main goal here is to provide a compressed review of the debates thus far, and point out possible shortcomings in these debates regarding naturalized citizens' integration. Through a review of the evolution of different dimensions of citizenship in the last few centuries, I will explore the discourse and debates of social and political theorists on the relationship between the state and the individual in a given liberal democracy. All the way through, I will explain how major schools of thought, including classic liberalism, cultural pluralism, cosmopolitan and communitarian schools of thought come up short in explaining the problematic of immigrants' integration in the liberal system. 
I make three main arguments, which I think have not been addressed appropriately in these debates. First, that citizenship should be conceptualized as a dynamic process between the immigrant individual and the state, as well as market and employment relations, neighborhoods, communities and households. Citizenship is best understood as a balancing of competing interests, demands and concerns, an arena in which relations linking immigrants to the new community, social, and political contexts are continually discussed, reworked, and contested. It is about everyday life and how a new comer understands and negotiates rights and responsibilities, belonging and participation in the new society.

Second, I maintain that the granting of the legal status of citizenship does not automatically resolve the question of identity, belonging and tolerance. When an immigrant has the feeling that, despite having a citizenship paper, she is being treated in everyday life as an outsider - whether due to cultural or religious differences, media representations or state actions- she experiences a 'disjunctive' form of citizenship discussed by Caldeira and Hoston (1999), in which rights and formal aspects of citizenship are extended, even as social and substantive membership are not. When this happens, formal citizenship may be decoupled from belonging and identification with the political community, which is the nation-state.

And finally, substantial citizenship can be achieved only by the active exercise of rights and participation of immigrants in different aspects of social life. As McLaughlin (1992) points out in his explanation of differences between 'minimal' and 'maximal' conceptions of citizenship, a true democracy or political justice can be achieved not by merely passive respect for the law, but by an active exercise of rights. To have a sense of 
membership and feel part of a society does not simply mean that the individual immigrant does not break the law, exploit the system, and harm others. It involves her duty to use her political rights to participate in the political process in order to promote self interest, elevate the public good and hold political authorities accountable. It also includes using her civil, social, and cultural rights to participate in building a lively and just society. The prosperity and stability of a modern democracy depend not only on the justice of the system and the rights its citizens enjoy, but also on the activities and attitudes of citizens in exercising those rights for promoting the general good.

I contend that the successful integration process for immigrants requires, on the part of new immigrants, three distinct views, or conceptions, which I will discuss along with my review of citizenship theories. I will refer to these as a conception of society, a conception of justice, and a conception of role. The conception of society refers to the first requirement of citizenship, which is the recognition of immigrants members of society by the state on the one hand, and immigrants' understanding of the limits of this recognition on the other. To define the conception of justice, I borrow John Rawls (1985) definition of political justice, where he describes it as the fair terms of social cooperation. I utilise this definition to study the way in which immigrants perceive the rules and structures governing their relationship with the state and with other members of the society. And finally, development of immigrants' conception of their role in the new society, and how they characterize their membership in a given political community. My argument about the integration of new immigrants and the role of these three conceptions is as follows. In her day to day life, through interaction with state and non-state organizations, as well as with other members of society, the new immigrant develops a 
conception of society and the rules of membership. Based on expectations, on the one hand, and the outcomes of these interactions on the other, immigrants conceptualize these rules and society as either just or unjust. This perception of justice affects the immigrant's perception of her role in the society. Obviously, if she found the society just and welcoming, there is a much higher possibility of active participation.

Conversely, a negative perception of justice will result in a passive membership, at best, or a rebellious attitude, at worse. I believe a good understanding of these conceptions will open the way to understanding why the outcome of the interaction between the new immigrant, the state and civil society varies over time, in different spaces, between different countries, and for different migrant groups.

The goal of the next few sections is to identify recent debates on changes happening in different dimensions of citizenship. It explores also the scope of citizenship theories and their relevance to an examination of immigrants' integration in liberal societies. It concludes with an extensive critique of liberal, cosmopolitan, cultural pluralist and communitarian schools of thought, pointing to their shortcomings in describing the configuration of conceptions of society, justice and role among new immigrants.

\section{Citizenship dimensions and their evolution:}

Citizenship is a complex notion to define because it lies at the intersection of law, social science, and political theory. The term itself can denote a relationship to a polity, a social status, a package of rights, a package of responsibilities, or a combination of them. 
From a historical perspective, since ancient Greece through the end of the Dark Ages and the development of the modern liberal state, to the dawn of the $21^{\text {st }}$ century, citizenship has always been about two relationships: First, the relationship members of a political community have with their respective political authority. And second, the mutual relationships of support and solidarity that exist among such members because they are members of that community. For political and social theorists, however, citizenship is not an abstract concept about relationships and it is - and it must be seen as- dimensions and values that define this relationship. For example, Werbner and Yuval Davis define "citizenship as a relationship, inflected by social positioning, cultural assumptions, institutional practices and a sense of identity and belonging" (Werbner and Yuval Davis 1999, 4). Similarly other political and social theorists like Joppke, Bosniak, and Jenson \& Pappilon pay particular attention to different dimensions of this relationship and the interaction between them. In an attempt to identify a comprehensive theory of citizenship, Christian Joppke argues that it must distinguish between more than simple relationships, and must be capable of connecting developments in one aspect of citizenship with developments in other aspects (Joppke 2007, 38).

A summary of the range of opinions found in the literature on citizenship show that most authors identify at least three dimensions of citizenship. The first dimension is citizenship as status, which denotes formal membership of a given state and the rules of access to it. The second dimension emphasizes citizenship as rights, which is about formal capacities and immunities connected with such a status. And the third is citizenship as belonging, which refers to the behavioral aspects of individuals acting and conceiving of themselves as members of a collectivity, which classically is the nation. 
The first dimension of citizenship rests on the idea of a political community as the basis of citizenship. From the time of ancient Greece, the status of citizen identified those who were part of the political community, distinguishing them from those excluded from it, whether because they were strangers or because they were not deemed deserving. To be a citizen in this dimension, one has to be a bona fide member of a political community, to participate in its economic and social life and to enjoy its support in case of need. Citizenship defines the boundaries of who is a citizen and who is not, giving specific recognition and status to the ones entitled to participate and benefit from the political community.

Most Western models of citizenship link the status dimension of citizenship to a territorialised political community, most often represented by the notion of the nationstate (Castles and Davidson 2000, 81). When individuals become citizens, they not only enter into a set of relationships with the state and other members of the political community that confer upon them their rights and obligations, but they also become members of a political community with a particular territory and history. In this respect, citizenship reflects the historical articulation of national communities, where citizenship serves equally as a mode of inclusion and incorporation in society and as a legal and cultural framework for excluding those who are different.

Historically, the liberal state has played an essential role in delimiting the formal boundaries of citizenship. Today however, it seems globalization is undermining the territorial basis of politics, and that territory is playing a less important role in the determination of political community. At the start of $21^{\text {st }}$ century, the immigration and refugee flows associated with globalisation, as well as the movement of persons within 
economic free trade zones, all raised fundamental questions about who is in and who is out, and about where the boundaries of citizenship should be.

In the last few years, under pressure from growing numbers of foreign residents, many receiving states in the West have adjusted their legal systems, citizenship policies and models of integration in a manner that diminishes the significance of formal citizenship and of national ideologies. Soysal (1994), for instance, shows that Western states, having subscribed to international human rights norms, have begun to permit dual citizenship and to extend the rights of citizenship to non-citizens. The universalistic extension of civil and social rights, and in some cases, of political participation rights as well, to immigrants and denizens is heralding a new institution of citizenship. We are moving away from citizenship understood as national membership and increasingly moving towards a citizenship based on residency, which strengthens the multiple ties to locality, to the region, and to transnational institutions. This new modality decouples citizenship from national belonging and being rooted in a particular cultural community.

These changes in the status dimension of citizenship are challenging the liberal notions and theories of citizenship. Historically, liberalism has evolved in close relationship to the modern state. Ideas of citizenship and rights both reflect the attempt to construct proper relationships between the individual subject and the sovereign state. Liberals often rely on the idea of 'nation' to give an account of why particular people belong together as the 'people' of a particular state. But, for the most part, liberal theory has not focused on the status dimension of citizenship and the sources or nature of solidarity, but rather on questions related to the individual's rights in their relationships to states mediated by citizenship. For example, the English sociologist, Thomas $\mathrm{H}$. 
Marshall, took the ties between nation and state for granted. The English state was seen as the provider and guarantor of rights, while the 'British nation' was the assumed focus of citizenship status (Delanty 2000,19). As long as the imaginary tale of a perfect match between nations and states was plausible, this was relatively unproblematic, though there are current developments that are undermining this match and begging for a new approach.

The most prominent groups of political and social theorists addressing this problematic are transnationalists and cosmopolitan schools. The growing scholarship on transnationalism examines recent changes on the citizenship status of immigrants by focusing on the ways in which new comers attempt to expand fields of social action and social life beyond the nation-state. This literature specifically highlights the continued engagement of immigrants with their place of origin, facilitated by new technologies of high-speed communications and transportation, thereby creating overlapping memberships in territorially separated and independent polities (Baubock 2003, 700). The main premise of this approach is that, though transnational activity existed in the past, contemporary transnationalism is different, being larger in scope and more persistent. It reflects not simply immigrants' nostalgia for their origin, but a new political geography structured between the origin and destination. Immigrant groups are said to exist in a new global market of political loyalties, engaging in a complex politics of belonging to both sides and resisting attempts by the liberal state to "fix the parameters of political community and territory" and to integrate them into a national culture.

In response to those transnationalists who claim that the rise of transnational activism is undermining national autonomy and the ability of the state to fix the 
parameters of political community, one can argue that, in spite of growing internationalism and increasing globalization, political life still revolves around the nation-state. There is not yet any empirical evidence that domestic political structures and citizenship relationships are getting shaped by merely transnational manipulations. In contrast, as Sideny Tarrow (2005) pointed out, domestic politics continues to shape everything about how contentious issues and policies are played out, including who the actors are, what strategies they use, whom they target, and what response they invoke. As well, with regard to the subject of our study, an immigrant's conception of society, justice, and his role takes shape mostly through interaction with local and national players, not through transnational relations.

Similar to transnationalists, cosmopolitan theorists argue that markets and other social relations extend across nation-state borders, that migration and cultural flows challenge nationalist notions of the integral character of cultures and political communities, that states are not able to organize or control many of the main influences on the lives of their citizens, and that most challenges of humanity today are intersocietally global and thus cannot be addressed by national measures. Many cosmopolitans thus argue that the highest obligation of each person is due to humanity as a whole, not to a nation-state. The most radical approach to cosmopolitanism starts from this point of view, which bases its argument on the ethical obligation of individuals to humanity. This is the position of Martha Nussbaum (1997 and 2002). She would recognize and value other obligations of individuals, such as those to family and immediate community, only on the condition that this particularism is the best way to meet the requirements for the universal good of all humanity. As an example, it is right 
for parents to care most for their own children, but only because this will ensure the best possible global childcare arrangements. From this point of view, claims of other loyalties or responsibilities, such as those to nations, communities, or ethnic groups, are subordinate to the larger good of humanity, and fall under suspicion of illegitimacy.

The moderate version of cosmopolitanism starts with rights rather than obligations, and argues that anywhere people are joined in any kind of social relations they have a collective right to share the power of it. This approach is mainly rooted in democratic theory advocated by David Held (1995 and 1999). According to this school, there ought to be a democratic polity to administer affairs at every level at which people are connected to each other, including supra-national levels. They trust that in an era where nation-states have lost some of their historic sovereignty and have become 'decisiontakers' as much as 'decision-makers', a meaningful citizenship requires democratizing those transnational institutions that are increasingly responsible for important economic, environmental and security decisions. This cosmopolitan democracy laid out by Held is based on a view that everyone can enjoy political membership in the diverse political communities that significantly affect them and so by extension, people can enjoy multiple citizenships. From this point of view, people can be citizens of their immediate political communities, and of the wider regional and global networks that impact upon their lives. It is fair to say that, in comparison to other cosmopolitan theorists, Held's approach is moderate, because he does not suggest that people necessarily put universal loyalty and belonging ahead of the particular in all cases, nor does he conceive of cosmopolitanism as a form of deracination of freedom from cultural particularity. 
The cosmopolitan approach to citizenship has been criticized from different angles. One of the softest criticism comes from Kymlicka, who maintains that Held's suggestion of cosmopolitan democracy citizenship is not realistic. Kymlicka also believes that even though globalization is producing a new civil society, it has not yet produced anything that can be recognized as transnational democratic citizenship. He agrees with Held that many moral principles like human rights, democracy, and environmental protection should be cosmopolitan in scope, but he thinks that democratic citizenship is, and will remain for the foreseeable future, national in scope (Kymlicka 2001, 320).

Another problem with much of recent sociological discussion of cosmopolitanism and belonging is that it rarely draws upon any relevant, recent, or original empirical data. While many sociologists have espoused the virtues of a cosmopolitan ethic, there is relatively little evidence to suggest how widespread such attitudes are. In contrast to cosmopolitan claims and speculation about supranational relationships, findings of a number of surveys show that attachment to place remains remarkably strong. For example, according to a report by Statistics Canada in 2005 that examines the link between this sense of belonging and an individual's self-perceived physical and mental health, nearly two-thirds of Canadians aged 12 and over had a strong sense of belonging to their local community (Statistics Canada 2005, 5).

This brings us to the main argument against the universalistic approach of cosmopolitan theorists. As Craig Calhoun $(2003,531)$ points out, it is impossible not to belong to social groups, relations, or a culture. He thinks the idea that individuals are selfdetermining enough to be able to choose all their identifications to all humanity is deeply misleading. He believes that cosmopolitan theorists are extremely unrealistic, and they do 
not provide a clear idea of what the next steps of actual social action might be for the real people who are necessarily situated in particular webs of belonging, like the nation-state, with access to certain others but not to humanity in general. Calhoun's point has been supported by a growing number of scholars who believe that citizenship is understood and experienced within specific national and local social and political contexts, reflecting historical traditions and institutional and cultural complexes (e.g. Lister et al 2007, 23). In short, even though belonging appears to be less linked to territory than it has been in the past as a lived experience, it still cannot be divorced from its context, including its spatial context.

Despite its pragmatic connotations and potential for tying people to a place and social relationships, belonging also evokes conceptions and emotions. Most recent studies on the notion of belonging identifies it not solely based on location and relationships, but also through the optics of culture and identity and the means in which individuals define their connections to the wider society (Castles and Davidson 2000,125). This view of belonging is especially salient in discussions of immigration, since it captures the potential schism of 'being' from 'longing'. My goal here is to shed light on the gap between belonging and substantial membership.

In my view, belonging constitutes a social, political, and cultural field of daily contestation for an immigrant. As I argued before, immigrants understand and negotiate the parameters of their membership in the new society through their everyday interactions with other fellow citizen in their workplace, neighborhood, club, and so on. These interactions play a key role in new comers' understanding of the boundaries of the new 
society and in answering the principle question of who belongs to this society and who does not.

By developing and administering the rules and policies that govern these interactions, state institutions are directly involved in this process. To begin with, it is the state that clarifies the legal status of individual immigrants in a given new society. It is important to note, however, that formal legal status as a citizen is a necessary starting point for immigrants to become a member of society, but it is not sufficient. To be equal citizens, individuals also need civic equality or equal standing in their day to day interaction with other members of society. This is where states intervene indirectly by providing the rules of the game, as well as funding for different sets of activities and programs. These policies and programs, developed and funded by the state, are crucial in constructing a dynamic environment where newcomers can interact equally with other fellow citizens. More importantly, these programs provide directions and answers to questions, such as the following: Are foreign-born residents to be welcomed or shunned? Should they be treated as equal citizens or simply temporary labor? Does national membership include diverse origins and cultures? What accommodations, if any, must newcomers and native-born residents make in remaking the national and civic community? Should public programs or policies provide material resources, such as funding, for integration of new comers? Are there policies in place to materially affect immigrants' ability to acquire citizenship, such as language training?

Besides state institutions, other mainstream actors - such as political parties, unions, churches, and other groups - can also influence this process. By opening their doors to new citizens and treating them as they would any other member, regardless of 
their ethno-cultural or social status, they provide an example of how open the society is and what the rules of membership are. A person who feels welcomed by these institutions pursues contacts and relationship with other members. In the opposite case, someone who has not been treated well and respected by these organizations develops a negative perspective and avoids any more contacts.

Based on the nature and outcome of these interactions with the state, civil society and members of the majority, the new immigrant develops a positive or negative conception of society. A feeling of being accepted as a member of the new community is the main foundation of a positive conception of new society. This kind of positive conception helps build a stronger relationship between the new comer, the state and other members of the society. These direct or indirect relationships in turn strengthen communal solidarity and collective identity.

Conversely, those who are routinely deprived of the chance to be full and equal members of the political community develop a negative conception of the new society. When the individual immigrant reaches the conclusion that she will never be accepted into the host society-whether due to cultural or religious differences, media representations or state actions - she experiences the disjunction between formal citizenship and a sense of membership in the political community. Since she does not see herself as a member of the team, she becomes a passive recipient and consumer of social outcomes, without any real partnership in social, political, and cultural outputs of the society. By real partnership, I mean different forms of civic and political participation, as well as an active contribution to the economic, social, and cultural products of the society. A notable example of the lack of such behaviour could be seen in the long term 
dependency of some immigrants on social programs and welfare assistance, as well as lower than normal rates of political participation. As I argued before, these kind of passive behaviours are the by product of a "disjunctive" form of citizenship in which rights and formal aspects of citizenship are extended, while social and substantive rights are not. When this happens, formal citizenship may be decoupled from substantial citizenship and identification with the nation-state.

As to the issues related to the "rights" dimension of citizenship, this section assesses the evolution of citizenship rights and critically review those ideas that we find most promising in investigating these evolutions. Here, I argue that a conception of justice is of crucial importance to understanding the immigrant's successful integration into the new society and realization of substantial citizenship. Moreover, I insist that the immigrant's conception of justice depends on patterns of social rules that define access to equal rights and opportunities, as well as mutual respect within the communities where new immigrants live and act.

Even though the origins of citizenship go back to political communities of ancient Greece and Rome, the focus on the rights dimension of citizenship became apparent only after the foundation of the modern nation-state. The creation of the nation-state coincided with the evolution of citizenship, involving a set of rights that recognized claims of citizens to collective resources of the nation-state, and their contributions to the state through taxation and military service. Events such as the English civil war, the American War of Independence, and the French Revolution in the early modern era, opened the way for a distinction between subjects and citizens. Each revolution, however, interpreted citizenship in a different manner. The republican French tradition interpreted citizenship 
in a way to manage differences between citizens who shared a common loyalty to the republic. In the United States, citizens participated in the state through civil society, which was composed of a multitude of voluntary associations such as chapels, denominations, and towns. Citizens shared a radical doctrine of egalitarianism, and there was a profound suspicion of the central institutions of government. In the British case, citizenship was constituted within the framework of the common law, which safeguarded the privileges of property owners, and was a barrier against the power of the state over the individual. Parliament and the rule of law established a system of checks against the rise of an absolutist state.

While different philosophers had been studying issues like freedom, rights and obligations of people toward law and state for centuries, it is after these key events that we see a considerable shift of focus on citizenship. In contrast to previous philosophical approaches that completely focused on the rights and obligations of citizens in relation to the state, modern thought initially concentrated on the social structures that shaped this relationship. These structures are typically social class, gender and race and historically they have distorted and limited formal rights of citizens. During the last fifty years, after the end of WWII, we have witnessed a large growth in philosophical debates on the normative issues related to citizenship. But the debate has not only grown in size, the very terms of the debate have also dramatically changed, and this is what I would like to focus on. I will try to distinguish two distinct stages in the debate. I will use the same terminology as Isin \& Turner $(2007,7)$ and will call the first "struggle for redistribution" and the second "struggle for recognition". The former mainly refers to the allocative 
function of citizenship and the access of individuals and groups to scarce resources in society, and the latter focuses on the questions of identity, difference and membership.

The work of the English sociologist Thomas H. Marshall (1893-1982) serves as a good beginning for understanding the "redistribution" aspect of citizenship. In his work, Citizenship and Social Class, Marshall (1950) provides a heuristic framework for analyzing citizenship rights. Focusing mainly on the evolution of citizenship in Britain, he presented a full historical account of citizenship evolution since the $17^{\text {th }}$ century. To summarize his rich historical argument, Marshall described the expansion of citizenship rights over the recent centuries as a constant search for stability and balance between democratic equality and guarantees of individual freedom. According to him, three categories of rights emerged in a historical sequence to create this balance: civil rights in the $18^{\text {th }}$ century, political rights in the $19^{\text {th }}$ and social rights in the $20^{\text {th }}$. Civil rights guarantee fundamental freedoms (such as freedom of expression, religion, and so on), and particularly the right to follow the occupation of one's choice. It also expanded the legal rights through access to legal resources such as the right to a trial, the right to a fair hearing, and the jury system. In the eighteenth and nineteenth century Political rights gradually extended to the whole adult population. The political rights included the right to vote and to stand as a candidate. These rights were eventually institutionalised in parliamentary institutions. Finally, he described social rights, such as the right to education, access to housing and health services or income security. These rights were institutionalised in the welfare state (Marshall 2006, 37).

Marshall then argues that citizenship overcomes, mitigates, and reduces the impact of economic inequalities that have their origin in the market place. In his view, social 
citizenship tends to resolve or minimise the conflict between social classes which are characteristic of the rise of capitalist economies and the capitalist market system. He argued that citizenship reduced the level of class struggle and class antagonism because it redistributed some of the resources that had become available as a consequence of economic growth. Like many other social thinkers of his time, Marshall had in mind the fact that in the late nineteenth century many European societies went through a significant period of class antagonism and class conflict. ${ }^{4}$ More to the point, we must read Marshall's ideas through the perspective of post war reconstruction and the dominance of John Maynard Keynes's economic and social policies. As a complement to Keynes, Marshall introduced social citizenship as an institution that would guarantee the poor a civilized life by protecting them from the unpredictable flaws of market economy. The domination of this pattern of Keynesian welfare economics and Marshallian citizenship has been eroded by the transformation of the welfare state, extensive changes in the labour market, the decline of civil society and accelerated global movements.

By the late 1970s, debates had broken out within different political traditions about the achievements and usefulness of social citizenship. The academics and political forces on the right of the political spectrum criticized social citizenship for the lack of usefulness and the expensive consequences of too much investment and spending on the poor. They mainly focused on two points. First, the effects of ballooning expenditures of the welfare state on the future economic growth and stability of the liberal economies. Second, an understanding that entitlements under citizenship encouraged some citizens to disengage from the labour force and willing to live in the semi-poverty of social welfare.

\footnotetext{
${ }^{4}$ In his classic, The Great Transformation, Karl Polayni shows how laissez-faire economic liberalism broke away from the distributive justice of the welfare state.
} 
This understanding led them to believe that the only way out was reintroducing the responsibility dimension of citizenship, in particular by developing incentives for individuals to take responsibility for themselves and their families. On the other side of the spectrum, the academics and political activists of the left criticized social citizenship as not doing enough for erasing economic exclusion and poverty. Even though from time to time they defended the welfare state, in the face of political assaults of the right, they still criticized the hierarchical and bureaucratic structure of the welfare state.

The relevance of social citizenship following the changes of economic conditions in the post 1960 s is not the only source of criticism of the Marshallian project. Many writers have focused on the shortcomings of the questions he posed as much as, or more than the answers he provided. Those in the Feminist school note that Marshall's theory of citizenship depends upon Fordist assumptions, where men go to work to generate income to care for the future of their household and women are domestic labourers who serve their men and reproduce society through child-bearing. They argue that Marshall's theory reproduced the dominant assumptions of patriarchy, which reproduced the public/private division (Turner 1997, 14). Some feminists argue that the historical review of the evolution of women's citizenship, using the same Marshallian categories, reveals a developmental sequence of female rights acquisition in Britain and other European states that is different from the male pattern of rights progression highlighted in Marshall's writings (e.g. Fraser and Gordon 1994, 8-12).

The major criticism of Marshall's theory of citizenship relates to his treatment of political community. Marshall took for granted that modern societies are homogenous in ethnic, religious, and cultural terms. Nowhere did he address the issue of ethnic, 
religious, and cultural diversity. His whole theory is based on an assumption that the only diversity in the community is based on social class and that governments can overcome that class diversity by creating a common basis of citizenship. As Turner pointed out, the particular position of women and ethnic minorities not only highlights a major weakness of omission in Marshall's analysis, it also pinpoints a more general failure to explore the important relationship between formal and substantive citizenship and its implications for active and passive membership in society (Turner 1993, 1). Turner's point brings us to the main question of this dissertation. For Marshall, the central line of conflict in the modern age is functional, not territorial. For Marshall, the central point of contention in citizenship is the matter of degree and not kind. In other words, for him it is resolving "the degree" of citizens' enjoyment of societal goods, and not settling "the kind" of citizenship the denizens conceive and feel. His theory addresses the question of how workers can be citizens. This shies away from the main question of this study which is based on state membership, particularly, how new immigrants can be active members of the new liberal society. This comes in the phase of "struggle for recognition".

The rapid and sustained economic growth in the post-war decades generated a sense of material well-being in much of the industrialized world, leading some toward a post-materialist era in which psychological, cultural, and quality-of-life values rise to the fore. In recent years, especially after the demise of communism, the prospects for radical redistribution were severely diminished and concerns with the distribution of economic opportunities and resources have been displaced by a preoccupation with the acknowledgement of cultural identities and differences. In fact, new social movements 
like feminism, gay rights, and multiculturalism pressed social and political philosophers to formulate new theories of justice based on recognition and not redistribution.

In their jointly authored book entitled "Redistribution or Recognition?" (Fraser and Honneth 2003), Axel Honneth and Nancy Fraser present one of the best arguments for a new theory of justice. While Honneth argues that a suitable differentiated account of recognition can provide the basis of a theory of justice on its own, Fraser contends that recognition and redistribution are two mutually irreducible elements of an account of social justice. For Axel Honneth, recognition is a vital human need. In his opinion, someone who lacks recognition can not achieve full "self-realization", therefore we do not just desire recognition, but we need it. For Honneth, the harm done by nonrecognition and misrecognition is the worst form of social injustice (Fraser and Honneth 2003,133). For Nancy Fraser, on the other hand, recognition plays a significant but partial role in a theory of justice. Rather than treating recognition as instrumental to individual self-realization, she treats it as instrumental to acquiring justice as an equal and full partner in social interaction. By rejecting the view that struggles over recognition are separate from and opposed to struggles over distribution, she defines justice as involving issues of both economic distribution and cultural recognition. She argues that struggles for cultural and economic justice do not inevitably conflict and, further, should be combined. Fraser defines both misrecognition and maldistribution as hampering "participatory parity", which is a social arrangement that permits all members of society to interact with one another as peers (Fraser and Honneth 2003, 36). Participatory parity has, in her view, both 'objective' and 'intersubjective' preconditions, which she traces to just patterns of economic distribution and cultural value, respectively. 
In comparison to Axel Honneth's approach, Fraser provides a much closer argument for the subject of this dissertation. Her notion of participatory parity certainly can be useful in understanding the immigrant's integration into liberal societies. As well, Fraser's framework of combining redistribution and recognition can be utilized to analyze the notion of cultural rights raised by different schools of thought. However, along the way of reviewing different approaches to cultural rights, I would argue that Fraser's framework falls short in explaining why an increasing number of immigrants are unable to achieve substantial citizenship.

The recognition of group-based claims to end discrimination and for genuine, not just nominal equality, contributed to a growing emphasis on cultural rights. Often those who ask for recognition of their diversity are seeking to redesign the content of rights, especially the way to access it by increasing confluence of culture and citizenship. In general, they find the universal conceptions of citizenship based on the abstract individual fundamentally unjust. Critics like Iris Marion Young argue that historically disadvantaged groups such as women, cultural minorities and homosexuals have been oppressed by the norms and values of the majority being considered the only acceptable rule.

Indeed, within the liberal academic mainstream, normative political theory has in recent years been struggling to come to terms with the demands and challenges posed by these groups. Critics particularly challenged two main principles of classic liberalism, namely 'individualism' and 'state neutrality'. Initially, for classic liberalism, the political community is a framework of rights and obligations that guarantees citizens preference of whatever values and ways of life they choose. In this view, community always comes 
second to the individual, since it is the individual's will which creates the community. In Ackerman's word: the ideal liberal political community is "nothing more than a collection of individuals" (Ackerman 1980, 72). Justice, in such a context, means above all, respecting the will of the individual and the choice about how to live. Hence, we need a universalistic approach to citizenship status, which can apply equally to all individuals willing to fulfill the minimal requirements of citizenship. In this context, the state should be neutral with respect to different values and ways of life; it should be "difference-blind, so as not to privilege particular cultures, races, genders, or religions" (Taylor 1982, 57).

This brings us to the second principle of classic liberalism, which is the neutral position of the state. Classic liberalism seeks to build social co-operation against an assumption that society is composed of individuals with a variety of cultural beliefs, or what is referred in the liberal literature as 'conceptions of the good.' Political liberalism not only assumes that there are many such beliefs in a society and that they may conflict, but also agrees that in the words of John Rawls, they can be "reasonable". Political liberalism assumes this fact of reasonable pluralism as a permanent feature of complex societies. Thus, in order to achieve social co-operation political liberalism adopts what has been referred to as a stance of 'epistemic abstinence' (Raz 1990, 3). That is to say, as a political theory it abstains from taking any position about the cultural and moral claims of both religious and secular doctrines and supports any of them as the main conception of the good. Therefore, to avoid disconnection of citizens, political liberalism asserts the following principle: To the greatest extent possible, the state should be neutral between citizens. By having these principles in place liberal theorists hope to achieve an ideal social cooperation among all members of the society (Rawls 1985, 235). 
These principles of liberal citizenship have been criticized by feminists, communitarians, multiculturalists, and cultural pluralists. Based on historical evidence, critics argue that this 'individualistic', 'neutral' and 'difference-blind' strategy has not prevented the exclusion of women, blacks, Jews, Native Americans and gays and lesbians from equal citizenship (Marion Young 1995 and 2000). Although an eclectic bunch, all these theorists challenge the universalist and exclusionary tendencies of the liberalist notion of citizenship and as an alternative propose an inclusionary approach, which promises real citizenship. For example, feminist theorists of citizenship add complexity and contribute to a theory of citizenship by pointing out the weaknesses in the concept and practice of liberal citizenship. By arguing that all kinds of differentiations, including the gender-based ones, present obstacles to real citizenship, they aim for substantive equality regardless of gender, race, religion, lifestyle or cultural affiliation.

In general, feminists' criticism of the liberal approach to citizenship overlaps with that of the radical left, whose members have highlighted "the failure of citizenship rights vested in liberal democratic institutions to meet the needs of women and racialised groups and the socially and economically marginalised" (Taylor 1989, 19). The starting point of most feminists is to expose how a purported gender-neutral concept is in fact deeply gendered. In their opinion, citizenship has always been constructed in masculine terms. From a historical point of view, they argue that citizenship from its origins in ancient Greece, through the Enlightenment era in the works of Hobbes, Locke and Rousseau was constructed on the exclusion of women (Pateman 1988, 19-26). A key tenet of feminist citizenship theory is that understanding lived citizenship involves a challenge to the public-private dichotomy that underpinned the traditional association of 
citizenship with the public sphere. They argue that liberal citizenship is founded upon separation of public and private spheres. In the public sphere, the relationships form based on a notion of justice, where everyone should be treated equally. In the private sphere, by contrast, citizens may act upon personal ideas and notions of morality. There is thus a disparity between public and private spheres. From a feminist viewpoint, a gap between formal equality and substantive equality usually arises from the nature of the private sphere and its separation from the public sphere. Therefore, citizenship should be about a transition from private to public patriarchy and not just a civilising of capitalism (Walby 1994, 379).

By examining the exclusionary nature of liberal citizenship, which in feminists' words has served to maintain women's segregation from full citizenship, emphasis has been placed on the importance of "a conception of citizenship which would accommodate all social cleavages simultaneously" (Leca 1992, 30). As a solution, a conception of citizenship has been suggested by Ruth Lester, which is grounded in a notion of differentiated universalism. According to Lester, this notion represents an attempt to reconcile the universalism which lies at the heart of citizenship with the demands of a politics of difference. Lester argues that closing the gap between private and public spheres, together with the notion of differentiated universalism, can provide the building blocks for "a feminist theory of citizenship, which draws on principles of synthesis rather than dichotomy. Thus, recast on feminist lines, citizenship offers us both a valuable perspective on the position of women in their diversity and an important political tool for women and other oppressed groups" (Lester 1997, 42-43). 
Like feminists, communitarians are also preoccupied with the fate of disadvantaged groups. However, while still considering citizenship as a relationship between individuals, the state and political community, they ask for more attention to be given to communal identities and cultural specificity. According to communitarians like Charles Taylor and Joseph Carens, healthy and full citizenship is only possible if citizens feel a sense of belonging to the community. They argue that development of this feeling of attachment will not be possible without taking into account cultural identities. In order to achieve a more inclusive citizenship, communitarians propose distinctive models of citizenship that seek to recognize multiple forms of belonging to the political community and overlapping identities and citizenships. Taylor and Carens use the cases of Aboriginal peoples and French-speaking Quebeckers as examples of communities that have long felt - and indeed still feel - excluded from the Canadian citizenship regime on cultural grounds to argue for a more inclusive mode of citizenship. (Carens 2000 and Taylor 1993).Taylor develops his model of citizenship based on the principle of deep diversity, which is an arrangement that grants collective group rights to many minorities. Both Taylor and Carens argue that liberal democratic states should not only seek to accommodate, but should embrace such deep diversity as a positive basis for unity and a common identity (Carens 2000, 172).

This model works on an assumption that equal individual freedoms are better defended by means of collectivist ontology and epistemology than an individualistic approach. Communitarians challenge the liberal conception of the autonomous individual. Instead, they view individuals embedded in particular social roles and relationships. This embeddedness, in its part, helps the development of individual's 
conception of the good life. Therefore, instead of viewing group practices as the product of individual choices, communitarians view individuals as the product of social practices. Based on this argument, Charles Taylor concludes that it is impossible to define the individual without the community and without taking into account cultural practices (Taylor 1985,8$)$. In this view, in order to reach substantial equality, citizenship institutions must allow and encourage the expression of cultural diversity and specific identities for the individual to develop a sense of belonging to the political community. For Taylor, sustainability of a political community is founded upon its members' sense of solidarity and belonging to that community. Such solidarity is only possible if individuals feel fully equal, including allowance for cultural practices within the citizenship regime.

It is evident that communitarian arguments can explain the campaigns by some national minorities, like Quebeckers for greater regional autonomy to establish distinct legal and political frameworks. The emphasis that such groups place upon collective identity, and their subsequent demands for group rights, supports the base assumptions of communitarian theorists. However, the communitarian approach falls short in explaining other types of identity challenges, including the question of immigrant integration. First of all, most of immigrants' activism do not reflect a wholesale attachment to a particular religious or ethnic identity. For example, how we can define the dominant cultural identity of an Iranian Kurd immigrant in Canada, who is a Sunni Muslim, speaks Kurdish and Persian, as well as English or French, and celebrates Christmas, Persian Norooz, and Kurdish and Muslim traditional holidays. It is often not simple to identify a dominant cultural aspect to build a homogeneous immigrant group and identity. Then again, even if we were able to clarify that problem, there is still no guarantee that specific cultural 
aspects will stay the dominant feature forever. As Christopher Houston noted (1998, 238239), part of the difficulty goes back to the manner in which communitarians explain the construction of an individual's cultural identity. Especially for a new immigrant, who possibly has moved from being a member of majority to a member of cultural minority in a new society there is no single point in the reconstruction of cultural identity. In the process of integration, the new immigrants choose between multiple competing cultural narratives, including the cultural aspects of country of origin and cultural norms of the new society. Hence, it will be misleading to expect the outcome of this process to be similar for every single immigrant.

The reconstruction of an immigrant's cultural identity is an inherently fluid process characterized by powerful intracultural struggles between diverse factors. In this struggle, the immigrant's choice of a new cultural narrative is influenced by a variety of sociocultural and political determinants. Certainly, cultural closeness, age, and language fluency provide a number of essential socio-cultural factors. From a cultural perspective, for a new immigrant who comes from a society with a somewhat similar lifestyle as the host country, reconfiguring the old habits based on the dominant behaviours of the new society could be much easier than for an immigrant to whom everything is new. Age and presence of children at home are other key variables. Younger immigrants have less solidified identity in their country of origin than older ones, thus it is easier for them to harmonize the new way of life with their more fluid older routines. And finally, language fluency and more frequent interrelationships with members of the dominant majority facilitate an immigrant's learning and acceptance of the dominant social behaviours of new society. 
In addition to socio-cultural determinants, there are some political factors that influence the individual's ability to choose a new cultural narrative. Definitely, citizenship models and practices play a significant role in defining the access of individuals to different cultural options. Joseph Raz insists that an individual's ability to make a choice amongst variety of alternative cultural options is intimately tied up with access to the original culture, with the prosperity and flourishing of that culture, and with the respect accorded to this culture by the dominant society and the state ( $\operatorname{Raz} 1994,177)$. Other liberal culturalist writers, like Kymlicka, Parekh and Tamir, make similar arguments. Even though the details of their arguments vary, unlike communitarians, all of them believe that liberal principles are still consistent with cultural freedoms and can assure access to special cultural rights to minorities, including immigrants.

Liberal culturalists share with classic liberals the goal of equal citizenship for all. Their fundamental focus is also on the individual, not the group. However, in contrast to classic liberals, who define citizenship purely in terms of adherence to certain principles of democracy and justice and a neutral position of the state with respect to the ethnocultural identities of their citizens, liberal culturalists seek special cultural rights for members of minority groups. By and large, they argue that the difference-blind strategy of classic liberalism does not work and try to show that minority rights supplement, rather than diminish, individual freedom and equality, and help meet the needs that would otherwise go unmet in a state that clung rigidly to ethnocultural neutrality. They insist that substantial citizenship should be assured through policies that range from giving all individuals' beliefs and practices recognition in the educational system and public events, to institutionalizing minority rights in affirmative action programs and the legal system, 
to group representation in political and civic institutions. According to Kymlicka, these policies should be pursued with the intention of promoting integration into what he calls a "societal culture." By a societal culture, he means a territorially-concentrated culture, centred on a shared language that is used in a wide range of societal institutions, in both public and private life (schools, media, law, economy, government, etc.). He calls it a societal culture to emphasize that it involves a common language and social institutions, rather than common religious beliefs, family customs, or personal lifestyles. Exercising freedom, he goes on, "involves making choices amongst various options, and our societal culture not only provides these options but also makes them meaningful to us" (Kymlicka $2001,25)$. For such a choice to be a real one, Kymlicka argues that society must include a diversity of cultures, norms and values within it; too little diversity can stifle individuality. As such, the state has a responsibility not simply to protect but to allow for the growth of cultural diversity and groups which carry it (Kymlicka 1995, 83). So, in Kymlicka's word, we need to replace the idea of an "ethnoculturally neutral" state with a new model of a liberal democratic state-what he calls the "nation-building" model (Kymlicka 2001, 26). He clarifies his point by claiming that his model of nation-building is not to say that governments can only promote one societal culture. It is possible for government policies to encourage the sustaining of two or more societal cultures within a single country, especially in multination states like Canada, Switzerland, Belgium, or Spain.

The question now is how does nation-building affect minorities? In answering this question, Kymlicka correctly makes a distinction between national minorities and immigrants. While he recognizes the right of national minorities to have a separate 
societal culture, he concludes that having a separate societal culture is not feasible for immigrant groups. Instead, he expects that immigrants should integrate into the societal culture of larger society, though Kymlicka insists that the state must minimize the costs involved in integration of immigrants by assuring fairer terms of integration for them. It follows that, in his mind, the fair terms of integration:

have two basic elements: (i) we need to recognize that integration does not occur overnight, but is a difficult and long-term process that operates intergenerationally. This means that special accommodations (e.g. mother-tongue services) are often required for immigrants on a transitional basis; (ii) we need to ensure that the common institutions into which immigrants are pressured to integrate provide the same degree of respect, recognition and accommodation of the identities and practices of immigrants as they traditionally have of the identities and practices of the majority group.... (t)he question is not whether immigrants have given us a compelling reason to diverge from the norm of ethnocultural neutrality, but rather how can we ensure that state policies aimed at pressuring immigrants to integrate are fair? (Ibid., 30).

Despite apparent shortcomings, Kymlicka's narrative of fairness for immigrants provides us a reasonable starting point to analyze immigrants' rights and their conception of justice. Kymlicka correctly goes beyond other liberal culturalists' simplistic version of immigrants' rights, where it is assumed that if immigrants get access to their original culture then they will flourish in the liberal society. He approaches immigrants' rights (including cultural rights) as a part of a larger framework of immigrants' integration 
process, which generally takes time and requires some special accommodations on the part of the state and the larger society. In his opinion, these measures are needed to ensure that liberal states are offering immigrants fair terms of integration.

He stops short, however, in expounding this issue and instead turns his focus to the wider question of national minorities and their cultural rights; he avoids explaining what he means by fair terms of integration. But his two basic elements mentioned above give us some ideas that his main focus is on avoiding cultural domination, non-recognition, and disrespect for immigrant culture, or what Fraser (1997) calls cultural justice. In this sense, I would argue that a conception of fairness is not uniquely linked to cultural justice but includes distributive justice (equal access to economic resources) and associational justice as well. Associational justice here is defined as the absence of "patterns of association amongst individuals and amongst groups which prevent immigrants from participating fully in decisions which affect the conditions within which they live and act" (Power and Gewirtz 2001, 41). Development of a conception of fairness does not take place in social vacuum. It occurs through struggles of daily life, where immigrants formulate a conception of state, society and the rules governing their relationship with both the state and the native born.

My approach may seem similar to both classic and cultural liberalist approaches, but there are clear distinctions. The main difference is in what I add to the arguments around the questions of equality and autonomy of individuals. In their conception of the individual, both classic and cultural liberalists present a view similar to that articulated by John Rawls in his book Political Liberalism (Rawls 1993). According to Rawls, all individuals are rational, logical and reasonable. Rawls preassumes that individuals are 
able to consider and order their own interests. In their rationality, individuals have the basic logical capacity to understand the social rules and relate to them based on their own interests. In their reasonableness, individuals are assumed to be able to take account of the perspective of others and fairly consider their claims. Individuals, therefore, have the capacity to make judgments that are guided by a sense of justice as fairness.

My addition to these discussions is the way in which I perceive the configuration of the sense of justice and fairness among different individuals. For classic liberals, the question of justice is reduced to a moral ideal of personal self-realization and removing socio-economic and political barriers against it. Cultural liberals add a cultural dimension on top of the same approach and argue that personal self-realization depends also on the recognition of cultural rights. In both cases, the focus is on the results, therefore the question of justice is reduced to some specific variables in a static condition, where the state guarantees a set of rights and then we expect the person to flourish and enjoy her equal rights.

In contrast, my approach covers not just the results, but also the process of achieving them. I argue that, with regard to an immigrants' integration, the dynamic of the integration process itself has significant effect on the outcome and the end results. In my opinion, an immigrant's realization of substantial rights is dependent on both the assurance of formal rights, as well as on the way these rights are being redefined in her daily life. From this point of view, an individual immigrant's sense of justice as fairness takes shape in an actual encounter with the rules of society and the way she is being treated by the majority. As Mark Warren (in the case of deliberative democracy) pointed out, day to day struggles at the workplace, school or in the community lead individuals 
(in my case immigrant) to reflect and interact in a way that is more logical, rational, just, and considerate of others (Warren 1992, 20). Here, an individual immigrant is not only a rational actor who makes choices and acts to satisfy personal interests. She is also an ethical and moral agent who reflects on the rules and the way she is being treated. Here, fairness is no longer just a matter of an equal access to social, political or cultural rights, but a combination of rights and social norms that facilitates her respectful involvement in all aspects of community life, including economic, social, cultural and political participation.

It seems this position is close to Kymlicka's view, where he asks for fair treatment of immigrants during the integration process. As I already noted, contrary to other cultural liberalists, Kymlicka makes a far greater effort to make a distinction between minority rights and specific rights for immigrants. In addition, he notices the importance of the integration process and fair treatment of immigrants, though, as I pointed out before, he stops short of explaining what he means by "fair treatment" and it seems he is only interested in cultural aspects of fairness, which I have already critically analyzed.

For myself, however, the most problematic feature of Kymlicka's approach is what he shares with other cultural liberalists. In general, for all of them the question of the immigrant's integration and active engagement in society is reduced to the politics of identity. As mentioned above, this is an outcome of over focusing on the question of cultural rights on the one hand and categorizing the problematic of the immigrant's integration under the umbrella of minority rights on the other. I feel by reducing all aspects of immigrant's integration to the issue of cultural rights and identity, they totally neglect other aspects, especially the question of active engagement and participation. 
Different studies show that being actively engaged and connected to other people or to a community can foster a sense of a shared fate and a common identity (see for example Albanesi, Cicognani and Zani 2007). Fair rules of participation and respect for each other can thus produce the emotional connections that lead both immigrant and native born individuals to sympathize with and care for one another.

In the light of this argument it has become clear that whether individual immigrants have genuinely equal opportunity depends not only government actions, but also on the actions of institutions within civil society-corporations, schools, stores, landlords etc. If prejudiced shop-owners or real estate agents discriminate against the immigrant individual, then she is being denied equal citizenship, even if the state itself does not discriminate. By failing to provide an equal opportunity for employment and promotion in the job market for a significant portion of new immigrants, the market perpetuates an inferiorized notion of membership among those who are kept away from employment chances. This inferiorized notion ultimately shapes a negative conception of justice and role in the individual immigrant.

As we will see, sometimes the root of this market behavior goes back to the common perception about new immigrants. In general, migrants, particularly those from non-English speaking backgrounds labelled as visible or racial minorities, are perceived by the majority groups (and often by other minorities) as "true ethnics" along a scale of "migrantness" used to measure the distance between majority as us and them as others. Frequently, such ethnic markers, real or imagined, ignore the possibility that generations of persons so categorized may be born within the society of settlement. As a result, immigrants as ethnics may still be deemed to be outsiders, despite the possibility that 
they are permanent residents or full citizens and have been acculturated the same as other members of society. Clearly, no one can expect that in such a situation an immigrant would develop a conception of society as inclusive and fair.

Whether we should encourage all individuals and civil society to be more accommodative is an important issue that I will return to it in the next chapter. Yet, I believe, the main question to address here is the role of immigrants themselves. There are always a number of immigrant individuals who do not appear to wish to become engaged or integrate into the larger society. As a consequence, these immigrants self-segregate from others and live parallel lives in a given society. An example of this behaviour has been acknowledged in Britain. Two of the independent reports into race riots that took place between ethnically British and immigrant youths across the north of England in June 2001, documented examples of such a deliberate self-segregation (Cantle Report 2006 and Burnley Task Force Report 2001). The increasing number of such cases is an alarming sign of growing proportion of these tendencies. So the real question is what the liberal state could and should do to integrate these 'unwilling immigrants'? In other words, should the liberal state push these immigrants to be actively engaged in a given society? And theoretically, how far can a liberal state push an immigrant and still stay fair?

From a theoretical perspective, in this approach, justice as fairness is not merely the assertion of equality. To be an equal citizen the individual needs to have autonomy as well. Only an autonomous citizen is able to express and adjust his interest and values in the larger society. Autonomy here refers to the capacity to reflect rationally and potentially revise personal values and the conceptions of good. On the one hand, equality 
is a necessary precondition of autonomy. It is only in a cooperative exchange between equal individuals that a citizen can truly reflect on her values and interests. Therefore, to develop a fair conception of justice, both equality and autonomy of the individual immigrant should be assured. In the final analysis the question changes to "Is the liberal state entitled to promote individual autonomy? or should it accept the marginalization of a number of immigrants?"

Answering this question leads us to the issue of civic duties, and the extent to which a good citizen must participate in civic life, and particularly in social and political life, and therefore the need to educate them to do so. In these cases, as Kymlicka pointed out in his argument on civic virtues, one could argue that, having chosen to exercise their rights as full citizens, immigrants must accept the sort of education needed to promote responsible citizenship, including the obligation to attend citizenship education. The question of the content of citizenship education for immigrants remains highly contested, however. Citizenship education not only involves promoting active engagement, it also requires promoting autonomy by developing habits of civility and capacity for public reasonableness. The idea behind all types of civic education and such initiatives is to break down the wall of negative perception toward government and other members of society. Historically, cultural boundaries have often been maintained by visible expression of prejudice towards outsiders. People stayed within their group because they were not welcome in other domains in the society. The spread of civility through civic education helps to break down these boundaries. In short, citizenship education makes relationships between the members of different groups more likely and hence helps the breakdown of cultural barriers. 
However, contrary to young immigrants who are generally able to access for civic education through attendance in school, adult immigrants have limited access to citizenship education. Therefore, as Reva Joshee and Tracey Derwing pointed out, any kind of civic education programs, though not sufficient by themselves, would constitute a beginning (Joshee and Fanning 2005, 61).

An underlying principle of my approach is that, for adult immigrants, the main arena of citizenship education is through their daily struggles in real life, where they learn about their rights and responsibilities as a new citizen. This learning is much deeper than any kind of citizenship training. Contrary to civic education taught in school, which mainly covers the formal features of citizenship, new citizens learn substantial citizenship in the real life arena and what in reality their rights and responsibilities are. Therefore, I argue that whether active engagement should be encouraged or not mainly depends on the immigrant's conceptions of society, justice and role. If the individual immigrant feels the society is just and there is a space for him as an equal and respected member of community, then we should expect a much higher possibility of involvement. On the other hand, it is expected that a low conception of justice increases the possibility of separation, marginalization or rebellion. 


\section{Chapter II: Problems}

Canada is a country that has been defined by its patterns of immigration. For centuries different generations of immigrants have moved to Canada with hopes of building a better life for themselves and their families. The key facet of establishing their dream life in Canada relates to obtaining employment and generating income. These immigrants' hard work to achieve their goals not only served their personal interests and realization of their dreams, but at the same time has increased the general prosperity of Canada by contributing to the continued growth of country's gross domestic product (GDP) and standard of living. In the last 400 years, continuous waves of immigrants helped Canada maintain labour force growth and provided necessary skilled labour in different sectors and regions across the country.

At the start of $21^{\text {st }}$ century, immigration remains more important than ever for Canada's economic performance. At the local and national levels, immigrants account for a significant portion of Canada's population growth, especially in major metropolitan areas. According to Statistics Canada, immigration is becoming increasingly important to Canada's economic well-being. Roughly two-thirds of Canada's population growth comes from international migration. Population projections show that net immigration may become the only source of population growth by about 2030 and could account for virtually all net labour force growth by 2011 (Statistics Canada 2007).

At the international level, in order to remain globally competitive, Canada is facing new challenges, such as intense global competition based on technological advancements, as well as the emergence of developing countries as new economic powers. The latest global annual survey by "Manpower Inc." reveals that around the world, the percentage 
of employers having difficulty securing skilled labour is very prevalent, particularly in Romania (73\%), Japan (63\%), Hong Kong (61\%), Singapore (57\%) and Australia (52\%). Based on the same survey, in Canada, nearly one in three Canadian employers (31\%) has difficulty filling skilled job openings. While this percentage shows a decrease from last year (close to $40 \%$ ) due to the slowdown of the US economy, the reprieve is temporary and the skills shortage will get worse, according to Manpower Canada (Manpower Inc. $2008,1)$. Facing these challenges, countries with active immigration programs, such as Australia, New Zealand, and recently, the European Union, have altered their immigration programs to attract and integrate a larger proportion of skilled immigrants. The new immigration programs look to the human capital of potential immigrants and their admissibility in the new society as bases of immigration selection criteria. Likewise, as will be shown in chapter 3 , since the 1980 s, Canada has adopted a "point system" of selecting immigrants on the basis of education, experience, knowledge of official languages, as well as the ability to integrate into the current labour market. As a result of the implementation of this system, a large majority of immigrants arriving in Canada during the last 25 years are more educated and skilled than immigrants before, and are almost twice as likely as their native-born counterparts to have a university education.

On the other side of the spectrum, in the arena of global competition for the best and the brightest potential immigrants with high levels of education or skills look to opportunities for gainful employment and achievement of a better standard of living for themselves and their families in the new country. For them, the large costs of emigrating and settling are often worth the perceived long term benefits. A majority of immigrants believe that, after a period of adjustment and hard work, they will have a better economic 
status than that which they left behind in their country of origin. If, after a few years, the host countries are unable to successfully integrate new immigrants into the labour market and the new immigrants are unable to convert their knowledge and skills into gainful employment, then the expectations of both the host society and the new immigrants are not satisfactorily fulfilled. With no doubt, if potential skilled immigrants hear that people with $\mathrm{Ph} . \mathrm{Ds}$ are driving taxis in Toronto, that others with Master's degrees are security guards in Ottawa, BAs and BScs are parking attendants in Vancouver, and that MDs work in seniors' homes, a large majority of them will at least think twice about immigrating to Canada. On the other hand, members of the host society question the high numbers of unemployed new comers and availability of social benefits and public supports to newly arrived and unemployed immigrants, and ask for a cease in immigration or at least a limitation in the immigration flow.

Considering these facts, the urgency of political, social and economic integration of newcomers is self evident. The present chapter will address the problems, difficulties and challenges that immigrants face in all three areas. First, we shall address the problems associated with economic integration.

\section{The Problematic of Immigrants' Economic Integration:}

The main objective of this section is to addresses issues and problems related to the economic integration of immigrants to Canada. By reviewing the empirical findings of censuses, surveys and previous studies, my goal is to answer four sets of questions: Are there significant differences in the economic outcomes of native-born and immigrants? To what extent can these differences be accounted for by differences in the observed characteristics of the two groups? Are immigrants relatively more vulnerable to 
unemployment? Do they suffer from a "wage rebate" compared to native-born with comparable skills and, if so, how much and for how long?

The goal is to understand immigrants' general economic performance over the period of the last 35 years by keeping in mind their higher educational attainment and the rising share of immigrants in the skilled economic class. To this end, the main question is as follows: Did the economic outcome among new immigrants improve (or worsen) during the 1990 s and early 2000 s in comparison to the early 1980 s?

In theory, it is expected that newly-arrived immigrants will have lower income than comparable non-immigrant individuals, but that their initial earnings gap will narrow by the time immigrants adjust to the labour market of the receiving society (Chiswick, 1978 and Meng, 1987). Contrary to this rule, findings of the last few censuses, as well as longitudinal surveys and research studies initiated by academics and different governmental and non-governmental organizations during the last few years, reveal that the earning gap between immigrants and their Canadian-born counterparts is widening and may not close as quickly as expected. These surveys and studies indicate an emerging trend of declining earnings among successive waves of immigrants compared to Canadians born during the last 25 years.

The deterioration of new immigrants' economic status happened during a significant economic recovery and the growth of the knowledge based economy over the last 30 years, where a very dynamic job market created millions of jobs for skilled individuals. In theory, one might expect the return of the "good old days" of 1970s, when the gap between immigrant and native-born was not high. In reality, not only did the gap not narrow, but instead it widened during this period. What is disheartening is that the 
deterioration of economic status and the rise of low income rates among new immigrants cut across all groups and the majority of immigrants, regardless of their age, sex, family type, knowledge of official languages, and their educational level.

According to Statistics Canada (Galarneau and Morissette 2004, 6) the gap in lowincome rates between the Canadian born and recent immigrants is highest among skilled individuals, particularly those with a high level of education and is most pronounced among recent immigrants from Africa, the Asian regions and Latin America, who are considered visible minorities. On this latter point, a number of studies have revealed the double disadvantage of new immigrants who are members of visible minorities (De Jong and Madamba 2001 and Li 2001). As a result of both growing low-income rates among visible minority immigrants, and their rising share of the population of major metropolitan areas, virtually all of the increase in the city low-income rates during the 1990s was concentrated among the immigrant population (Picot and Sweetman 2005, 4).

A good area for examination is the difference between the economic integration of recent immigrants and more settled immigrants. There are many reasons why newly arrived immigrants might fare badly in the labour market and have a lower income, such as lack of language ability and lack of Canadian work experience. These reasons would not apply to the same extent to established immigrants, or to the second generation. In fact, the experience of established immigrants and of second generation Canadians is the key test of whether the Canadian system extends principles of 'equality of opportunity' to all citizens. As an example, recent French experience suggests that grievances among the second generation over perceived inequalities of opportunity may be a factor contributing to social disorder. 
No doubt, successful economic integration and well being is fundamental to the immigrant's overall integration and success in the new society. As noted in the introductory chapter, based on his general expectations on one hand and the outcome of his interactions in the labour market on the other, the immigrant conceptualizes the rules of market as just or unjust. By opening their doors to new citizens and treating them like their Canadian-born employees, employers provide an example of how open the society is. An immigrant who feels fairly treated and equally respected at the workplace develops a positive perception of justice and role and a stronger sense of membership. On the other hand, by failing to provide equal opportunity for employment and promotion in job market to a new immigrant, the market perpetuates an inferiorized notion of membership among those who are kept away from employment chances. This inferiorized notion ultimately shapes a negative conception of justice and role in the individual immigrant. While a positive perception paves the way for a general positive perception of justice and role in society, a negative perception results in passive membership at best or a rebellious attitude, at worse.

The past two decades have shown not only a difference in the economic engagement between native-born and new comers, but also a substantial deterioration in the economic success of recent immigrants relative to earlier cohorts. For example, Teelucksingh and Galabuzi $(2005,14)$ demonstrate that the declining labour force participation rate for recent immigrants, from 75.7 percent in 1981 to 68.6 percent in 1991, and to the 65.8 percent in 2001 seems to have been experienced most strongly among immigrants from non traditional source countries. More recent surveys and the 2006 census confirmed the continuation of this disturbing trend in the last few years. 
First, the longitudinal labour force survey by Statistics Canada (2006) revealed that recent immigrants who have been in Canada five years or less, that is, who landed between 2001 and 2006, had the most difficulty in finding a job in their field of interest, even though they were more likely than the Canadian-born population to have a university education. The survey particularly highlighted the greater disadvantage experienced by immigrant women compared to immigrant men and their native-born counterparts (Statistics Canada 2007b).

Based on the findings of the longitudinal survey of immigrants to Canada, close to one-fifth (20\%) of prime working-age immigrants had not had any employment after two years in Canada. The majority of these individuals were women (74\%), many of whom were spouses or dependents of immigrants in the economic category or immigrants in the family category. The survey revealed that one in ten skilled workers $(10 \%)$ had not taken an employment by the end of their second year. More than half $(56 \%)$ of these individuals were enrolled in education or training programs, and the rest were still trying to enter the workforce by looking for jobs or by starting a business (20\%). Considering other immigrant categories, $22 \%$ in the family category and $38 \%$ of refugees had not worked during their first two years in Canada. Of immigrants in the family category who had not had employment, $68 \%$ were homemakers or providing care to family members and $24 \%$ were enrolled in education or training. Of the refugees who had not had employment, $49 \%$ were enrolled in education or training and $41 \%$ were homemakers or providing care to family members.

Later, the 2006 census confirmed the findings of this survey. Based on the census, in 2006 , the national unemployment rate for recent immigrants was $12.3 \%$, close to 
double the rate of $6.4 \%$ for the native-born population. This issue was particularly pronounced for recent female immigrants, where their unemployment rate was 2.4 times higher, and their participation and employment rates significantly lower, than those of native-born women (Statistics Canada 2006 Census results). Even though the situation was comparably better for immigrants who had been in Canada between 5 and 10 years, their unemployment rate was $8.4 \%$, still $2 \%$ higher than the general population. Table 1 shows the major findings of the 2006 census.

Table 1: Labour Force Activity by Period of Immigration \& Sex

\begin{tabular}{|c|c|c|c|c|c|}
\hline & & $\begin{array}{c}\text { In the } \\
\text { Labour force }\end{array}$ & Employed & Unemployed & $\begin{array}{c}\text { Unemployment } \\
\text { Rate } \\
\end{array}$ \\
\hline \multirow[t]{2}{*}{ Total Labour Force } & Total & 17146135 & 16021180 & 1124955 & 6.6 \\
\hline & Male & 9020595 & 8431530 & 589065 & 6.5 \\
\hline & Female & 8125540 & 7589645 & 535890 & $\underline{6.6}$ \\
\hline \multirow[t]{2}{*}{ Non-immigrants } & Total & 13386300 & 12524690 & 861600 & 6.4 \\
\hline & Male & 7019290 & 6553770 & 465520 & 6.6 \\
\hline \multirow{3}{*}{ Immigrants } & Female & 6367005 & 5970920_ & 396085 & 6.2 \\
\hline & Total & 3634845 & 3383710 & 251135 & 6.9 \\
\hline & Male & 1931465 & 1813790 & 117675 & 6.1 \\
\hline \multirow{3}{*}{ Before 1991} & Female & -1703385 & 1569920 & 133465 & 7.8 \\
\hline & Total & 1949270 & 1857075 & 92190 & 4.7 \\
\hline & Male & 1048160 & 1001515 & 46640 & 4.4 \\
\hline-------- & Female & 901110 & -8555660 & 455555 & 5.1 \\
\hline \multirow[t]{3}{*}{1991 to 1995} & Total & 559415 & 518260 & 41155 & 7.4 \\
\hline & Male & 284855 & 266205 & 18655 & 6.5 \\
\hline & Female & 274555 & 252060 & 22500 & 8.2 \\
\hline \multirow[t]{2}{*}{1996 to 2000} & Total & 530150 & 485860 & 44290 & 8.4 \\
\hline & Male & 279750 & 260060 & 19695 & 7 \\
\hline \multirow{3}{*}{2001 to 2006} & Female & 250395 & 225805 & 24595 & 9.8 \\
\hline & Total & 596010 & 522515 & 73500 & 12.3 \\
\hline & $\begin{array}{l}\text { Male } \\
\text { Female }\end{array}$ & $\begin{array}{l}318695 \\
277315\end{array}$ & $\begin{array}{l}286010 \\
236505\end{array}$ & $\begin{array}{l}32680 \\
40815\end{array}$ & $\begin{array}{l}10.3 \\
14.7\end{array}$ \\
\hline
\end{tabular}

The 2006 census also reveals that immigrants in core the working age group of 25 54 years old had much more difficulty in the labour market than their native-born 
counterparts. On the whole, immigrants in this age group who had been in Canada for five years or less had an unemployment rate of $11.7 \%$ in 2006 , more than twice of the average rate of $5.1 \%$ for their native-born counterparts. The unemployment rate for very recent immigrant women aged 25 to 54 was $14.4 \%$, well above the rate of $5.6 \%$ among native-born women in same age groups.

For recent immigrant youths aged 15 to 24 , the labour market outcomes were not very different from those of native-born youths. The unemployment rates for both youth groups were not significantly different $(15.4 \%$ vs. $12.5 \%)$. The employment rate for established immigrant youths was $42.6 \%$, compared with $58.9 \%$ for native-born youths. However, the results of Canadian labour force survey reveals that immigrant youths were much more likely to be attending school, with $65 \%$ attending school in 2006 compared to $55 \%$ of Canadian-born youths (Zietsma 2007, 11).

Table 2: Unemployment rate by highest certificate, diploma or degree, 2006.

\begin{tabular}{|c|c|c|c|}
\hline & $\begin{array}{c}\text { Non- } \\
\text { Immigrants }\end{array}$ & Immigrants & $\begin{array}{c}\text { Recent } \\
\text { Immigrants }\end{array}$ \\
\hline Total & 6.4 & 6.9 & 12.3 \\
\hline No certificate, diploma or degree & 11.6 & 8.9 & 14.9 \\
\hline High school certificate or equivalent & 7.1 & 7.9 & 12.5 \\
\hline Apprenticeship or trades certificate or diploma & 6.2 & 5.8 & 11.7 \\
\hline College, CEGEP or other non-university certificate or diploma & 4.8 & 5.6 & 11.2 \\
\hline University certificate or diploma below the bachelor level & 4.5 & 6.5 & 12.8 \\
\hline University certificate or degree & 3.5 & 6.6 & 12 \\
\hline
\end{tabular}

Source: Statistics Canada, 2006 census results.

As noted before in 2006 , the unemployment rate among recent immigrants was close to double the Canadian born unemployment rate $(12.3 \%$ compared with $6.4 \%)$. Table 2 shows that, as education levels increase, the relative difference between the unemployment rates of immigrants and the native-born also increase. Consider recent 
immigrants with a bachelor's degree or higher; they have unemployment rates that are 3.5 times greater than native-born degree holders ( $12.0 \%$ compared with $3.5 \%)$. Clearly, despite the fact that for the Canadian born the level of unemployment decreases with the rise in the educational level, the same pattern is not present for immigrants, especially the recent ones. It seems that, though the demand for post-secondary credentials appears to be high, recent immigrants with university education have roughly the same rate of unemployment as those who did not complete high school. At the time of the 2006 census, close to half (47\%) of unemployed recent immigrants held a university degree at the bachelor's level or higher. In comparison, only one in ten $(10 \%)$ of the Canadian-born unemployed had post-secondary credentials (Statistics Canada 2006 Census results). We will discuss the reason behind the very high level of unemployment rates among educated immigrants in the next few pages.

From a regional perspective, the unemployment rate among very recent immigrants living in prairie regions is much lower than those living in the rest of Canada. Based on 2006 census, the lowest unemployment rate among core-working-age recent immigrants has been recorded in Saskatchewan, where the unemployment rate was $6.4 \%$, close to half the national average for this group. It is followed by Alberta (6.7\%) and Manitoba (9.1\%) (Statistics Canada 2006 census results). These rates were, however, at least a couple of percentage points more than the average unemployment rates for Canadianborn and immigrants landed before 1991. It seems the booming labour market in the prairie regions had a positive impact on immigrants' employment levels and, like their native-born counterparts, they benefited from the economic boom in this region. 
Yet worse off, were the recent immigrants living in Quebec, who experienced the highest unemployment rate (19.5\%), followed by those living in Newfoundland and Labrador (14.9\%), Nova Scotia (12.1\%), and Ontario (11.9\%). Very recent coreworking-age immigrants had much higher unemployment rates than their Canadian-born counterparts in all three of Canada's largest census metropolitan areas (CMAs) in 2006, especially in Montreal. This group of very recent immigrants in Montreal had an unemployment rate of $19.8 \%$ in 2006 , more than three times the rate of $5.7 \%$ among Canadian-born Montrealers. Similarly, very recent immigrants in Toronto and Vancouver also faced unemployment rates that were close to two or three times the rates experienced by the Canadian born in their cities. In Toronto, the unemployment rate for core-workingage very recent immigrants was $11.8 \%$, and $6.2 \%$ among Canadian born. In Vancouver, the rate was $10.9 \%$ for these very recent immigrants, compared with $4.9 \%$ among the Canadian born. Among all mid-sized CMAs, Calgary's hot labour market benefited immigrants and Canadian-born workers alike in 2006. Canadian-born workers aged 25 to 54 in Calgary had one of the lowest employment rates (3.9\%) among the eight mid-sized CMAs. The strong demand for labour in 2006 was particularly apparent among the city's immigrants who had been in the country for five years or less. Their unemployment rate was $7.0 \%$-still higher than that of their Canadian-born counterparts in Calgary but lower than that of very recent immigrants in all other mid-size and major CMAs, as well as Montreal, Toronto and Vancouver. (Statistics Canada 2006 census results)

This high level of unemployment among immigrants, particularly the educated ones, is more disturbing when we acknowledge the sustained annual decline of national 
unemployment rates in the last few years which resulted in a 30-year low level of unemployment in $2006(6.3 \%)$. Apart from issues of equity, health, well-being, or social cohesion of immigrants, all Canadians and different level of governments should be worried about the longer period of time new immigrants stay unemployed in Canada. The prolonged unemployment of immigrants not only puts more pressures on welfare programs, but, more importantly, adds up to an increasingly prolonged under-utilization of skilled labour, which, as mentioned before, is particularly important in light of growing concerns about skill shortages.

Even though the high level of unemployment among immigrants is alarming, this is not the only dilemma they are facing in the Canadian labour market. Another major issue is underemployment or employment in non-intended occupations. In this regard, the Canadian labour force survey in 2006 reveals that, of those immigrants who found employment, only about four in ten (42\%) found a job in their intended occupation. Onethird (33\%) did so during their first year in Canada, while another $9 \%$ did so during their second year. The remaining $58 \%$ did not find employment in their intended occupation. Among skilled worker immigrants aged 25 to 44 , the vast majority (90\%) found employment during their first two years in Canada. Of those with employment, close to half of them (48\%) found a job in their intended occupation. Four in ten (40\%) did so during their first year in Canada, while another $8 \%$ did so during their second year. The remaining $52 \%$ found a job, but not in their intended occupation (Statistics Canada 2005, 9). Not surprisingly, a large majority of them are in low-education jobs. 
Table 3: University graduate immigrants by type of job, 1991 -2001.

\begin{tabular}{|c|c|c|c|}
\hline & 1991 & 1996 & 2001 \\
\hline \multicolumn{4}{|c|}{ University graduates in job requiring less than university } \\
\hline \multicolumn{4}{|l|}{ M } \\
\hline Canadian Born & 30 & 34 & 33 \\
\hline Recent Immigrants & 50 & 54 & 47 \\
\hline Other Immigrants & 32 & 38 & 39 \\
\hline \multicolumn{4}{|l|}{ Women } \\
\hline Canadian Born & 30 & 34 & 33 \\
\hline Recent Immigrants & 64 & 67 & 61 \\
\hline Other Immigrants & 42 & 45 & 47 \\
\hline \multicolumn{4}{|c|}{ University graduates in job requiring secondary school or less } \\
\hline \multicolumn{4}{|l|}{ Men } \\
\hline Canadian Born & 11 & 14 & 12 \\
\hline Recent Immigrants & 27 & 32 & 25 \\
\hline Other Immigrants & 13 & 17 & 18 \\
\hline \multicolumn{4}{|l|}{ Women } \\
\hline Canadian Born & 13 & 17 & 13 \\
\hline Recent Immigrants & 41 & 47 & 38 \\
\hline Other Immigrants & 21 & 25 & 24 \\
\hline
\end{tabular}

Source: Diane Galarneau and René Morissette. Immigrants : Settling for Less. Statistics Canada: Perspective on Labour and Income. Catalogue \#: 75-001-XIE, June 2004.

When comparing new immigrant to native-born, statistics present a gloomy picture. A Statistics Canada publication shows that in $2001,25 \%$ of recent immigrant men with a university degree had low-education jobs; the same proportion of their native-born counterparts was only $12 \%$. The corresponding numbers for women were even worse; $38 \%$ to $13 \%$ (Table 3 ). Recent immigrants were therefore at least twice as likely to be in low-education jobs, a phenomenon observed throughout the decade (Galarneau and Morissette 2004, 6). Another Statistics Canada study based on the results of the Survey of Labour and Income Dynamics (SLID) showed similar findings. According to this study, more than one-half (52\%) of recent immigrants with a university degree worked in a job requiring only high school education at some point during the last decade. This was almost twice the proportion (28\%) among their native-born counterparts. (Li, Gervais and 
Duval 2006,8$)$ It is expected that these numbers had increased as a result of high-tech downturn in 2002 and latest economic crisis.

Table4: Occupational distribution before and after landing.

\begin{tabular}{|l|c|c|c||}
\hline \hline & $\begin{array}{c}\text { Before } \\
\text { landing }\end{array}$ & $\begin{array}{c}\mathbf{6} \text { Months } \\
\text { after } \\
\text { landing }\end{array}$ & $\begin{array}{c}\text { years } \\
\text { after } \\
\text { landing }\end{array}$ \\
\hline Management Occupations & $10 \%$ & $4 \%$ & $6 \%$ \\
Business, finance, administration & $12 \%$ & $13 \%$ & $14 \%$ \\
Natural \& applied science & $23 \%$ & $14 \%$ & $15 \%$ \\
Health occupations & $5 \%$ & $3 \%$ & $4 \%$ \\
Social sciences, government services, education, religion & $10 \%$ & $5 \%$ & $6 \%$ \\
Art, culture, recreation \& sports & $2 \%$ & $1 \%$ & $2 \%$ \\
Sales \& services & $9 \%$ & $30 \%$ & $27 \%$ \\
Trades, transport, equipment operations & $6 \%$ & $7 \%$ & $9 \%$ \\
Occupations unique to primary industry & $2 \%$ & $2 \%$ & $2 \%$ \\
Occupations unique to processing, manufacturing and utilities & $4 \%$ & $20 \%$ & $15 \%$ \\
Occupation not identified & $16 \%$ & $1 \%$ & $0 \%$ \\
\hline
\end{tabular}

Source: Longitudinal Survey of Immigrants to Canada - Wave 1 (2001) and Wave 2 (2003)

Table 4 shows the occupational distribution of newcomers before immigration compared to 6 months and 2 years after their landing. It clearly characterizes the movement of skilled immigrants from jobs requiring higher educational level and skills, such as natural and applied sciences, social sciences, management and government services to jobs requiring lower education level in sales and service sectors.

Unfortunately, the breakdown tabulation of the 2006 census for the occupation of immigrants was not available during this study. For that reason, we had to rely on the findings of the Canadian labour force survey to follow the occupation path of the immigrants after landing. Based on the survey, sales and service jobs were the most widely-held occupations in Canada for immigrants and among the most widely held by Canadian-born, though very recent immigrants were comparatively over-represented in 
these occupations. Whereas the share of native-born people working in sales and service occupations was $18.4 \%$, the share of very recent immigrants was higher at $23.3 \%$. Immigrants were also more represented in the accommodation and food services industry than Canadian born. While $3.7 \%$ of Canadian born of core working-age were working in the industry, $6.9 \%$ of very recent and $7.1 \%$ of recent immigrants were employed there (Zietsma 2007, 23).

There were also notable differences in the proportion of immigrants working in occupations unique to processing, manufacturing and utilities compared to the nativeborn. In 2006 , while $12.3 \%$ of newly arrived and $10.5 \%$ of all immigrants were working in these occupations, just $5.7 \%$ of Canadian born worked in these jobs. It is important to note that the manufacturing sector was one of the main employers of immigrants in 2006 , regardless of how long ago they had landed in Canada. In 2006, 20.1\% of immigrants worked in the manufacturing industry, compared to $13.0 \%$ of Canadian born. The share of newly arrived immigrants was also higher than the Canadian born in the manufacturing sector, at $19.6 \%$. Immigrants, including the very recent ones, were also more likely to be working in professional, scientific and technical services than the Canadian born. In 2006, a greater share of immigrants were working in the natural and applied science and related occupations compared to the Canadian born. In fact, the share of recent immigrants working in these occupations was more than twice $(15.8 \%)$ that of the share of Canadian born (7.2\%). Business, finance and administrative occupations were the most widely held occupations by Canadian born and the second among immigrants. In 2006, there was a smaller proportion of very recent immigrants working in these occupations (15.7\%) compared to the Canadian born (19.5\%). 
We will discuss in detail the impact of immigrants' occupational pattern and their higher share of low-education jobs on their general earning in the next section of this chapter, but suffice it to say here that, as expected, having a low-education job considerably decreases the employment earnings of highly skilled and well educated recent immigrants. Compared with other men employed in jobs requiring a university degree, recent immigrant men employed in full time jobs requiring no more than high school education earned at least $42 \%$ less per week in 2000 . The same gap for women was $39 \%$. For young men the earning gap was $47 \%$, up sharply from the $29 \%$ observed in 1990. It is not unexpected that new immigrants working in low-education jobs get paid less than those in jobs requiring university education. What is surprising, however, is that they also earn less income than their Canadian born counterparts who worked in the same situation in 2000. Recent immigrants employed full time in low-education jobs had an income at least $20 \%$ lower than their Canadian-born counterparts (Galarneau and Morissette 2004, 12).

Failure of a large portion of immigrants to find a decent job in Canada not only affects their successful integration into Canadian society, it has major implications for the Canadian economy. Given that Canada relies heavily on immigration to keep up with its global competitors in terms of its stock of skilled workers, the extent to which immigrants are actually able to find a job in their intended occupations in the Canadian labour market can be a significant factor in the retention of this skilled labour in Canada. Research shows that, in the last few years, well-educated and highly skilled immigrants were more likely to leave Canada than their less educated counterparts (Aydemir and Robinson 2006, 11). In addition, immigrants' inability to find a job that reflects their 
expectations could harm the image of Canada as a preferred destination for skilled immigrants and could reduce the brain gain from abroad.

On the other end of the immigration spectrum, when visible minority immigrants are unable to find a job in the area of their expertise and are forced to compete for low level jobs, one should expect that they develop a negative perception of fairness. While most professional jobs go vacant, this unconstructive situation creates more competition for lower paid jobs between immigrants and low skill native-borns. Besides, as Keung noted, immigrants living in poverty could create pressure - or at least the perception of pressure - on the social safety net. This might result in public demand for a reduction in social programs and other support for immigrants (Keung 2005).

For immigrant themselves, obtaining employment in their preferred area not only allows them to have higher earnings and support their families, it provides them with a sense of pride and dignity and helps them build equal relationships with others. These relationships help them become actively engaged in the new society and develop a sense of belonging and shared identity with others and the political community at large. On the other hand, immigrants with no jobs not only become a burden on their local communities and social welfare system, they become less engaged and marginalized from society as well.

Another aspect of the comparison between recent immigrants with both native-born and the more established ones relates to income level. In theory, it is assumed that the immigrant's income level is below average at entry, but after a number of years in Canada their earnings gap with comparable Canadians narrows, or disappears. This phenomenon is known as the "years since immigration" effect. However, recent research 
suggests that the initial earnings gap may not close as quickly as assumed, even among established immigrants who came to Canada 30 years earlier, during the 1970s (Hum and Simpson 2004). No matter what the earnings gap at entry, these gaps have increased in the past 30 years. Subsequent research indicated a trend of declining earnings among successive waves of immigrants in comparison to the native-born population (Bloom and Gunderson 1991 and Abbott and Beach 1993).

Table 5: Low income rates by immigration status, Canada, 1980-2000.

\begin{tabular}{|c|c|c|c|c|c|}
\hline & 1980 & 1985 & 1990 & 1995 & 2000 \\
\hline \multicolumn{6}{|c|}{ Low income rates } \\
\hline Total Population & 0.171 & 0.187 & 0.156 & 0.191 & 0.156 \\
\hline Non Immigrants & 0.172 & 0.185 & 0.151 & 0.176 & 0.143 \\
\hline $\begin{array}{l}\text { All Immigrants } \\
\text { Years of residence in Canada }\end{array}$ & 0.170 & 0.193 & 0.171 & 0.247 & 0.202 \\
\hline-5 & 0.246 & 0.342 & 0.313 & 0.470 & 0.358 \\
\hline $6-10$ & 0.187 & 0.260 & 0.242 & 0.353 & 0.283 \\
\hline $11-15$ & 0.144 & 0.198 & 0.190 & 0.272 & 0.227 \\
\hline $16-20$ & 0.147 & 0.159 & 0.152 & 0.221 & 0.191 \\
\hline $20+$ & 0.167 & 0.165 & 0.126 & 0.156 & 0.133 \\
\hline \multicolumn{6}{|c|}{ Low income rates relative to native born } \\
\hline $\begin{array}{l}\text { All Immigrants } \\
\text { Years of residence in Canada }\end{array}$ & 1.0 & 1.0 & 1.1 & 1.4 & 1.4 \\
\hline-5 & 1.4 & 1.8 & 2.1 & 2.7 & 2.5 \\
\hline $6-10$ & 1.1 & 1.4 & 1.6 & 2.0 & 2.0 \\
\hline $11-15$ & 0.8 & 0.9 & 1.3 & 1.6 & 1.6 \\
\hline $16-20$ & 0.9 & 0.9 & 1.0 & 1.3 & 1.3 \\
\hline $20+$ & 1.0 & 0.9 & 0.8 & 0.9 & 0.9 \\
\hline
\end{tabular}

Source: Statistics Canada. 1981 and 2001 Census 20\% sample micro data.

Based on a series of studies by Statistics Canada, in the aggregate level, the low income rates rose steadily among immigrant groups over the past three decades, while it fell among the native-born population. The findings of Statistics Canada shows that, overall, the low-income rate among the native-born fell from $17.2 \%$ to $14.3 \%$ between 1980 and 2000. Even among groups that one traditionally associates with low-income 
people, like seniors and lone-parent families, the low-income rate has fallen noticeably during last thirty years. The experience of recent immigrants, however, was the opposite; the proportion of recent immigrants with family incomes below the low-income average rose from $24.6 \%$ in 1980 , to $31.3 \%$ in 1990 , and $35.8 \%$ in 2000 . Hence, recent immigrants had low-income rates 1.4 times that of Canadian-born in 1980, and by 2000 this had increased to 2.5. This deterioration of low-income rates over the past 20 years was not restricted to recent immigrants. Table 5 shows that low income status was observed among all immigrant groups, no matter how long they had resided in Canada, with the exception of those living in Canada for more than 20 years (Picot and Sweetman $2005,11)$.

The latest research shows that after 2001, the differences between low-income rates among Canadian born and immigrant changed a little. Among immigrants in Canada for less than one year, however, the rate rose 3.3 percentage points, from $38.9 \%$ to $42.2 \%$ in 2004. Among those in Canada for two years, the rate also rose significantly, from $32.9 \%$ in 2001 to $37.2 \%$ in 2004. Among immigrants in Canada for longer period, there was little change. According to Statistics Canada, the low-income rate among immigrants during their first year in Canada has risen considerably in the last ten years. Findings of latest studies reveal that the low income rate of this group was about three times higher than that of the native-born over the 1992 to 2000 period, but by 2002 and 2003, it was almost 3.5 times higher. A similar trend is also observed among all immigrants to Canada for ten years or less. According to Picot and Sweetman, as a result of both rising lowincome rates among immigrants and their increasing share of the population in Canada's major cities, virtually all of the increase in the city low-income rates during the last 20 
years was concentrated among the immigrant population (Picot and Sweetman 2005, 4). Picot and Hou confirm that in Canada's three largest cities, where the vast majority of recent immigrants settle, the low-income rate increased between 1990 and 2000. It rose 1.9 percentage points in Toronto, 3.1 points in Vancouver, and only 0.3 points in Montreal (Picot and Hou 2003, 16-18).

The major component of family income is, of course, earnings. Hence, explanations for the decline in entry level earnings will no doubt explain to a considerable extent the rise in low-incomes. Analysis of immigrants' earnings by Statistics Canada shows that, in spite of the increasingly economic nature of immigration during the late 1990s, earnings among 15-64 years old male recent immigrants who worked full-time fell by 7\% (from $\$ 40,649$ to $\$ 37.909$ ) between 1980 and 2000 . During the same period, earnings among Canadian-born adult males working full-time rose by $7 \%$ from $\$ 45,625$ to $\$ 48,623$. The case of female recent immigrants was much better and their average earning increased by close to $13 \%$ from $\$ 23,780$ to $\$ 26,793$. However, this increase was still lower than that of native-born women, whose average earning increased $19 \%$ from $\$ 28,836$ to $\$ 34,418$ (Frenette and Morissette 2003, 19). So for both male and female immigrants, the gap in earnings widened considerably between the years of 1980 and 2000.

Additional analysis of immigrants' earnings reveals that the comparative deterioration of immigrants' earnings is not limited to recent immigrants and happened to more established immigrants as well. Chart 1 presents a comparison of immigrants and Canadian born earnings. The chart suggests that the earnings gap for the cohort of the late 1970s had more than closed after twenty years in Canada. However, the earnings gap at entry has been increasing with successive cohorts. Among men, the cohort of the late 
1970 s earned $83 \%$ of that of the native-born at entry and among the early 1990 s cohort, this number had fallen to less than $60 \%$. Among the late 1990 s cohort, however, the entry earnings gap appears to have been reduced. It seems that, while the traditional pattern of economic integration is relevant for immigrants entering in the late 1970 s, for others entering after the 1980 s this pattern is not applicable. The majority of researchers who did study these patterns concluded that the elimination of the average earnings gap for immigrants entering Canada after 1980s will be if not impossible, more difficult than ever.

Chart 1: Earnings of Immigrants as a Proportion of Those of Canadian-Born (Picot \& Sweetman 2005, 9)
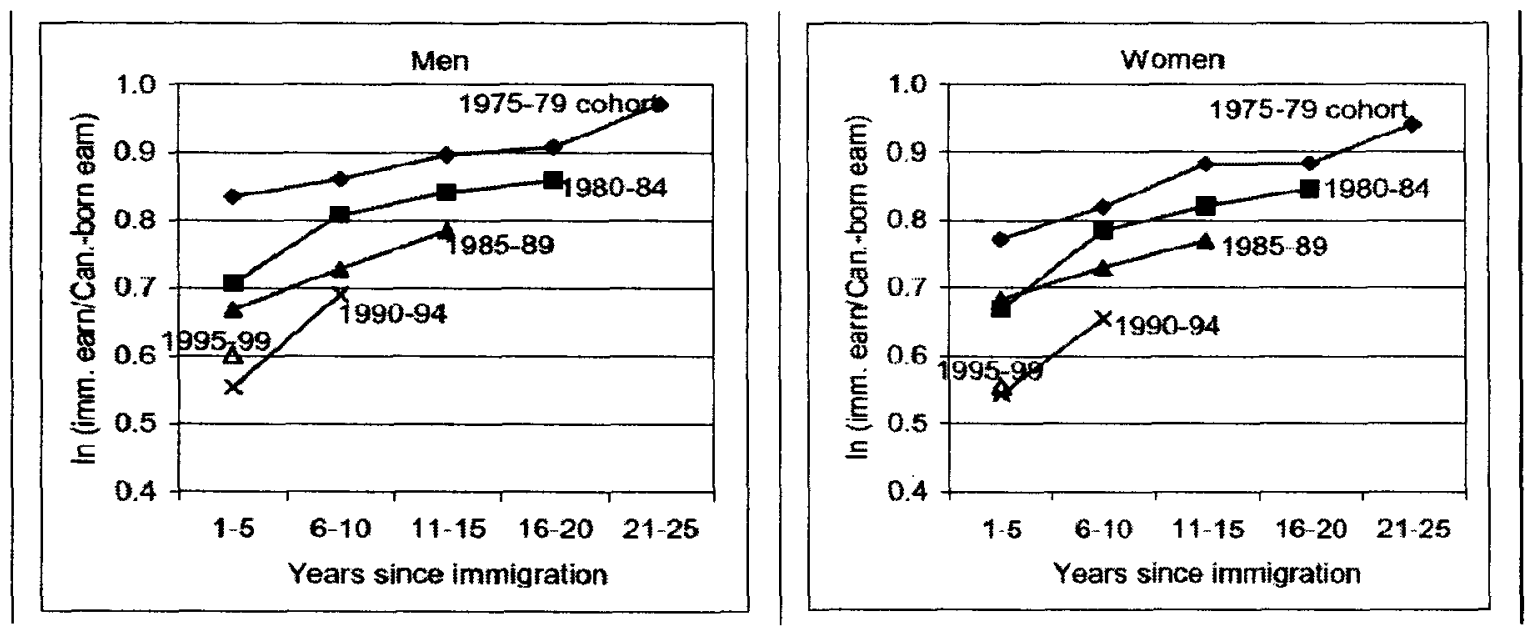

Another alarming sign is the passing on of earning disadvantages from first generation immigrants to the second generation among visible minority immigrants in the last few years. The outcome of the second generation (the children of immigrants) is an important dimension, both for the receiving country and for the entering immigrant. Whereas studies of the children of immigrants entering before the 1980 s show that second generation economic outcomes were very positive, some recent studies suggest that second-generation young men show little evidence of an earnings' advantage. In fact, 
everything else being equal, some visible minority men with two immigrant parents appear to have a significant earnings disadvantage compared with their peers from nativeborn parents (see Aydemir, Chen and Corak, 2005).

Moreover, one of the most disturbing findings is that increasing poverty rates are evident for newcomers in all age groups, at all educational levels, of all language backgrounds, and in all family types. Generally speaking, researchers and policy analysts working on immigrants' economic integration often need to know the distribution of low income among immigrants. Particularly, they are interested in finding an answer to the question of which groups account for most chronic low income among immigrants, and how this is changing. Latest studies carried out by theses scholars and analysts, as well as the results of surveys and censuses, show that the increase in recent immigrants' lowincome rates was common among all immigrants, regardless of their age, sex, whether immigrants spoke an official language or not, in all family types, all educational levels and all source regions, except the traditional source regions of Europe and the United States.

Chart 2 presents the distribution of chronic low income by immigrant class, education, age, occupation, family type, source region, and declared language ability in year 2000. The following are the salient observations derived from this chart:

Not surprisingly, refugees are more likely to experience chronic low income than other groups. Among the 2000 entering cohort, this rate was almost twice those of the skilled class $(29.5 \%$, compared to $15 \%)$. But they constitute a small portion of immigrants (13\% of landed immigrants in 2000), and thus, account for a relatively small share of immigrant chronic low income: $24 \%$ among the 2000 cohort. In contrast, skilled 
workers accounted for $52 \%$ of all immigrants in the chronic low income bracket for that cohort, even though they had a below average chronic rate. Among the three major immigrant groups, the family class has the lowest rate of low income individuals, with $13.4 \%$. This may be because family class immigrants find themselves in a family that is already established to some extent, hence reducing the negative family welfare effect of the earlier period.

Chart 2: chronic low income by immigrant class, education, age, occupation, family type, source region, and declared language ability in year 2000.

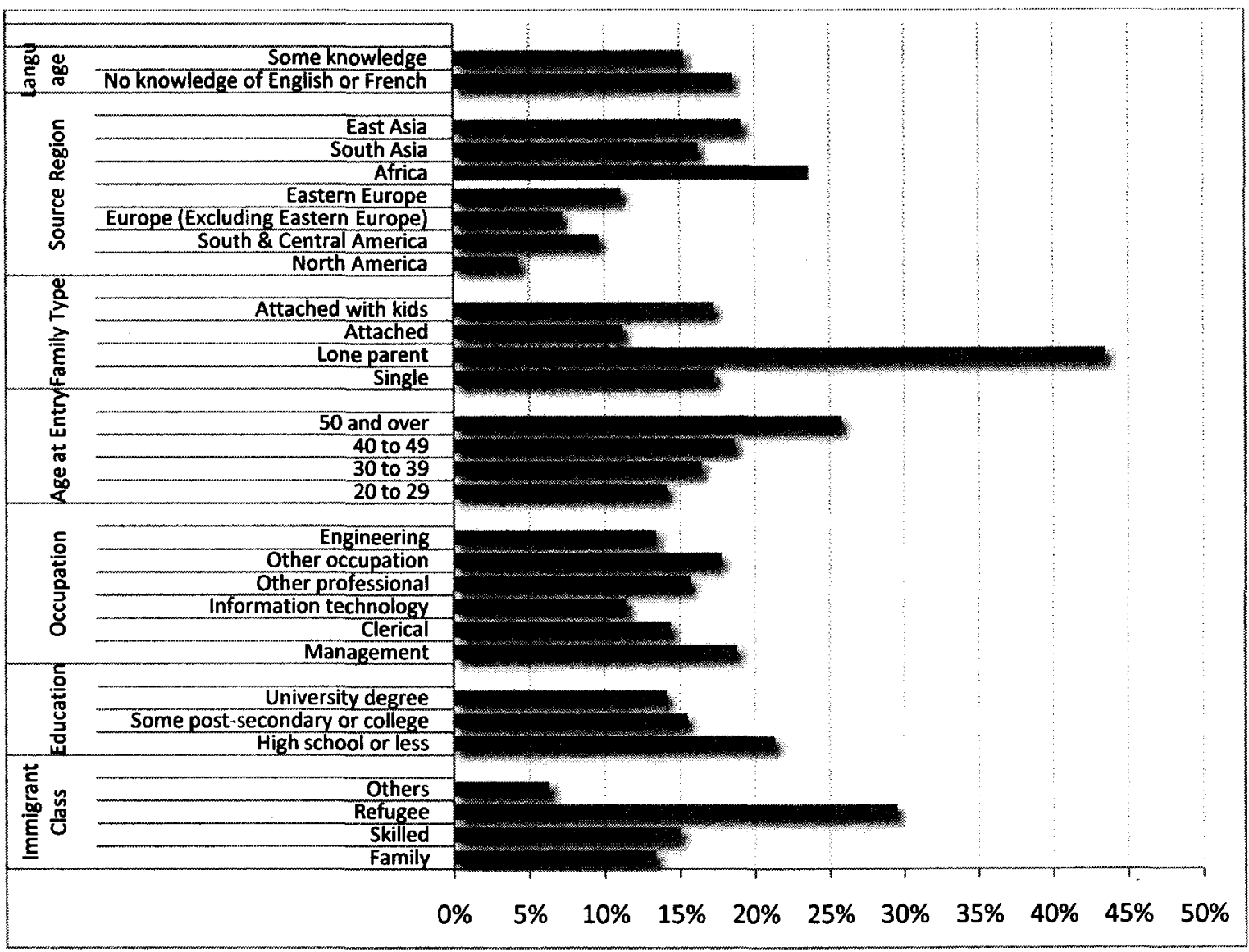

Sources: Statistics Canada, Longitudinal Administrative Database and Longitudinal Immigration Database.

The findings of regressions by Statistics Canada analysts show the older the immigrant at landing, the higher the likelihood of being in the chronic low income 
category. After controlling for other variables among immigrants landed in the year 2000, the rate of low income earners was $14 \%$ among those aged of 20 to 29 , and $27 \%$ among those over the age of 50 at the time of landing. Similar to the Canadian born, lone parents are much more likely to be chronic low income earners than other groups. However, they constitute a small percentage (2.8\%) of immigrants at the time of landing.

As noted above, the income rate is not low among entering immigrants from North America and Europe. Chart 2 also shows that while the average rate for these regions was less than 7.5\%, immigrants from Africa and South and East Asia experienced low income rates close to or above $20 \%$. In general, considering their high proportion among entering immigrants, Asian immigrants had the highest share of low income new comers. They accounted for one-half of chronic low-income earners in the 2000 cohort.

The high levels of poverty among immigrants are not restricted to those with lower levels of education. According to Picot, Hou and Coulombe $(2007,8)$ over $40 \%$ of the chronically poor in the 2000 cohort had a university degree. With no doubt, this increase was largely because graduates constituted a much greater share of all immigrants in recent years. It is important to note in this chart that even though the probability of earning a low income was higher for immigrants with less than a high school education than among the university educated, the magnitude of the difference was not as great as would be expected.

To summarize, even though the possibility of low income is present for all immigrant groups, it varies depending on education, age, immigration class and the source country. As one might expect, the possibility of low income decreased with education, increased with age at landing, was higher among the refugee class, differed 
little between skilled and family class, was much higher among single parents, higher among East Asian and African immigrants, and lower for immigrants from Western Europe and the United States.

A key conclusion of the above discussions on immigrant earnings in Canada is that more recent cohorts of immigrants have poorer earnings when compared to both earlier immigrants and native-born workers, even with higher levels of education and experience. Upon their arrival to Canada, most new comers are ready to work. They are motivated and are looking for an opportunity to build a better life in Canada, so motivation is not an issue. The issue is transference of their qualifications and an opportunity to integrate into the Canadian labour market. Ironically, the Canadian immigrant selection process of point system accepts immigrants with skills in demand and assumes that finding employment would not be difficult, and that their skills and experience will be recognized. For the same reason, many highly skilled immigrants entering Canada believe that they are going to compete in a job market based on adequate criteria that equally applies to all competitors in the job market. Only after their arrival so many of them realize the difficulties in entering Canadian job market and the problematic of transferring their knowledge and experience.

In this situation, while some feel that they have been seduced and fed wrong information, many others begin to have self-doubt about their abilities. In both cases, the inability to find a job matching their accumulated human capital results in the growth of negative perception about the Canadian labour market and the rules and principles governing it. Our review of literature in this section showed that newcomers' difficulties with economic integration are strongly tied to structural forces located in the labour 
market. Indeed, too often employers look at the personal and demographic attributes of new comer job seekers before looking at their qualifications and skills. In addition, there is a clear disconnect between employers' perceptions of immigrants' human capital assets and the high levels of skills and professionalism that they actually possess. Subsequently, newcomers most of the time are screened out in hiring processes, resulting in their exclusion from the labour market. Even for those already in the labour force, the same biased attitudes prevent them from being promoted within an organization. Even though the official policies governing work relations try to sell an image of a labour market based on meritocracy and first-come first-served principles, in reality it seems that those who came first racialized labour relations by creating an informal hierarchical structure, which is woven into the governing structure and culture of labour market. A report released by the Canadian Race Relations Foundation at the break of $21^{\text {st }}$ century entitled "Unequal Access: A Canadian profile of Racial Differences in Education, Employment and Income" confirmed that ethnoracial diversity is generally seen at the bottom and the middle level of the labour force pyramid, but the higher the pyramid, the less diverse and the whiter it becomes (CRRF 2000, 37).

The dilemma of visible minority immigrants within the Canadian labour market has different implications. Primarily, as noted before, a person's job is an essential component of his or her sense of identity, self worth and emotional well-being. As Harrison Trice noted in his paper, an individual's job not only provides him financial support, but also access to many of the resources that allow them to define themselves as part of a community and, hence, provided an identity and sense of belonging (Trice 1993). Therefore an immigrant's negative sense of hopelessness and frustration in the job 
market can result in a feeling of exclusion not only from the job market and economy, but from all other aspects of social life.

\section{The Problematic of the Immigrant's Political Integration:}

Contrary to the economic integration of immigrants, little attention has been given to the question of how well immigrants adapt to their political environment. A clear sign of this neglect is a lack of specialized datasets about the political participation of immigrants, particularly of visible minority groups, who form more than one fifth of Canada's population.

Some observers argue that since the primary goal of immigration is to build a better life in terms of wealth and social mobility, political participation of immigrants is not essential for their success and one may reach those goals without adapting to their political environment. Therefore, with economic advancement as the primary benchmark of the immigrant's successful integration, a low level of political participation should not be a concern. Others may extend these arguments even further and claim that with successful economic integration of new immigrants, their needs and preferences will be similar to the host society and be represented like others, therefore no one should be concerned with new comers' political participation.

Most scholars insist, however, that the importance of the immigrant's political integration has never been as acute as it is today. These scholars argue that immigration to Canada has become a very complex issue, not only in terms of the large number of recent immigrants, but above all in terms of the multifaceted cultural, social and economic dynamics of immigration and it's implications for the Canadian society in general (see for example Pikkov 2006 and Ginieniewicz 2007). They maintain that, since 
the new waves of immigrants come from sources with different religious, ethnic and cultural backgrounds, there are reasons to believe that their needs and preferences may be different from those of Canada-born and earlier immigrants. As a result, there is a high possibility that immigrants from non-traditional source countries may not see their views adequately represented in the host society if they do not participate in the political process.

In addition to empirical realities, yet from a theoretical point of view, the widespread understanding of good citizenship holds a notion that people should be actively involved in politics; they should hold strong democratic values, such as tolerance, and they should be knowledgeable about the main issues facing their society (Almond \& Verba 1963 and Barber 1984). At the heart of virtually all strategies for achieving these objectives is some form of participation. Furthermore, it is expected that active participation of immigrants in their new society will boost their knowledge of society and its issues, and make them more tolerant of and attached to their new country and fellow citizens.

This section assesses the degree to which immigrants, particularly those in visible minority groups, are actively involved in mainstream formal political channels in Canada. My goal here is to analyze the available empirical information and to point out the most obvious gaps in the political participation of new immigrants and the main society. Two points are important to note with regard to the goal and the scope of this section. First, here I exclusively concentrate on the numbers and facts concerning the widening gaps in political participation of immigrants and leave the reasons behind these facts to be reviewed in the coming chapters. Second, my review of available facts covers only the 
three areas of formal political participation: voting, involvement in political parties, and degree of representation. Some may correctly argue that the term political participation includes much more than these three. Limitation of data on informal political activities of immigrants is the main reason why I decided to restrict this part to the above mentioned areas.

The body of research on the political participation of immigrants in Canada is not extensive, but some does exist. To summarize the key insights from these studies, one can argue that overall two views have been expressed by the authors of these research papers. The first one, mainly suggested by those analyzing immigrants behaviour during 1970s and 1980s, argues that there is little difference between the political behaviour of immigrants and those of the native-born. For example, based on the data from the 1984 Canadian National Election Study, Chui, Curtis, and Lambert, (1991) found no statistically significant difference in participation between immigrants and native-born Canadians. In this study, they examined relative political participation of immigrants compared to native-born with respect to seven different factors, including involvement in campaigning, interest in elections, voting, membership in political organizations, exposure to political motivations, contacting politicians, and paying attention to politics in general. The only area with significant difference was contacting politicians, where immigrants were less likely to get in touch with politicians. However, in their analysis of the main factors having an effect on political participation, they found a few points which are still relevant to any analysis of immigrants political participation. For example, they reveal that the length of stay factor only reduces the likelihood of voting and engaging in political discussions among immigrants, particularly those who have stayed less than 10 
years. Furthermore, on generational patterns, they did not find any clear evidence that political participation increases with the number of generations in Canada (Chui, Curtis and Lambert 1991, 387). According to them, political involvement tends to peak in the second-generation category with respect to almost all measures of political participation.

The second perspective, mainly raised by those who worked on this issue more recently, suggests that putting all socio-economic characteristics aside, immigrants have a lower tendency to get involved in Canadian politics than their native-born counterparts. According to these studies, immigrant groups, especially recent ones, have lower participation rates in almost all areas in comparison to the native-born population. Analyzing the results of different surveys, as well as participations rates in a number of federal and provincial elections, these studies concluded that immigrants had lower than average rates of voter participation (e.g., Simard 2000).

Looking to the main differences between earlier studies and more recent ones, a major shortcoming of earlier studies is noticeable. In their analysis of immigrants' political behaviour, almost all earlier studies paid insufficient attention to the diverse ethnocultural and religious backgrounds of immigrants in Canada. Obviously, since a large majority of immigrants entering Canada before 1970s were European-born and their political behaviour was somewhat similar to one another, there was not much of a need for inter ethnic comparative analysis in the 1970s. However, later research showed that, just as political behaviour and attitudes may vary between the native-born electorate and immigrant populations, so do they vary among ethnocultural groups, particularly for visible minority groups. 
Given the unavailability of reliable data, so far, the extent to which visible minority status influences the voting behaviour of immigrants is more the object of speculation than profound empirical testing. However, three surveys, namely Equality, Security and Community Survey (ESC) by York University, Ethnic Diversity Survey (EDS) by Statistics Canada, and Survey of non-voters by Elections Canada provide some facts and useful insights in this area. The results of these surveys revealed that people who settled in Canada between 1991 and 2001 were far less likely to report they voted than those arriving before 1991. Yet it is not clear that visible minority status or length of stay is the main reason for lower political participation. Therefore, to avoid a one sided understanding of the issue, it is necessary to use multiple sources of information. There are two additional types of information which can be used in this study. The first one is mainly non-representative sample surveys done by researchers of the field. These studies are often limited by the fact that their analyses are confined to particular racial or ethnic group (Chinese, Sikh, Jews, ...) or to particular geographic areas (Toronto, Ottawa, Montreal). They generally offer an analytical test of some hypothesis related to an immigrant's political adaptation within the scope of the study and can be used as a supplementary source of information. The other source of information is a poll by poll analysis of election data in the areas with high concentration of immigrants. In this type of research, the author generally compares the voter turnout in ridings with higher numbers of immigrants with the average voter turnout in the rest of country or province (e.g., Jedwab 2006).

The goal of this section is to compare the political engagement of immigrants from non-traditional source countries to that of earlier waves of immigrants and members of 
the local population to discover the main gaps in political participation of these groups. As noted before, to examine how immigrants are adapting to the Canadian political environment, we investigate several measures in this section. The first factor to be analyzed here is the immigrant's voting behaviour and their turnout in elections in comparison to native-born voters. Then, I will look at the immigrant's level of affiliation and membership to the political parties. Finally, immigrant representation in political power is the last issue to be examined in this section.

Political participation is dependent upon a number of factors, such as interest in politics, exposure to information and political knowledge, to name a few (Verba, Schlozman and Brady 1995, 16). Without these basic essentials, immigrants may not have the necessary motivation to participate in politics and make connections between their needs and the policy outcomes. Therefore, any examination of how immigrants adapt to politics in Canada should start by looking at the extent to which immigrants are interested, informed and knowledgeable about Canadian politics.

The results of a survey of non-voters by Elections Canada indicate that immigrants from both European and Non-European origins are somewhat more interested in politics than the native-born population ( $68 \%$ vs $65 \%$ respectively). However, the numbers presented in chart 3 (taken from Bilodeau and Kanji 2006, 44) show that not all immigrants share the same degree of interest in politics. Based on their study of Canadian Election results from 1993 to 2004, immigrants from traditional source countries have a greater degree of interest in politics than immigrants from non-traditional source countries ( $67 \%$ vs $59 \%$ and $56 \%)$. 


\section{Chart 3: Interests in Politics by Origin.}

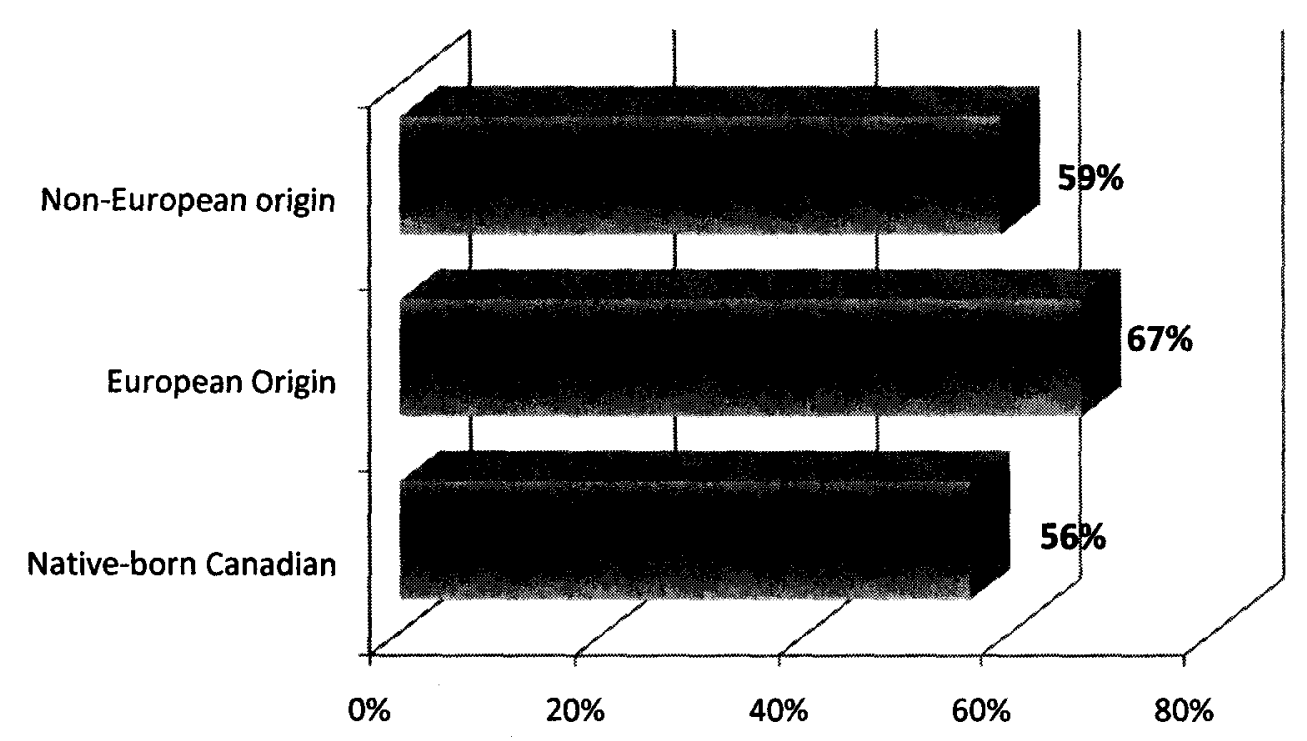

Source: 1993, 1997, 2000 and 2004 Canadian Election Studies

Interestingly, in the case of immigrants, a higher level of interest in politics does not mean a higher level of knowledge of Canadian politics. As Bilodeau and Kanji (2006, 46) found in their analysis of immigrant's knowledge of Canadian politics, immigrants from Non-European countries have less knowledge of Canadian politics than immigrants from traditional regions, as well as the native-born population. Based on a rough analysis of non-voter surveys, one can explain this issue based on the immigrant's higher level of interest and knowledge of politics of their country of origin. So, in short, even though immigrants are in general more interested in politics, they are interested in the politics of their country of origin possibly even more than politics in Canada. Of course, more research is needed to provide greater understanding of this behaviour. 
Considering the first factor, namely voting, a number of surveys and studies looked at the voting patterns of immigrants and compared them to the participation of nativeborn Canadians in federal, provincial and municipal elections. Here, I will study the Ethnic Diversity Survey (EDS) and the Equality, Security and Community Survey (ESC), as well as some observations from other surveys and studies with respect to the voting behaviour of immigrants.

Based on the findings of the EDS, nearly 8 in 10 Canadians who were eligible to vote said that they had voted in the last federal and provincial elections, while 6 in 10 said they had voted in the last municipal election (EDS, multicultural P 15), regardless of the number of generations a person or their family had lived in Canada or regardless of their ethno-cultural differences. However, a more detailed analysis of information shows that there are considerable differences among different ethnic groups' voting behaviour. Chart 4 shows the proportion of respondents of the ESC survey who said they voted in the last federal and provincial elections by their region of origin. As shown here, turnout rates for non-European immigrants are more than 20 percentage points lower than native born Canadians and approximately 10 percentage points lower than immigrants from European countries. 


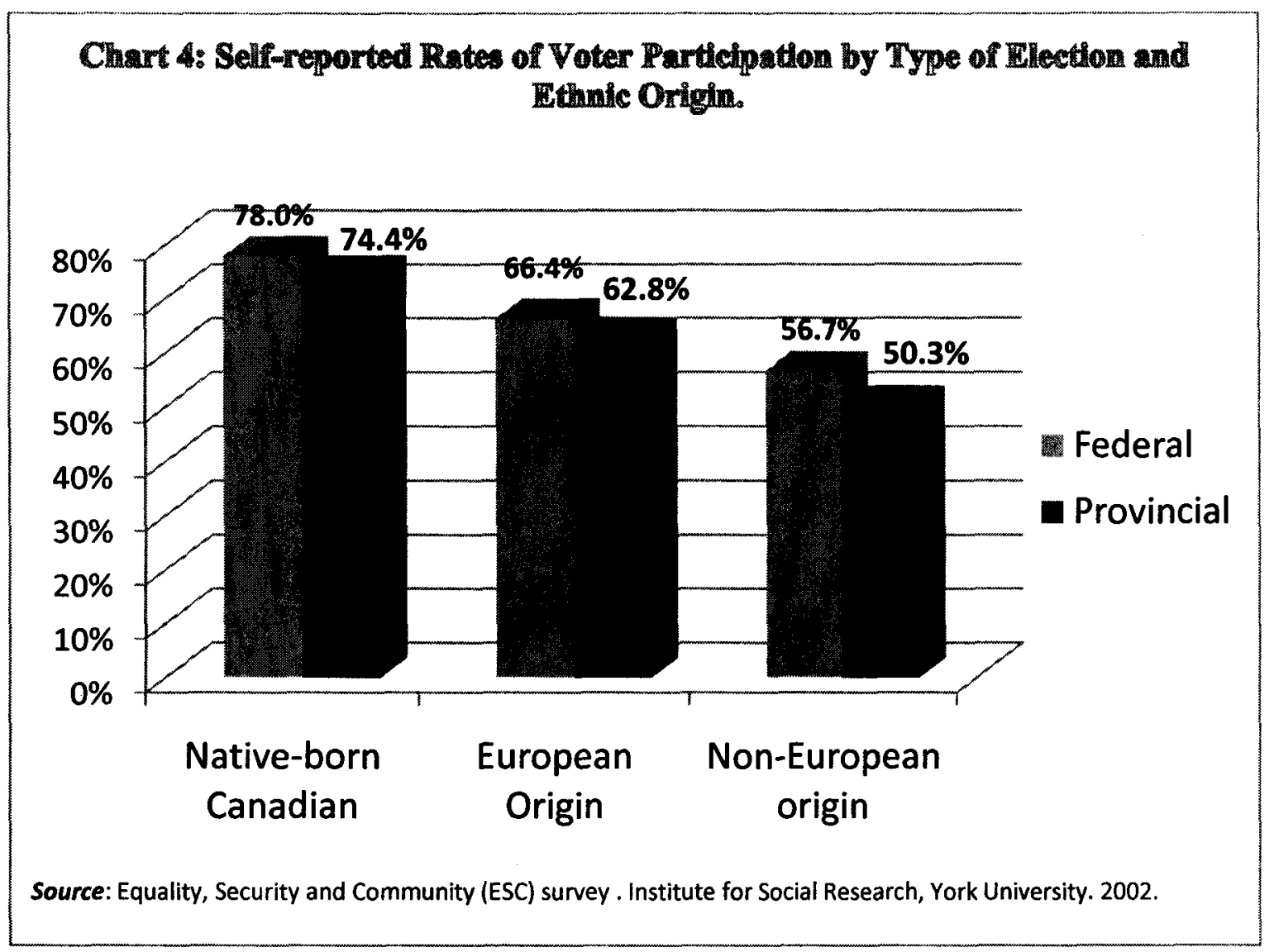

We should not forget that these three groups possess diverse ethnocultural makeup. The ESC results shows that among Europeans, those from Eastern and Southern Europe have a lower tendency to vote than those from Northern and Western Europe. Among Non-European immigrants as well, immigrants from East Asian countries and Africa had lower turnout rates in elections than those from South Asia and Central America.

Looking to other databases and studies, similar trends are observable. For example, by using EDS data, Jack Jedwab came to the conclusion that immigrants born in Asia, the Middle East and Latin America report lower rates of voting in federal elections than the Canadian-born electorate (Jedwab 2006, 7). Chart 5 presents the findings of EDS. 


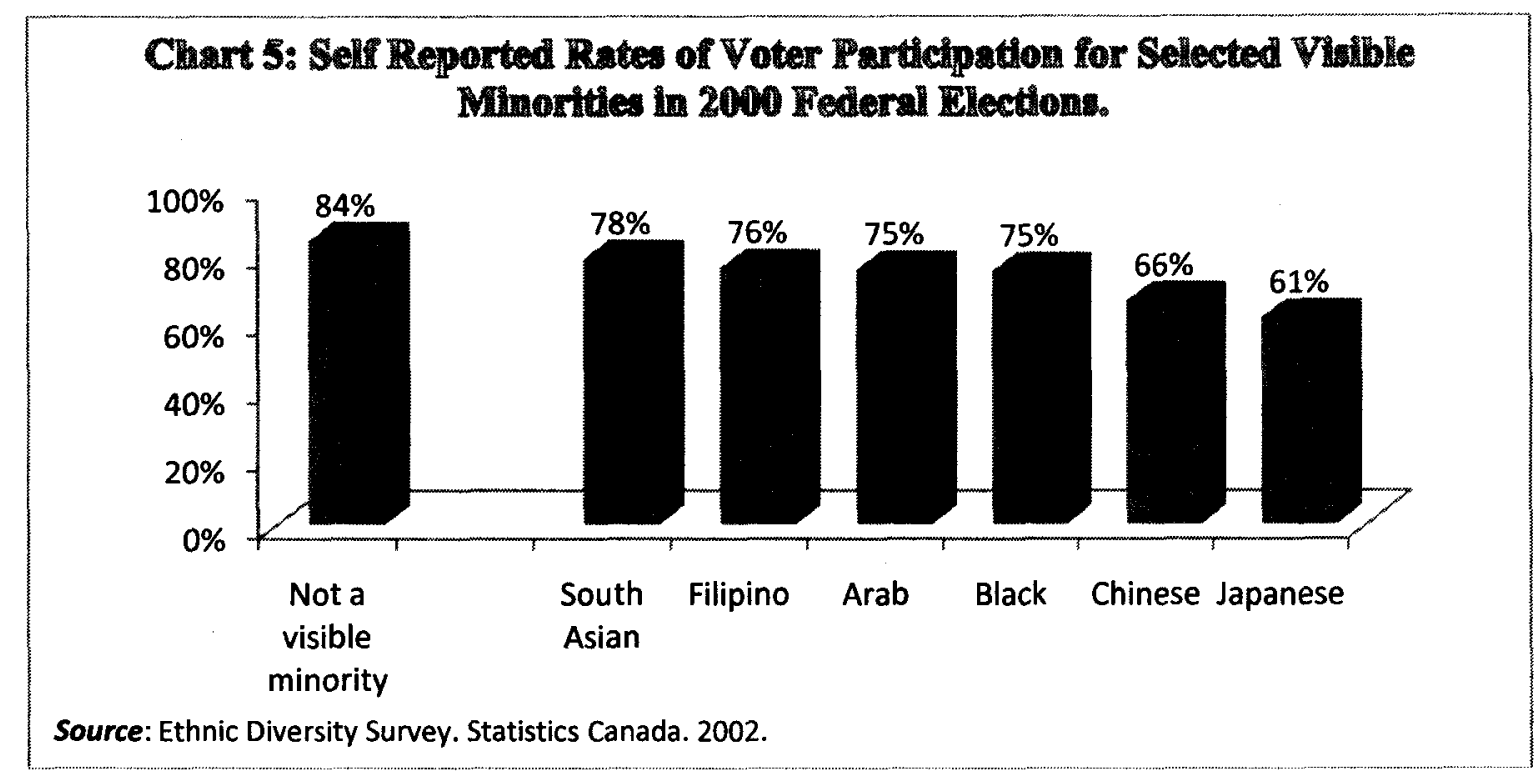

The findings of Non-voters survey by Elections Canada reveal that in comparison to the native-born electorate, immigrants reported more cases of being busy at work and lack of information as the main reasons they did not vote in the last election.

The partisan attachment of immigrants would be important for understanding the nature of their actions in the political arena. This kind of association with formal political players shows immigrants adaptation in the formal political process, as well as their ability to affect change through recognized political structures. The crucial role that political parties play in filtering candidates and giving them the prospect of getting into Parliament must also be considered. Even though the link between immigrants and their support for specific parties has been an issue analyzed and reported (See for example Tossutti and Najem, 2002 and Blais, 2005), so far little attention has been paid to the formal membership patterns of immigrants in political parties. As well, limited datasets containing quantitative information on the subject of immigrants' membership in political parties confines any effort to study this issue in detail. 


\section{Chart 6: Self Reported Rates of Membership in Federal Political Parties.}

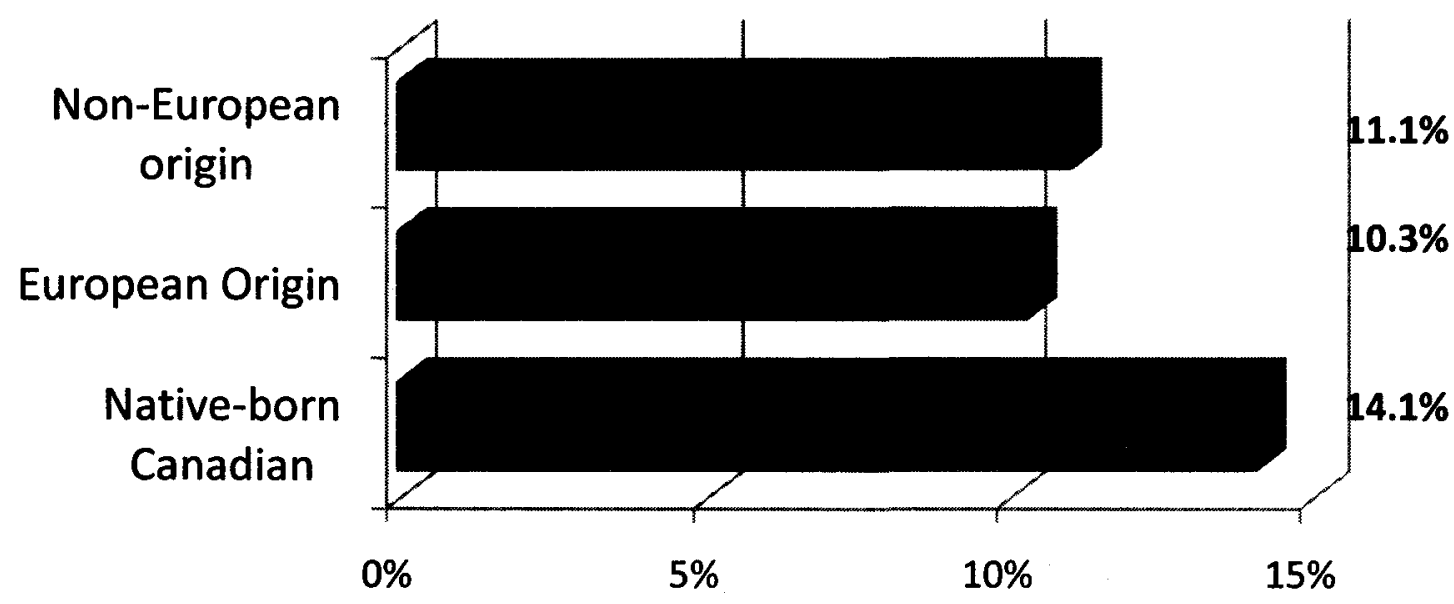

Source: Equality, Security and Community (ESC) survey . Institute for Social Research, York University. 2002.

Among available datasets that contained information on the affiliation and membership of respondents (including immigrants) in political parties, ESC provides some useful insights on this issue. Chart 6 shows the average rates of ESC respondents' membership in federal political parties. Interestingly, the proportion of non-European origin immigrants who report membership in political parties exceeds the rates of those with European origin, though both groups still report lower levels of membership in political parties than the native-born population. In a more detailed review of membership patterns in political parties, ESC results reveal that members of special ethnic groups report much higher rates of partisanship than others. For example, immigrants from Jamaica (36.4\%), and India (21.2\%) report much higher levels of partisanship than others. This finding explains somewhat why the average rate of partisanship among non-European immigrants is higher than European immigrants. 
As noted above, those conducting research on the relationship between immigrants and political parties deal mainly with the extent to which immigrants support a specific party in elections at federal and provincial levels (See for example Gerber, 2006). In the last few years, just before any federal election, media has been covered by reports pointing out the role of the immigrant vote in the gains of Liberal party in major metropolitan areas (see for example Cowan, 2006 and Jimenez, 2008). However, the results of ESC presented in graph 5 show that immigrants have in general less feeling of closeness to one specific party, compared to the native-born. Looking to this number, it is not clear why "for years immigrants voted in a bloc" as Linda Gerber noted in 2006. Marina Jimenez suggests that Liberals rely on their brand as a pro-immigrant party. She argues that immigrants who arrived under the Liberal governments of the 1960s, 70 s and 80s remained loyal, as the party reaped the benefit of being the point of first contact. It was the Liberals who introduced multiculturalism and the point system in 1967, selecting immigrants based on skills and education instead of ethnic background. It seems the Liberals are losing their support among immigrants; the latest studies show that $58 \%$ of visible-minority newcomers supported the Liberals in the 2006 federal election, down from $71 \%$ in 2000 , according to an analysis of the Canadian Election Study (Jiménez $2008,6)$. Generally, though, immigrants do not have a formal and long term affiliation to one specific party, yet in time of election they mainly support the Liberals more than others. 


\section{Chart 7: Proportion of Respondents Who Feel Closer to One of Federal Parties Than Others}

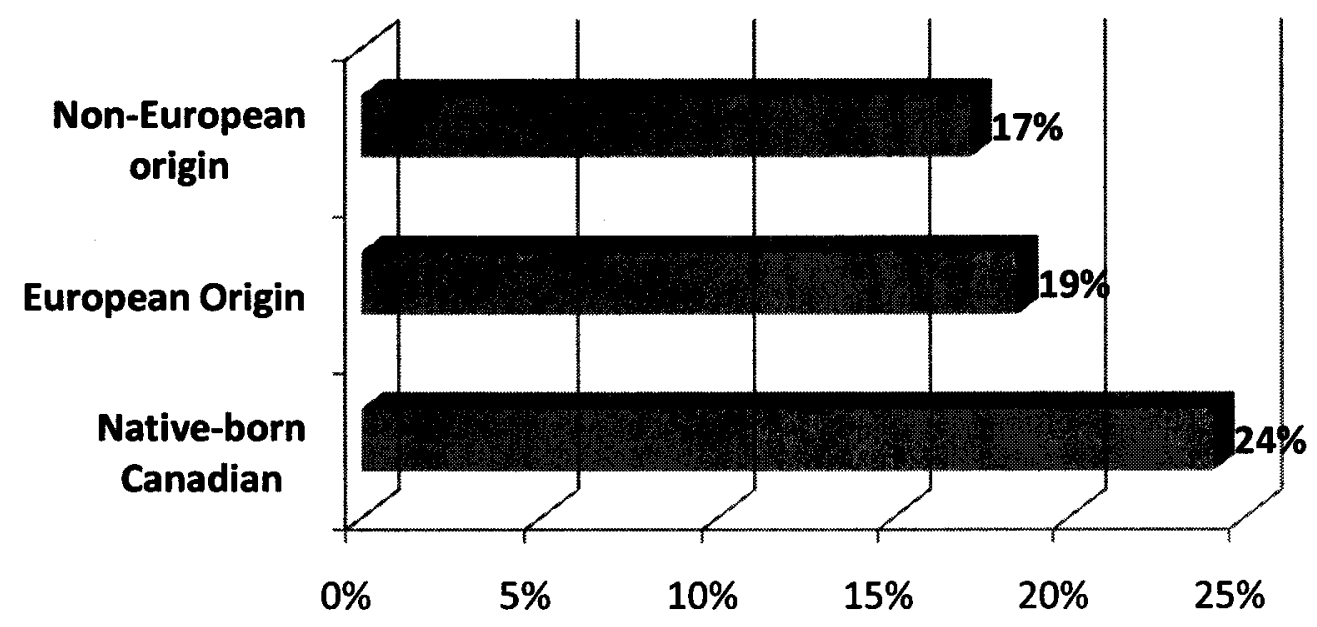

Source: Equality, Security and Community (ESC) survey . Institute for Social Research, York University. 2002.

Another aspect of the comparison between recent immigrants with both the nativeborn and those who are more established, relates to their level of representation in different levels of government. No doubt, seeking or holding a political office by immigrant groups is a clear symbolic sign of their integration in the Canadian political system, which is based on the representation of different elements of society.

The study of representation is caught in a permanent tension. While some authors are concerned with the substantive representation, which mainly focuses on what is represented, others tend to focus on the importance of mirror representation. The latter means the legislature is representative of the general public if it mirrors the ethnic, gender, or class characteristics of the public (Birch 1964, 16). According to Carolle Simard, the significance of representation is beyond the creation of policy measures and the drafting of legislation, and political representation also carries with it a symbolic importance, especially in a nation whose numbers and proportion of visible minority immigrants are expected to increase considerably in the next couple of decades. She 
argues that it is crucial that all communities, regardless of race, ethnicity or country of origin, feel they have access to the political system (Simard 2000).

Considering the unpleasant political experiences of visible minority immigrants in the past, it is not easy to ignore the symbolic value of mirror representation. Historically, for varied reasons, immigrants from non-European countries have long been absent or notably under-represented in all three levels of government in Canada. Even as late as the early 1950s, selected immigrant groups were explicitly excluded from the political system. The effects of these exclusions still have some implications today and although gains have been made in the last two decades, available data suggests that visible minority immigrants are not represented in elected offices in proportions accurately reflecting their share of the overall Canadian population.

With regard to under-representation of immigrant groups in different levels of government, the latest data suggests a few gains in some areas in the last twenty years, but still gaps between visible minority immigrants and native-born Canadians persist in most areas. Based on numbers presented by Anderson and Black $(2008,62)$, the number of visible minority immigrants winning a seat in federal elections rose from a handful to 13 in 1993 federal elections, which was still far below their corresponding share of population. In comparison, European origin immigrants won enough seats in the same election to achieve parity with their respective population. Since then, the increases in representation of visible minority immigrants in Canadian parliament have been irregular and fairly small. For instance, in the 1997 federal election, 19 visible minority MPs were elected to Parliament, but in the next election their number dropped to 17 . In 2004 the number rose to 22 seats, which represented $7.1 \%$ of the total seats in the House of 
Commons. At the same time, based on 2001 census results, visible minorities constituted $14.9 \%$ of the general population. For 2006 , the proportion of visible minority MPs climbed to $7.8 \%$, but again the share of visible minorities in the general population increased to $15.9 \%$ (Black, 2007).

It is important to note the variations in representation across different visible minority groups. As table 6 shows, compared to South Asians and Arabs, Chinese and Blacks are sharply underrepresented in Canadian Parliament (Matheson, 2006).

Table 6: Visible Minority Representation in $39^{\text {th }}$ Parliament

\begin{tabular}{|l|c|c|c|}
\hline $\begin{array}{l}\text { Minority } \\
\text { Community }\end{array}$ & $\begin{array}{c}\text { MPs in 39 } \\
\text { Parliament }\end{array}$ & $\begin{array}{c}\text { \% of seats in } \\
\text { Parliament }\end{array}$ & $\begin{array}{c}\text { \% of general } \\
\text { population }\end{array}$ \\
\hline South Asian & 10 & 3.3 & 3.1 \\
Chinese & 5 & 1.6 & 3.7 \\
Black & 4 & 1.3 & 2.2 \\
Arab & 3 & 1 & 0.7 \\
Latin & 1 & 0.3 & 0.7 \\
Japanese & 1 & 0.3 & 0.3 \\
Filipino & 0 & 0 & 1 \\
\hline
\end{tabular}

Source: Andrew Matheson. Seeking Inclusion: South Asian Political Representation in Suburban Canada. Electoral Insight. December 2006.

http://www.elections.ca/eca/eim/article search/article.asp?id=146\&lang=e\&frmPageSize $=\&$ textonly=false

According to Anderson and Black $(2008,63)$, the reason behind the limited number of visible minority MPs is their relative absence among parliamentary candidates. They note that over the $1993-2000$ period, visible minorities comprised only 4 to $5 \%$ of candidates running for the main parties. In a similar note, Jean-Pierre Kingsley, chief electoral officer of Canada, indicated in a speech in Ottawa in March 2002 that, based on a study conducted by for the Royal Commission on Electoral Reform and Party Financing, visible minority candidates were more likely to be presented in electoral districts the party considered unlikely to support them in any case (Kingsley 2002). 
Table 7: Electoral representation across Canada

\begin{tabular}{|c|c|c|c|}
\hline & & Visible Minority & Foreign Born \\
\hline Calgary & $\begin{array}{l}\text { Percentage among elected officials } \\
\text { Percentage among population } \\
\text { Proportionality index }\end{array}$ & $\begin{array}{c}11 \\
17 \\
0.64\end{array}$ & $\begin{array}{c}18 \\
21 \\
0.83\end{array}$ \\
\hline Edmonton & $\begin{array}{l}\text { Percentage among elected officials } \\
\text { Percentage among population } \\
\text { Proportionality index }\end{array}$ & $\begin{array}{c}10 \\
15 \\
0.66\end{array}$ & $\begin{array}{c}22 \\
18 \\
1.23\end{array}$ \\
\hline Halifax & $\begin{array}{l}\text { Percentage among elected officials } \\
\text { Percentage among population } \\
\text { Proportionality index }\end{array}$ & $\begin{array}{l}0 \\
7 \\
0\end{array}$ & $\begin{array}{c}4 \\
7 \\
0.57\end{array}$ \\
\hline Hamilton & $\begin{array}{l}\text { Percentage among elected officials } \\
\text { Percentage among population } \\
\text { Proportionality index }\end{array}$ & $\begin{array}{c}4 \\
11 \\
0.37\end{array}$ & $\begin{array}{c}8 \\
25 \\
0.33\end{array}$ \\
\hline Montréal & $\begin{array}{l}\text { Percentage among elected officials } \\
\text { Percentage among population } \\
\text { Proportionality index }\end{array}$ & $\begin{array}{c}3 \\
21 \\
0.15\end{array}$ & $\begin{array}{c}7 \\
33 \\
0.21\end{array}$ \\
\hline Ottawa & $\begin{array}{l}\text { Percentage among elected officials } \\
\text { Percentage among population } \\
\text { Proportionality index }\end{array}$ & $\begin{array}{c}3 \\
18 \\
0.17\end{array}$ & $\begin{array}{l}11 \\
22 \\
0.5\end{array}$ \\
\hline Regina & $\begin{array}{l}\text { Percentage among elected officials } \\
\text { Percentage among population } \\
\text { Proportionality index }\end{array}$ & $\begin{array}{l}0 \\
5 \\
0\end{array}$ & $\begin{array}{c}13 \\
8 \\
1.63 \\
\end{array}$ \\
\hline Saskatoon & $\begin{array}{l}\text { Percentage among elected officials } \\
\text { Percentage among population } \\
\text { Proportionality index }\end{array}$ & $\begin{array}{l}0 \\
6 \\
0\end{array}$ & $\begin{array}{c}3 \\
8 \\
0.39\end{array}$ \\
\hline Toronto & $\begin{array}{l}\text { Percentage among elected officials } \\
\text { Percentage among population } \\
\text { Proportionality index }\end{array}$ & $\begin{array}{c}11 \\
43 \\
0.26\end{array}$ & $\begin{array}{c}33 \\
49 \\
0.67\end{array}$ \\
\hline Vancouver & $\begin{array}{l}\text { Percentage among elected officials } \\
\text { Percentage among population } \\
\text { Proportionality index }\end{array}$ & $\begin{array}{r}23 \\
49 \\
0.47 \\
\end{array}$ & $\begin{array}{c}31 \\
48 \\
0.65\end{array}$ \\
\hline Winnipeg & $\begin{array}{l}\text { Percentage among elected officials } \\
\text { Percentage among population } \\
\text { Proportionality index }\end{array}$ & $\begin{array}{c}7 \\
13 \\
0.54\end{array}$ & $\begin{array}{c}15 \\
17 \\
0.88\end{array}$ \\
\hline $\begin{array}{l}\text { Members of } \\
\text { Parliament (MPs) }\end{array}$ & $\begin{array}{l}\text { Percentage among elected officials } \\
\text { Percentage among population } \\
\text { Proportionality index }\end{array}$ & $\begin{array}{c}7 \\
15 \\
0.48\end{array}$ & $\begin{array}{c}12 \\
18 \\
0.67\end{array}$ \\
\hline
\end{tabular}

Source: Executive summary of "Electing a Diverse Canada: The Representation of Immigrants, Minorities and Women" edited by Caroline Andrew, John Biles, Myer Siemiatycki and Erin Tolley. Presented at Breakfast on the Hill. February 28, 2008.

http://www.fedcan.ca/english/pdf/advocacy/BOH_Andrew0208.pdf

Surprisingly, as noted by Karen Bird $(2005,80)$, visible minorities are far less numerous in local politics in Canada than they are in other immigrant-receiving countries. Most notably, in the case of the three largest metropolitan areas of Toronto, 
Vancouver and Montreal, which are Canada's main multicultural hubs, visible minority councillors occupy lower share of seats in comparison to their share of the general population. In Toronto, for example, just 11.1 per cent of seats on city council are held by visible minorities, though 36.8 per cent of the population in the metropolitan area identify themselves as a visible minority.

Certainly, more extensive research is needed to better understand the barriers preventing effective representation of visible minority groups and to better understand the role played by these representatives once elected. Nevertheless, the evidence presented above points to some crucial questions facing the democratic structures of Canadian political system and how to ensure proper representation of visible minority immigrants in the House of Commons and other decision making political structures. So far, the slow reaction of the electoral system and political parties to the quickly changing demographic make-up of the Canadian population has resulted in a noticeable disconnect between visible minority immigrants and representative bodies. Based on a survey of non-voters by Election Canada, almost half (48\%) of respondents with a first language other than English or French pointed out that they did not vote in the last election because they thought their vote would not matter. The same measure for English and French speakers were $40 \%$ and 30\% respectively (Pammett and LeDuc 2003). Another cross tabulation between the place of birth and the reason for not voting produced a similar result. While close to half (47\%) of immigrant respondents mentioned that they did not vote because it would not matter, only $37 \%$ of native-born Canadians gave that reason for not voting.

I think this negative feeling about political participation is pointing to a larger disconnect and feeling of marginalization among visible minority immigrants. It is 
somehow an expression of their wider disconnect for the liberal state, which they feel cares less about them than about native-born white citizens. On the other side of the spectrum, some feel that immigrants' hesitation to get involved and connected to Canadian political structures is mainly a demonstration of their connection to their origin more than to Canada. They argue that ethnic organizations are more vocal and active in lobbying the Canadian government to push for specific foreign policy issues than they are with respect to important issues facing Canada today, such as health care, the economy, and the environment, to name a few.

\section{The Problematic of the Immigrant's Social Integration:}

Limited access to the labour market and a lower level of political participation are not the whole story of the problematic of immigrant integration. In fact, as Gunnar Myrdal pointed out in his classic study of racial inequalities in United States in the 1940s (Myrdal 1944), inequality and limited access to economic and political resources may not be perceived unfair if it is regarded as the result of understandable and legitimate circumstances, such as newcomer status and lack of sufficient language skills or training that does not match Canadian job requirements. However, systemic racism, prejudice and discrimination are another matter. Not unexpectedly, discriminatory treatment is more likely to be perceived by immigrants as unjust and lead to more segregation, exclusion and negative feelings about the state, the host society, and their fairness and justice.

While some observers suggest that Canada is doing well in this area and the patterns of immigrants' social integration is generally positive, others believe that policies designed to integrate socially new immigrants are failing to produce the intended 
results and the speed of integration for new waves of immigrants is much slower than previous generations.

On the positive side, observers mainly compare Canada with Western European countries and sometimes to the United States. They argue that in Canada there is little evidence of the deep social segregation felt in parts of Europe. Even though the income level of visible minority immigrants is generally lower than their native-born counterparts, there is not as much deep-rooted racial concentration in poor ghettos. With regard to learning the common language, a large majority of immigrants have at least a basic level of language proficiency and can manage their day to day life in Canada. The general attitude of people toward immigrants and immigration is still more positive in Canada than other Western countries, and so on. On the other hand, those who compare current trends of new immigrants' social integration with previous waves of immigrants to Canada believe that, not only is the speed of integration very slow, but that in many ways even some second and third generations of visible minority immigrants are still facing the challenges of social integration.

In this section, we review these arguments and evidence provided by both sides with regard to the social integration of immigrants in Canada. From an academic point of view, thus far the limited number of studies and analysis related to the social integration of new immigrants in Canada has shown a notable confusion. Different disciplinary approaches tend to emphasize different modes of comparison and different types of factors in their understanding and measurement of the extent of immigrants' social integration. While some stress the importance of the personal and socioeconomic factors, others emphasize the systemic and institutional variables. In fact, in my review of the 
information, I did not find anything inherently contradictory between these two sets of factors. Therefore, I will look at both of them, to a greater or lesser degree. However, to avoid inconsistency and to be more organized, these factors will be studied from two separate angles. The first angle covers the native-born population and their feelings and attitudes toward immigrants, as well as their general concerns regarding immigration, diversity, and multiculturalism. The second slant examines the extent to which immigrants feel comfortable in Canada and see themselves as an equal and integral part of the Canadian society. In both cases, I look at the effect of individual characteristics, as well as institutional structures, on the interaction between these two groups, particularly from the perspective of social cohesion.

To begin with the first set of factors, the general attitudes of native-born Canadians toward immigrants and immigration has been an issue addressed by most immigration related surveys and studies. Compared to most other Western nations, Canadians' attitude toward immigration has been uncommonly stable, and shown to be predominantly liberal and moderate. Unsurprisingly then, aside from Australia and Israel, since 1945 Canada has received more immigrants per capita than any other country in the world. Findings of recent research published in International Migration Review (Simon \& Sikich 2007) shows that, in general, Canadians have a more positive attitude toward immigration and immigrants than other Western societies. For example, table 8 clearly shows that Canadians have a more positive attitude toward the flow of immigration, while close to $80 \%$ of respondents in countries like Great Britain or Germany asked for a reduction of the number of immigrants. In this study Simon and Sikich also looked at people's attitude towards immigrants' impact on the economy, crime and cultural development and, as 
expected, in all categories Canadians have more positive feelings about immigrants than those of other nations. This is remarkable, even though, there have been occasions when outsiders have abused Canada's immigration system (Griego 1994, 120).

Table 8: Opinions about Whether the Number of Immigrants to the Country Should be Increased, Reduced or Remain the Same, 1995-2003 (In Percent)

\begin{tabular}{|c|c|c|c|c|c|c|}
\hline Country & $\begin{array}{c}\text { Increase } \\
\text { a Lot }\end{array}$ & $\begin{array}{c}\text { Increase } \\
\text { a little } \\
\end{array}$ & $\begin{array}{c}\text { Remain } \\
\text { Same }\end{array}$ & $\begin{array}{l}\text { Reduce } \\
\text { a Little } \\
\end{array}$ & $\begin{array}{c}\text { Reduce a } \\
\text { Lot }\end{array}$ & Total \\
\hline $\begin{array}{l}\text { Australia } \\
1995 \\
2003 \\
\end{array}$ & $\begin{array}{l}2 \\
6 \\
\end{array}$ & $\begin{array}{c}9 \\
17 \\
\end{array}$ & $\begin{array}{l}28 \\
38 \\
\end{array}$ & $\begin{array}{l}31 \\
21 \\
\end{array}$ & $\begin{array}{l}30 \\
18 \\
\end{array}$ & $\begin{array}{l}100(2,237) \\
100(2,018)\end{array}$ \\
\hline $\begin{array}{l}\text { Canada } \\
1995 \\
2003 \\
\end{array}$ & $\begin{array}{l}7 \\
7 \\
\end{array}$ & $\begin{array}{l}14 \\
22 \\
\end{array}$ & $\begin{array}{l}37 \\
39 \\
\end{array}$ & $\begin{array}{l}23 \\
21 \\
\end{array}$ & $\begin{array}{l}19 \\
11 \\
\end{array}$ & $\begin{array}{l}100(1,307) \\
100(1,080) \\
\end{array}$ \\
\hline $\begin{array}{l}\text { West Germany } \\
1995 \\
2003 \\
\end{array}$ & $\begin{array}{l}1 \\
1 \\
\end{array}$ & $\begin{array}{l}2 \\
5 \\
\end{array}$ & $\begin{array}{l}20 \\
24 \\
\end{array}$ & $\begin{array}{l}26 \\
27 \\
\end{array}$ & $\begin{array}{l}52 \\
44 \\
\end{array}$ & $\begin{array}{c}100(1,100) \\
100(762) \\
\end{array}$ \\
\hline $\begin{array}{l}\text { East Germany } \\
1995 \\
2003 \\
\end{array}$ & $\begin{array}{l}1 \\
1 \\
\end{array}$ & $\begin{array}{l}1 \\
2 \\
\end{array}$ & $\begin{array}{l}19 \\
19 \\
\end{array}$ & $\begin{array}{l}22 \\
24 \\
\end{array}$ & $\begin{array}{l}57 \\
55 \\
\end{array}$ & $\begin{array}{c}(100(553) \\
100(402) \\
\end{array}$ \\
\hline $\begin{array}{l}\text { Great Britain } \\
1995 \\
2003 \\
\end{array}$ & $\begin{array}{l}1 \\
2 \\
\end{array}$ & $\begin{array}{l}3 \\
4 \\
\end{array}$ & $\begin{array}{l}28 \\
16 \\
\end{array}$ & $\begin{array}{l}26 \\
24 \\
\end{array}$ & $\begin{array}{l}43 \\
54 \\
\end{array}$ & $\begin{array}{l}100(954) \\
100(816)\end{array}$ \\
\hline $\begin{array}{l}\text { Japan } \\
1995 \\
2003 \\
\end{array}$ & $\begin{array}{l}4 \\
3 \\
\end{array}$ & $\begin{array}{l}12 \\
10 \\
\end{array}$ & $\begin{array}{l}42 \\
35 \\
\end{array}$ & $\begin{array}{l}26 \\
27 \\
\end{array}$ & $\begin{array}{l}16 \\
25 \\
\end{array}$ & $\begin{array}{c}100(1,046) \\
100(902) \\
\end{array}$ \\
\hline $\begin{array}{l}\text { United States } \\
1995 \\
2003 \\
\end{array}$ & $\begin{array}{l}2 \\
4 \\
\end{array}$ & $\begin{array}{l}6 \\
7 \\
\end{array}$ & $\begin{array}{l}26 \\
32 \\
\end{array}$ & $\begin{array}{l}30 \\
31 \\
\end{array}$ & $\begin{array}{l}36 \\
25 \\
\end{array}$ & $\begin{array}{l}100(1,075) \\
100(1,093) \\
\end{array}$ \\
\hline $\begin{array}{l}\text { France } \\
2003\end{array}$ & 3 & 5 & 26 & 24 & 41 & $100(1,421)$ \\
\hline
\end{tabular}

Source: Rita J. Simon, and Keri W. Sikich. 2007. Public Attitudes toward Immigrants and Immigration Policies across Seven Nations. International Migration Review. Volume 41 Number 4, 956-962

From another standpoint, Wilkes, Guppy and Farris (2008) examined the way individual-level characteristics and national context affected attitudes toward immigration in Canada over time. Taking advantage of seventeen national Canadian Gallup surveys between 1975 and 2000, they concluded that while ethno-cultural considerations, 
personal interests and national economic outcomes affect anti-immigration sentiments, only ethno-cultural considerations affect pro-immigration sentiments. They found that people who speak a language other than English or French hold more positive attitudes toward immigration than do members of the majority group. Table 9 captures the respondents' views about the levels of immigration. Other than language, education level shows the strongest association with individual attitudes. People with a university education are twice as likely as those with only elementary education to want more immigration ( $21 \%$ vs. $9 \%$ ). Conversely, people with only elementary or high school education

Table 9: Percentage of each Group Who Want Given Levels of Immigration, 1975-2000.

\begin{tabular}{||l|c|c|c|c||}
\hline & Less & Same & More & N \\
\hline Gender & 42.36 & 43.07 & 14.57 & 7,068 \\
Male & 43.8 & 46 & 10.2 & 7,278 \\
Female & & & & \\
Language & 46.72 & 42.14 & 11.14 & 8,883 \\
English & 40.92 & 48.32 & 10.76 & 3,812 \\
French & 28.59 & 48.88 & 22.53 & 1,651 \\
Other & & & & \\
Education & 48.53 & 42.79 & 8.69 & 1,865 \\
Elementary School & 48.58 & 42.47 & 8.95 & 6,035 \\
High School & 41.94 & 46.25 & 11.82 & 3,224 \\
College/Trades & 30.81 & 47.73 & 21.46 & 3,210 \\
University & & & & \\
Occupational Characteristics & 44.25 & 44.56 & 11.19 & 4,219 \\
Union Household & 42.61 & 44.55 & 12.84 & 10,127 \\
Non-Union Household & 36.61 & 46.69 & 16.7 & 3,761 \\
Higher Skill & 46.36 & 43.33 & 10.51 & 5,569 \\
Lower Skill & 42.43 & 44.68 & 12.88 & 9,330 \\
In Labour Force & 44.32 & 44.32 & 11.36 & 5,016 \\
Not in Labour Force & & & & \\
Vote Today & 47.9 & 40.57 & 11.53 & 3,002 \\
Conservative & 38.28 & 47.64 & 14.08 & 4,305 \\
Liberal & 44.49 & 41.23 & 14.28 & 1,870 \\
New Democratic Party & 44.38 & 45.04 & 10.58 & 4,727 \\
Other & 43.09 & 44.56 & 12.35 & 14,346 \\
\hline Total & & & & \\
\hline
\end{tabular}

Source: Rima Wilkes, Neil Guppy and Lily Farris. 2008. "No Thanks. We're Full": Individual Characteristics, National Context, and Changing Attitudes Toward Immigration. International Migration Review. Volume 42 Number 2. P 314. 
are among those wanting less immigration (about $49 \%$ each). From a political standpoint, supporters of the Liberal party are less likely to want less immigration than supporters of Canada's other major political parties.

The findings of a similar study by Fortin and Loewen (2004) is consistent with numbers provided in table 9. They also found that respondents born outside Canada and/or considered visible minorities are 40 to 60 percent less likely to favour a decrease in immigration levels than Caucasian and/or Canadian-born individuals. Their finding also reveal that those who identify with the Bloc Quebecois are more likely to favour restriction over the status quo on immigration levels, while those who self-identify with the left are less likely to favour this restriction. Nevertheless, the factor which, according to them, strongly predicts support for reduction in the number of immigrants to Canada is a negative evaluation of the impact of immigrants on Canadian unity and society. Answers provided to questions measuring disagreement or agreement to comments like "immigrants do not make an important contribution to Canada", that "Canadian unity is weakened when Canadians of different ethnic and cultural backgrounds stick to their old ways", and that "too many immigrants just don't want to fit into Canadian society," makes one close to 100 times more likely to favour restrictionist policies.

In fact, since the 1960s when Canada and other Western democracies opened their doors to diverse ethnic and religious groups of immigrants, fears and questions about the adoptability of new waves of visible minority immigrants and their impact on the cohesiveness of the host societies have been prominent. Across Western Europe in particular, a series of incidents in the last few years has boosted a widespread concern that multiculturalism and policies designed to integrate visible minority immigrants have 
gone too far, and have even been harmful. These concerns go well beyond issues of economic and political exclusion. In many countries, the majority doubts immigrants' respect for the values of liberal democracy and human rights, as well as the customs and traditions of the host society. They feel that visible minority immigrants do not do enough on their part to learn the language and history of the new country and there is no commitment to social, cultural, and political processes and national identity.

Likewise, in Canada, the results of a new survey for The Globe and Mail and CTV News published in April 2008, also show that a majority of Canadians say their country bends too much in trying to make visible minorities feel at home (Laghi 2008). According to the poll, 61 per cent of those surveyed believe that Canada makes too many accommodations for visible minorities. In Quebec, 72 per cent of those surveyed feel that way. So, it is not a surprise that in Quebec, the government called public hearings into the "reasonable accommodation" of immigrants.

Another poll conducted one month after the start of cross-Quebec hearings by the Bouchard-Taylor commission, which had a mandate to examine the issue of the "reasonable accommodation" of minorities, found that even though, like other Canadians, most Quebecers are happy in principle with immigrants and ethnic groups, unlike the rest of the country, they want minorities to assimilate. The poll showed that 56 per cent think minorities should be discouraged from forming their own communities in Quebec and in fact they wanted immigrants to abandon their cultural practices (Calgary Herald 2007). Even though other Canadians are more tolerant of immigrants' custom and traditions than Quebecers, after 3 decades of multiculturalism, 1 in 4 Canadians still want immigrants to give up their customs and traditions and assimilate. 
In the last couple of decades, research on the general attitude of the majority toward specific ethnic and immigrant groups has made an important contribution to ethno-racial studies. The preference for immigrants from specific regions or religious backgrounds has been an issue addressed in these studies (Kalin \& Berry, 1994). More than 30 years ago, in 1977, John Berry and his colleagues studied attitudes toward seven ethnic groups and found that the English were at the top, that is, they were evaluated the most favourably, followed by the French, the Jews, the Ukrainian, the Italian, Chinese and finally Indians (Berry et al 1977). Another study in the mid 1990s indicates that European groups (British, French, but also German, Italian, Portuguese) are still rated most favourably, whereas visible minorities (West Indian Black), groups from the middle east (Muslim and Arab), and from the Indian subcontinent (Indo-Pakistani, Sikh) tend to be rated less favourably. Eastern Asian, including the Chinese, occupy an intermediate position (Sabbatier \& Berry, 1994).

The findings above suggest that, more than anything else, it is the ethno-cultural origin of immigrants that is most highly correlated with negative sentiments of the majority toward immigration. These facts are also strongly relevant to the evaluation of the level of racism and discrimination in Canada. Surprisingly, even though systemic discrimination as a result of prejudice based on cultural and racial notions is cited as the possible explanation of slow integration of new immigrants, no one has thoroughly studied this parameter. Nonetheless, while it is difficult to document acts of racial discrimination, hate or bias, there are a few studies that confirm the significance of the phenomenon in Canada and its importance in the integration process of visible minority immigrants. 
To look at discrimination and prejudice in Canada, it is important to note that discrimination takes many forms. In a recent study published by the Canadian Race Relations Foundation, Kunz, Milan and Schetagne (2002) looked at discrimination in the educational system, employment and the labour market and its impact on income in Canada. They concluded that even though anti-racism legislation and policies could alter the behaviour of employers, it has a limited impact on the culture of the workplace or on individual attitudes (Kunz et al. 2002, 3). They also pointed out different subtle forms of discrimination, such as exclusion from social circles in the workplace and invisible walls in access to job promotions.

In a recently published study by the University of British Columbia and Metropolis Project, Philip Oreopoulos (2009) addressed the question of why skilled immigrants struggle in the Canadian labour market. As a part of this research, thousands of résumés were sent in response to online job postings across multiple occupation possibilities in Toronto. Résumés were constructed to represent plausibly recent immigrants under the point system from the three largest countries of origin (China, India, and Pakistan) and Britain, as well as non-immigrants with and without ethnic-sounding names. In addition to names, the research team randomized where applicants received their undergraduate degree, whether their job experience was gained in Toronto, Mumbai or another foreign city, and whether they listed being fluent in multiple languages, including French. Overall the results of this study suggest considerable employer discrimination against applicants with ethnic names or with experience from foreign firms, in spite of antiracism legislation. According to Oreopoulos, this research produced four main findings. First, the rate of inviting candidates to interview for English-named applicants with 
Canadian education and experience was three times higher than the rate of those with Chinese, Indian, or Pakistani names who has a foreign education and experience (5 percent versus 16 percent), but was no different compared to foreign applicants from Britain. As well, Canadian employers valued experience gained in Canada much more than experience acquired in a foreign country. Changing résumés to include only experience from Canada raised call back rates for interviews to 11 percent.

The next major finding was related to the impact of about degrees obtained from Canada or abroad. Researchers found that for applicants who had a few years of Canadian work experience, it would not matter if their degree was obtained in Canada or abroad; they would receive the same rate of call backs. And finally, Canadian applicants that differed only by name had substantially different call back rates. Those with Englishsounding names received interview requests 40 percent more often than applicants with Chinese, Indian, or Pakistani names (16 percent versus 11 percent).

There is other evidence of discrimination against visible minorities that are as telling as Oreopoulos' survey data. For example, Banting et al (Banting, Courchene and Seidle 2007,656 ) pointed out that close to 7000 human rights cases are filed in the Ontario criminal justice system. On their review of data, they note that police stop Blacks twice as often as Whites. Whites are less likely to be detained before trial than Blacks, particularly on drug charges, and Blacks are denied bail more often and convicted more often. In view of the findings of studies like the two mentioned here, it is not a big surprise that one in five visible minority Canadians reported discrimination or unfair treatment 'sometimes' or 'often' in the EDS (Statistics Canada 2003, 18). Based on the survey results, about $20 \%$ of visible minorities, or 587,000 people, said they had 
sometimes or often experienced discrimination or unfair treatment in the previous five years because of their ethnicity, culture, race, skin colour, language, accent or religion. An additional $15 \%$ of visible minorities reported such treatment occurring rarely. Among visible minorities, Blacks were more likely than other groups to report feeling that they had been discriminated against or treated unfairly by others because of their ethnocultural characteristics. Chart 8 graphs the percentage of respondents reporting discrimination by race. As presented in the chart, other groups reporting high levels of discrimination are South Asians (21\%) and Chinese (18\%). Another 17\% of Blacks, $13 \%$ of South Asians and 15\% of Chinese reported that these experiences had occurred occasionally. Interestingly, the number of generations in Canada or length of stay did not make a big difference. According to the EDS results, about $21 \%$ of first-generation visible minorities, compared to $18 \%$ of visible minorities who had been in Canada for two or more generations, reported that they had sometimes or often experienced discrimination or unfair treatment in the previous five years.

\section{Chart 8: Percentage reporting discrimination or unfair treatment 'sometimes' or} 'often' in the past five years, by visible minority status, 2002

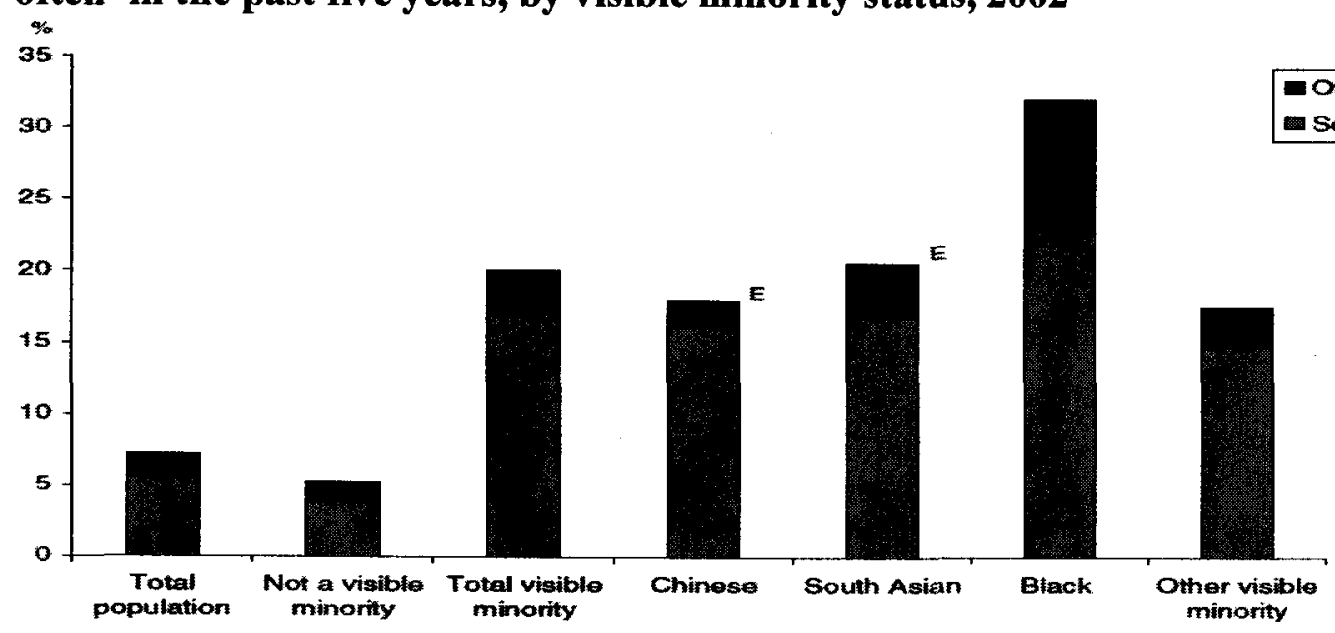

Source: Statistics Canada, Ethnic Diversity Survey, 2002. 
Another question of EDS was whether they thought they had been mistreated because of their ethnicity or culture, race or skin colour, language or accent, and/or religion. As expected, visible minorities who had experienced discrimination or unfair treatment were most likely to say that this had occurred because of their race or skin colour. Based on the survey results, more than 7 in 10 visible minorities $(71 \%)$ who reported discrimination or unfair treatment mentioned race or skin colour as the reason, either alone or in combination with other reasons.

In addition to perceived discrimination or unfair treatment, EDS revealed other interesting facts that are directly related to the social integration of visible minority immigrants in Canada. For example, this survey asked people how often they felt out of place in Canada at the time of the survey because of their ethnicity, culture, race, skin colour, language, accent or religion (Statistics Canada 2003, 17). In their response to this question, close to 1 in $4(24 \%) \%$ of all visible minorities in Canada said that they felt uncomfortable or out of place because of their ethno-cultural characteristics all, most, or some of the time. This was almost three times greater than the share of non-visible minorities who felt uncomfortable (8\%).

There are a number of studies that used the EDS findings to analyze the patterns of immigrant social integration in Canada. One of the best examples of such studies is a recently published paper by Reitz and Banerjee (2007). In this study, the authors utilized the large scope and richness of the EDS data to analyze the experiences of visible minority immigrants and compare them with their white counterparts. By distinguishing different generations of immigrants in Canada, they also ran a comparative analysis of attitudes and engagement of recent and earlier immigrants and their children born in 
Canada. Table 10 provides a summary of their major findings. It compares the results for Whites and visible minorities on the basis of all six indicators analyzed by Reitz and Banerjee. On five of the six indicators, visible minorities appear less integrated. The greatest gap between visible minorities and Whites is in self-identification as Canadian (30.7\%). There are also significant gaps in citizenship (18.3\%). The gap in citizenship undoubtedly reflects, at least in part, the significantly higher proportion of immigrants among visible minorities. There are smaller racial gaps in life satisfaction $(5.5 \%)$ and volunteering $(7.2 \%)$. On two indicators, sense of belonging and trust, there does not appear to be a significant overall racial difference. Interestingly, with regard to the sense of belonging to Canada, whereas overall it is higher for recent visible minority immigrants than for Whites, for the second generation respondents, all visible minorities have less of a sense of belonging to Canada than the Whites. Based on EDS findings, this is most striking in the case of Blacks, Chinese and even for South Asians (Reitz and Banarjee 2007, 609).

Table 10: Patterns of Visible Minority Social Integration into Canadian Society, $2002(\%)$

\begin{tabular}{|l|c|c|c|c|c|c|}
\hline & Belonging & Trust & $\begin{array}{c}\text { Canadian } \\
\text { Identity }\end{array}$ & Citizenship & $\begin{array}{c}\text { Life } \\
\text { Satisfaction }\end{array}$ & Volunteering \\
\hline Whites & 54.8 & 49.9 & 64.3 & 97.3 & 47.2 & 33.8 \\
All Visible Minorities & 58.6 & 47.9 & 33.6 & 79.0 & 41.7 & 26.6 \\
\hline Specific minority origins \\
\hline Chinese & 52.7 & 60.1 & 40.5 & 83.9 & 30.8 & 20.7 \\
South Asian & 64.9 & 49.0 & 30.5 & 73.3 & 48.4 & 29.1 \\
Blacks & 60.6 & 30.6 & 29.0 & 80.8 & 43.5 & 34.6 \\
Other visible minorities & 58.3 & 45.5 & 32.0 & 78.0 & 45.2 & 26.1 \\
\hline
\end{tabular}

Source: Reitz, Jeffrey and Rupa Banerjee. 2007. Racial Inequality, Social Cohesion and Policy Issues in Canada. In Belonging? Diversity, Recognition and Shared Citizenship in Canada. Eds Keith Banting, Thomas Courchene and F. Leslie Seidle. Montreal: Institute for Research on Public Policy. P 609 
The largest gap between visible minorities and the Whites is in the area of self identification as a Canadian. Interestingly, according to Reitz and Banerjee, for recently arrived immigrants there is no significant gap. Indeed, the Chinese group is more likely to identify as Canadian than are groups with European origin. However, the main gap is between recent immigrants and earlier generations. Based on their findings, for earlier immigrants of European origin, Canadian identification is higher than it is for newcomers by almost 32 percentage points, whereas for earlier immigrants who are racial minorities, Canadian identification is higher than for newcomers by only 13 percentage points. Thus, visible minorities are acquiring the sense of identification as Canadian at a much slower rate than their European counterparts. More significantly, among the second generation, the rate of Canadian identification for Whites is quite high (78.2\%), while for racial minorities it lags by over 20 percentage points (Reitz and Banarjee 2007, 610).

With regard to life satisfaction, Reitz and Banerjee concluded that recent visible minority immigrants are not less satisfied than Whites. They found that among recent immigrants, except for Chinese, visible minorities report higher levels of satisfaction than do those of European origin. It is expected that high levels of satisfaction for recent immigrants may be based on comparisons they make between life in their homeland and the future they expect in Canada. However, this is different for immigrants who have been in the country longer and for the second generation. According to Reitz and Banerjee, for second generation visible minority immigrants the levels of satisfaction are lower than for Whites (612). Regarding trust, while those of Chinese origin report a high level of trust, Blacks reported a very low level of trust. On the other hand, while Chinese 
and South Asians report a very low level of volunteering, Black levels of volunteering even surpass those of Whites.

The most striking conclusion of the Reitz and Banerjee study concerns the integration of second-generation immigrants. Based on their findings, they argue that patterns of immigrants' social integration are time-sensitive, and there are time-related variations between recent immigrants, earlier immigrants and the second generation. Chart 9 shows these variations, plus the effect of visible minority status on life satisfaction and sense of belonging.

\section{Chart 9: Effects of Visible Minority Status on Life Satisfaction and Sense of Belonging.}

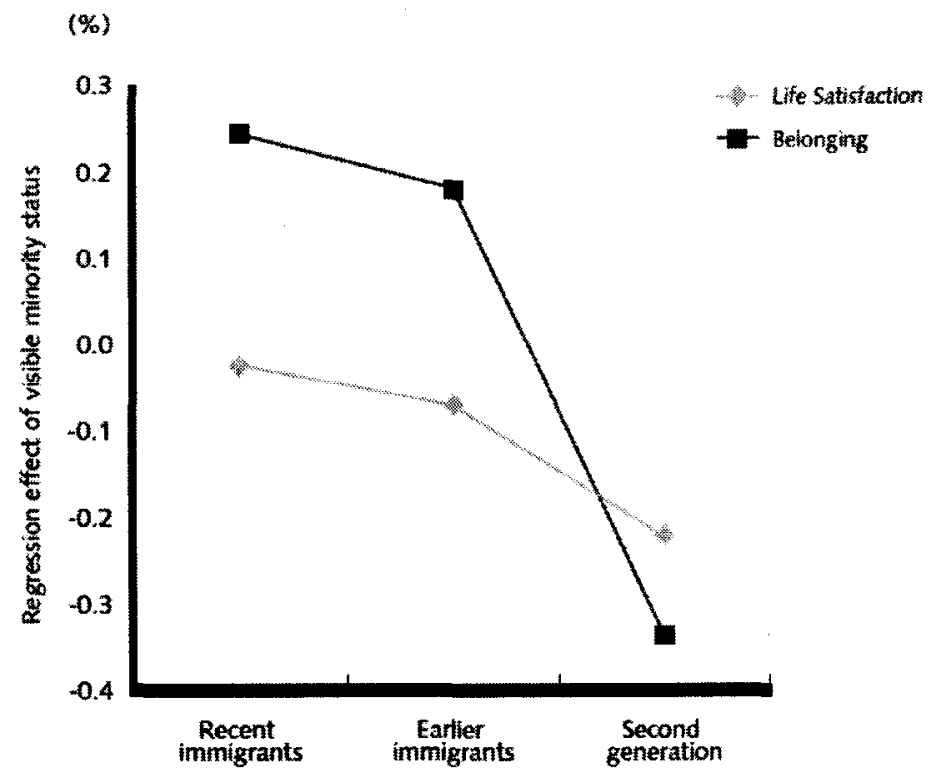

Note: Standardized OLS regression coefficients for effect of visible minority status with controls for age and, for immigrants, years since immigration.

Source: Reitz, Jeffrey and Rupa Banerjee. 2007. Racial Inequality, Social Cohesion and Policy Issues in Canada. In Belonging? Diversity, Recognition and Shared Citizenship in Canada. Eds Keith Banting, Thomas Courchene and F. Leslie Seidle. Montreal: Institute for Research on Public Policy. P 619 
As clearly presented in chart 9 , as one moves from recent immigrants to earlier immigrants and the second generation, the visible minority status has a significant negative impact on the social integration of immigrants, especially in their sense of belonging to Canada. Based on the facts summarized above, Reitz and Banerjee concluded that the social integration of visible minority immigrants into Canadian society is slower than for immigrants of European origin.

Another important dimension of immigrants' social integration is the degree to which diverse groups of immigrants actively participate in the daily life of their community, neighbourhood and society. The theory of social capital introduced by Robert Putnam (1995 and 2000) suggests that their day to day relationships with other members of society and the immigrants participation in their community and neighbourhood organizations strengthens their sense of belonging and boosts the general cohesion of society. On the other hand, in multiethnic societies, lack of contact between different ethnic groups increases the possibility of exclusion, discrimination and mistrust. In spite of multicultural policies in Canada, some empirical findings make it clear that ethno-cultural boundaries are a reality of Canadian social life. For example, even as most Canadians deny having racist views, they still prefer not to interact with members of other racial groups and maintain some sort of social distance from visible minorities (Reitz and Breton 1994). Memories of "Hérouxville code of conduct" is still fresh and people are still divided on their views on the question of cultural accommodation and intercultural relationships. In one of the inquiries headed by Charles Taylor and Gerard Bouchard, the co-chairs of the "Reasonable Accommodation Commission" conducted as a clear response to rising cultural cleavages in Quebec, one of the attendants sarcastically 
pointed out how we want immigrants to be themselves, but like ourselves. We want to welcome them, we are happy they are here, but they should not be seen (Than Ha 2007).

On the other side of the dialogue, visible minority immigrants hesitate to develop relationships with the majority. Much attention has recently been given to the impact of social networks and relationships on the successful integration of immigrants. Clearly, central to the process of creating trust and respect between different individuals is their capacity to develop relationships with others, especially those outside their cultural and ethnic group. Indeed, participation in social activities with those outside their limited cultural cycles helps immigrants widen their social networks and facilitates their learning about the daily lives of people in the new country and their adaptation in society.

The current pattern of Canadian diversity is one of greater concentration of visible minorities in a few metropolitan areas and their constrained and guarded relationships only with those from their ethnic group. Even though the patterns of relationships vary greatly from one place to another and from one cultural group to another, it seems in general that visible minority immigrants are somehow uncomfortable developing relationships with those outside their ethno-cultural groups because of economic and socio cultural fears, and particularly because of limited language abilities. For example, in an analysis of patterns of participation in informal social activities among Chinese immigrants in Toronto, Fong and Ooka found out that the majority of Chinese immigrants have limited participation in informal social activities in the wider society. Based on their findings, only about 15 percent enjoyed a high participation level in the social activities of the wider society, while about 54 percent and 30 percent maintained low or moderate levels $(2006,359)$. 
Similarly, the published results of EDS show that only about one-third of the first generation immigrants (34\%) who arrived in Canada in the 1990s indicated that they had taken part in the social activities of at least one group or organization in the previous year. This figure climbed to $37 \%$ for those who had arrived during the 1980 s and to $41 \%$ among those who had arrived before 1981. In comparison, almost half of second- and third-plus-generation Canadians reported participating in groups or organizations $(49 \%$ and $48 \%$, respectively). Not surprisingly, one area where the first generation tended to have a higher participation rate was in ethnic or immigrant associations (Statistics Canada 2003, 14).

This section pointed out several different ways in which socio-cultural borders are separating new visible minority immigrants and the native-born Canadians. As argued in the introductory chapter, for immigrants, integration is more of a process than a fixed moment. Starting in the early stages of settlement, inclusion in the economic, political, as well as social and cultural life of their new country is an ongoing challenge. In many ways, as we have seen in the attitudes and behaviours of the second generation, this challenge also continues into the next generations, which seek to strike a balance between their Canadian roots and their parents' origin.

As pointed out, negative attitudes toward immigrants and racial discrimination, as well as the lack of social contact between visible minority immigrants and native-born Canadians, can contribute to the rise of mistrust and prejudice in very significant ways. In the same way, these trends may adversely affect the social integration of visible minority immigrants in two ways. When it results in inequality and exclusion, it may undermine the sense of fairness, justice and belonging among immigrant individuals. It may also 
weaken the commonality of values, commitments and social relations among visible minority groups and the majority, thereby affecting the social cohesion and the capacity of people to cooperate in the pursuit of common objectives. Each dimension is important in its own way and they may have a combined effect on the substantial integration of visible minority immigrants into Canadian society. 


\section{Chapter III: Characteristics of New Immigrants}

When people live together for a long period of time, they interact, they intermarry and develop certain common characteristics, values and behaviours, which they pass to their succeeding generations. Having similar characteristics and beliefs, helps them communicate and relate to each other with no major difficulty and creates a sense of common belonging. When an immigrant enters a new country, she needs time (maybe a couple of generations) to develop the same kind of characteristics as that of the majority and develop the same sense of belonging. Research shows that developing this sense of belonging is influenced by demographic characteristics of the new immigrant, as well as her individual interests, habits, values and so on. New comers often re-evaluate and adjust their behaviour and understanding of their limits over time and through interaction with the social networks and the culture of the majority. In addition to their age and sex, as well as the differences between the culture of the country of origin and destination, other factors like religiosity, family values, language proficiency, education and economic well being play key roles throughout this process.

I pointed out the importance of immigrants' perceptions of the new society, justice and role for their successful integration in the new society in the first chapter of this dissertation. Understanding the relationship between demographic and socio-cultural characteristics of immigrants with the formation of these perceptions among them provides helpful insight into the integration of new immigrants. Knowing more about how and where these characteristics weigh in the process of integration is central to the objective of this dissertation and toward a better understanding of the immigrant's relationship with the liberal state and society. The goal of this chapter is to review the 
available information on demographic, educational, linguistic and religious characteristics of new immigrants and to find out what has changed during the last fifty years and how these changes affect the integration of new immigrants. I am particularly interested in understanding those factors that influence the dynamics of the relationship between the immigrant and the state, as well as other relationships such as employment relationships and immigrants' involvement in the labour market, community, neighbourhood and so on.

The empirical study on immigrant characteristics starts with a short review of the historical background of immigration in Canada. As a first step in examining what has been changed in the last fifty years, I will go over the rise and fall of immigrant numbers and the reasons behind them. Then, in a broader review of immigrants' origins, I will check the pull and push factors that affect the immigration patterns in Canada. I am especially interested in the impact of Canadian immigration policies on this process.

\section{Historical Patterns and Policies:}

In 1534 Jacques Cartier made his way through the Gulf of St. Lawrence and reached the shores of Canada, of which he took possession in the name of the king of France. On a second voyage in 1535 , he sailed up the St. Lawrence river and reached Quebec. Later in the second half of the $16^{\text {th }}$ century, several attempts were made to establish French settlements, none of which met with success. The agricultural and industrial revolutions in Western Europe and the subsequent expansion of the European population that began during the $17^{\text {th }}$ century changed this situation slightly and resulted in some interest in North America. However, throughout the seventeenth and eighteenth century, the settlement of Canada was not a high priority for the French government. On 
the European side of the Atlantic, migration was still not that popular among the people, and on the American side French traders were afraid that settlers would interfere in their profitable trade with the native people. In addition, the environmental conditions of Canada were harsh and the survival of early settlements depended to a great extent on the continuing flow of traders, soldiers, priests, and administrators from France. As a result, up to the end of the $17^{\text {th }}$ century the population of French inhabitants in this vast territory never reached a significant number. In 1666 the population of New France was just 3215 (Herrick and Stuart 2005, 138). As was typical of early settlements, most of the inhabitants were single and male, but increasing numbers of settlers arriving from France ultimately established a population capable of sustaining itself through natural increase. During the next 100 years, birthrates ranged from 50 to 65 births per 1000 population and produced a sufficient excess of births over deaths for the population to reach 65,000 by the time British had won political control of the region in 1763.

Even though the British takeover of the French possessions in North America did not cause a rush of English immigration, the situation changed with the American Revolution, as loyalists fled for Canada. The War of 1812 attracted more attention to the necessity for a larger population in Canada, particularly of those with British sympathies. Therefore, as a result of this war, a policy of encouraging immigration was adopted. As part of this policy, free grants of land and subsidies were provided to new immigrants from England, Scotland and Ireland. However, in general, the number of immigrants settling in Canada continued to be small and mainly dependent on the "push factors" in 
the sending countries, rather than Canadian "pull factors." For example, the massive Irish migration to Canada in the middle of $19^{\text {th }}$ century was driven by the potato crop failure in 1845 and 1846 in Ireland, leading to the "famine migration" of more than 500,000 Irish to Canada ( $\mathrm{Li} 2003,16$ ). Some of the Irish who immigrated to Canada during this period eventually left for the better climate and economic conditions of the United States. In fact, in the second half of $19^{\text {th }}$ century, Canada was more a land of emigration than immigration.

These conditions started to change near the end of the $19^{\text {th }}$ century. The twentieth century opened with a boom in the Canadian economy and a quick escalation of immigration. The number of immigrants arriving sharply increased from nearly 42,000 in 1900 to a record high of over 400,000 in 1913. During these years, more than 2.9 million people entered Canada, nearly four times as many as had arrived in the previous 14-year period. In general, there were three reasons for this rapid escalation. First, the Canadian economy was growing more rapidly than ever and immigrants were drawn by the promise of good job prospects. The building of the transcontinental railway, the settlement of the prairies, higher staple prices, declining transportation rates, higher European demand of Canadian products and expanding industrial production intensified demand for labour and new immigrants (Kelly and Trebilcock 1998, 111-63). At the same time, it was generally believed that good land in the United States was disappearing and potential immigrants now had to look to other destinations. Finally, the aggressive

\footnotetext{
5 "Push factors" are those variables that prompt people to leave their country of origin such as economic weaknesses, political upheaval, demographic pressures and social problems. At the same time, a number of "pull factors" made Canada an appealing choice to those searching for a new home. It seems that better economic opportunities, higher quality of life, peace and democracy are the major "pull factors" for international immigrants.
} 
recruitment campaigns by the Canadian government to boost immigration and attract workers played a decisive role in attracting international immigrants.

After coming to power in 1896, Prime Minister, Sir Wilfrid Laurier, initiated policies that enabled all new settlers to obtain 160 acres of land for free in return for a $\$ 10$ registration fee. The new settlers also had a pre-emptive right on another 160 acres at the cost of one, two or three dollars per acre. Laurier and his interior minister Clifford Sifton launched enormous campaigns to recruit new settlers. These campaigns took place in Ontario, Quebec and the United States, but in particular in Europe, Great Britain, Scandinavia, Germany, Ukraine and Poland, as well as France, Belgium and Switzerland (Louis Gareau 2005, Speech). Accompanying this aggressive immigration policy, there was considerable activity in railway construction, resulting in the development of two additional transcontinental systems, the Canadian Northern and the Grand Trunk Pacific. The railways were also positively interested in securing settlers along their lines, and cooperated actively with the government. Attention of Canadian immigration was mainly directed toward securing immigrants from the United States, where conditions, particularly in agriculture, were largely similar to those in Canada. From 1907 to 1915 , close to $40 \%$ of the homestead entries by immigrants were made by Americans. Many of these were returning Canadians, or their descendants. In addition to the immigrants from Britain and the United States, Canada also had a large influx of Eastern European nationals like Ukrainians, Doukhobors, and other groups from the Austrian Empire. Hence, for the first time the numbers of American and non- British European immigrants for a time surpassed those of British origin. 
The outbreak of the First World War in Europe in 1914 put an abrupt end to the surging migration to Canada. Although the number of immigrants rebounded after the war, they never again reached the levels attained before 1914, mainly because there was not much difference between economic opportunities in Europe and Canada. The number of immigrants coming to Canada climbed again during the 1920 s, with well above 150,000 per year entering in the last three years of the decade. During this decade, the aftershocks of World War I and the Russian Revolution stirred migration from Germany, Russia, the Ukraine, and eastern European countries including Poland and Hungary. But the Great Depression and the Second World War severely curtailed arrivals during the 1930s and early 1940 s - numbers varied between 7,600 and 27,500 , and there was actually a net migration loss of 92,000 as more people left Canada than entered between 1931 and 1941. Great Britain was still the leading source of immigrants, but the arrival of people from other parts of the world also continued.

The eruption of Second World War in 1939 kept the number of immigrants to less than 12000 per year until 1945 . With the return of peace, both Canada's economy and immigration boomed. Between 1946 and 1950, over 430,000 immigrants arrived, exceeding the total number admitted in the previous 15 years. The immediate post-war immigration boom included the dependents of Canadian servicemen who had married abroad, refugees, and people seeking economic opportunities in Canada. The devastation of the European economy, on the one hand, and the unprecedented boom in Canada on the other, also favoured high immigration levels. Numbers continued to grow throughout most of the 1950 s, peaking at over 282,000 admissions in 1957 . The first few years of the 1960 's were a period of slow growth and unemployment, therefore Canadian government 
intentionally slowed down the admission of new immigrants. Starting in 1964, the inflow of immigrants increased again and reached to more than 220,000 in 1967. Even though the main origin of immigrants arriving during this period continued to be the United Kingdom, the portion of immigrants from other countries slowly increased year by year, and formed a predominant part of the mix. During the late 1940s and 1950s, substantial numbers also arrived from Germany, the Netherlands, Italy and Poland. Following the 1956 Soviet invasion of Hungary, Canada also admitted over 37,000 Hungarians, while the Suez Crisis of the same year saw the arrival of almost 109,000 British immigrants. During the 1960s, the trend increased. By the 1971 Census, less than one-third of the foreign- born population had been born in the United Kingdom, and half came from other European countries, many from Italy (Boyd and Vickers 2000, 2-12).

From the 1970s through the 1990s, immigration numbers fluctuated. Even though the number of immigrants never reached the level before the First World War, overall, immigration made a significant contribution to Canada's total population growth. During the early and mid-1970s, net migration represented nearly $38 \%$ of the total increase in the population; with consistently high levels of arrivals between 1986 and 1996, it accounted for about half of the population growth. These percentages exceeded those recorded in the 1910s and the 1920s. The cumulative effect of net migration from the 1970s onward was a gradual increase in the percentage of foreign-born Canadians. By the time of the 2006 Census, foreign born immigrants comprised just over $20 \%$ of the population, the largest proportion in more than 70 years. In another development, the visible minority population passed 5 million in 2006, an almost four-fold increase over 1981 (Statistics Canada 2008a). 
It is important to note that since the early years of $20^{\text {th }}$ century, the Canadian government has adjusted the inflow of immigrants on the base of short-run economic conditions - the famous "absorptive capacity model." This approach was abandoned in 1985 after Prime Minister Malruney's new Conservative government undertook a review of immigration policy (Department of Employment \& Immigration 1985). Since then, the government has set levels independently of short-run economic conditions, essentially ignoring the level of unemployment or the growth rate in setting a total level. The new policy represented a victory for those who saw immigration as a long range policy tool. Immigration would be used primarily to bolster population growth and to try to readjust the overall age structure of the population, so that there would be enough workers to pay for the baby boomers' pensions and health care. The outcome of these policy deliberations was a removal of the prerequisite of arranged employment for independent applicants in January 1986. The level of the inflow jumped from 83,402 in 1985 to 99,219 in 1986 and then to 152,098 in 1987 . These were the first in a series of increases that eventually led to a level of nearly 250,000 in 1993 . Since then, with the exception of 1997 and 1998, the inflow of immigrants to Canada stayed above 200,000 immigrants per year. Chart 1 presents a historical perspective of immigration flows from 1860 to 2006 . It shows all the fluctuations in the last 146 years. It seems, however that after 1990 we have a more stable intake of immigrants, and in general the numbers of arrivals stayed in the range of 200,000 to 250,000 , and close to the government targets.

\footnotetext{
"According to Bumsted "absorpative capacity" could be interpreted in a variety of ways. Most Canadians choose to see it as a purely economic issue: Immigration we needed to supply labour that would not disturb the Canadian labour market. Other Canadians thought absorpative capacity was partly a coded term of racism, a definition that gained force from King's spirited defence of a nation's right to pursue a discriminatory immigration policy that would not appreciabely alter the makeup of the Canadian population. (Bumsted 2003, 207)
} 


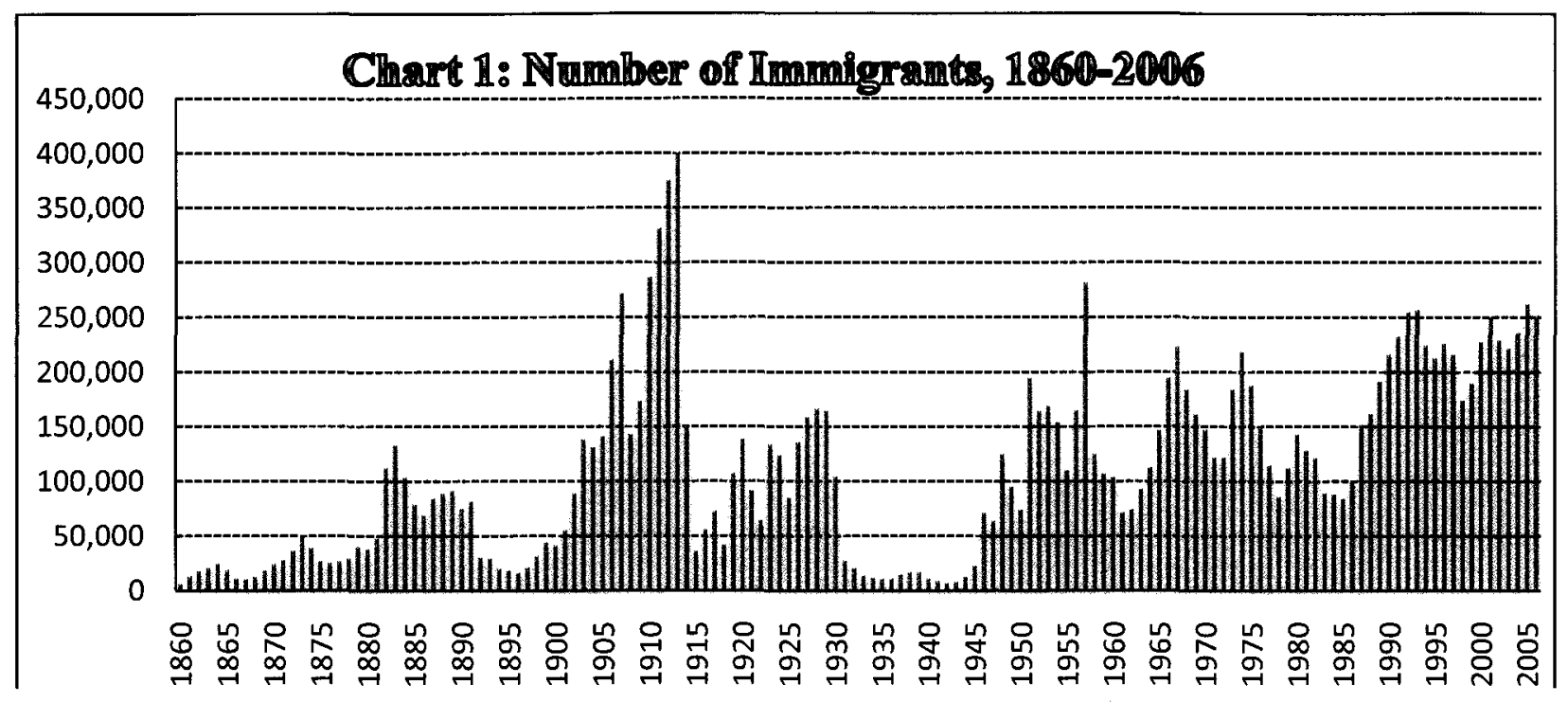

Source: www.chass.utoronto.ca/datalib/other/immig_1852-2004.xls

All immigration projections on the bases of current global trends and future Canadian demographic and economic needs suggest a similar or higher level of immigration to Canada in the next few decades. In the global context of immigration, in a conference on "Canadian Immigration Policy for the 21st Century" at Queens University in October 2002, Janice Stein, commentator and University of Toronto political scientist, outlined three factors that are central to shaping global population movement in the next few decades: The first is the "demographic divide" referring to the economic and social consequences of a widening gap in ages between developed and less-developed countries (Stein 2003, 27-29). Beyond North America, Western Europe, Australia, Japan and China, the demographic transition, especially the population pressures associated with the phase of rapid population growth, produces emigration pressure. Given this out-migration pressure, the medium term will show no shortage of a potential pool of people who want to come to Canada, and these outside pressures are probably increasing. Second is the impact that access to the newest technology will have on the growth in income inequality both within and between countries. Finally, as the demographic divide interacts with 
widening income inequality, ever greater pressure will be placed on countries like Canada to take in more immigrants. These factors, plus a number of other regional and local problems and "push factors", will increase the level of migration from less developed regions to Canada and other OECD countries. Canada will not be able to isolate itself from these consequences.

From a "pull factor" point of view, in all scenarios considered by Statistics Canada (2005a) for the projection of Canada's population in the next few decades, international immigration will play a vital role. In all these scenarios, the natural increase of population would become negative in the medium or long term: in 2020 under the low-growth scenario, in 2030 under the medium-growth scenario, and in 2046 under the high-growth scenario. As a result, migration increase would become Canada's only factor of population growth. Under five of the six considered projection scenarios, it is expected that Canada's international immigration would stay the same or increase between now and 2031. According to Statistics Canada, the 2031 level of immigration would be 150,000 in the low-growth scenario, 223,000 in the medium-growth scenario, and 305,000 in the high-growth scenario.

The fluctuating history outlined above may be classified as five phases, based on the type of people who would be accepted as desirable immigrants. During the first phase, from 1867 to 1895 , the immigration strategy was essentially an open-door policy towards those with European origin, especially those from Britain and the United States. When the volume of immigration remained relatively low, the government encouraged settlement of Mennonite, Scandinavian, and Hungarian immigrants (Kelly \& Trebilcock 1998, 72-77). During this period Canada's immigration policies ranked immigrants 
according to their desirable characteristics and placed them in one of three classes: (1) British or Americans; (2) Preferred Class or immigrants from western and northern Europe; and (3) Non- Preferred Class or immigrants from Eastern Europe and the Baltic States, who were admitted as farmers if they had sufficient capital.

During the second phase, which extended from 1896 to the beginning of the First World War in 1914, immigration policies were in favour of massive immigration for agricultural settlement, especially in the Prairie provinces. From an economic point of view, a "good immigrant" was someone who would go to the West to farm in the Prairies. A "bad immigrant" was someone who moved to the cities of the East to compete with Canadians for scarce industrial jobs. From ethnic and religious points of view, a "good immigrant" was someone white, Anglo-Saxons and protestant. The closer you were to these characteristics, the more likely you were to be accepted by the government and the people of Canada. The more one diverts from the model, the more "foreign" one would be and the more difficult to enter Canada and, once entered, the more likely to face discrimination. The "most preferred" immigrants were those from Britain, the United States or Western Europe. The "less-preferred" immigrants were East Europeans (Russians, Ukrainians, Poles) and South Europeans (Italians, Greek, Spaniards). A regulation of 1923 clarified that immigration from these countries was limited to agricultural and domestic workers and sponsored immigrants. The lowest in the category of "less preferred" were the Jews. They diverged from the preferred immigrants by virtue of their language, culture, and religion, as well as the fact that they would go to the cities of Montreal, Toronto and Winnipeg. In 1921, only 4\% of Canadian Jews lived in rural 
Canada and they were the most subjected to discrimination of all the white settlers to Canada in the pre-1945 period.

Members of visible minorities formed the "non-preferred" and "non-acceptable" category. Laws and/or regulations were issued to prevent them from coming to Canada. Yet, businesses (such as railways) frequently required that they be admitted to Canada so that a pool of "cheap labour' would be available for them. These immigrants performed the jobs that nobody else in Canada would do. The Canadian government used different measures to keep members of visible minorities out of Canada, including the "Chinese head taxes" (1885, 1900 and 1903) to discourage Chinese people from migrating to Canada. In 1903 , the head-tax was set at $\$ 500$ per person, which was a considerable amount of money in the early years of $20^{\text {th }}$ century. The "continuous voyage" policy was passed to prevent South Asian immigrants from entering Canada. It stipulated that immigrants had to travel directly to Canada without stopping, which was impossible from India. For Africans and Blacks in general, health regulations were developed and used to keep them away. They were deemed "unsuited to Canada" by virtue of the climate of Canada. In its policies regarding Japanese in Canada, the government followed the lead of the United States and relocated and deported many of them during the Second World War, which is the third phase of immigration.

In this phase, from 1915 to 1945 , Canada continued the previous policies of accepting immigrants for land settlement. As before, British and American immigrants continued to be the most desirable, followed by North European and then Central Europeans. Southern and Eastern Europeans were tolerated (Kelly and Trebilcock 1998, 442), and the least desired were Asians, Blacks and Jews. For example, in 1939, a 
shipload of German Jewish refugees aboard the S.S. St. Louis, were refused sanctuary in Canada and forced to return to Europe. During the Holocaust, Canada admitted only about 5,000 Jews - one of the worst records of any of the refugee receiving countries. During that period, Mackenzie King recorded in his diary that any action permitting an appreciable number of Jews to settle in Canada would undermine the unity of the Nation. He wrote:

We must nevertheless seek to keep this part of the Continent free from unrest and from too great an intermixture of foreign strains of blood, as much the same thing as lies at the basis of the Oriental problem. I fear we would have riots if we agreed to a policy that admitted numbers of Jews. Also we would add to the difficulties between the Provinces and the Dominion (cited in Abella and Troper 2000, 421).

The end of the Second World War marked the beginning of a new phase in Canadian immigration policy. During this phase $\left(4^{\text {th }}\right.$ phase: $\left.1945-1967\right)$ the immigration policy progressively shifted and the discriminatory clauses in the Immigration Act were altered, and later removed. Important dates to chart these changes are 1947, 1962 and 1967. This phase started with Mackenzie King's public statement on immigration policy in May 1947, which established the main principles of Canada's immigration policy for the next fifteen years. It was a racially discriminatory policy recruiting an almost entirely white immigration population from Europe, the United States and, in the 1950's, the Middle East. Its rationale was economic development and population growth based on a concept of Canada's absorptive capacity, which no one knew how to assess. The statement was followed by the creation of a new Department of Citizenship and Immigration in 1950. 
The second major policy development in this phase took place in 1962 and involved the official abandonment by Canada in the Immigration Regulations of racial discrimination in immigration policy, as well as a move to universality and admission based on skills, family reunion and humanitarian considerations. The following reasons contributed to the shift: First, racial discrimination in immigration policy was working against Canada's national interests, and was incompatible with her constructive role in the international arena; second, supply of immigrants from Europe shrunk and demand and competition for skilled labour from the United States increased; third, a new era of rapid industrial growth changed the economic needs of Canada. There was a great need for highly skilled, educated immigrants who can contribute to the technological revolution, which was taking place in 1950's and 1960's; fourth, as a result of the economic prosperity of the United States and the huge demand for skilled labour in the south, Canada lost many professional and technical workers to the United States; and finally' a progressive change took place in Canadians' attitude toward Non-European immigrants during the 1950 's and 1960 's. During those years, work was plentiful and immigrants were not perceived as competing for scarce jobs. In addition to higher levels of education, new technology (radio, television, cinema) and foreign travel brought Canadians into contact with people from the rest of the world, and made them curious and more open to other cultures.

The $5^{\text {th }}$ phase of immigration started in 1967 and still continues. In this phase, the point system was introduced. By focusing on the professional and economic attributes of immigrants and their human capital, instead of the country of origin, the point system reduced the inherent racism in immigration regulations and opened the door for skilled 
immigrants from non-European countries. Under the point system, an immigrant could apply either as an independent or as a relative sponsored by a Canadian citizen or permanent resident. In either case, the immigrant would be assessed on the basis of his or her education, occupational demand, proficiency in English or French and age. The new regulation reaffirmed the importance of human capital. These changes in the immigration policies facilitated the flow of immigrants in professional and technical occupations. Between 1956 to 1969 , new immigrants in professional, technical and managerial occupations made up 22.9 percent of all immigrants entering Canada. Between 1970 to 1972 this type of skilled immigrants increased to 32.7 percent of all admitted immigrants (Department of Manpower and Immigration 1972). The 1967 regulations also reaffirmed the right, first extended in the 1950s, of immigrants to sponsor relatives to enter Canada. Family-based immigration had always co-existed alongside economically motivated immigration, but now it was clearly defined.

Following these changes in immigration policies, the number and proportion of European immigrants decreased sharply in the early 1970's. In 1967, European immigrants accounted for approximately 160,000 , or $70 \%$, of total arrivals, but by 1976 they accounted for less than $33 \%$ of total new immigrants. Meanwhile, the proportion of immigrants born in Asian countries and other regions of the world began to rise, slowly at first and then more quickly through the 1980s and 1990s. According to the last figures from the Department of Citizenship \& Immigration Canada, more than $70 \%$ of immigrants arriving to Canada in the last ten years (1998-2007) came from Asia Pacific, Middle East and Africa, while only less than $20 \%$ came from Europe and the United States (Department of Citizenship and Immigration Canada 2007). Based on the latest 
statistics more than $50 \%$ of recent immigrants ( 1 out of 2 ) came from Asia-Pacific alone. The second major origin of immigrants is the Middle East and North Africa (20\%).

As a result of sustained immigration from non-European countries, Canada's cultural diversity has increased considerably during the last two decades. As expected, the 2001 Census of Population reveals that Canada's ethnic and cultural makeup is undergoing a rapid change, especially in major urban centres. Statistics from the 2001 census showed an increase in the numbers of immigrants, people belonging to visible minorities ${ }^{7}$, allophones (people whose mother tongue is neither English nor French) and non-Christian religious denominations, and an increase in the proportion of the Canadian population belonging to one of those groups. Table 1 shows that the proportion of visible minorities to all immigrants increased consistently during last 40 years.

Table 1: Visible Minority Groups by Immigrant Status and Period of Immigration, 2001

\begin{tabular}{|l|c|c|c|c|c|c|c|c|}
\hline & $\begin{array}{c}\text { Total } \\
\text { Population }\end{array}$ & $\begin{array}{c}\text { Native-born } \\
\text { population }\end{array}$ & $\begin{array}{c}\text { Immigrant } \\
\text { population }\end{array}$ & $\begin{array}{c}\text { Before } \\
1961\end{array}$ & $1961-1970$ & $\begin{array}{c}1971- \\
1980\end{array}$ & $\begin{array}{c}1981- \\
1990\end{array}$ \\
$1991-2001$
\end{tabular}

Source: Statistics Canada. 2001 Census.

\footnotetext{
${ }^{7}$ Under the Employment Equity Act, members of visible minorities are "persons, other than aboriginal peoples, who are non-Caucasian in race or non-white in colour". The 10 visible minority groups included are the Chinese, South Asian, Black, Filipino, Latin American, Southeast Asian, Arab, West Asian, Japanese and Korean groups.
} 
Three major forces caused this dramatic shift in immigrants' country of origin. First, as noted, a deliberate change in Canadian immigration policy opened the door to non-European immigrants. Second, low population growth and positive economic development in Europe decreased the desire to emigrate among Europeans and, for the first time, Europe had become a focus of immigration, rather than emigration (Papademeteriou 1988, 311-312). By the 1980s, even such long-time sending nations as Italy had become destinations for immigrants from poorer countries in the Middle East and Africa. Finally, social, economic and political transformations in the less developed countries of Asia, Africa and Latin America motivated people to seek employment and a safer environment outside their country of birth. Economically, immigration originates not from simple wage differentials between poor and rich countries, but from the spread of economic development to rapidly growing Third World populations and from a persistent demand for low-wage labour in developed nations. In most developing countries, population growth and the "green revolution" in rural areas led to massive surplus populations in the past 30-40 years. People moved to burgeoning cities, where employment opportunities were limited and social conditions inadequate. Consequently, demographic, social, economic and political factors push the population toward more developed countries, where there is a huge demand for labour.

Immigration has many social foundations that must also be taken into account to achieve a complete understanding of contemporary immigration patterns. As Massey pointed out, immigration is far more complex than standard economic analysis suggests, because it tends to feed back on itself through social networks $(1990,68-70)$. In due course, immigration becomes progressively independent of economic conditions and it 
perpetuates subsequent migration regardless of economic fluctuations. This feedback process has been called "the circular and cumulative causation of migration" by Myrdal and it relies mainly on social networks between immigrants and those in their country of origin $(1957,39-42)$.

Regulations established in the sixties remained largely intact during the next two decades. Later, the Canadian government did bring in a new Immigration Act on April 10, 1978. This Act defined three main goals of immigration policy as: (1) to facilitate the reunion in Canada of Canadian residents with close family members from abroad; (2) to fulfil Canada's legal obligations with respect to refugees and uphold its humanitarian traditions; and (3) to foster the development of a strong and viable economy in all regions of Canada. Under these provisions, family members and refugees were given top processing priority and Canada was committed to bringing in a substantial number of refugees every year, rather than just during emergency situations. The Act also specified that total immigration levels were to be set annually, after consultation with the provinces.

Further changes to immigration policy were made in 2001 with the adoption of the Immigration and Refugee Protection Act (IRPA). New regulations passed under IRPA further stressed the need for highly skilled immigrants to meet the changing needs and labour demands of Canada's increasingly globalized economy. IRPA clearly distinguished between immigration and refugee protection and listed 10 objectives with respect to immigration and 8 objectives regarding refugees. The first two objectives for the immigration program are "to permit Canada to pursue maximum social, cultural and economic benefits of immigration" and "to enrich and strengthen the social and cultural 
fabric of Canadian society". The act also promotes "the successful integration of permanent residents into Canada, while recognizing that integration involves mutual obligations for new immigrants and Canadian society." The act recognizes the importance of cooperation between different levels of government in Canada in order to reach immigration goals, as well as reasonable distribution of immigration benefits across all regions of Canada. (Department of Justice, Immigration and Refugee Protection Act).

Considering the high concentration of immigrants in a few metropolitan areas, it is not a surprise that one of the main objectives of the act is to have a more balanced distribution of immigrants across all regions. In fact, one of the main areas of policy debate around immigration in the last few years has been to find a way for a better distribution of immigrants among the regions. (For example see Canadian House of Commons: Standing Committee on Citizenship and Immigration debates). The motives of immigrants to settle in specific regions and the implications of their concentration in these regions are the subject of next section.

\section{Immigrants' Destination:}

One of the most striking differences between recent and earlier immigrants is where they choose to live. When the first French settlers came to Canada in the 17 th century, they settled along the shores of the St. Lawrence River in Quebec, and the Seigneurial System of New France distributed land in long narrow strips so that every farmer had a shorefront and access to the river. Later, the same pattern of settlement carried on for both French and English newcomers who settled in the Maritimes and Ontario. In the $19^{\text {th }}$ century, expanding tracks of the Canadian National Railway (CPR) paved the way for the mass settlement of Western Canada. By connecting outlying communities and small 
towns to the major cities and waterways, the railways played a crucial role in the expansion of agricultural lands and settlement of new immigrants. After the end of First World War, Canada became an industrial nation. This, in turn, decreased the opportunities for employment on the farm and the flow of immigrants moving to rural areas slowed down. Later, alongside Canada's transition to a knowledge-based economy in the second half of twentieth century, immigrants, like native-born Canadians, increasingly found employment in the manufacturing and service sectors of the economy. Consequently, immigrants have increasingly become attracted to major urban centers in Ontario, Quebec and British Columbia.

Based on the 2006 Census results, virtually all immigrants (97\%) who had arrived in Canada over the previous ten years (1997-2006) resided in a metropolitan area (MA), and only $3 \%$ resided in smaller cities or towns or in rural areas. Although recent immigrants have long had a propensity to settle in MAs, the proportion of them doing so has been on the rise-increasing from $84 \%$ to $94 \%$ between 1981 and 2001 . In comparison, the share of Canadian born persons residing in MAs increased from 53\% to $59 \%$ over this period. Not only have recent immigrants become increasingly concentrated within Canada's large metropolitan areas, they have been increasingly concentrated within a few of these - specifically Toronto, Vancouver and Montreal. Indeed, between 1981 and 2001, the share of recent immigrants residing in these 'top three' MAs increased from $58 \%$ to $73 \%$, while the share of recent immigrants residing in the 'top five' MAs (i.e., Toronto, Montréal, Vancouver, Ottawa-Hull and Calgary) increased from $67 \%$ to $80 \%$. 
The extent to which immigration is an urban phenomenon goes beyond the locational decisions of immigrants themselves and is also evident in the extent to which the Canadian-born children of immigrants, that is, second generation immigrants, also reside in large metropolitan areas. Consider individuals aged 15 to 29. Almost two-thirds (64\%) of second generation immigrants resided in Montréal, Toronto or Vancouver in 2001 , while this was the case for less than one-quarter (22\%) of persons born in Canada to two Canadian-born parents. Of course, some of these individuals still resided with their parents, so the difference between these groups was to be expected. Yet, even among persons aged 30 to 54 , second generation immigrants were about twice as likely as persons born in Canada to two Canadian-born parents to reside in Montreal, Toronto or Vancouver, at $47 \%$ and $24 \%$ respectively (Statistics Canada 2004a, 14).

When all immigrants, including second generation immigrants, are considered together, the extent of ties between Canada's largest MAs and immigration is even larger. According to Statistics Canada, almost three-quarters of Torontonians aged 15 or older have some direct ties to immigration. A little over half (52\%) are themselves immigrants, while another $22 \%$ are second generation immigrants. The remaining $26 \%$ is comprised of persons born in Canada to two Canadian-born parents. With respect to other metropolitan cities, we see the same trend in Vancouver, Hamilton and Abbotsford, where over one-half of the adult population of these cities have some direct ties to immigration. In the case of cities like Windsor, Calgary, Kitchener, Edmonton, London and Winnipeg, this trend is still relevant for over $40 \%$ of the adult population. It now seems safe to claim that any discussion about immigrants is, almost without exception, a discussion about immigrants in large urban areas. 
Over the past decade, social scientists have devoted a considerable amount of effort identifying geographic mobility of immigrants (For example see: Bourne 2000; Frey 2002; Kritz and Nogle 1994; McDonald 2003 and Newbold 1999). In general, the theoretical starting point for most analyses of this subject is the notion that immigrants compare the expected utility they would receive across all the regions to which they potentially can settle. Therefore, since metropolitan areas provide a higher degree of utility than small towns, immigrants prefer to settle there. It is important to note that urbanization is a global trend that is related to economic development and industrial growth, and urban areas in high-income countries now account for the majority of the gross national product of these countries. Immigrants tend to congregate in metropolitan areas of Canada partly because of the growth and vitality of the cities and partly because of other reasons, such as pre-immigration networks, the existing immigrant community, job prospects, and so on.

Information from the Longitudinal Survey of Immigrants in Canada (LSIC) provides some insights on why immigrants settle where they do. The survey shows that in general, the settlement pattern of these new immigrants was similar to the intended destination they had stated when they applied to immigrate to Canada. Three-quarters of the immigrants who had stated a destination at the time of admission to Canada actually settled where they had intended to. The remaining quarter ended up settling in a different area from their planned destination, mostly in one of the three major immigrant gateways. Overall, Toronto, Vancouver and Montreal were the top destinations of choice for most immigrants. Close to half of the immigrants (47\%) had targeted Toronto as their intended place of residence. About $12 \%$ had planned to settle in Vancouver and another 12\% in 
Montreal. Less than one fifth (18\%) have an intention to reside in another metropolitan area, and only $1 \%$ planned to settle outside an urban area. In total, one in ten $(10 \%)$ of the immigrants did not state any intended destination before coming to the country (Statistics Canada 2003c).

When asked why they chose to live in a particular city, the largest share of newly arrived immigrants $(41 \%)$ cited the presence of a spouse, partner, family member or a close relative in the area and an additional $18 \%$ cited the presence of friends. Clearly, familial and social networks are primary considerations in the decision of where to live. Immigrants in the family category appear to be the best connected, with only a small fraction of them $(4 \%)$ reporting that they knew neither relatives nor friends in Canada when they arrived, as did $12 \%$ of skilled worker principal applicants and $25 \%$ of refugees. By ethnic origin, immigrants who identified themselves as South Asian or South East and East Asian reported a predominance of having family in Canada upon arrival (36\% and 26\% respectively), while South East and East Asians reported a predominance of friends in Canada at the time of arrival (44\%) followed by South Asians $(15 \%)$

Table 2: The five most important reasons principal applicants in the economic class chose to settle in Toronto, Vancouver or Montreal, 2001

\begin{tabular}{||l|l|l|l|l|l|l|l|}
\hline \multicolumn{2}{|c|}{ Toronto } & \multicolumn{2}{c|}{ Vancouver } & \multicolumn{2}{c|}{ Montreal } & \multicolumn{2}{c|}{ All other MAs } \\
\hline Family or friends & 49.7 & Family or friends & 41.3 & $\begin{array}{l}\text { Family or } \\
\text { friends }\end{array}$ & 31.3 & Family or friends & 35.6 \\
\hline Job prospects & 23.4 & Climate & 20 & Language & 18.5 & Job prospects & 32.3 \\
\hline Lifestyle & 4.9 & Lifestyle & 11.7 & Job prospects & 15.8 & Education Prospects & 12.1 \\
\hline Housing & 4.9 & $\begin{array}{l}\text { Education } \\
\text { Prospects }\end{array}$ & 7 & $\begin{array}{l}\text { Education } \\
\text { Prospects }\end{array}$ & 10.1 & Lifestyle & 5.6 \\
\hline $\begin{array}{l}\text { High number of } \\
\text { same ethnic group }\end{array}$ & 4.6 & Job prospects & 6.1 & Lifestyle & 8.3 & Business Prospects & 5.5 \\
\hline
\end{tabular}

Source: Statistics Canada, 2003b. P15. 
These results are consistent with both immigration categories and immigration history of different ethnic groups. Perceptibly, for countries that have been sending immigrants for longer periods of time, recent immigrants have a greater chance of knowing relatives and friends in Canada. Therefore, they are more likely to be admitted to Canada under the family category of immigration and will be more likely to report knowing family rather than friends at the time of arrival. With respect to the top five MA's, the proportion of newcomers who had no network at landing ranges from $11 \%$ for immigrants who settled in Toronto to $17 \%$ for immigrants who settled in Vancouver. Newcomers who settled in one of the other metropolitan cities were more likely to know only friends in Canada upon arrival (on average 35\%). These results are also consistent with studies in other countries. For example Newbold (1999) finds the same trends in the United States.

While the most important reason to settle in major metropolitan areas was to join family and friends, the next most important reason for choosing a particular area varies by city and immigrant group. In Toronto, the second most common reason was the possibility of finding a job, while in Montreal, language was the next most important factor. In the case of Vancouver, the second most important reason, cited by just over $13 \%$ of immigrants, was not cultural, social or economic-related. The reason was simply the climate.

The implications of immigrant settlement patterns are not limited only to their successful economic, socio-cultural and political integration of newcomers in the new society. It also has major implications for the labour market, housing, public services and the development of ethnic neighbourhoods in the metropolitan area of destination. There 
is a wide literature in sociology, economics and urban studies on how massive immigrant settlement in major metropolitan areas is changing different aspects of life in these cities. For example, a study of housing price movements in Toronto and does show a strong historical correlation between rising housing prices and immigration in these two major Canadian cities (Ley and Tutchener 1999). This study reveals that the price increase in housing in these two MAs, and the timing of the upturn corresponds with the rapid increase of immigration numbers in the 1990 's. As recent arrivals concentrate in the metropolitan areas, they are blamed for rising housing costs, declining housing quality and deteriorating social amenities.

Another prominent outcome of immigrant settlement in large metropolitan areas has been the development of ethnic neighbourhoods in metropolitan areas of other western countries after World War II. The Turkish community of Kreuzberg in West Berlin, Germany, the Italian neighbourhood in the Carleton area of Melbourne, Australia, and Chinatown in the center of Sydney, Australia, are few examples of these neighborhoods. Ethnic neighbourhoods are urban localities where a specific ethnic group has a strong, although not necessarily predominant, presence. Ethnic neighbourhoods may differ by their type, the processes of formation, and socioeconomic conditions. As Logan, Alba and Zhang $(2002,299-322)$ point out, there is a difference between immigrant enclaves, minority ghettos, and ethnic neighbourhoods. Immigrant enclaves are transitional communities where recent immigrants with limited economic and social resources cluster together for inexpensive housing and mutual support. After these immigrants become socially and economically integrated, they tend to move away from these neighbourhoods. Minority ghettos, on the other hand, reflect the historical outcome 
of discrimination and social exclusion. Like immigrant enclaves, minority ghettos are characterised by unpleasant housing environments, persistent poverty, and other poor social conditions.

By contrast, ethnic neighbourhoods refer to the residential concentration of members of specific ethnic group who have adequate resources to choose their place of residence. This concentration is primarily a result of preference, rather than economic necessity. These neighbourhoods could form through three distinct demographic processes that may differ both in causes and outcomes. One possible process is relative concentration in a new neighbourhood, where both the members of an ethnic group and other group members increase, but at different rates. The second possible process is a gradual transition of the population mix, where some families are moving out to meet their new housing needs and are being replaced mainly by a specific ethnic group. The third possible process is a partial replacement that involves the out-movement of established residents in large numbers when a visible minority population moves into a neighbourhood in a short period of time.

Historically, ethnic neighbourhoods in Canada's large cities have long been a vibrant reflection of the adjustment process experienced by successive waves of immigrants. The once up-and-coming neighbourhoods of some earlier European immigrant groups, such as "Little Italy", "Little Portugal", "Little Greece", and the Jewish communities of many large North American cities, have been in gradual dispersion or at least stopped further growth as the result of immigration decline. On the other hand, since the 1970's and with the arrival of a large number of visible minority 
immigrants, a new wave of rapidly expanding visible minority neighbourhoods ${ }^{8}$ started to grow in Canadian metropolitan areas. Based on information provided by Statistics Canada, the number of such neighbourhoods in Canada's three largest metropolitan areas increased dramatically from 6 in 1981, to 77 in 1991 and finally 254 in 2001. More than $60 \%$ of these minority neighbourhoods were Chinese (157 out of 254), and they were primarily in Vancouver and Toronto. About one third were South Asian (83), distributed primarily in Toronto and Vancouver. There were relatively few Black neighbourhoods in Canadian cities: 13 in 2001. This may be because the Black population in Canada is a diverse population made up of people who have been in Canada for several generations, as well as immigrants from diverse regions, especially the Caribbean and Africa. Toronto and Vancouver have many more visible minority neighbourhoods (135 and 111, respectively in 2001) than Montreal (Hou and Picot 2004, 11).

Immigrant tendency to settle in specific neighbourhoods and metropolitan areas has been the subject of numerous studies. For the most part, these studies concluded that concentration of immigrants in general has negative effects on their integration into the larger society. For example, a recent study by Statistics Canada found that those immigrants who settled in smaller cities and towns with a smaller concentration of immigrants experienced a much faster integration process. The study concluded that in larger urban centres, immigrants face a large initial income disadvantage and subsequent increases are not enough for them to achieve parity with other Canadians. Better economic integration of immigrants outside the larger urban centres is found, even after

\footnotetext{
${ }^{8}$ In Statistics Canada definition, a visible minority neighbourhood is a census track that has over $30 \%$ of its population from a particular visible minority group (Statistics Canada: catalogue No. 11-008).
} 
taking into consideration differences in education, ability to speak an official language, admission class and country of origin (Bernard 2008, 14).

\section{Demographic Characteristics of Immigrants:}

\section{Sexual Distribution:}

Just as the ethnic origins and religion of immigrants have changed, so too has their sexual and age distribution. Historically, men greatly outnumbered women among people settling in Canada. For example, the 1911 Census recorded 158 immigrant males for every 100 females, compared with 103 Canadian-born males for 100 females. These unbalanced gender ratios are not uncommon in the history of settlement countries such as Canada, Australia, and the United States. They often reflect labour recruitment efforts targeted at men rather than women, as well as the behaviour of immigrants themselves. Generally in migration flows, especially those motivated by economic reasons, men frequently precede women, either because the move is viewed as temporary and there is no need to uproot family members, or because the man intends to become economically established before being joined by his family. By the time of the 1921 Census, the gender ratio for immigrants had become less skewed, standing at 125 immigrant males for every 100 immigrant females. The gender distribution gap of immigrants decreased slowly during $20^{\text {th }}$ century and finally the 1978 Immigration Act closed this gap by opening the door for more refugees and family reunification, where females by and large are outnumbering males. 


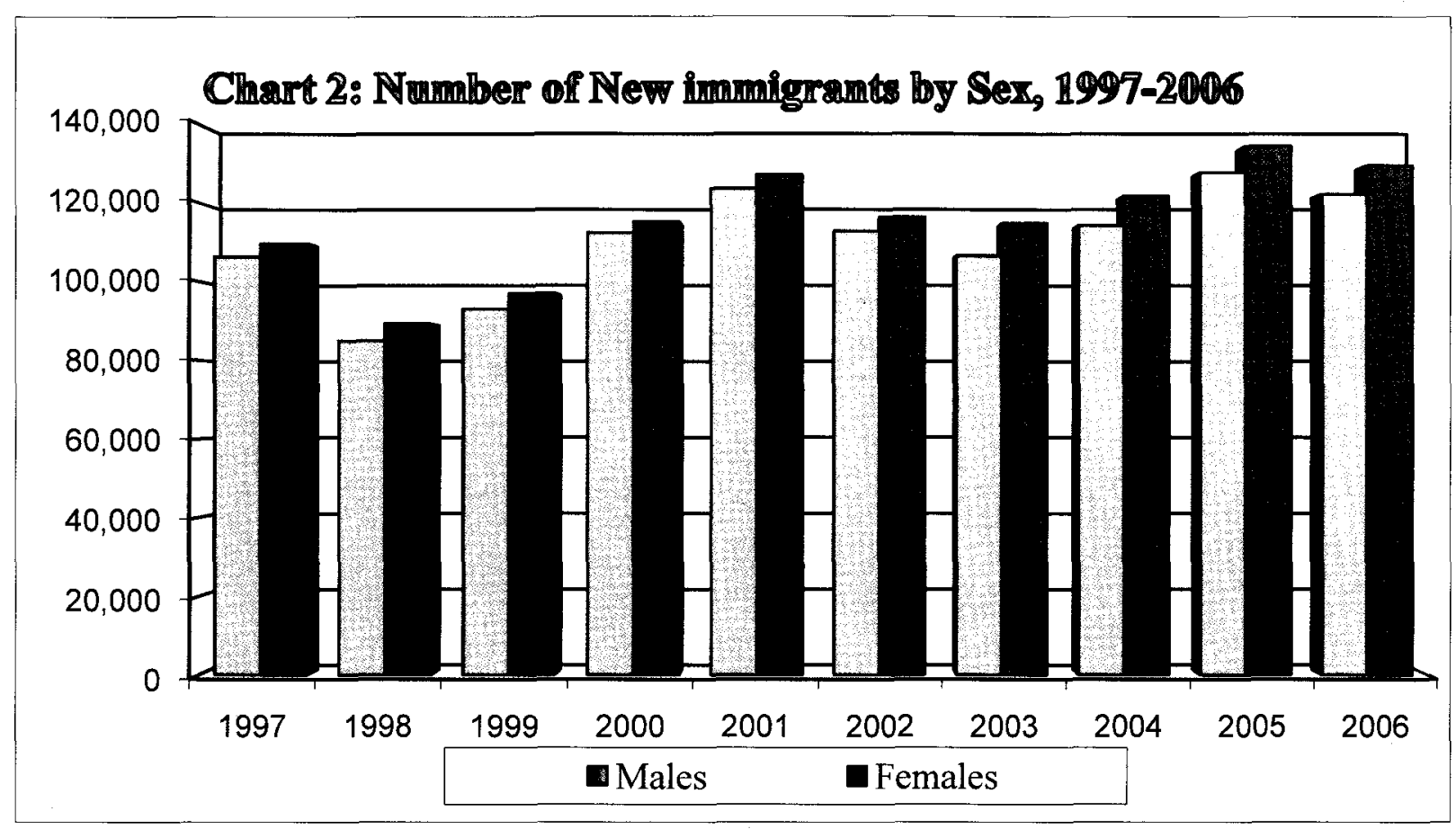

Analysis of 2006 census reveals that the number of foreign-born females living in Canada has grown considerably more rapidly than the native-born female population in recent years. Between 2001 and 2006, for example, the foreign-born female population in Canada increased by $19 \%$, almost six times faster than did the Canadian-born female population, which grew only $3 \%$ during the same period. Considering the high number of immigrant females entering Canada each year, it is expected that this trend will continue in the near future. A study of recent Canadian Citizenship and Immigration data (Department of Citizenship and Immigration 2006, 7-8) shows that, in general, females and males are almost equally represented in the incoming immigrant population. For example, during the ten years before 2006 census (1997-2006), the percentage of female and male immigrants to Canada was consistent at 51 per cent and 49 percent, regardless of the fluctuating overall numbers. However, once the various programs, categories, and relationships are examined, a clearer picture emerges of the gendered dimensions of 
migration to Canada. The next few points are worthy to note regarding sex distribution of immigrants:

- In the Family Class category, the gender ratio is $60 \%$ female and $40 \%$ male, where in the case of spouses and parents, females exceed males by approximately $10 \%$ in 2006 . However, in the children dependant category they are evenly distributed.

- Male immigrants comprise 84 to 89 percent of the principal applicants accepted in the Business Class category in the last ten years, while more than 60 percent of Business Class "dependants" are female.

- Between 1997 and 2006, the proportion of female principal applicants in the skilled workers category has been steady around 30 percent.

- The Live-in Caregiver Program is one venue through which women migrate independently to Canada. Women migrants comprise more than 95 per cent of the principal applicants accepted through this program.

- During the last ten years (1997-2006) the proportion of female refugees has been consistently increasing and rose from $45 \%$ in 1997 to close to $49 \%$ in 2006 (Department of Citizenship and Immigration 2006, 14-15).

Chart 3 presents precisely the sex ratio of recent immigrants (arrived 2001-2006) by the region of origin. The split in the sex ratio of immigrant is evident in this chart. While over those 5 years, female immigrants from Asia-Pacific, South and Central America and the United States outnumbered men from those regions, for Middle East and Africa the result were totally opposite and males outnumbered females for all those years. 


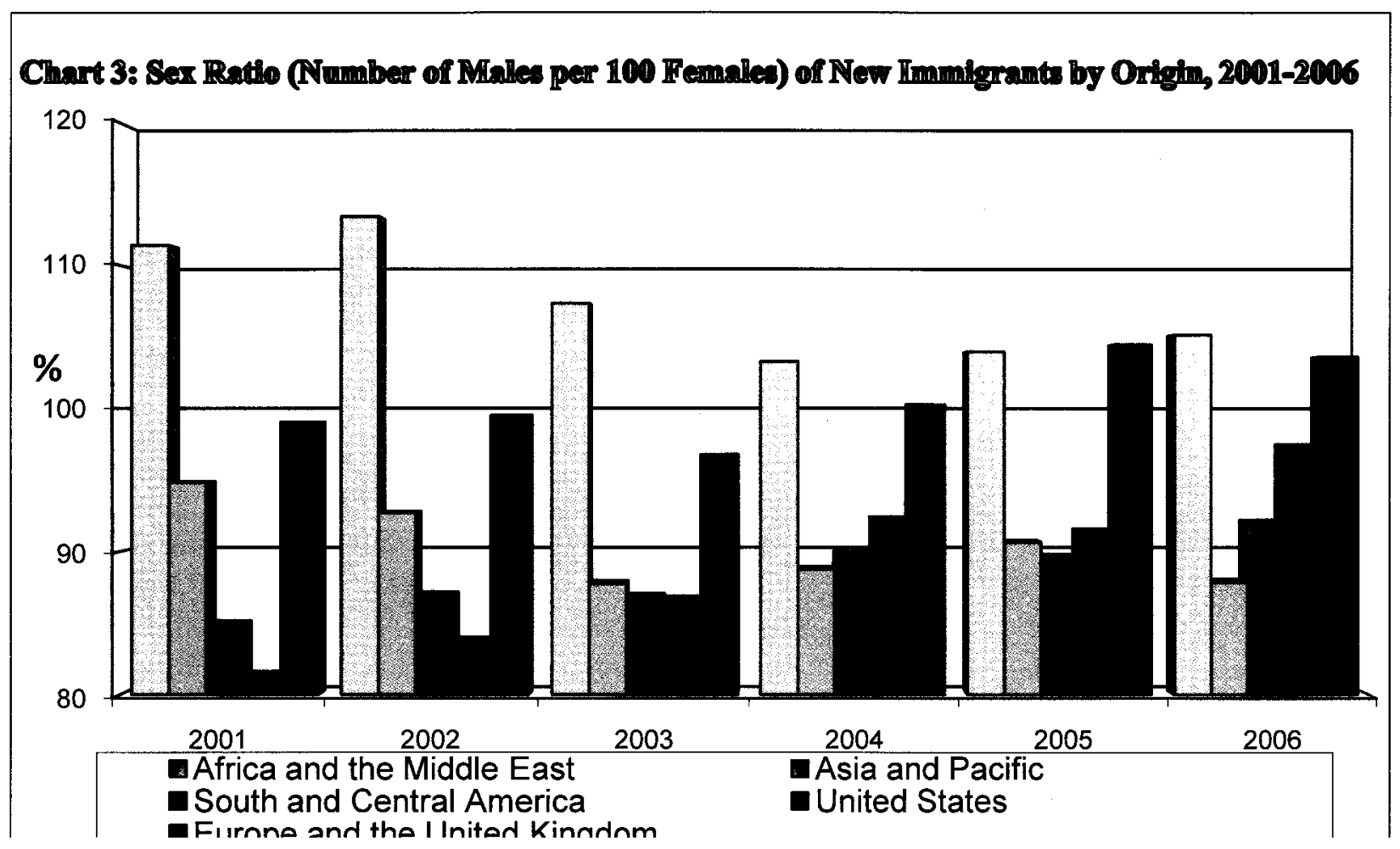

The growing proportion of female immigrants coming to Canada is not an isolated phenomenon. In fact, according to a number of researchers (See for example Martin 2007), a key development in international migration in recent years has been the feminization of migrant populations or the growing number of female migrants and refugees on the move. As of 2005 , about 49.6 percent of the world's migrants were women, up from 46.8 percent in 1960 (United Nations Population Division, 2005). The literature indicates three factors as major drivers of the feminization of migrant flows. First, it is the refugee movement and the high proportion of women and children among international refugees. Based on the UNHCR 1999 report: "The faces of refugees are overwhelmingly those of women and children, as they comprise up to 80 per cent of most refugee populations" (UNHCR 1999). The second major factor is the continuing and increasingly high level of global poverty among women, which pushes them to look for 
new alternatives. Finally, globalization and the desire of women to better their lives and those of their children through migration is the other motive worthy to note.

\section{Age Distribution:}

International immigration is one of the demographic factors that influence the age composition of Canada's population, especially in periods of settlement and expansion. While there are many studies on other demographic characteristics of new immigrants, they generally ignore the age composition of new arrivals and its implications for immigrant integration in Canadian society. Almost all the literature surrounding the age structure of immigrants is concentrated around two questions. First, what are the implications of the immigrant age structure on their socio-economic performance? And second, what is the impact of immigrant age distribution on the total fertility rate, population growth, and aging of the Canadian population?

As noted in the previous chapter, given the widening gap between the economic well-being of new immigrants in comparison to their native-born counterparts over the past decade, important questions arise pertaining to the economic performance of immigrants in terms of their earnings and participation in the labour market. A large body of work addressing these questions shows that the most significant factors explaining the labour market participation of new immigrants includes age, total years of schooling, and years in Canada.

Acknowledging the importance of the age of immigrants in their overall integration and in order to maximize the participation rate of new arrivals, starting in the 1960's the government of Canada introduced a new point system to determine whether a skilled worker would be accepted or refused. Age is one of six factors for which points are 
awarded by Citizenship and Immigration Canada. Up to 10 points are awarded under the Age Factor on the following basis. Table 3 shows the number of points given for age at the time of application.

Table 3: Points given for age at the time application is received by Immigration Canada (Factor 4: Age)

\begin{tabular}{|l|l|l|l|l|l|l|l|l|l|l|l|}
\hline $\begin{array}{l}\text { Age of } \begin{array}{l}\mathbf{1 6} \\
\text { Applicant }\end{array} \\
\text { years } \\
\text { or } \\
\text { less }\end{array}$ & $\begin{array}{l}\mathbf{1 7} \\
\text { years }\end{array}$ & $\begin{array}{l}\mathbf{1 8} \\
\text { years }\end{array}$ & $\begin{array}{l}\mathbf{1 9} \\
\text { years }\end{array}$ & $\begin{array}{l}\mathbf{2 0} \\
\text { years }\end{array}$ & $\begin{array}{l}\mathbf{2 1} \\
\text { years } \\
\text { to } 49 \\
\text { years }\end{array}$ & $\begin{array}{l}\mathbf{5 0} \\
\text { years }\end{array}$ & $\begin{array}{l}\mathbf{5 1} \\
\text { years }\end{array}$ & $\begin{array}{l}\mathbf{5 2} \\
\text { years }\end{array}$ & $\begin{array}{l}\mathbf{5 3} \\
\text { years }\end{array}$ & $\begin{array}{l}\mathbf{5 4} \\
\text { years } \\
\text { and } \\
\text { over }\end{array}$ \\
\hline Points & $\begin{array}{l}0 \\
\text { points }\end{array}$ & $\begin{array}{l}2 \\
\text { points }\end{array}$ & $\begin{array}{l}4 \\
\text { points }\end{array}$ & $\begin{array}{l}6 \\
\text { points }\end{array}$ & $\begin{array}{l}\mathbf{8} \\
\text { points }\end{array}$ & $\begin{array}{l}10 \\
\text { points }\end{array}$ & $\begin{array}{l}\mathbf{8} \\
\text { points }\end{array}$ & $\begin{array}{l}6 \\
\text { points }\end{array}$ & $\begin{array}{l}4 \\
\text { points }\end{array}$ & $\begin{array}{l}2 \\
\text { points }\end{array}$ & $\begin{array}{l}0 \\
\text { points }\end{array}$ \\
\hline
\end{tabular}

Source: Department of Citizenship and Immigration Canada. 2009. Eligibility Guide for permanent residence: Federal skilled worker class (IMM 7000). http://www.cic.gc.ca/english/information/applications/guides/EG72.asp

According to Statistics Canada, the majority of immigrants who arrived in Canada during the 1990s were in the working ages of 25 to 64 years and increased the size of Canada's working age population by more than 1.1 million (Statistics Canada 2003b, p8). The 2006 census shows that, while the majority of immigrants in Canada are still adults between the ages of 25 and 64 , the proportion of immigrants who are aged 65 and older has increased considerably over the decades, from less than $6 \%$ in 1921 to $18 \%$ in 1996. Two main demographic trends explain this development. The first is the ageing of the longer established immigrant population, many of whom arrived in Canada shortly after the Second World War. The second trend is the growth in the proportion of recent immigrants who are elderly; this has resulted from immigration policies that put greater emphasis on family reunification, thereby allowing Canadians to sponsor elderly relatives as immigrants. Another explanation is that the majority of new immigrants come to Canada after completion of their secondary and tertiary education as a result of the point system. Analysis of new immigrant's median age supports this explanation. In general 
the median age of immigrants at arrival has been relatively stable before 1970 's at around 25 years of age. Then it increased to 27 years in 1981, 28 years in 1990 and 30 years in 1999 (Beaujot 2003, 5). In comparison, the median age of the entire Canadian population has changed much more, increasing from 26.3 in 1961 to 37.6 in 2001 . In effect, the median age of arriving immigrants was about one or two years younger than that of the receiving population in 1961, compared to 7 to 8 years younger by 2000 .

On the other hand, recent studies show that fertility is higher for women who immigrated to Canada than for Canadian-born women (Statistics Canada 2006a). Considering the younger age composition of immigrants and higher fertility rate among them than the native-born population, there have been and still are calls for a higher level of immigration to maintain both the labour force and ratios of workers to retirees at a constant level. Canada's contemporary demographic profile has been profoundly influenced by the end of the baby boom, the decline in the fertility rate, ageing of the population and prospects for an absolute decline in population in the near future. Since there have been similar trends in other developed countries, the Population Division of United Nations issued a report in 2000 on using immigration to counteract the ageing population in eight industrial countries (United Nations Population Division 2000). Using population projections, the analysis estimated the amount of migration necessary to maintain both labour forces and the ratios of workers to retirees at a steady level. This report came to a conclusion that substituting migration for low fertility requires politically insupportable levels of migration.

In Canada, several studies have shown that immigration cannot change the aging trend, mainly because there are very few young immigrants, and these individuals, like 
other Canadians, also get older (Beaujot, 2003; and Guillemette and Robson, 2006). Other analysis confirms that immigration slightly reduces the average age. As an example, with zero international immigration over the period of 1951-2001, the median age in 2001 is only 0.8 years older than the actual figure for that year. In their analysis, Denton, Feaver and Spencer (1997) show the effects of three immigration assumptions to 2051: (i) the standard case of 225,000 , (ii) immigration $50 \%$ higher, and (iii) doubles the standard case. The median age is 46.5 in the standard case, 45.1 with immigration $50 \%$ higher, and 44.2 with immigration of 450,000 per year.

With regard to the health status, overall, immigrants, especially recent arrivals, have better health status than their native-born counterparts. According to Statistics Canada, a majority of the newcomers (78\%) rated their health status as either excellent or very good in 2001(Statistics Canada 2003c, 36). Another 19\% reported themselves to be in good health. Only $3 \%$ rated their health as fair or poor. In comparison, results of Statistics Canada's latest Canadian Community Health Survey show that $61 \%$ of the Canadian population aged 15 years and older rated their own health as either excellent or very good, $27 \%$ as good, and $12 \%$ as fair or poor. A possible reason for this may be that healthier individuals are more willing to participate in the immigration process and that, in order to be admitted into Canada, immigrants must meet certain health status criteria, as stipulated in the Immigration Act of 1976.

\section{Education:}

Another characteristic of immigrants that has major implications for their integration in the labour market and their social and political participation is their preCanadian education level. As noted in the previous chapter, the growing migration of 
skilled workers is one of the prominent features of recent international migratory trends to Western countries, many of which, including Canada, have adopted measures to facilitate their immigration. According to the latest OECD report, in general immigrants with higher education degrees find it easier to enter the host-country labour market compared to those immigrants with lower levels of education. However, the relative situation of immigrants vis-à-vis the native-born varies considerably. The report found that the gap in terms of the employment and unemployment rates between the native-born and immigrants tends to increase with the level of education. Based on this report, qualified immigrants encounter special difficulties in all OECD countries. This could be attributable to i) unobserved differences in the "value" of degrees or in intrinsic skills; ii) problems with the recognition of degrees acquired in the country of origin; iii) a lack of human and social capital specific to the host country (e.g. proficiency in the language); iv) the local labour market situation; and v) various forms of discrimination (OECD 2007, 132).

Table 4: Levels of educational attainment among immigrants of the 1970s, 1980s and 1990s

\begin{tabular}{|l|c|c|c|}
\hline & $\mathbf{1 9 7 0}$ & $\mathbf{1 9 8 0 \boldsymbol { s }}$ & $\mathbf{1 9 9 0} \boldsymbol{s}$ \\
\hline All levels of education & 100.0 & 100.0 & 100.0 \\
Less than high school & 32.5 & 27.2 & 20.2 \\
High school & 19.1 & 24.3 & 19.0 \\
Trades & 14.0 & 10.9 & 7.6 \\
College & 12.1 & 12.6 & 12.6 \\
University & 22.2 & 25.1 & 40.7 \\
\hline
\end{tabular}

Source: Statistics Canada, Education in Canada: Raising the standard, Catalogue no: 96 F0030XIE2001012

Recent censuses, studies and surveys shows that Immigrants arriving in Canada in recent years are more educated than immigrants who arrived in the past and are twice as likely as the native-born population to have a university education. According to Statistics Canada, the educational profile of the Canadian working-age (25-64 years old) 
population has benefited greatly from the contribution made by immigrants during the last 50 years. The 2001 census reveals that $41 \%$ of working age immigrants who arrived in the 1990 s were university trained. Another $13 \%$ had a college diploma and $8 \%$ a trade certificate. In total, $61 \%$ of immigrants had qualifications above the secondary level, much higher than $48 \%$ for immigrants of the 1970 s and 1980 s (Statistics Canada, 2003b). Among recent immigrants, both sexes tended to be highly educated. About $45 \%$ of men and $37 \%$ of women had a university degree in 2001 . For the rest of the working age native-born population, $23 \%$ of both men and women were university graduates. Table 4 shows the educational qualifications of immigrants since the 1970s.

Based on the latest Labour Force Survey in 2007, the difference between educational attainment of recent immigrants aged 25 to 54 with the native born is more pronounced, since more than half of immigrants (54\%) who landed since 2002 had a university education (Statistics Canada 2008b, 7).

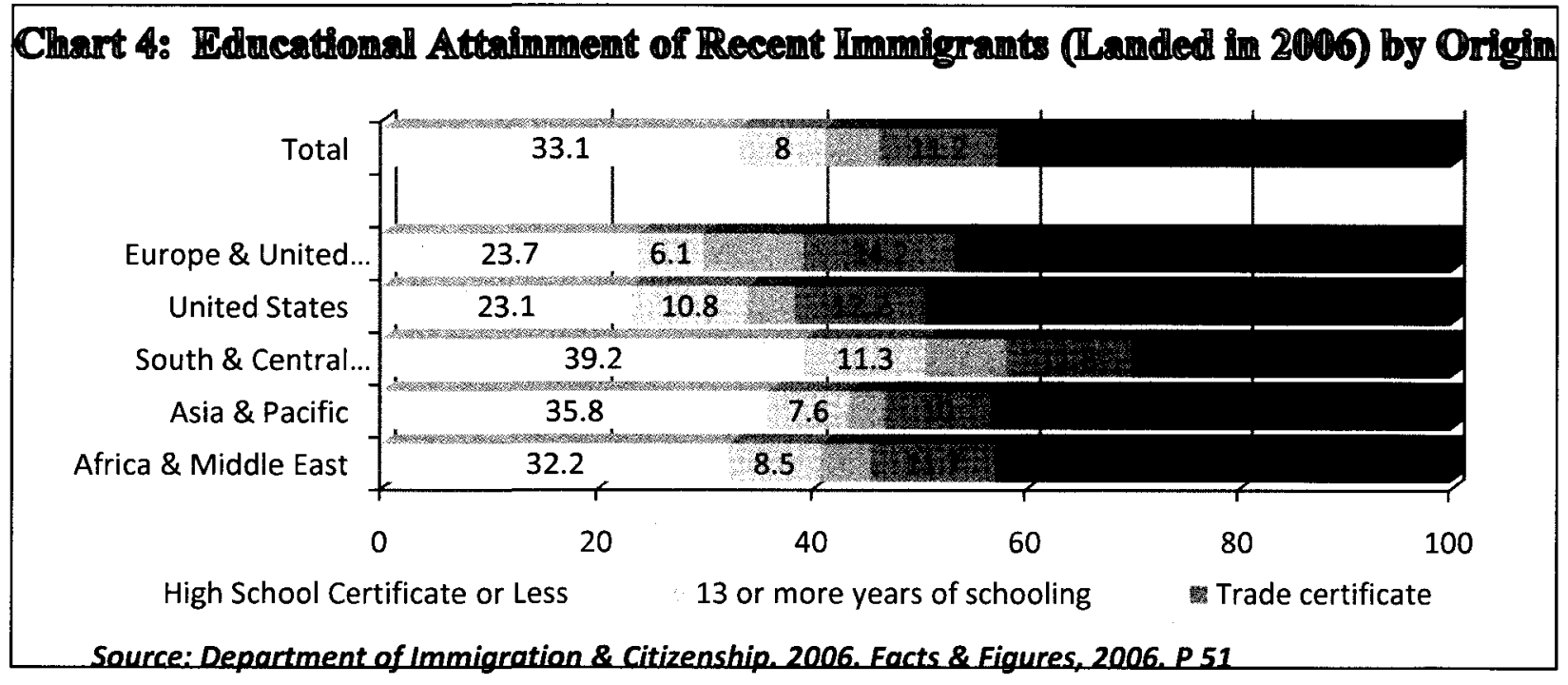




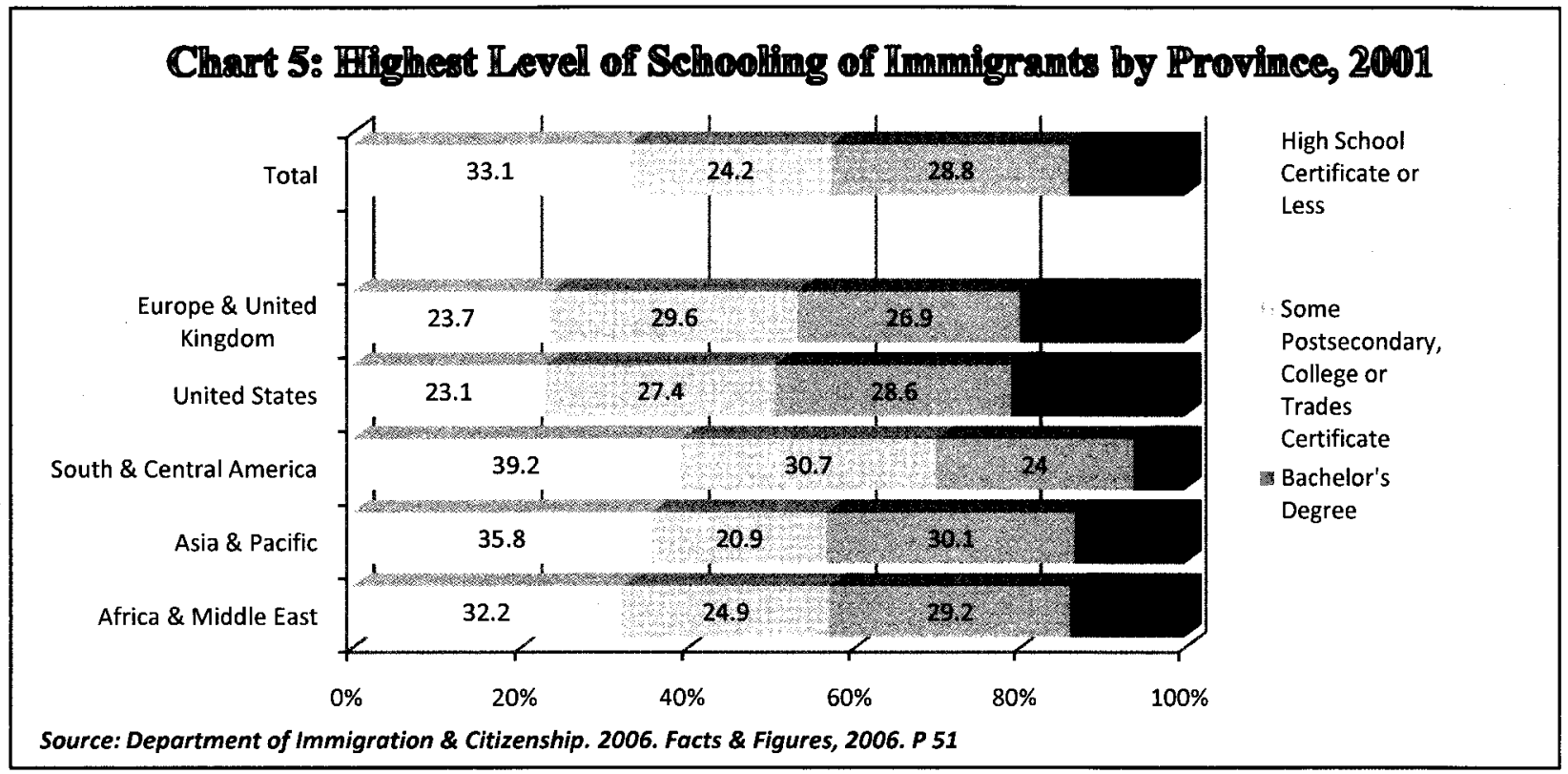

Charts 4 and 5 display the highest level of schooling of immigrants by their origin and destination. Chart 4 shows that, on average, immigrants ariving from Europe, the United Kingdom and the United States in 2006 have the highest level of schooling (close to $50 \%$ university graduate) and immigrants arriving from South and Central America have the lowest (close to $30 \%$ university graduates). Unfortunately, the latest reliable data available for the highest level of schooling of immigrants by destination goes back to the 2001 census. Based on 2001 census results, while on average more than $40 \%$ of immigrants settling in different Canadian provinces between 1996 and 2001 were university graduates, only $21.3 \%$ of immigrants settling in Prince Edward Island had a university degree. Manitoba, had the second lowest educated immigrants, with only $30 \%$ university graduates.

\section{Religion:}

The links between an immigrant's values and beliefs and the speed of their integration in the new society has been another area of interest for immigration scholars. 
Research shows that participating in religious activities and maintaining of customs and traditions of the place of origin created a strong bond with the immigrants' sense of belonging to their ethnic community or cultural group (Tran, Kaddatz and Allard 2005, 24). Based on the findings of Statistics Canada's Ethnic Diversity Survey (EDS), in general those with stronger cultural and religious associations to their ethnic group are more connected to their country of origin and are less likely to have interethnic and interreligious connections with people outside their communities. As an example, those immigrants who cited strong religious affiliations are less likely to have interreligious unions through marriage with other ethnic groups (Clark 2006, 18).

Just as the ethnic origins of immigrants arriving in Canada have changed during the last 40 years, so too have their religious affiliations. Table 5 presents the distribution patterns of new immigrants' religious background upon their arrival time in Canada. It shows a steady decline in the proportion of immigrants who reported one of the branches of Christianity as their religion. At the same time, the number of immigrants who reported religions such as Islam, Hinduism, Sikhism and Buddhism has increased substantially (Statistics Canada 2003e, 19). This change is consistent with changing immigration patterns toward more immigrants from regions outside Europe, in particular South Asia and the Middle East. Another visible change in the table is the proportion of immigrants who reported no religious affiliation, which has almost doubled in the last 50 years. The 2001 census results show that one-fifth of the 1.8 million immigrants who arrived in Canada between 1991 and 2001 reported they had no religion, especially individuals born in the People's Republic of China, Hong Kong and Taiwan. 
Not only has the religious distribution of immigrants changed during the last 50 years, but also their public religious behaviours. Research shows wide differences in the public religious behaviours of immigrants and their native-born counterparts. According to Clark and Schellenberg $(2006,2)$ since 1985 , the gap between the public religious behaviours of immigrants and persons born in Canada has started to widen. Based on their research, the percentage of native-born (15 to 59 year-olds) with no religious affiliation or not attending religious services has increased from $33 \%$ in 1985 to $48 \%$ in 2004. In contrast, immigrants' religious behaviours have changed very little, from $36 \%$ to $35 \%$. This was mainly because of more religious affiliation among recent immigrants arriving after 1980. The 2001 census results revealed that more than forty percent of the immigrants who arrived in Canada between 1982 and 2001 have a high degree of religiosity, compared with $26 \%$ of persons born in Canada.

Table 5: Immigrants by major religious denominations and period of immigration, Canada, 2001

\begin{tabular}{|c|c|c|c|c|c|}
\hline & \multicolumn{5}{|c|}{ Period of Immigration (\%) } \\
\hline & $\begin{array}{c}\text { Before } \\
1961\end{array}$ & $\begin{array}{l}1961- \\
1970 \\
\end{array}$ & $1971-1980$ & $1981-1990$ & $1991-2000$ \\
\hline Total Immigrants & 100 & 100 & 100 & 100 & 100 \\
\hline Roman Catholic & 39.2 & 43.4 & 33.9 & 32.9 & 23 \\
\hline Protestant & 39.2 & 26.9 & 21 & 14.5 & 10.7 \\
\hline Christian Orthodox & 3.8 & 6.3 & 3.8 & 3 & 6.3 \\
\hline Christian, Other & 1.3 & 2.2 & 3.8 & 4.9 & 5.3 \\
\hline Jewish & 2.7 & 2 & 2.2 & 1.9 & 1.2 \\
\hline Muslim & 0.2 & 1.3 & 5.4 & 7.5 & 15 \\
\hline Hindu & 0 & 1.4 & 3.6 & 4.9 & 6.5 \\
\hline Buddhist & 0.4 & 0.9 & 4.8 & 7.5 & 4.6 \\
\hline Sikh & 0.1 & 1.1 & 3.9 & 4.3 & 4.7 \\
\hline No Religion & 11 & 13.5 & 16.5 & 17.3 & 21.3 \\
\hline Other Religions & 2.1 & 1 & 1.1 & 1.3 & 1.4 \\
\hline
\end{tabular}


It is important to note that there is considerable variation in levels of religiosity among immigrants from different regions of the world. High levels of religiosity are most prevalent among immigrants from South Asia (e.g. India and Pakistan), South East Asia (e.g. the Philippines) and the Caribbean and Central and South America. In contrast, high levels of religiosity are least prevalent among immigrants from East Asia (e.g. China and Japan) and Western/Northern Europe (e.g. France and the United Kingdom) and Eastern Europe (e.g. Hungary).

Despite the fact that South Asians differ considerably in terms of their religious affiliations to Muslim, Hindu, Sikh and Buddhist traditions, as a whole, this group is unified in attaching a strong sense of importance to their religion. According to data from the 2002 EDS, $83 \%$ of South Asians responded that their religion was important or very important to them compared with a similar proportion of Chinese, $53 \%$ of all Canadians and $78 \%$ of Blacks. The importance of religion was maintained by second generation South Asians, $76 \%$ of whom said that their religion was important to them, compared with 55\% of all second generation Canadians (Tran, Kaddatz, and Allard 2005, 23).

\section{Language:}

When an immigrant arrives in a new country, his ability to express himself in the language of the new country has a major impact on how successfully he will integrate. This ability no doubt is a core socio-cultural necessity as well as a major economic asset. Research shows that for new immigrants to Canada, knowledge of one or both official languages is closely tied to their social integration and economic success. Immigrants who are able to speak one of Canada's official languages have higher levels of interaction with those outside their ethnic group and are more involved in social, cultural, and 
political life. In addition, their employment rates and income levels are much higher than those who cannot communicate in English or French. In answer to a question about labour market barriers in the 2003 Longitudinal Survey of Immigrants to Canada (LSIC, Wave 2), most recent immigrants (aged 25 to 44) cited lack of language skills as one of the major problems they face in finding a job in Canada (Statistics Canada 2007c, 13).

A review of literature shows that major drivers influencing immigrants' proficiency in English or French upon arrival includes: age, education, immigration category, mother tongue and country of last permanent residence. At the time of the 2006 Census, there was no clear difference between the two genders in their spoken language at home or at work. However, in general, older immigrants tend to speak a language other than English or French more than their younger counterparts both at home and at work. The results of the 2006 Census shows that immigrants who landed in Canada at older ages, particularly after the age of 50, were more likely to use a non-official language at home or at work. While the use of a language other than English or French is less frequent among younger immigrants, close to one in five (18\%) of immigrants over the age of 65 who worked in 2006 used a non-official language on the job. This finding is consistent with the results of the longitudinal survey of immigrants (LSIC). Based on the survey, nine in 10 immigrants between 25 and 44 years of age were able to converse in at least one of Canada's official languages ( $91 \%$ ), followed by $68 \%$ of immigrants between 45 and 54 years and $41 \%$ of immigrants 65 years of age and older. Also, $14 \%$ of immigrants between 25 and 44 years of age reported knowing both English and French, followed by $8 \%$ of immigrants between 45 to 54 and 3\% of immigrants 65 years of age and older (Statistics Canada 2005b, 30). 
The longitudinal survey of immigrants also reveals that immigrants' self-perception of language ability is closely associated with their level of education. Based on LSIC findings, a little more than half (55\%) of immigrants whose level of education was less than high school reported that they could carry on a conversation in either English or French. This is compared to $70 \%$ of those with a high school certificate or its equivalent, and $87 \%$ of immigrants with an undergraduate degree. Almost all (95\%) of immigrants with a master's or doctoral degree reported that they were able to speak either English and/or French. Similarly, based on 2006 Census results, immigrants who used a language other than English or French at work generally tended to have less formal education than those who did not. Almost a quarter of them did not have any high school certificate or diploma and another quarter only had a high school degree. In contrast, among those who made no use of non-official languages, about one-third had a high school diploma or less and about 1 in 10 had no diploma or certificate. The story for those immigrants with post secondary education is more complex. A newly released study by Statistics Canada reveals that in 2006, there were a number of immigrant workers educated at the university level who regularly worked in a non-official language environment. However, few of these highly-educated workers use a non-official language to the exclusion of official languages (Statistics Canada 2009, 6). Perhaps some of these immigrants are professionals who were unable to find a job in their intended occupation and ended up working in an ethnic business transitionally or permanently. 
Table 6: Immigrant's Knowledge of Official Languages by Immigration Category, 2001

\begin{tabular}{||l|c|c|c|c|c|c||}
\hline \multirow{2}{*}{} & \multicolumn{5}{|c|}{ Immigration Category } & \multirow{2}{*}{} \\
\cline { 2 - 7 } & Family & $\begin{array}{c}\text { Skilled } \\
\text { worker } \\
\text { principal } \\
\text { applicants }\end{array}$ & $\begin{array}{c}\text { skilled } \\
\text { worker } \\
\text { dependents }\end{array}$ & $\begin{array}{c}\text { Other } \\
\text { economic }\end{array}$ & Refugees & $\begin{array}{c}\text { All } \\
\text { Immigrants }\end{array}$ \\
\hline $\begin{array}{l}\text { Canada, excluding } \\
\text { Quebec (number) }\end{array}$ & $\mathbf{3 9 , 0 4 0}$ & $\mathbf{4 6 , 5 3 7}$ & $\mathbf{3 6 , 0 1 5}$ & $\mathbf{9 , 6 2 5}$ & $\mathbf{7 , 6 4 2}$ & $\mathbf{1 3 9 , 5 2 8}$ \\
English only & 60 & 91 & 78 & 68 & 60 & 76 \\
French Only & $\mathrm{F}$ & $\mathrm{F}$ & $\mathrm{F}$ & $\mathrm{F}$ & $\mathrm{F}$ & F \\
English and French & 3 & 6 & 6 & 4 & 3 & 5 \\
Neither English nor French & 37 & 3 & 16 & 28 & 36 & 19 \\
\hline \hline
\end{tabular}

Another key fact closely tied to an immigrant's ability to perform in one of Canada's official languages is the category under which immigrants are admitted to Canada. The LSIC results reveal that while only close to two third (63\%) of immigrants who arrived under the family or refugee category were able to speak one of the official languages, almost all skilled worker principal applicants (99\%) reported being able to speak English and/or French, including 17\% who were able to speak both French and English. This may reflect the point system and selection criteria for skilled worker principal applicants, which gives a high mark to language ability. Based on LSIC results, nearly $85 \%$ of the skilled worker spouse and dependents reported that they were able to speak English and/or French. As well, almost three quarters (72\%) of economic immigrants other than skilled workers reported that they were able to speak at least one of the official languages. Table 6 presents immigrants' knowledge of official languages by immigration category (Statistics Canada 2005b, 30). 
There are a couple of questions in the Census of Population which can be utilised to look at the links between official language proficiency and mother tongue. Table 7 shows that four out of the top five groups who had the highest proportion of people with neither English nor French knowledge have a mother tongue in the Chinese group of languages. On average, more than $15 \%$ of immigrants in these groups are not able to perform in one of Canada's official languages. On the other hand, Northern Europeans, particularly those speaking a Scandinavian language, had the lowest proportion of immigrants with neither English nor French knowledge. As expected, the percentage of immigrants with no language proficiency declines over time spent in Canada and immigrants who have been in Canada for a longer period of time have better command of English or French.

The high proportion of Chinese with no knowledge of English or French is not a surprise. The high proportion of Chinese immigrants combined with their concentration in major gateways create an environment where new immigrants can find a job in their ethnic community and carry out a life with no immediate need to speak an official language. Based on the 2006 census results, more than 1 million people reported one of the Chinese languages as their mother tongue. This was an increase of $18.5 \%$, or 162,000 , from 2001. In 2006, they accounted for $3.3 \%$ of the total population of Canada, up from $2.9 \%$ five years earlier. These numbers reaffirm the position of the Chinese languages as Canada's third most common mother tongue group, behind the two official languages (Statistics Canada 2007b). 
Table 7: Percentage of immigrants with the knowledge of neither English nor French by Mother Tongue, 2006.

\begin{tabular}{|c|c|c|c|c|c|c|}
\hline Ranking & Mother Tongue & $\begin{array}{c}\text { Total } \\
\text { Immigrants }\end{array}$ & $\begin{array}{c}\text { Arrived } 2001 \text { to } \\
2006\end{array}$ & $\begin{array}{l}\text { Arrived } 1996 \text { to } \\
2000\end{array}$ & $\begin{array}{c}\text { Arrived } 1991 \text { to } \\
1995\end{array}$ & $\begin{array}{c}\text { Arrived Before } \\
1991\end{array}$ \\
\hline 1 & Cantonese & $23.40 \%$ & $37.60 \%$ & $21.60 \%$ & $24.60 \%$ & $21.20 \%$ \\
\hline 2 & Chinese, n.o.s. & $19.20 \%$ & $21.30 \%$ & $15.60 \%$ & $23.90 \%$ & $17.80 \%$ \\
\hline 3 & Panjabi (Punjabi) & $18.60 \%$ & $24.00 \%$ & $20.50 \%$ & $19.80 \%$ & $13.40 \%$ \\
\hline 4 & Taiwanese & $16.80 \%$ & $21.30 \%$ & $17.60 \%$ & $19.30 \%$ & $11.00 \%$ \\
\hline 5 & Mandarin & $14.90 \%$ & $18.60 \%$ & $10.30 \%$ & $16.10 \%$ & $13.60 \%$ \\
\hline 6 & Vietnamese & $14.50 \%$ & $24.70 \%$ & $19.40 \%$ & $19.20 \%$ & $11.10 \%$ \\
\hline 7 & $\begin{array}{l}\text { Khmer } \\
\text { (Cambodian) }\end{array}$ & $14.50 \%$ & $30.80 \%$ & $21.00 \%$ & $18.80 \%$ & $11.90 \%$ \\
\hline 8 & Portuguese & $13.50 \%$ & $8.90 \%$ & $10.50 \%$ & $15.40 \%$ & $13.80 \%$ \\
\hline 9 & Pashto & $11.00 \%$ & $14.50 \%$ & $6.70 \%$ & $9.50 \%$ & $7.90 \%$ \\
\hline 10 & Korean & $10.60 \%$ & $11.70 \%$ & $8.20 \%$ & $11.30 \%$ & $11.00 \%$ \\
\hline : & : & & : & : & : & \\
\hline : & : & : & : & : & $:$ & : \\
\hline 57 & Estonian & $0.60 \%$ & $15.80 \%$ & $0.00 \%$ & $0.00 \%$ & $0.30 \%$ \\
\hline 58 & Czech & $0.50 \%$ & $4.00 \%$ & $2.30 \%$ & $0.90 \%$ & $0.20 \%$ \\
\hline 59 & Latvian & $0.50 \%$ & $0.00 \%$ & $0.00 \%$ & $0.00 \%$ & $0.50 \%$ \\
\hline 60 & Maltese & $0.30 \%$ & $0.00 \%$ & $0.00 \%$ & $0.00 \%$ & $0.30 \%$ \\
\hline 61 & Dutch & $0.30 \%$ & $0.80 \%$ & $0.50 \%$ & $0.80 \%$ & $0.20 \%$ \\
\hline 62 & Hebrew & $0.30 \%$ & $0.30 \%$ & $0.90 \%$ & $0.70 \%$ & $0.00 \%$ \\
\hline 63 & Danish & $0.10 \%$ & $0.00 \%$ & $0.00 \%$ & $0.00 \%$ & $0.10 \%$ \\
\hline 64 & Frisian & $0.00 \%$ & $0.00 \%$ & $0.00 \%$ & $0.00 \%$ & $0.50 \%$ \\
\hline 65 & Swedish & $0.00 \%$ & $0.00 \%$ & $0.00 \%$ & $0.00 \%$ & $0.00 \%$ \\
\hline 66 & Flemish & $0.00 \%$ & $0.00 \%$ & $0.00 \%$ & $0.00 \%$ & $0.00 \%$ \\
\hline 67 & Norwegian & $0.00 \%$ & $0.00 \%$ & $0.00 \%$ & $0.00 \%$ & $0.00 \%$ \\
\hline
\end{tabular}

Source: Statistics Canada, 2006 Census of Population, Statistics Canada catalogue no. 97-557XCB2006021

Clearly, the lack of language skills has significant impacts on the lifestyle and relationships of immigrants with other members of society. It also has negative effects on the political integration of immigrants. Furthermore, the considerable increase in the number and proportion of allophones with limited English or French abilities affected the Canadian labour market. As expected, those who cannot conduct a conversation in one of the official languages are more likely to be unemployed or not in the labour market. They are also more likely to work in a low pay environment, with no or limited usage of English or French. 
This chapter presented a comprehensive overview of the characteristics of new immigrants including: their origin and destination, demographic characteristics, education, language, and religion. More than revealing the changing patterns on the origin and destination of new immigrants, this chapter highlighted significant shifts in demographic characteristics, as well as educational, cultural, and linguistic profile of new immigrants. As argued in the introductory chapter, these changes play a major part in the integration process of immigrants and their relationship with the liberal state.

The major shift in the origin of immigrants is the most significant point. Findings of this chapter showed that compared to earlier immigrants who came mostly from JudeoChristian Europe, many new immigrants to Canada come from Asia, Africa and Latin America. As noted before, a series of studies confirms that immigrants from these regions (visible-minority immigrants) do not follow the trajectories of the earlier ones and integrate into Canadian society at a much slower pace. Since this factor is widely covered in other chapters of this study, I avoid repetition of arguments here, but simply insist that compared to earlier immigrants from Europe, new immigrants are more prone to isolation and marginalization.

This chapter also revealed a clear shift in the destination of new immigrants and their increasing concentration in large metropolitan areas. It confirmed that with more than 90 percent of immigrants living in one of the 33 Canadian Metropolitan Areas (CMA), immigration today is primarily an urban issue. Even though concentration of immigrants in CMAs adds to the human and cultural capital of these regions, it has significant implications on both the infrastructures of these cities, as well as the integration process of new immigrants. This uneven distribution of immigrants in certain 
regions places significant strains on the labour market, housing, health, education, public transit, and other social services. It also can cause an unbalanced development between different regions, with central metropolitan areas overwhelmed with a surplus of human resources, while other regions suffer from the lack of human capital.

With regard to the successful integration of new immigrants in the main society, the concentration of immigrants in CMAs has a double affect. While it offers the opportunity for community formation and the development of ethnic infrastructure and institutions which helps the settlement process of immigrants, we will see in the $5^{\text {th }}$ chapter that in some cases it causes the segregation of ethnic communities and their relative isolation from the majority of population. Isolation of immigrants from the majority usually means being less exposed to an English or French environment and prolonging the time to gain language ability. It means fewer employment opportunities and a lower level of income. More importantly, it means a lower level of trust and sense of belonging.

Just as the ethnic origins and destination of immigrants have changed, so too have their demographic characteristics. As noted, in the last 30 years the median age of immigrants at arrival has gradually increased from close to 25 years of age in 1970 to 30 years of age in 2000 . Even though, as a result of a rapidly aging Canadian population, new immigrants are, overall, younger than native-born population, this aging trend is not beneficial for the integration process. A review of literature shows that younger immigrants integrate into a new society at a much quicker rate than older ones. In general, employers are more attracted to younger immigrants than to older newcomers because of their longer number of productive years in the workforce and greater difficulty in training them. In addition, there is a strong link between age and the ability to learn a 
new language, and younger immigrants are more open to change and learning the culture and rules of a new society. Therefore, they have fewer problems developing relationships with others who belong to a different culture and have a different lifestyle.

The gender distribution of immigrants has changed as well. In addition to the increasing number and proportion of female immigrants, there is rising evidence that gaps in the economic, social and political performance of male and female immigrants are growing. For example, there is evidence of that the labour participation of recent immigrant women is declining compared to that of immigrant men and Canadian-born women (Statistics Canada 2007a). A number of current studies shows that, in addition to a poor knowledge of English or French, new immigrant women's access to job, language training, and further education is constrained by domestic responsibilities at home. The poor economic performance of women is considered to be one of the reasons why recent immigrant families are doing less well economically than in the past.

Another characteristic of immigrants that influences the speed and outcome of their integration process is their level of education. Findings of this chapter confirmed my argument in chapter 2 that, as the proportion of immigrants with a high level of education and skills has increased in the last 20 years, so too has the number and proportion of skilled and well educated immigrants in low paid jobs with low educational requirements. Even worse, this trend has not only included recent immigrants, but also established ones, signalling a much larger and consistent problem. Research shows that the difficulties faced by immigrants with a high level of education have been attributed to several factors. One of the major problems is the low rate of recognition of immigrants' credentials, as noted by Ferrer and Ridell (2004), as well as Green and Worswick (2004). 
These studies show that the accreditation process for regulated occupations had a major impact on recent immigrants' chances of finding a job commensurate with their educational attainment. One should expect these trends to have significant implications on the formation of negative perception of justice and role among well educated and highly skilled immigrants. Furthermore, since the immigrants' educational level also affects their general lifestyle preferences and their level of involvement in larger society, this type of treatment can result in a negative perception of society and sense of belonging.

In the last twenty years, and particularly after September 11, 2001, the religious activity of immigrants has attracted increasing interest from governments, media, and academics. One of the main areas of focus has been how the religion and cultural traditions of immigrants affect their process of integration in particular local and national settings. Much of the interest, especially in Europe, has been directed to Muslim communities, but increasing attention is being paid to other religious traditions as well. In Canada, the latest censuses and surveys show a sharp increase in the numbers and proportion of Muslims, Hindus and Buddhists, as well as those with no religious affiliations. This chapter highlighted the significant effect of a strong religious affiliation of some immigrants on their daily life, particularly on their relationships with people outside their religious circle. The effect of religious affiliation on social integration will be discussed in detail in chapter 5 , but suffice it to say here that people with strong religious affiliations are more likely to have a strong cultural association with the values and traditions of their country of origin. Even though these immigrants are committed to 
Canadian citizenship, evidence suggests it takes a comparably longer time for them to socially integrate into the larger society.

Clearly, language ability is a critical component of immigrants' integration process. To understand what others are saying and to be understood is fundamentally important to any kind of relationship between the immigrant and others, including the state. However, in order to integrate successfully and become an equal member of society, language proficiency goes far beyond basic communication and an immigrant may need to improve or perfect his English or French language skills to be able to find a decent job, to get involved in the community, and to engage in political activity. As an indication of the significance of language abilities to the immigrant's integration, in the Federal budget for immigrant settlement, half of the financial allocation goes to language and skills training 9 .

Indeed, the considerable increase in the number and proportion of allophones with limited English or French abilities had its affect on immigrants' economic, social and political integration. As expected, those who cannot conduct a conversation in one of the official languages are more likely to be unemployed or not in the labour market. They are also more likely to work in an environment with no or limited usage of English or French. Not surprisingly, the occupational profile of these immigrants includes jobs that usually require lower educational levels and less formal training. Based on the findings of the 2006 census, this type of immigrant was almost twice as likely to be low income compared to those who communicate in English or French at work ( $22 \%$ vs. $12 \%)$. The

\footnotetext{
${ }^{9}$ Interview with Yves Saint-Germain, Director, Information, Language and Community Policy. Citizenship and Immigration Canada. 23 February 2009.
} 
Census also reveals that, in 2005 , those who only used non-official languages at work earned less than half as much as those who did not (Thomas 2009b, 14).

A review of preceding literature and census and survey data shows that the negative effects of limited language abilities is not restricted to the economic integration of immigrants. There are also strong relationships between language proficiency and political and social integration of immigrants. For example, in a study of a group of Latin American immigrants in Toronto, Jorge Ginieniewicz found a clear relationship between lack of language skills and lower levels of political participation (Ginieniewicz 2007, 337).

Clearly, from a social integration viewpoint, the lack of language skills has significant impacts on the lifestyle and relationships of immigrants with other members of society. Those immigrants with low or no communication skills in one of the official languages have difficulties in such areas as accessing health care services, education, and employment and rely on their family members, relatives, and friends for their basic needs. Research shows that the social networks of these immigrants in general are limited to their family, relatives, and those who can speak their ethnic language (Chiswick and Miller 2000). Overall, immigrants with limited language abilities are more likely to live in larger metropolitan areas with a high concentration of their ethnic counterparts. In turn, this means more isolation from the majority, which in the end has a negative effect on their integration. 


\section{Chapter IV: transformation of the Liberal State}

The main focus of this chapter is on the transformation of the liberal state in the last few decades, as well as the social, political and economic consequences of this transformation. A critical review of these changes will help us to better understand the negative effects of the transformation of the liberal state on the integration of new citizens into Canadian society. As noted earlier in the introductory chapter, a combination of global factors, plus a mixture of local socio-demographic, cultural and political pressures has transformed the Canadian political system, which now functions differently and delivers different outcomes, in spite of the apparent continuity of its forms. At the international level, in addition to the economic pressures such as global competition for economic resources and new markets, development of universal human rights principles and delegitimization of extreme nationalism have had major impacts on the structures and functions of the nation-state. On the other hand, on the national stage, the slowdown of economic growth and productivity and a shift to service employment, combined with other socio-demographic, cultural and political pressures, such as an aging population, changes in household formation, and the transforming political culture of Canadians, the relationship between the liberal state and it's fellow citizens has gone through serious transformation.

\section{Welfare State and Workfare State}

A review of literature shows that the postwar evolution of liberal states in advanced capitalist societies began with fundamental transitions in the mid-1970s that were characterized by privatizing, liberalizing, shrinking, or deregulating the political, economic, social, and environmental sectors. A number of studies on social policy argue 
that the traditional postwar 'Keynesian welfare state' has been transformed into a 'Schumpeterian workfare state' (Jessop 1993 and Torfing 1999). Others conceptualize these changes as a shift towards an enabling state (e.g. Gilbert 2002). Beyond the general perception that the structure and functions of the traditional welfare state have changed, all these studies agree that in contrast to the welfare state model of providing a variety of expensive social services to citizens from birth to death, the new transformed state model competitively conforms to the dictates of the market economy.

The argument that the 'Keynesian welfare state' is being transformed into a 'Schumpeterian workfare state' has been advanced in particular by the regulation school, which emphasises the macroeconomic aspects of this reform. One of the most prominent scholars of this school, Bob Jessop, distinguishes three major characteristics of this transformation as; (1) national labour market and employment relationships are restructured in favour of global competitiveness; (2) social rights and functions of redistributive justice lose their ground to social policies encouraging more productivity; and (3) the dominant role of the nation state is replaced by other governance mechanisms operating on various levels (Jessop 1999, 16). In policies governing the national labour market, in particular, there is a clear shift from the Keynesian model based on demand management, to the management of supply, where major policy changes push for increasing the flexibility of employment relationships in order to create more jobs and increase productivity. Activating the labour market, therefore, is justified by a paradigm shift of welfare state policies. This shift is understood to involve a mix of the enforcement of labour market participation, the conditioning of social rights and growing obligations of the individual on one side, and an increase of services to promote 
employability on the other (Torfing 1999, 374). In this context, most government programs pressured the unemployed individual, particularly welfare recipients, to return to work, even to lower income jobs.

Furthermore, according to Jessop (2003, 30-46), during the process of this transformation, the regulating powers of the postwar welfare state are successively being hollowed out by a combination of pressure centers of various sorts. He points out to six broad factors, namely: denationalization of statehood; redrawing of boundaries between the state and the non-state spheres; replacement of territorial states with non-territorial forms of governance; articulation of economic and political spheres in new ways; coshaping of state policy making by external actors; and finally, expansion of new political communities along ethnic and non-ethnic lines. However, the liberal state is not defenceless and is actively responding to the challenges posed by these changes and reforms itself from within. Altogether, from Jessops point of view, the Keynesian national welfare state gives way to a Schumpeterian postnational workfare regime.

The key concept is the notion of the enabling state. What this means is that the state's main duty is to enable citizens to create, produce, and reproduce services that used to be offered by the state. From the perspective of this approach, the shift from welfare state to the enabling state is portrayed as a change from the publicly provided benefits as a social right of citizenship, towards a more market oriented approach that promotes active participation in the labour force and the expansion of individual responsibility (Gilbert 2002, 44). In this model, emphasis on individual responsibility and active engagement in the labour market is accompanied by the delivery of social programmes aimed at the enhancement of individual human capital. This model is based on a new 
definition of roles and responsibilities of citizens, where citizens are supposed to be actively involved in the economic, social, cultural and political spheres of the society. In exchange, the liberal state is expected to provide programs and services that open the way for equal opportunities for all members of society to become actively involved. For example, the economic framework of this model is centred on the improvement of employability, particularly for disadvantaged groups like women, aboriginals and visible minorities, and on policy measures that include training policies to improve human capital of these groups.

Canada is a fine example of this transformation. Similar to other Western countries, Canadians has witnessed an unprecedented erosion of the postwar welfare state institutions and services during the last three decades and their replacement by a so called workfare state. A historical review of the rise and fall of the Canadian welfare state from one based on a Keynesian economic model to one founded upon neo-liberal ideas reveals that various international and domestic forces worked to promote this restructuring.

The development of Canadian welfare state systems can be traced back to the 1940s. Reference may be made back to a number of reports submitted to Parliament that were followed by the development and delivery of universal social programs. One of the first reports that can be regarded as a landmark at the beginning of the progressive phase in the construction of the Canadian welfare state system was prepared by Leonard Marsh on the subject of social security in Canada in 1943. This report underlined the need for a combination of social programs, including health insurance, unemployment insurance, old age pension and maternity allowances. For the most part, the findings and recommendations of this report were based on the lesson Canada had learnt during the 
Depression of the 1930s. Complementing this report was another report by the Special Advisory Committee on Health Insurance, which was established in 1942 under the chairmanship of J.J. Heagerty, then Director of Public Health Service in the Department of Pensions and National Health. The report of this committee helped the development of Canada's National Health Insurance Act of 1943 (Vivekanandan 2002, 46). Both these reports emphasized the importance of health and unemployment insurance. The collective effect of these reports was a series of legislative and executive measures over the following years. For example, in 1944, Parliament passed the Family Allowances Act, under which all mothers were entitled to receive an allowance on behalf of their children below sixteen years. Then, in 1948, the National Health Grant Programme was introduced to provide health services. Later, in 1951 the old age pension system was launched, which guaranteed a pension to all Canadians over the age of 70 . The Canadian welfare state system expanded in the 1950 s and 1960 s, particularly during the period between 1963 and 1968, as a result of the joint efforts of the Liberal and the New Democratic Party, under Prime Minister Lester Pearson. This period witnessed the introduction of measures such as social security, health insurance and public housing. Lester Pearson's government piloted three major social legislations, namely Medicare, the Canada Pension Plan, and the Canada Assistance Plan.

If the 1960 s witnessed the flowering of welfare programs, the 1980s and 1990s saw the grand setback of the Canadian welfare state system. The impetus for this change arose from both internal and external sources. At the macroeconomic level on the national stage, there was a growing recognition that significant elements of the post war welfare state paradigm were no longer relevant and were no longer providing the expected 
outcomes. Rates of inflation had risen during the 1970s, annual budget deficits had become the norm and public debt started to mount rapidly. Financial markets began to lose confidence in the outlook of the Canadian economy and the value of the Canadian dollar. As jobs faded away and the unemployment rate passed the $10 \%$ mark, the country's economy seemed to be in a fiasco.

Another domestic driver of change was the concern that the generous federal system of unemployment insurance, in conjunction with provincial welfare payments, was discouraging work ethic having a negative impact on the work efforts. There was similarly a growing worry that the combined effect of federal and provincial regulations was undermining economic efficiency, unnecessarily inflating business costs and discouraging entrepreneurship and innovation. Government ownership of large corporations like airlines, oil companies and hydro also began to seem outmoded.

A third impetus for change was an understanding that the social conditions that had given rise to many welfare programs were no longer relevant. Most of these programs were based on a family structure of two parents, with one income earner. By the $1980 \mathrm{~s}$, the family structure was much more diverse and the role of women had changed dramatically. In addition to a sharp increase in the proportion of women at work and families with two bread winners, there has also been a remarkable increase in the number and proportion of single parent families. The demographic transformation of Canada has also played a role in weakening the welfare system. The ageing of a substantial section of the Canadian population and low fertility rates began to overload the capacity of the welfare state system. By and large, these changes have led to an increasing proportion of 
social expenditures being diverted from younger people and families to the ageing population and single parent families.

Some commentators point to the increasing diversity of population in Western societies caused by immigration as another driver of change (eg, Gould and Palmer 1988, Alesina et al 2001). In general, these commentators argue that it is difficult to sustain strong social welfare programmes in the face of comparatively high ethnic diversity. Soroka et al (2002) recognize two major approaches with respect to the conflict between ethnic diversity and a stable welfare state. One theory starts from notions of community and mutual obligation. In this view, the expansion of the welfare state in the twentieth century was underpinned by a sense of community and collective responsibility of citizens for each other (Marshall 1950). These bonds of community seem more difficult to sustain as the population becomes more diverse. In short, the essential premise of this approach is that the redistributive state is rooted in a sense of community and collective responsibility, and that this solidarity becomes more difficult to sustain as a population becomes increasingly diverse. On the other hand, another group of scholars provides a subtly different perspective, with an emphasis on trust as the solution to collective action games. The argument is best described by Miller (1995:90-99). He states that mutual trust facilitates solutions to collective action problems inherent in social welfare programmes, where citizens must trust each other to participate as contributors and refrain from taking advantage as beneficiaries. Trust is aided by identification with fellow citizens. Identification with fellow citizens occurs easier among ethnically and culturally homogenous societies, and it will be more difficult to foster identification with fellow citizens in societies that are ethnically or culturally diverse. As an example, the 
supporters of this approach point to studies comparing social expenditures across US cities and states that find ethnically heterogeneous states tend to spend less on redistributive programmes (e.g. Alesina et al 1997).

On the other hand, the defenders of multicultural policies insist that no empirical study exists on the connection between individuals' opinions and perceptions as affected by the experience of diversity, on one hand, and support for the welfare state, on the other. They argue that the relationships between ethnic diversity and support for the welfare state are far more complex than portrayed by much of contemporary discourse. According to Banting (2005, 99), Western democracies with large foreign-born populations have not had more difficulty in sustaining and developing their welfare states than other countries. He maintains that despite the worries of some critics, the adoption of robust multiculturalism policies does not systematically exacerbate relations and erode the welfare state.

Drivers of changes that transformed the welfare state were not merely limited to the internal factors. At the international level, the ideological movements in Western Europe and the United States were becoming increasingly hostile towards state-run welfare systems. The 1980 s were characterized by sustained attacks on the welfare state system by the right leaning administrations of Prime Minister Margaret Thatcher and President Ronald Reagan in Britain and the United States respectively. In both countries, the consensus for publicly funded welfare programs vanished in a short period of time. The alternative approach was to leave public welfare programs and services in the hand of free market forces and private enterprises. No doubt these ideological trends had their impact on Canada's political culture. According to Telford and Lazar (2002) the political, 
economic, and social values of Canadians seemed to have shifted over the past twenty years and Canadians have become more conservative in their economic thinking. They indicate that a broad consensus has emerged among Canadians for the elimination and the reduction of overall government debt; that freer trade has generally been positive for Canada; that lower taxes are required to stimulate investment, maintain productivity growth, and remain competitive with the United States; that governments should privatize their business enterprises and deregulate important segments of the economy; and generally that governments should be managed in a more responsible and business-like fashion, in accordance with the ideas associated with the new theory of public management (Telford and Lazar 2002, 5).

Overall, a combination of these internal factors and external pressures provided an opportunity for the right leaning political parties and institutions to attack the principles and functions of Canada's welfare state system. After the defeat of Pierre Trudeau's Liberal government in 1984, the Progressive Conservatives, under Brian Mulroney's leadership, sought to cut down social spending. The Mulroney government criticized Canada's welfare state system on two fronts; the sharply growing debt crisis and the budget deficit. It was argued that the debt problems became so acute that there was no choice but to cut social spending. It insisted that social welfare programs generated massive inefficiencies and that financing them required very high levels of taxation $\&$ inflationary budget deficits. During this period, the NDP and a group of civil servants were the only defenders and main supporters of the traditional welfare state. A centrist party, Liberals positioned itself in between, with no strong commitment to either position. 
The record of the following years speaks for itself. At both federal and provincial levels, the policies promoted by governments took a significant turn to the right during the 1980s and 1990s. Government spending on social programs was reduced significantly, and most of them were outsourced. Most regulations were reviewed and, in places, eliminated. State corporations were sold off to the private sector. In the 1990s, all levels of Canadian governments stopped growing and by the late 1990s, they had shrunk substantially as a share of the economy.

Besides ideological and domestic pressures, Canada's Free Trade Agreement with the United States in 1989 also greatly influenced government's tendency to whittle down welfare benefits. These treaties obliged Canada to give up some regulatory powers and accept limits on state action. As a result of these treaties and obligation, Canada's welfare system, which was historically influenced by British and other Northern European models, increasingly moved closer to the minimalist welfare model of the United States. According to Vivekanadan, the Canadian state dismantled its distributive system and attuned itself to the priorities of the market. A steady process of trade liberalization, winding down of capital controls, and globalization of production undermined the state's capacity to regulate the entire country as one economic unit. The federal government began to desist from setting minimum national standards for social assistance, while assigning a greater role to the provinces to administer labour market services (Vivekanadan 2002, 58).

After coming to power in 1993, the Liberal government headed by Jean Chrétien endorsed these neo-liberal policies and stayed the course of cutting the federal government's budgetary deficit, partly by reducing the transfer payments to the 
provinces. Similarly, by the mid 1990 s, almost all provincial governments began acting forcefully on the economic front to eliminate their budgetary deficits. Interestingly, these trends met the endorsement of various party affiliations, including right leaning Conservative governments in Ontario and Alberta, center of the spectrum Liberal governments in British Columbia and New Brunswick, as well as the leftist New Democratic government in Saskatchewan.

Even though all these governments played leadership roles in dramatically altering welfare policies and transforming the welfare state system, they went about achieving this goal in distinctive ways. In a study of the similarities and differences between the welfare reforms in Ontario and British Columbia, Little and Marks (2006) concluded that in both provinces, the neo-liberal elected governments had similar concerns about the problems of the welfare system. In both provinces, politicians claimed that too many people relied on social transfers, that the majority of those who were receiving welfare payments were lazy and needed to get jobs, that they remained on welfare for far too long, and that, given the priorities of deficit reduction and tax cuts, welfare costs were far too high. In a clear example of how politicians perceived the problem of welfare payments, Ontario Premier Mike Harris stated that: "People have got to learn again to take responsibility for themselves and their families and not leave it to everyone else to do. ... We're paying a significant number of people, over a million ... to sit home and do nothing" (Ontario Legislative Assembly [OLA], 1995). In British Columbia, Premier Gordon Campbell argued that employable people on welfare could get jobs if they wanted to, while various $\mathrm{BC}$ ministers responsible for income assistance trumpeted the 
need to replace "a culture of entitlement [with] a culture of self-sufficiency" (Little and Marks 2006, 17).

In short, from this perspective the problem with the classic welfare state is that it encouraged clientelism among citizens and offered those in need a handout, not a hand up. They accused the passive welfare state of promoting a dependency culture among its citizens, and that, the only solution was to replace this kind of passive state by an active state that managed resources more efficiently. As Giddens (1994) pointed out, this approach no longer envisions the welfare functions of the state in terms of meeting needs, but of managing risks. This is reflected in new public management doctrines, which look upon the recipients of welfare as autonomous individuals or consumers, not as social members or citizens. According to Giddens the slogan of "no rights without responsibilities" stands at the heart of this project (Giddens 1998, 65).

\section{The Great Transformation}

With this kind of approach, it is not surprising that soon after assuming power, these administrations adopted new legislation aimed at changing the work ethic and pushing welfare recipients to enter the labour force as soon as possible. For example, in 1997, the Ontario government introduced the Ontario Works Act and the Ontario Disability Act, which respectively replaced the old Family Benefits Act for single parents and the disabled and the General Welfare Act for all other low-income recipients. Based on the new policies, all able-bodied adults, including single parents with school-age children, are covered under the Ontario Works Act and only those who have recognized disabilities are covered by the more generous ODSP. Similarly, in 2002, the BC Liberal government replaced the BC Benefits (Income Assistance) Act with the Employment and 
Assistance Act, which applies to both those on temporary assistance and those on disability assistance, although levels of support are higher for those receiving disability assistance. These new policies reflect the general emphasis of politicians to change the work ethic of welfare recipients and, at the same time, required them to demonstrate their willingness to take on work through the implementation of workfare.

At the same time, at the federal level, a new form of what has been called the sustainable social policy has become the dominant vision. The hallmarks of this vision were a leaner and tougher social security system, more geared to employment; a reduced, though still significant, federal presence in social security; a commitment to base public spending on a zero-deficit fiscal foundation; an emphasis on "active" social programs that will invest in human capital as opposed to "passive" income programs that are believed to engender dependency; and the credo that governments do not have all the answers and must work together with partners, such as employers, the voluntary sector and communities (Battle 1998, 328).

There have been a good number of studies looking at the different aspects of the transformation of the liberal state and its main socio-economic, cultural and political implications. These studies cover a lot of ground, but in this dissertation I only review three sets of outcomes most relevant to the integration of new citizens in Canadian society. The first set of outcomes relate to the social and cultural policies and programs. Second, the implications of these changes for integration programs specifically will be reviewed. Finally, the significant changes in immigration policies will be analyzed.

To begin with, one of the main outcomes of the changing approach of different levels of Canadian governments was the revision of social and cultural policies based of 
new frameworks characterized by the domination of neo-liberal economic policies and conservative budget practices. The desire to limit government expenditures and redefine the social and cultural role of the state has resulted in the re-alignment of social programs with economic needs. The end result was a cut back in most major social programs in some way or another. Starting in the mid 1980 s, child benefits were partially de-indexed and payments have been reduced for middle-income and eliminated for high-income families. Elderly benefits have been transformed and attached to the income level of seniors and thus, depending on level of income, reduced or eliminated for better-off elders. Unemployment insurance has been renamed Employment Insurance and severely tightened. Federal social transfers to the provinces and territories for health, welfare, social services and postsecondary education were consolidated and substantially reduced under the Canada Health and Social Transfer (CHST) of 1996. The Canada Pension Plan has undergone a major acceleration in contribution rates to move it from pay-as you- go to partial funding, and benefits trimmed for future pensioners.

While different aspects of Canada's welfare state system have been subject to policy adjustment and payment cuts, none of them have been more affected by the restructuring process than public assistance for the unemployed. Unemployment insurance systems were one of the first pillars of social security regimes. The importance of unemployment insurance rested on an understanding that one of the major insecurities created by market society is loss of employment. In the summer of 1996, the newly restructured Employment Insurance (EI) programme replaced the old Unemployment Insurance system. The negative effects of the implementation of these new measures for the economic security of Canadians have been profound. As an example, by 1997 the 
percentage of the unemployed who remain eligible to collect employment insurance benefits declined to 36 per cent from 76 per cent in 1989 . The decline was the result of much tighter eligibility rules that have served to disenfranchise many of the unemployed from benefits. In addition, the increasing frequency of long-term unemployment alongside instability of the labour market resulted in substantial increases in selfemployment and part-time work. Furthermore, based on the newly implemented rules, these forms of employment either fell outside the coverage of EI, as in the case of selfemployment, or made meeting EI qualifying requirements far more difficult, as in the case of contingent work (Guest 1997, 281). Immigrants, particularly those who are visible minorities, are disproportionately represented in these forms of employment and thus suffered more under the new employment insurance regime.

Similarly, social welfare assistance has undergone deep restructuring (Jackson and Robinson 2000, 139-66). Benefit levels have faced significant cuts and a disciplinary workfare orientation has been introduced that discourages social assistance use. As noted above, the main objective of the newly implemented rules was to move away from socalled passive income support to active labour market engagement. From this point of view, the increased emphasis on employment-related measures is supposed to be accompanied by the development of social programmes aimed at enhancing human capital and helping the unemployed adjust to modern labour market requirements. Benefits are increasingly linked to behavioural requirements through incentives and sanctions (Gilbert 2002, 45). In fact, while in theory the emphasis on work and personal responsibility aims to prevent the exclusion of low skilled, low income groups from the labour market, in reality it entails an intensification of disciplinary social controls. In the 
case of immigrants, the adaptation of these social policies not only reduced that, they became more personally responsible for their integration into the labour market, but it has also entailed the enforcement of standard economic behaviour.

In recent years, there have been many formal and informal discussions, buzzes and anecdotes around substantial transfers of tax-payers' money to immigrants through social assistance payments. For example, a recently published report by the Fraser Institute estimated a tentative transfer of more than $\$ 18$ billion to new immigrants between 1990 and 2002 (Grubel 2005, 19). Interestingly, Grubel, himself admits that the calculation of this number is based on a number of assumptions that are open to question (Ibid, 20), but no doubt there are widespread beliefs that immigrants work less and rely more on welfare transfers. A more reliable report from the British Columbia statistics agency (BC stats) concluded that, in 1995 , close to $14.2 \%$ of immigrants who arrived in Canada between 1980 and 1995 received welfare benefits. As expected, the degree to which immigrants depend on welfare benefits varies by place of residence, age, sex, level of education, type of immigrant, state of the economy, and a number of other factors. In contrast to the general belief that immigrants in the refugee and designated classes tend to rely more on welfare benefits than those in other classes, possibly due to a lack of financial assets, supporting relatives, or even job skills, this study found that, while a very high percentage of refugee immigrants received welfare benefits initially after landing, they gradually became less dependent on welfare payments. On the other hand, for immigrants in other classes, especially family classes, the proportion who receive welfare increased the longer they are in Canada. This observation might be explained, in part, by the fact that all immigrants admitted under the family class were required to be sponsored by 
family members already in Canada. These family members are responsible for giving them financial support for a period of up to ten years after their arrival. On the other hand, most of these family members are parents of skilled immigrants, who after ten years of living in Canada become eligible for old age security benefits (BC Stats 2004).

The imposition of reforms to old age security and cuts to benefits for seniors, were also among the changes to the Canadian social welfare system in 1990s. As a first step of this reform, in 1989, the federal government introduced a special tax on Old Age Security and family allowance benefits, which came to be known as the "clawback." Later in the 1990s, the government introduced changes to the way benefits were calculated and required higher levels of contribution. In recent years, there have been a considerable number of discussions by different levels of government about increasing the age of retirement and introducing other measures to decrease the amount of payments and the length of period for these payments.

Even though the impact of the changes in social policies differs depending on the policy and the way it has been implemented, there are three common patterns and themes to the changes. First, there is general agreement that the underlying logic of welfare state policies has been redesigned and there has been a clear shift away from an inclusive universalistic model (Banting et al. 2001, 14). Universal programs, such as Universal Family Allowances and Old Age Security, two of the three bastions of universal social security, have given way to the income-geared Child Tax Benefit and Old Age Security, targeted at low- and middle-income families and seniors. Even though universal health care remains, the two-tier system which permits Canadians to purchase some health 
services if they have the desire, and obviously the money, has become more popular among some politicians.

The next common pattern is not about social policy and its consequences, but about the way it is developed and communicated. Major changes to important social programs, such as the removal of universal old age pensions and family allowances, the massive cuts in social transfer payments to the provinces and the gradual erosion of child benefits, were made with no advance notice and little effective public debate. Many unions and community agencies complained that changes to social policies were made without consultation or concern for the impact on marginalized communities. One of the lasting negative legacies of this transformation is its entrenchment of an elitist style of policy making through stealth, which is appalling for any democratic system.

Another factor in the transformation of the Canadian welfare state system is what might be called the problem of identity. Canada has traditionally taken great pride in its version of the social welfare state, particularly its public health care system, believing it has created a kinder and gentler society than that of the United States (Per Marchildon 1995, 141). This stance has been indicative of Canadians, compassionate nature and their refusal to follow the individualistic, every-person-for-him/herself ethic of Americans. Indeed, we will see in the next chapter how transformation in the state and political culture of Canadians has had a great effect on civil society and how Canadians look after the marginal groups of society, including immigrants.

Since the inclusion of different social and ethnic groups, including immigrants, is often considered one of the main objectives of social policies, any changes in this area would have a significant impact on immigrants' integration. The settlement and 
integration services for immigrants would seem particularly sensitive to such massive changes in development and implementation of social policies. The ability of immigrants to integrate into the Canadian labour market and society depends, not only on their personal characteristics, knowledge, skills, experience, and traditions they bring with them, but also on the social and economic conditions they encounter upon arrival. Many newcomers require assistance in adapting to a new and changing environment. The collective ability of different levels of government, as well as Canadian society to provide immigrants with essential settlement and integration services, has a vital effect on the ability of immigrants to successfully integrate into their new society.

Historically, different levels of government in Canada have delivered some settlement service to new comers to Canada since the 1940s. The first formal settlement services provided to immigrants go back to 1948 , when the federal government placed federal settlement officers throughout the country to help families of Canadian soldiers and war refugees adjust to life in Canada. Prior to World War II, settlement of immigrants was left to those responsible for bringing them to Canada, such as the Canadian National Railway, Canadian Pacific Railway and the Hudson Bay Company, and to voluntary agencies and the immigrants themselves. In 1966, with the creation of the new Department of Manpower and Immigration and changes in immigration policies, the Settlement Service was disbanded and the federal government withdrew being actively involved in the settlement needs of immigrants. Instead, the prevailing philosophy was that immigrants should turn to existing mainstream services available to all Canadians for their settlement needs. Later in the 1970s, with the influx of Indochinese refugees and a new wave of immigrants, the mandate for operation of federal 
settlement programs and services was reaffirmed and the federal government started to work both with other levels of governments and non-governmental organizations to provide settlement services. Consequently, programs, such as The Immigrant Settlement and Adaptation Program (ISAP), provided funds to businesses, non-profit corporations, non-governmental organizations, community groups, educational institutions at the individual and community levels, as well as provincial and territorial governments, to deliver direct and essential services to newcomers. Through ISAP, essential, direct services are provided to newcomers to Canada, including: reception, referral, orientation, interpretation and translation, para-professional counselling and employment-related services.

Later in the mid 1990s, the federal government undertook the Settlement Renewal initiative to consider the policy and management direction of immigrant settlement services in Canada. This led to the federal government signing immigration agreements with several provincial governments. Under Canada-Quebec accord, the federal government agreed to provide yearly grants for immigrant selection and settlement services with minimal supervision. In British Columbia and Manitoba, the federal government agreed to support settlement services through contribution funding, but delegated the design, delivery, and administration to the provincial governments. In all other jurisdictions, the federal government kept the authority for management and delivery of settlement services through contribution agreements with service providers, with different forms of co-management in Ontario and Alberta.

At the same time, Ontario, the largest immigrant receiving province, elected a Conservative government in 1995 with Mike Harris as Premier. Like other areas of social 
policy reviewed above, the new government restructured its primary immigrant settlement program, now called the Newcomer Settlement Program, cut funding by nearly $50 \%$ (to less than $\$ 4$ million in $1998-9$ ), shifted from core to project funding and eliminated many useful programs entirely (Simich 2000, 7). The government also shut down the Ontario Welcome Houses that provided settlement support across the province (Ontario Council of Agencies Serving Immigrants 2009, 2). According to Nicholas Keung (2009), in Quebec, another major immigrant receiving province, the provincial government moved federal transfer payments for settlement into general revenue and it is not clear what portion of the federal funds has been spent on settlement and integration.

These cutbacks, as well as the unwillingness of different levels of government to take the lead on this issue, left the settlement sector dealing with considerable uncertainty, and its ability to meet the needs of new immigrants was undermined. In recent years, immigrant advocates, as well as workers for immigrant services and NGO agencies, have complained that cutbacks in the funding made immigrants much more vulnerable to being excluded from the labour market and society at large. For example, recently, the Ontario Immigration Minister, Michael Chan, said, "Heading into the current recession, Ontario's immigrants were already experiencing significant challenges in the job market. Since the start of the economic downturn, immigrant unemployment here has risen dramatically, from 12 per cent to 16 per cent over the last 12 months. Among the most affected were those who have been here between five to 10 years, whose unemployment rate doubled from 8 per cent to 16 per cent in a one-year period ended in April" (cited in Keung 2009). 
In the last couple of decades, almost everywhere, the welfare state trimmed down many of the numerous social tasks it acquired in the last half-century. The domain of social policies, particularly the services vital to immigrant settlement and inclusion in Canadian society, is suffering from the welfare state's continued retreat. At the same time, newly arrived immigrants, as one of the more vulnerable groups to economic uncertainties, are more and more under the threat of exclusion from Canadian society. It has been argued that the more socioeconomic inequalities and insecurities increased, the more people took refuge in exclusive, but protective, cultural and ethnic affiliations, leading to a rise in the tendency to reject others because they are different. In this way, culture and cultural identity can become not only a means of compensating for frustrations experienced elsewhere, but also a weapon of domination (Martiniello 2003, 137).

Aside from major changes in social policies, another key implication of transformation of what has been called the passive welfare state to the active workfare state has been the alteration of immigration policies to make them more homogeneous with the general objectives of the workfare state. As a result of the gradual dominance of economic priorities over social, demographic, and cultural considerations, the main goal of immigration has changed from nation building to one of securing the consistent flow of new immigrant blood to the labour force. At present, almost all contemporary developed western societies are highly dependent on securing and utilizing the skills and human capital of immigrants. Their economic innovation and prosperity critically depend on attracting and keeping well-trained immigrants. Therefore, in a global contest for the 
best brains, Canada should use effective immigration policies to position itself as a competitor for highly skilled immigrants in the global market.

Canada was one of the first countries to alter the immigration policies to secure both the constant flow of labour and maintain a competitive advantage in the global arena. Hence, to achieve this goal, like other immigrant receiving countries with aggressive immigration policies, Canada moved to reduce the number of unwanted and illegal immigrants and settlers, and increase the number of highly educated and well qualified young migrants, who could integrate to the labour force and boost the level of human capital of the society.

Canada has a long history of economic-utility-driven immigration and Canadian immigration laws and policies have long been aligned with economic interests. In Canada's early period of colonization, manpower needs shaped immigration and settlement policies (Baudar 2008, 131). However, consideration given has always been to social cohesion and population growth, and throughout Canadian history all governments have strived to balance economic, social, and cultural factors in the development of immigration policies. A historical review of Canadian immigration policies shows that, through time, economic priorities start to move to the top of the list of priorities in the development of immigration policies.

In fact, social cohesion and maintenance of national identity had been the top priority of all Western governments, including Canada, until a few decades ago. As Jopke $(2005,48)$ points out, the main paradigm for immigration and citizenship policies of the classic nation-state of the late $19^{\text {th }}$ and early $20^{\text {th }}$ century was to create and maintain the society in the image of a particular nation. Immigration and citizenship policies were thus 
in the service of reproducing internally homogenous, yet externally sharply bounded, collectivities, which was achieved by selecting newcomers on the basis of their ethnicity, race, or national origins. He argues that these immigration policies were both archaic, relegating individuals to the status of replicas or like-units within an ascriptive group, and, in an overshooting way, modern, driven by the plan to rationally steer society from the top to what Parker calls "A scientific plan for keeping America American" (Warner Parker 1924, 740).

It was only after the Second World War that modern nation-states began to move away from extreme nationalism as the main basis for their immigration and citizenship policies. This was motivated by an international push to respect the basic universal human rights of people, regardless of their religious, ethnic or national affiliations. The key document for this is the 1948 UN Universal Declaration of Human Rights which, according to Michael Ignatieff, has since become the 'lingua franca of global moral thought' (Ignatieff 2001, 53). The fact that shared humanity cannot be restricted by extreme nationalism had major implications for immigration policies and forever altered the meaning of exclusion in these policies. While foreigners continue to be excluded, this exclusion is primarily different from what it used to be. While historically they were getting excluded because of their ethnic or other particular group characteristics, now they can only be excluded because, as individuals, they are not citizens of the state. In a huge shift from past racist policies, now this foreigner can become a citizen, first through becoming a resident and later through passing a naturalizing process. In short, the rules of inclusion and exclusion have changed from group-based to individual-based 
characteristics. This opened the door for different individuals to enter the country, provided they possess the required individual characteristics determined by the state.

Indeed, moving from group based to individual based exclusion methods was in line with the general objectives of the workfare state. As noted above, the active workfare state is primarily concerned with human capital and the economic productivity of the new immigrants. The goal is to recruit the best brains that will increase the productivity level of the state by entering the labour market in a short period of time. Obviously, group based exclusion model are founded on cultural and social criteria that are not aligned with the mainly economic goals of the workfare state. On the other hand, moving to individual based exclusion modes makes it easier for the state to exclude those individuals who need a higher level of social support to integrate and could become a drag for the welfare programs. In short, shifting to the individual based form of exclusion paved the way for the implementation of new immigration policies that would serve the general objectives of the workfare state.

Beside human right considerations, there are some other external factors that facilitated the implementation of new immigration policies based on the objectives of the workfare state. Some scholars have argued that freedom of circulation required by a global economy and regional markets have pushed the liberal states to alter their immigration policies. Globalists, such as Sassen (1996, xvi), perceive migration as one of the areas where nation-states are losing control over their borders. In the Canadian case, a good example is treaties, such as GATT and NAFTA. The core objective of these treaties is to facilitate the movement of capital and people in order to achieve better economic outcomes. Consequently, in the case of immigration policy, to the extent that it supports 
higher level of economic production, it would be aligned with the broad objectives of the workfare state.

The increasing weight of economic considerations in the development of immigration policies has led some commentators to argue that in the last couple of decades, immigration policies have been simply a continuum of economic policies in Canada and other Western developed countries (e.g. Veugelers 2000). In the same vein, some identified the lobbying by the private sector and business pressures as the main drivers of immigration policies. Others, like Simmons and Keohane (1992, 425-426), believe that, although economic considerations are important, the federal immigration policies have not totally mirrored economic interests, but addressed a combination of concerns. Focusing on the development of immigration policies during the Mulroney era, they show how policy in this area is a by-product of the state's attempt to maintain legitimacy amid a flurry of conflicting public interests. A review of immigration policy making in Canada over the last few years supports this argument. In fact, a review of the Department of Citizenship and Immigration Canada's (CIC) Annual Reports to Parliament over time confirms that the federal government generally seeks to strike a balance between different socio-political and economic priorities.

Nevertheless, the signs are obvious that, during the last three decades, economic priorities have moved to the top of the list in immigration policy making. An examination of methods used by the federal government to achieve its immigration objectives reveals clear precedence of economic concerns over other considerations. The key measures applied by the federal government to ensure the success of immigration objectives in the last couple of decades are the quota system and selection of immigrants based on points. 
While the quota system restricts the number of immigrants that will be accepted annually in each admission class, the point system ensures the exclusion of unwanted individuals.

Table 1: Immigration Levels Plan 2009

\begin{tabular}{|l|c|c|c|c|}
\hline $\begin{array}{l}\text { Immigrant } \\
\text { Category }\end{array}$ & $\begin{array}{c}\text { Low } \\
\text { Scenario \# }\end{array}$ & $\begin{array}{c}\text { Low Scenario } \\
\%\end{array}$ & $\begin{array}{c}\text { High Scenario } \\
\#\end{array}$ & $\begin{array}{c}\text { High Scenario } \\
\%\end{array}$ \\
\hline Economic class & 140,300 & $58.5 \%$ & 156,600 & $59.1 \%$ \\
Family class & 68,000 & $28.3 \%$ & 71,000 & $26.8 \%$ \\
& & & & \\
Protected Persons & 23,600 & $9.8 \%$ & 27,200 & $10.3 \%$ \\
Others & 8,100 & $3.4 \%$ & 10,200 & $3.8 \%$ \\
TOTAL & $\mathbf{2 4 0 , 0 0 0}$ & $\mathbf{1 0 0 . 0 \%}$ & $\mathbf{2 6 5 , 0 0 0}$ & $\mathbf{1 0 0 . 0 \%}$ \\
\hline
\end{tabular}

Source: Department of Immigration and Citizenship, Annual report to Parliament, 2008.

The quota system is justified by most Western democracies, including Canada, on the basis that completely open borders would be problematic because of political concerns and economic stresses that would be placed on the system. The quota system not only limits the total number of immigrants admitted per year, it is also a measure associated with the distribution of immigrants admitted across different categories, namely economic immigrants, family class immigrants and refugees. Based on the latest report of the CIC to Parliament (2008), while the federal government had a plan to admit close to 250,000 new immigrants in 2009 , there were more than 925,000 individual applicants waiting for CIC's response to their request to immigrate to Canada. This number is only representative of those individuals who not only wish to move to Canada, but believe that they have the required qualifications to be admitted through the point system. Of course, there are millions more who wish to move here, but since they believe their chance to pass the point system hurdle is very slim, they never bother to apply. Another objective of the quota system is to balance economic needs on the one hand, and 
the government's commitment to support family reunification and humanitarian objectives on the other. Table 1 shows the planned range of immigration by category.

Another tool that complements the quota system is the so called point system of selecting immigrants. This system is a merit-based selection process that determines access to permanent residency in Canada. By granting points based on objective skills acquired by immigrants, as well as their age and other criteria, the system ensures that only those with needed attributes may immigrate permanently to Canada and gain a path to Canadian citizenship. The minimum number of points needed to pass the selection process is 67 out of 100 total points, and the worker must have had at least one year of full-time work experience in a desired skill within the last 10 years. Table 2 shows the selections factors and the maximum earnable points.

Table 2: Point System Selection Factors.

\begin{tabular}{||l|l|}
\hline \multicolumn{1}{|c|}{ Selection Factor } & \multicolumn{1}{|c|}{ Points } \\
\hline Education & Maximum 25 points \\
Ability in English and/or French & Maximum 24 points \\
Experience & Maximum 21 points \\
Age & Maximum 10 points \\
Arranged employment in Canada & Maximum 10 points \\
Adaptability & Maximum 10 points \\
\hline Total & Maximum 100 points \\
\hline Pass mark & 67 points \\
\hline
\end{tabular}

Source: Department of Immigration and Citizenship. Skilled workers and professionals: Who can applySix selection factors and pass mark, http://www.cic.gc.ca/english/immigrate/skilled/apply-factors.asp

In addition to questions about the methodology of calculating quotas and points, these two measures have been criticized based on their effectiveness, as well as their 
impact on people's lives. One of the major shortcomings of this method is that it unduly slows down the flow of immigrants. As a result, some very highly skilled immigrants who are not able to wait for a long processing period, migrate to other countries instead of Canada. It also slows down the unification of families and has some major negative effects on an individual's life arrangements.

Another problem associated with immigration policies based on the quota and point system is that it is strongly influenced by neo-liberal ideas and priorities of the workfare state. In a selection process based on the quota and point system, all political, social, cultural and humanitarian priorities of a liberal society come second to economic interests and gains. The main criterion to be assessed is what can be called individual self-reliance, where the applicant provides proof that he or she is not going to be a burden on the welfare programs. In fact, the quota and point system should be seen as a continuum of the workfare state approach, where everything is assessed based on economic productivity and everyone, including citizens and immigrants, are obliged to produce more and rely less on the state. This minimalist approach of the workfare state leaves most immigration related issues, especially those related to the immigrant's integration, on the shoulders of the immigrants themselves and to the mechanisms of the market. Even though the state plays a key role in the development and application of immigration policies, since the goal is to ensure minimal involvement of the state in future, all selection processes are designed around personal responsibilities and the mechanisms of the market and labour force.

Therefore it is safe to conclude that the problematic of immigrants' integration starts from the moment the individual immigrant applies for Canadian residency. If the 
individual applicant does not possess the needed human capital, then he or she is automatically excluded. This does not mean that those who passed the quota and point system are guaranteed integration into the new society. As a result of major shifts in the structure and functions of the state, the minimalist workfare state provides only a very limited service to new immigrants and leaves it to them, as well as to the market and the civil society, to work out the integration process. We will see in the next chapter that the civil society, as well, is abandoning its responsibility by allowing the market to play the decisive role in dealing with new comers. 


\section{Chapter V: Transformation of Civil Society}

The immigrant and the state interact in the public sphere, thus the roles and responsibilities of semiformal institutions, generally called civil society, are as important, if not more, as the first two. The discourse on the integration of visible minority immigrants is lacking if one ignores this third dimension. Similar to the two main players, the public sphere and the mediating institutions that lie between them have undergone profound changes over the past few decades, which resulted in a renewed interest in the idea of civil society and the role these mediating institutions play in social cohesion. Civil society institutions have had a long history of acting as a buffer zone, where concerns of the citizens and limitations of the state's policies are debated, articulated and comprehended. As the multiplicity, heterogeneity, and variety change the fabric of a society the need for the new institutions of civil society or the reorientation, fine tuning and flexibility of the older ones grows more acute. In this chapter I will address the question of whether such change and readjustment has occurred or not.

Civil society is understood in many different ways. The concept itself presents a collective entity existing independently from the state (Seligman 1992, 5). It is the space citizens occupy when they are engaged neither in government activities, such as voting or paying taxes, nor in commerce, like working, producing or consuming (Lehning 1998, 223). It is part of the public space, that unlike the state, makes no claims to exercise a monopoly on the legitimate use of power. Rather, it is formed by individual volunteers or groups who are devoted to public concerns. To conceive such a civic space, we have to move beyond the binary model of government versus private sector and focus on the intermediate institutions that are defined by activities like attending church, mosque, or 
synagogue, doing community service, contributing to a charity, or being a member of a sports club. It is in this public space that such traditional civic institutions as foundations, schools, churches, public-interest organizations and other voluntary associations properly belong.

With regard to the integration of visible minority immigrants in Western societies, it has been argued that civil society and mediating institutions not only perform as a medium for restoring trust between this new individual and the state, they also play a significant role in providing social networks and settlement support to new immigrants. Traditionally, civil society has been a major provider of basic supports to marginalized groups, such as individuals in poverty, seniors, persons with disabilities, single parent families, newly arrived immigrants, and other segments of society that are considered vulnerable or at risk of exclusion. At a time, when welfare programs are being cut by the workfare state, religious centers, charity organizations and other social networks play a significant role in helping individuals manage their day to day needs. With reference to immigrants, historically churches, ethnic organizations and other types of social networks played a key role in the overall integration of new comers by providing them with different types of services and supports, varying from language training and finding employment to marriage counselling and emotional support.

In addition to providing settlement assistance, civic organizations play a significant role in enabling immigrants, especially new comers, who had little experience in the practice of democracy and freedom to choose in their country of origin, to learn democratic principles and play an active role in the arena of democracy. Correspondingly, perhaps the main function of civil society for a given democracy is its 
value as a reliable source of socialization and enhancement of social cohesion among different social and cultural groups, including immigrants and the native-born population. One of the main characteristics of a civil society organization is its emphasis on the pluralism and acceptance of the diversity of interests pursued by individuals and/or member institutions. Since almost all modern democratic societies are made up of different ethnic and cultural groups, this pluralism also has to take into account the heterogeneous multiple identities of cultural and ethnic minorities who live together in one state. Therefore, civil society not only includes groups that are based on associational ties, such as sport clubs, but also includes groups that are based more on communal ties, such as religious groups.

The analysis of the links between civil society and the performance or sustainability of democratic institutions has a long tradition. Probably the most illustrative example of this tradition is the classic work of Alexis de Tocqueville, Democracy in America. In this work, he highlights the link between the vibrancy of associational life, good governance, and democracy. A vigorous civil society enhances not only the accountability, but also the representativeness and vitality, of democracy. Based on his work, a new wave of neoTocquevillian scholars is emphasizing the importance of a vibrant civil society for democracy. They argue that participants of mediating institutions learn cooperation and trust. The members acquire a sense of belonging and perhaps even meaning in their lives. They develop the virtues of civility and sacrifice and they rise above narrow self-interest and take on a sympathetic perspective of the general interest of the group and associations they have joined. Even an author like Nancy Rosenblum, who is sceptical about the positive effects of associational membership, notes the moral contribution of 
these associations, which is cultivating cooperation among individuals (Rosenblum 1998, 59). Examining the relationship between the participation of visible minorities in mediating institutions and their political participation, the Dutch political scientists Fennema and Tillie $(1999,2001)$ claim that differences in the political participation of ethnic minorities are linked to differences in their participation in the ethnic associational life of the relevant group. In their research on Amsterdam, they found that the denser the network of associations of a particular ethnic group, the more political trust they will have and the more they will be willing to participate in the political process (Finnema and Tillie 1999, 703).

Considering the above mentioned attributes, it is not unrealistic to assume that the decline of civil society is not only troublesome for social cohesion and the overall stability of democratic institutions in the Western societies, it has also major negative implications for the integration of new immigrants in these societies. For well over half a century, many observers have drawn the conclusion that social participation is in decline in the United States and other Western democracies. In the mid-twentieth century, the so called Mass Society theorists argued that industrialization and urbanization, as well as bureaucratic transformations, are destroying the strong group ties of churches, clans, and local neighbourhoods that had previously brought order to society and meaningful participation for individuals. These theorists asserted that as a result of these transformations, ties of individuals to secondary groups had weakened and this weakening caused social problems, such as alienation or decreased interpersonal trust (Thomson 2005, 422). Later in the 1990s, using a similar language to that of mass society theorists, Francis Fukuyama declared the decay of a wide range of intermediate 
institutions, as well as the decrease of trust and sociability in American society. Distrust and asocial individualism "tend to isolate and atomize" Americans, Fukuyama suggested (Fukuyama 1995, 51). Besides Fukuyama, the most prominent advocates of the decline of civil society at the end of the twentieth century are the civic reorganization theorists and social capital theorists. Civic reorganization theorists such as Benjamin Ginsberg, Mathew Crenson and Theda Skocpol, focus on the machinery of the organizations and the role of influential members in the rise and fall of these institutions. These theorists suggest that elite members led the way in making new choices by abandoning cross-class organizations in favour of more specific affiliations. According to these theorists, civil rights movements of the 1960s and 1970s, the war in Vietnam, as well as new federal welfare-state policies and practices played a critical role in spurring the abrupt reorganization of the civic group universe and the nature of civic affiliations (Skocpol, Cobb and Klofstad 2005, 137).

On the other hand, social capital theorists led by Robert Putnam emphasize the importance of social connections and they see citizen withdrawal from affiliations with voluntary associations, especially membership groups, as an integral part of the recent decline of civil society. According to Putnam, this decline has led to a corresponding decrease in social capital, which refers to connections among individuals, social networks and the norms of reciprocity and trustworthiness that arise from them (Putnam 2000, 19). In his highly influential work, Bowling Alone, Putnam offers both a conceptual and methodological framework for understanding and measuring the decline of civil society, which he considers crucial to the health of democracy and stability. Sorting out the multiple dimensions of changes in social relationships, he has documented a long- 
term decline of American civic involvement since the 1960s. Using General Social Survey (GSS) data, he systematically analyzes different trends in many forms of civic engagement, including membership in voluntary associations (Putnam 2000, 19-20). His findings revealed a consistent decrease in average association memberships in the United States between the mid-1970s and the mid-1990s. He also reported on the results from American time-use studies, which showed a reduction in the average hours per month that were devoted to organizational life (Putnam 2000, 59-63).

In Chapters 10-15 of the book, Putnam considers various explanations for the apparent trend toward civic disengagement in the United States, including increased female labour force participation, decreased household size, the growth of the welfare state, increases in commuting time, and other factors. He concludes, however, that there were really two principal causes: The first is development of television; and the second is generational difference. He argues that $\mathrm{TV}$, and more recently video games and home computers, have come to occupy much of Americans' leisure time, leading to significant reductions in social interaction. He estimates that this reason alone explains 25 percent of decline of Americans' civic disengagement. Still, he believes the most far-reaching and profound explanation for declining social capital is the disappearance of the highly mobilized and civic-minded World War II generation. According to him, more recent cohorts of Americans are less motivated or inspired to get involved in civic activities than were their previous generation, especially those who lived through World War II. In his opinion, this generational difference explains as much as 50 percent of the decline (Putnam 2000, 104-5, 275-77). 
A number of distinct modes of criticism have emerged to counter Putnam's arguments. Some of the authors have claimed that Putnam idolizes the vanished hierarchical world of the 1950s, in which most women were home-makers and therefore had more time on their hands to engage in various civic duties. Others depict the decline thesis as pure nostalgia, a manifestation of the longing for a civic and engaged era that has clearly ended. Another set of critiques accepts that traditional social and civic participation have declined, but accuses Putnam of ignoring the role of the state and other major players (e.g. Lowndes and Wilson 2001). At the same time, some authors have taken Putnam's argument a step further; while they accept the claim that traditional forms of cohesion and participation are losing ground, they dispute its normative consequences. They emphasize that newer forms of participation and interaction, all too easily dismissed in the work of Putnam and others, can replace traditional forms. They also maintain that these old forms of participation are vanishing because they have become irrelevant to the future of democracy (Inglehart and Baker 2000). From an empirical perspective, another group of authors reject Putnam's arguments due to weak or misinterpreted empirical data. Their claim is that Putnam did not get his numbers right and therefore he does not offer an adequate description of real trends in contemporary American society. Proposing a careful reconsideration of time-series data for the United States, these critics argue that there are no grounds for pessimistic concern about participation levels and social cohesion. For example, Paxton used a multiple-indicator approach to analyze the same GSS data, assessing general social involvement by combining the association membership items with additional indicators for time spent with others inside or outside 
the neighbourhood. After extensive statistical controls, Paxton found no downward trend in association membership or in general social involvement (Paxton 1999, 114-16).

From an empirical point of view, results of different studies and surveys carried out by Canadian researchers both contradict and support social capital theorists' arguments about the decline of social capital in Canada. In a comparative study of involvement of people in civic activities in Canada, Netherlands, the United Kingdom and the United States, Anderson et al did not find major signs of decline in these countries, except in the United States. Based on their analysis of data collected for the Multinational Time Use Study (MTUS), they concluded that the United States is the only nation of the four under study to experience a clear reduction in the time given to civic association activity between the mid 1960s and the late 1990s. Their analysis clearly demonstrated that during the same period, the time spent on civic association activity in the other three nations did not decline (Andersen et al 2006, 395). Similarly, the results of a survey of Social Participation and Inclusion carried out by Statistics Canada supports Andersen (et $a l$,)'s findings. Based on the findings of this survey, while social activities, like attending religious services, have declined considerably since the $1980 \mathrm{~s}$, the percentage of the population who volunteered for different social causes has increased in the same period of time (Statistics Canada 2000). A more recent study of charitable giving and volunteering by Statistics Canada shows this trend is still continuing and the number of volunteers has increased from 11.8 million in 2004 to 12.5 million in 2007 , a $5.7 \%$ increase. However, this increase has not been consistent in all provinces and territories and while Nova Scotia, Saskatchewan and P.E.I. have witnessed a sharp increase in the 
number of volunteers, Ontario, on the opposite, witnessed a $3 \%$ decrease in the rate of volunteering (Statistics Canada 2009, 35).

On the other hand, a considerable number of studies and surveys devoted to social issues in Canada support the social capital theorists' arguments. For example, a trend analysis of time spent by Canadian workers during a normal working day shows a major decline in the social engagement of 15-64 year old Canadians. Using the results of a series of General Social Surveys (GSS), Martin Turcotte revealed a substantial decrease in the average time Canadian workers allocated to social activities outside the home. Table 1 presents major findings of the Turcotte study.

Table 1: Change in time Canadian workers devoted to certain activities during a working day.

\begin{tabular}{||l|c|c|c|c||}
\hline \hline & \multicolumn{4}{|c||}{ Minutes } \\
\cline { 2 - 5 } & 1986 & 1992 & 1998 & 2005 \\
\hline Time spent on work and work related activities & 506 & 523 & 528 & 536 \\
Time spent on personal care including sleep & 491 & 484 & 488 & 500 \\
Time for meals at home, snacks, coffee & 60 & 52 & 44 & 45 \\
Trips by car or public transport & 66 & 68 & 72 & 73 \\
Trips by foot & 5 & 5 & 5 & 3 \\
Social activities outside the home & 23 & 16 & 14 & 11 \\
Read books, magazines, newspapers & 18 & 17 & 15 & 10 \\
Television, including watching videos and DVDs & 95 & 89 & 84 & 79 \\
\hline
\end{tabular}

Source: Statistics Canada, General Social Survey, 1986, 1992, 1998, 2005.

It shows that in 2005, Canadian workers on average spent half the time they spent in 1986 at social activities outside the home (11 minutes versus 23 minutes during a day). Similarly, they spent less time for meals and reading a book or, interestingly, watching television. On the other hand, they devoted more time to work (30 minutes), commuting to work and personal care, including sleep (Turcotte 2007). 
Another interesting finding of Turcotte's study is about the time Canadians spent alone. According to him, time spent alone has been continually increasing for the last 20 years. Based on GSS results on time use, in 1986, workers engaged in solitary activities on average 133 minutes, or 2.2 hours per day (excluding time spent alone during working hours). By 2005, this time had increased by just over 40 minutes to 174 minutes, or 2.9 hours. These trends are consistent with those observed in a previous study about the time Canadians spend alone in an average day (Clark 2002, 27).

Findings of other studies on Canadian social trends are in line with Turcotte's results. A similar, but more comprehensive, study of Canadians social behaviour by Roberts et, al. concluded that availability of free time has decreased since the $1980 \mathrm{~s}$, as time spent on both paid and unpaid work (including domestic work, child care and shopping) has increased (Roberts et al. 2005, 531). On the other hand, they argue that even though the amount of free time left to individuals has decreased, their individual autonomy and number of choices has increased during the period of their study. According to the authors, increasing the number and diversity of components in a social system expands the range of course of action available to actors and creates the role conflict and strain that encourages the expression of choice and individual autonomy (Roberts et, al. 2005, 15). In addition to having less time to engage in social activities outside the home, a higher level of individual autonomy and a larger pool of choices may explain lower levels of social engagement. While attending religious activities and participating in sporting events have decreased during the last 20 years, Canadians spent more time alone or on vacations and tended to travel more and spend more time and 
money in restaurants (Ibid, 535-540). In short, social activities are being replaced by more individual or family level recreations.

What is the impact of this mixed report on the relation between the liberal state and the new immigrant? The purpose here is to understand the social network's role in the formation of substantial citizenship among individual immigrants. As noted in the introductory chapter, by substantial citizenship I mean that individual immigrants have a sense of membership and feel that they are part of a larger society and can actively exercise their rights. Thus, the main question to be addressed here is how and to what extent do different social networks facilitate the creation of this feeling of substantial citizenship?

In order to answer this question, I will utilise the same interdisciplinary approach used by Putnam in his discourse around the social capital process of bonding individuals within groups and bridging them to the wider society. As a starting point, the general idea of social capital is illustrated and the role of bonding and bridging social capital in the development of trust relations and habits of reciprocity is analyzed. After reviewing the idea of social capital, I narrow my attention to the new citizens and their social networks. Here, I mainly concentrate on the ethnic organizations and their role in bonding and bridging new immigrants with the wider society. My main argument is that, as a result of various obstacles, namely socio-economic, cultural and language barriers, recent immigrants are only involved in cultural organizations that bond them to their ethnic counterparts and their cultural backgrounds, not with civic organizations that can play a bridging role in connecting them with the wider society. I will also argue that since these types of organizations are more homogeneous than heterogeneous, participation in them 
not only does not lead to stronger connections to the wider society, but, quite the opposite, turns immigrants away from playing an active role in the wider society.

\section{The Idea of Social Capital:}

Once in a while a new idea captures the attention of both academic and nonacademic circles and opens the door for a new wave of discourse among different disciplines. The notion of social capital is such an idea. Research on social capital is done in sociology, political science, economics, geography, history, demography, education, and psychology, to name a few.

Claims as to who started these discussions and who established the theory of social capital alternates between Bourdieu, Coleman and Putnam. According to Portes, the concept of social capital was introduced in the field of sociology by James Coleman and Pierre Bourdieu (Portez 1998, 6). In The Forms of Capital, Pierre Bourdieu distinguishes between three forms of capital: economic capital, cultural capital and social capital. He defines social capital as the actual or potential resources that are linked to possession of a durable network of more or less institutionalized relationships of mutual acquaintance and recognition, or in other words, to membership in a group, which provides each of its members with the backing of the collectivity (Bourdeau 1986, 249). His treatment of the concept is instrumental, focusing on the advantages to possessors of social capital and the deliberate construction of sociability for the purpose of creating this resource. Like Bourdieu, Coleman conceptualizes social capital as a collective resource that is produced through the relations between members of the group for mutual benefit (Coleman 1988, 100). According to Coleman, social capital is located in the structure of relations between these actors and not in the actors themselves. Like Bourdieu, Coleman is interested in the 
function of social capital. He argues that the main function of social capital is the value of the social structure for the actors as assets that they can use to achieve their interests (Coleman 1988, 101). In short, both these sociologists see social capital as the ability of individuals to gain benefits through their membership in social networks.

Although Putnam shares Coleman's and Bourdieu's approach on the sources of social capital, he views it more as a collective resource benefiting all. In addition to being a private good, for Putnam social capital is simultaneously a public good as well. According to Putnam, the notion of social capital is a reservoir of collective good that is secured by the value of trust and habits of reciprocity. He defines social capital as features of social life, such as networks, norms, and trust that enable participants to act together more effectively to pursue shared objectives. He argues that social capital has externalities that affect the wider community, so that not all the costs and benefits of social connections accrue to the person making the contact (Putnam 2000, 20). From this point of view, social capital produces positive outcomes in which costly investments in social connectivity by individuals in time and effort end up unintentionally benefiting the community at large and democracy in general. In this sense and as a collective resource, social capital has qualities of being inclusive and non-rival. It is inclusive because its benefits are enjoyed by all persons, regardless of whether or not they participate in its production. Moreover, as a collective resource social capital, is non-rival because benefits enjoyed by an individual do not prevent others from benefiting as well.

In general, a big portion of the early literature on social capital covered positive correlations between higher levels of social capital with various indicators of well-being, such as child welfare, educational performance, decrease of violent crime, better health, 
and higher levels of political participation. However, contrary to early conceptions that all social connections contribute to social capital, later studies showed differing outcomes and effects in relation to social participation and cohesion. A review of related research reveals that context matters when it comes to social capital outcomes. These critics argue that social capital networks are value-based and context specific. According to them, particular expressions of social capital may be useful in achieving certain outcomes, while of limited value or even counterproductive in achieving others or in different contexts. As an example and from another perspective, Rodney Hero argues that most analyses of social capital do not confront the conditions or contingencies associated with race and do not recognize that what might be positively related to social capital for whites may in fact be negatively related for blacks. He suggests that the extent to which social capital is associated with better, more-equal patterns of civic life, one must ask, "better for whom?" (Hero 2003, 115).

Reflecting on critics like this, in their more recent papers authors such as Portes (1998) and Putnam (2000) have considered both positive and negative forms of social capital; the latter being potentially harmful to society as a whole or to a particular group. In the introductory chapter of Bowling Alone, Putnam agrees that social capital can be directed toward malevolent, anti social purposes, just like any other form of capital. He concludes that it is important to ask how we can maximize the positive consequences of social capital, on the one hand, and minimize the negative outcomes, on the other.

Putnam then notes a number of distinctions that are helpful in maximizing positive consequences of social capital and controlling the negative effects. In his discussion about varying outcomes of social capital, Putnam makes the clear distinction between 
social capital bonding people within narrow groups, which can have a possible darker side, versus bridging social capital, which can produce broader societal connectedness, trust, and reciprocity. In simple terms, bonding social capital refers to exclusive social ties that people build around homogeneity (Putnam, 1993, 2003 and Leigh and Putnam, 2002). It generally involves the establishment of relations within relatively homogeneous social groups, such as ethnic organizations, an élite group, or an interest group. In contrast, bridging social capital concerns voluntary associations and horizontal ties based on common interests that transcend heterogeneous differences of ethnicity, religion and socio-economic status. In general, bridging social capital is considered more valuable for social cohesion, since there is a fear that specific interest or ethnic groups may bond too much within their communities at the expense of integration into wider society. Recently, as a refinement to Putnam's work, another type of social capital has also been proposed; linking social capital. It refers to a vertical relation that helps individuals gain access to resources from formal institutions for social and economic development (Woolcock and Narayan, 2000). With regard to integration of immigrants, and in contrast to the stress on voluntarism, this form of social capital emphasizes the role of government institutions and their intervention to implement policies and programs that enhance the new immigrants' citizenship and help them access formal resources (Woolcock, 2003).

In most studies of immigration and diversity related issues, social capital is seen as belonging exclusively to a certain immigrant group, which is mainly the bonding side of the social capital (e.g. Favell 2003). These studies usually look at the dynamics of the group and how new immigrants develop trust relationships with one another. They generally insist on the negative externalities of these groups and how too much bonding 
leads to marginalisation and group isolation. (e.g. Svendson and Svendson 2004). While I am aware of these arguments concerning the negative dimensions of bonding social capital, I do not see bonding social capital merely as unhelpful in the integration process of new immigrants. In contrast, I should admit that an underlying assumption of this work is that all types of social capital are necessary to the well-being of immigrants and their successful integration in wider society. If a particular group or community has difficulty providing its children and adults with a sense of self worth and identity, then society as a whole suffers. At the same time, however, social bonds and the existence of strong and vibrant social groups do not by themselves guarantee successful integration and only in certain circumstances will bonding social capital facilitate successful integration. A positive type of bonding social capital, as Putnam argues (1993) carries along into wider society and transforms to bridging social capital. One example could be an immigrant's social interaction in a community or sports club where friendship ties are formed. Besides getting access to networking and more resources and possible jobs and economic gains, such regular face to face interaction in a club arguably facilitates bonding social capital, which again is carried along into society and thereby transformed to bridging. In other words, an immigrant's positive experience with other people in a voluntary organisation spills over into overall society and eventually increases the chance of successful integration.

On the other hand, as Bloemraad (2005) noted, linking social capital is also important for the successful integration of new immigrants. He argues that state intervention can foster immigrants' ability to establish and sustain other types of social capital. As an example, he argues that by facilitating development of community 
organizations and community building, the state and host society encourage immigrants' participatory citizenship in their new home (Bloemraad 2005, 307).

Academic dialogue on the relationship between social capital and immigration is not limited to the question of immigrants' integration. In fact, most discussion around these two factors involves the effects of increasing waves of immigration and ethnic diversity in Western democracies on social capital and social cohesion. At the heart of these discussions is a recent article by Putnam, discussing the impact of greater religious, linguistic, national and ethnic diversity on social capital and social cohesion in America (Putnam, 2007). According to Putnam, in ethnically diverse neighbourhoods, residents of all races tend to, what he calls, 'hunker down.' In spite of his expectation that in the long run diversity would possibly lead to positive outcomes, Putnam finds, on the basis of his research on US communities, that at least in the short run diversity is likely to reduce social solidarity and social capital, to lower social trust between citizens, to make them less likely to participate in the community and its politics and to make society less cooperative. He also found that not only is inter group trust lower in ethnically diverse communities, but also that intra group trust is lower as well, which is common in both majority and visible minority communities (Putnam 2007, 148). The high proportion of rapidly growing literature on social capital in Western societies supports Putnam's argument. In these studies, the impact of increasing diversity is routinely treated as a crucial problem, since it can undermine the normative consensus that is supposed to underlie the maintenance of social cohesion. For example, according to Newton and Delhey, generalized trust is strongest where we have something in common with others, especially where we are from the same ethnic background (2005: 324). 
Putnam's argument has been challenged from two different angles. The first criticism concerns its empirical validity outside the United States. As an example of the validity of these arguments outside the United States, Johnston and Soroka, in a study of trust in the Canadian context, found no strong evidence for the argument that a more diverse place has a smaller stock of social capital. Indeed, they argued that in the case of Canada the reverse is more nearly true (Johnston and Soroka 1999, 13). In the case of new immigrants, their findings revealed that even though groups with the largest percentage of immigrant are the least involved and the least interpersonally trusting, a big fraction of the initial difference disappears with demographic controls. In a more recent and thorough study of the relationship between ethnic diversity and social capital, Aizelwood and Pendakur analyzed the data drawn from the 2000 Equality Security Community Survey to test the applicability of these findings in a larger context. Their findings suggest that individual ethnocultural diversity characteristics do not appreciably affect scores on standard social capital measures, but that broad designations of ethnicity, such as visible minority and immigrant status do, though weakly. According to them, larger community size is a consistent predictor of lower interpersonal trust, lower propensity to join organizations, and less time spent with friends. They concluded that in Canada, where community size, diversity, wealth, and education are so closely and positively correlated to an urban lifestyle, it is possibly more accurate to look at what they call city effect as the main predictor of civic attitudes and behaviours (Aizlewood and Pendalur 2005). From almost a similar perspective, Natalie Letki (2008) argues that to assess properly the effect of racial diversity on social capital, the strong correlation between diversity and socio-economic status needs to be taken into account. In her study, 
she found that when the effects of diversity and neighbourhood deprivation on social capital are modelled simultaneously, and the relationship between neighbourhood status and racial diversity is accounted for, diversity has a negative effect on only attitudinal dimensions of social capital. At the same time, the low socio-economic status of a neighbourhood is the main factor undermining all types of interactions and positive attitudes among neighbours (Letki 2008, 99).

The second criticism has to do with the difference between living in a diverse society and actively and regularly interacting with people outside one's ethnic group. This phenomenon is probably better known to psychologists, since it constitutes the core of the social psychological study of intergroup relations. A great deal of research in social psychology and sociology on racial attitudes and inter-group relations shows that direct contact with diverse others can be important for building a common identity and thus a sense of trust that transcends group boundaries. A recent study in California found that intergroup contact typically reduces intergroup prejudice. It reveals that intergroup contacts result in a better feeling toward out group. Similar patterns also emerge for samples with racial or ethnic targets and samples with other targets (Pettigrew and Tropp, 2000).

As we have seen in chapter 3 , as a result of the sharply increasing proportion of visible minority immigrants on the one hand and their preference to settle in larger metropolitan areas on the other, a new wave of rapidly expanding visible minority neighbourhoods is growing in Canadian metropolitan areas. Based on information provided by Statistics Canada, the number of such neighbourhoods increased dramatically from 6 in 1981, to 77 in 1991 and finally 254 in 2001 in Canada's three 
largest metropolitan areas (Toronto, Montreal and Vancouver). As noted previously, this concentration of ethnic communities means immigrants have less contact with the majority of the population, and are relatively isolated. The reduced exposure to an English or French environment means it takes longer period of time to learn the language, creates fewer employment opportunities, and contributes to a lower level of income. Even more important, however, fewer contacts between immigrants and the majority leads to a lower level of trust and sense of belonging. As Oliver and Wong (2007) noticed, stereotyping and disdain of neighbors from other communities is by no means rare inside these ethnic communities.

Furthermore, my study of immigrants' characteristics in chapter 3 has also shown that even though recent immigrants have higher levels of education, generally speaking a majority of them are lagging behind their native born counterparts in the socio-economic status. Therefore it is expected that visible minority immigrants will have a lower level of social capital than the general social average. In fact, in his analysis of ethnoracial differences in income attainment, Nakhaei (2007) shed some light on the relationship between ethnocultural background, immigration status and social capital. Using the findings of the Ethnic Diversity Survey (EDS) he revealed that ethnoracial minorities are disadvantaged when compared with the British or whites in development and maintenance of social capital. According to him, the brunt of this disadvantage is experienced mainly by male visible-minority immigrants (Nakhaie 2007, 307).

\section{Immigrant's Social Capital:}


The extent of immigrants' involvement in social networks and their informal social relationships points to their level of comfort with the rest of society and their likelihood of realizing substantial citizenship. However, empirical research on immigrants' involvement in informal social networks is relatively rare and among those who do study immigrants' social networks, little attention is paid to the role of social relationships, norms and trust (i.e., social capital) in successful integration of immigrants. As noted before, most immigration research conceptualizes integration in objective economic terms with a parallel preoccupation with immigrants' human capital resources and the omission of other domains. Only recently has the importance of a range of other resources, such as social, cultural and psychological variables, emerged in immigration studies, though it still remains understated. The central goal of this part is to examine these variables, particularly the role of social capital in immigrants' integration process.

A review of literature shows a notable confusion with regard to immigrants' involvement in social networks in their communities or in the wider society. While some authors looked at the links between duration of stay and expansion of social networks, others studied the relationship between human capital, such as the level of education, income and language abilities within the immensity of social capital. Some others also looked at the characteristics of different types of immigrants, including their ethnic origin, and the relationship between these characteristics and development of social networks.

Although existing discussion provides different opinions about the extent of relationships between these variables and social capital, almost all agree that immigrants in general do not have access to the same type or level of social capital when compared to 
the native-born. For example, in Canada, in addition to Nakhaie's findings noted above, Livianna Tossutti reported similar trends of lower social capital levels for immigrants. Using sample data from the 2000 National Survey of Giving, Volunteering \& Participating, she found that foreign-born youths, ages 15-34, were generally less involved in formal, informal and associational membership activities than their Canadianborn counterparts. (Tossutti 2003, 70). Findings of other studies by Gidengil et,al. (2004) and Soroka et,al. (2007) supported Tessoutti's findings and showed that, in general, first and second generation immigrants had a lower membership in voluntary groups. In addition to low level of social activities, as noted before in the introductory chapter, immigrants commonly possess a lower level of trust of their fellow citizens and government compared to their native born counterparts (see Reitz and Banerjee, 2007).

Several reasons have been given to explain the lower level of social capital among immigrants. The main reason noted by most authors is that in the process of immigration, new comers leave behind their social support and other social relations that might help them develop relationships and social networks, to find a job and to successfully integrate in the new society. As Putnam argues, mobility, like frequent repotting plants, tends to disrupt root systems, and it takes time for an uprooted individual to put down new roots (Putnam 1995, 30).

The other explanation might be referred to as "status factor". Since immigrants tend, on average, to have a lower social status, at least in terms of education, wealth and income, and since social status is clearly related to associational involvement (Moya $2005,553)$, it can be expected that many immigrants would display lower than average rates of social capital. However, this argument runs into some difficulty in the Canadian 
context with respect to education. As noted above many, if not most, immigrants, at least from more recent cohorts, are better educated than the native-born average, so this would lead to the prediction that immigrants' social capital would actually be higher in relation to those who are native-born. It is, however, also clear from the previous chapters that immigrants not only suffer from an occupational status and income disadvantage, but appear to suffer further from a decreased economic return on educational credentials.

Another explanation for differences in social capital levels between immigrants and the native-born relates to linguistic barriers to participation. Language is clearly an important element in civic participation and, as we noted in the previous chapter, a considerable proportion of new immigrants display a markedly low level of English or French language proficiency. Without detailing the contextual social factors leading to differences between different groups of immigrants, it can easily be argued that those immigrants with low levels of English or French use will be less engaged with individuals and organizations outside their ethnic group.

Human capital and language do not exhaust the range of forces constructing the social capital level of immigrants. Family composition and cultural preferences are other variables that one should not disregard. The human capital and socio-cultural preferences of family members, especially parents, have major implications for the development of social networks. Normally, families with a higher level of human capital provide more opportunities for each individual to develop higher levels of social capital. However, socio-cultural, especially religious, preferences, could expand or limit the possible contacts with members of other ethnic or religious communities or the wider society. Recent surveys and studies show that immigrants are generally more religious than 
native-born Canadians. For example, the 2003 General Social Survey on Social Engagement shows that while only $22 \%$ of Canadian-born persons reported attending religious services, the case was $39 \%$ of immigrants aged 25 to 54 years who arrived in Canada during the 1990s (Statistics Canada 2004, 14).

The question of the role of religion in the successful integration of immigrants is often approached as a psychological one. The main question addressed by previous studies is whether religion holds back immigrants by reinforcing attachment to their original culture and old country or does it help them get more involved in the larger society and develop social network? According to Foley and Hogue, local worship communities can furnish valuable opportunities for immigrants to broaden their circle of acquaintances, providing resources of support, mutual aid and access to jobs and other benefits (Folley and Hogue 2007, 30). In Sacred Assemblies and Civic Engagement, Fred Kniss and Paul Numrich take a further step and study the religious life of groups and how it affects the degree to which and the manner in which a group engages in the larger civic sphere. In their study of 16 different congregations, including three Roman Catholic, three Protestant, two Orthodox Christian, two Muslim, three Hindu, two Buddhist and one Jewish in the Chicago area, they found major dissimilarities between different religions and congregations. Based on their findings, those congregations that put moral authority in the individual are more likely to encourage such individual involvement in public life and to provide programs or aid for doing so than those that not (Kniss and Numrich 2007). A study of religious differences in Canada supports Kniss and Numrich's findings. According to Ruiter and de Graaf (2006) differences between various religious 
groups are quite strong. For example, their research shows that Protestants are much more engaged in the wider society than other religious groups.

On the other hand, as noted a few times in previous chapters, a large majority of new immigrants have a religious background different from Christianity, which is the dominant religion of the majority. Therefore, unlike previous waves of immigrants from Europe who worship mainly in Catholic or Protestant churches shared with the majority, they worship in mosques or temples mainly shared with other immigrants. As a result, new immigrants have limited opportunities to create a relationship or to enter into a social network shared with the majority, compared to immigrants arriving in Canada 30 years ago. Regrettably, the problematic of limited access to the social networks of the majority is not restricted to places of worship, but extends to other types of social participation and voluntary organizations as well.

In the last few years, migration scholars are increasingly realizing the importance of immigrant organizations, including above mentioned religious centers, in shaping immigrants' integration patterns into the host society. For example, a recent report in the United States concluded that these organizations are "important agents of integration" (Newland, Tanak and Barker, 2007). However, despite apparent consensus on the importance of ethnic organizations, no theory has satisfactorily explained the conditions that encourage their founding or the factors that support or inhibit their continued existence. Furthermore, different researchers provide different answers to questions like following: Is an immigrant organization defined by its purpose, e.g. to help immigrants, or by its membership and control, e.g. immigrant majority on board of directors or in 
larger membership? Or should a multi-purpose organization that devotes a significant share of its resources to immigrant service be classified as an immigrant organization?

Jose Moya (2005) deals with these questions extensively. In an in-depth review of the international literature on migration and immigrant associations, he examines the factors that shape different types of immigrant organizations and their effects on immigrants' sociability. In a comparative study of immigration trends before and after the 1960s and the development of immigrant organizations in these two periods, he concludes that expansion of welfare governments and business social security systems after the 1960s has clearly discouraged the formation of what used to be the most common and widespread form of immigrant organisation. He argues that mutual aid societies are almost non-existent in new immigrant communities. On the other hand, he reports that activism in immigrants' hometown associations and ethnic advocacy groups have increased considerably during the last 30 years (Moya 2005, 856). He considers the support of governments and businesses as the main reason for these developments.

From a different perspective, and more in line with Putnam's definition of social capital, Soroka, Johnston and Baning (2006) divide immigrant organizations into those that are more clearly binding and others that promote bridging into the mainstream. Based on their comparison, bonding organizations primarily bring together people of the same ethnicity, while bridging organizations span ethnic divides. Service clubs, recreational groups, sport clubs, youth oriented groups, and political associations are, according to them, bridging organizations that are more important in building interpersonal trust, and more likely to facilitate the incorporation of newcomers into a society (Soroka, Johnston and Banting 2007, 571). 
Findings of the Ethnic Diversity Survey (EDS) confirm that participation in bridging organizations increases with the time lived in Canada. Based on the findings of the survey, among those who reported participating in a group or organization, first generation immigrants reported less frequent participation than the second generation and third generation or more. For example, just over half $(51 \%)$ of the first generation reported taking part in the activities of a group or organization at least once a week in the year prior to the survey, compared with $64 \%$ of those who had lived in Canada for two or more generations (Statistics Canada 2003, 12).

In addition to the growing gaps between different generations of immigrants, the EDS survey also reveals large gaps between the social engagement levels of different ethnic groups. While immigrants from countries such as Portugal and Jamaica are reporting high level of social engagement, immigrants from China in general report a very low level of involvement in social activities (Fong and Ooka 2006). In my review of immigrant` characteristics, I mentioned that immigrants from East Asia, especially Chinese immigrants, have a lower level of English or French proficiency; however, one should not simply conclude that the language barrier is the only factor preventing immigrants' involvement in various social organizations. One should expect that ethnic background and civic behaviour in the country of origin could have some effects on the way in which new immigrants interact with their social surrounding. Unfortunately it is extremely difficult to measure and compare the levels of civic engagement of immigrants in their home country, but based on most conventional standards, it is expected that the levels of civic engagement, like political engagement, are fairly low in the birth countries of current visible minority immigrants. 
Considering these factors, it is not shocking that, in general, first generation visible minority immigrants not only have lower levels of social engagement, but, in the case of civic engagement, they rarely get involved in social networks and organizations outside their ethnic group. Based on the EDS survey results, first generation immigrants were $50 \%$ less likely to participate in bridging organizations compared to second or third generation immigrants (12\% versus $23 \%$ ). Based on the findings of the survey, sports clubs or teams were the most common type of bridging organization across all generational groups. Not surprisingly, the EDS survey showed that one area where the first generation tended to have a higher participation rate was in bonding ethnic or immigrant associations (Statistics Canada 2003, 14). These findings were in line with social psychology literature that, study after study, shows that individual immigrants, like all other people, are attracted to those who are similar to them (e.g., Berscheid and Reis 1998).

They are also consistent with those from the Longitudinal Survey of Immigrants to Canada and the 2007 survey of Giving, Volunteering and Participating (CSGVP). The findings of CSGVP showed that immigrants were slightly less likely to give to charities and nonprofits than those who were Canadian-born ( $82 \%$ vs. $85 \%)$, but that they gave noticeably larger amounts when they did contribute $(\$ 505$ vs. $\$ 423)$. As expected, the likelihood of giving increases with the length of time immigrants have resided in Canada. Based on the CSGVP findings, the likelihood of donating was lowest among those who came to Canada in 1999 or later (72\%) and highest among those who arrived before 1971 (89\%) (Statistics Canada 2009, 26). Similar to donating behaviours, immigrants were less likely than native-born Canadians to volunteer ( $40 \%$ vs. $49 \%$ ). However, those 
immigrants who did volunteer contributed slightly more hours (171 vs. 163). The likelihood of volunteering does not change greatly with the length of time immigrants have been in Canada, with the exception of those who have been in Canada the shortest amount of time (from 1999 to the present) who were least likely to volunteer. There is a difference in the type of organizations to which immigrants and native-born Canadians donate or with which they volunteer. In general, immigrants allocated a larger percentage of their donations or volunteer time to religious and ethnic organizations than did Canadian-born individuals. The latter covered a more diverse set of organizations and activities (Statistics Canada 2009, 26). I suppose this tendency of immigrants to specific types of organizations is an apparent sign of their social and cultural preferences.

There are opposing arguments about the role of bonding ethnic organizations in the successful integration of new immigrants. While some looked at the positive side of these organizations and praised their role in assisting the economic integration of new comers and their general well-being (e.g. Hung 2007, 707), a majority of the researchers focused on their negative impact at the overall integration of new comers. From a positive point of view, some argue that participating in these bonding organizations enables an immigrant individual or family to receive ongoing support and direction from other immigrants and from the religious and social associations of the ethnic group. Consequently, community standards are established and reinforced among group members who may otherwise assimilate into an underclass subculture (see e.g., Zhou and Bankston 1994, 842).

From an opposing point of view, authors like Uslaner and Conley argue that immigrant individuals who associate primarily with people of their own kind either will 
withdraw from civic participation or will belong only to organizations made up of their own cultural background. Based on their research of the Chinese community in Southern California, they concluded that people with looser ties to ethnic bonding organizations are more likely to take an active role in the larger society (Uslaner and Conley 2003, 331). Similarly, others infer that this kind of identity-based participation in ethnic organizations is an obstacle to establishing common social references that serve the interests of the wider society. They argue that putting the group's interests before those of the broader population purportedly detracts from the building of shared values and common goals. For example, when ethnocultural organizations take a political stand and actively promote it, they are said to be ethnicizing the political debate (see e.g., Labelle and Levy 1995).

A review of social engagement of native-born Canadians and immigrants revealed a troubling trend in development of trust networks among new comers and native-born Canadians: The formation of bridging networks and social relationships between new immigrants and the general public, which has always been a difficult task, is getting more complicated by time. On one end of the spectrum, the native-born Canadians are spending less time engaging in social activities than they used to 30 years ago. On the other end, the new visible minority immigrants are less involved in general social activities and, when they get involved, they mainly limit their contacts to those of their ethnic origin or other immigrants.

Key social centres like churches, sport clubs and neighbourhood associations that historically played a bridging role between native-born and immigrants are losing ground and do not play an influential role in the integration process of immigrants anymore. 
With respect to churches, unlike previous groups of immigrants, a large majority of new immigrants are not Christian. Furthermore, the proportion of native-born attending religious services has declined considerably over the past 20 years (Lindsay 2008, 1). General decline in participation in sport related activities and sport preference is another issue to note. While for native-born Canadians hockey and winter sports have remained the most popular, not just for recreation but also as socializing occasions (Roberts et al. $2005,540)$, the majority of immigrants tend to participate in other sport activities, like soccer. A large majority of immigrants live and work in major metropolitan areas in neighbourhoods increasingly populated by other immigrants, and as a result they have less contact with native-born Canadians. Certainly, the deepening social bridging gaps between immigrants and native-born is not limited to these cases and extends to more areas, but even those few examples provide good indicators of waning opportunities for social contact between immigrants and native-born Canadians.

In short, similar to the new immigrant and the liberal state, the public sphere and the mediating institutions that lie between them have undergone profound changes over the past few decades. Consequently, it is getting even harder to create the needed social setting for successful integration of new immigrants. 


\section{Conclusion}

One of the most compelling challenges facing liberal democracies today is how to integrate visible minority immigrants into their societies. I began with the following question. What factors have caused such a formidable challenge? In my research of the causes, the findings pointed to changes in the definition, features and objectives of the main players of the immigration process. This study documented those changes that complicated and worsened the problematic of integrating new citizens in to liberal democratic systems. As noted, changes in the characteristics and functions of main players have major consequences for the institution of citizenship in Canada. This dissertation viewed citizenship as a process of immigrants' self-making and being made in relation to state, civil society and other social players. In the first chapter, I showed how the granting of the formal legal status of citizenship is the necessary starting point of this process, but it does not automatically resolve the question of identity, belonging and tolerance. I also asserted that substantial citizenship can be achieved only by the active exercise of rights and participation of immigrants in different aspects of social life, including using their civil, social, and cultural rights to participate in building a lively and just society. I maintained that a successful immigrant integration process requires, on the part of new immigrants, three distinct views, or conceptions, which I referred to as conceptions of society, justice, and role.

A given citizen produces his or her own version of these conceptions through negotiating a sometimes ambivalent and contested relationship with the state, civil society and other social players. Realization of substantial citizenship often depends on how these conceptions are constituted within the webs of power relationships among new 
immigrants and other players, particularly the state. In other word, the pragmatic construction of substantial citizenship is not merely a byproduct of laws and state policies, but an outcome of everyday activities of inclusion and exclusion based on a conception of who is Canadian and who is not.

Although new immigrants to Canada come from a variety of national, cultural and religious backgrounds, there is a tendency in daily interactions toward an ideologically constructed ethnicized citizenship. For example, even the second and the third generation visible minority citizens are being approached as ethnics, not homogeneous citizens. As Yasmeen Abu Laban pointed out, while all Canadians may be said to belong to one or more ethnic groups, the label "ethnic" has tended to be used in relation to visible minority groups only (Abu Laban 1998, 190). In the same way, while all Canadians, except aboriginals, have immigrant roots, the label "immigrant" brings to mind only visible minority immigrants, someone who, in the majorities' view is not a true or full Canadian. Therefore, it is no surprise that visible minority immigrants increasingly occupy a liminal position on the margins of society, a position that reproduces unconstructive conceptions of society, justice, and role. This in turn negatively effects realization of substantial citizenship.

We must now ask why, despite ample policies and programs in the last 30 years, the issues related to the successful integration of visible minority immigrants are still standing. Moreover, while questions about whether and how to integrate visible minority newcomers into the Western liberal democratic systems have been debated for decades, these debates have increased significantly in volume and complexity during the last few years. Citing the growing number of liminal citizens, as well as some religious and ethnic 
anxieties, some critics argue that current approaches and policies formulated under multiculturalism not only failed to produce the intended outcome of strengthening liberal democracy, but, in fact have become a liability for Canadian democratic systems (see for example Orwin 2009). On the other hand, exuding a discourse of relatively peaceful coexistence of multiple ethnicities, religions, and cultures in Canada, defenders of Canadian multiculturalism still persist in lauding the success of multicultural policies in reaching their goals.

Though I partially agree with the critics of multiculturalism who claim it did not reach its perceived objectives, I have shown that, contrary to their arguments, the problem does not lie in multiculturalism itself, but on the changes in characteristics and behaviours of the main players. These transformations have had significant negative effects on both the approach and commitment of the main players, making their relationship more complicated than before and the success of multicultural policies and programs doubtful. Nowadays, one can argue that both the immigrant and the state are disregarding the comprehensive nature of their relationships and are mainly focused on gaining some victories on one or two small issues, even at the cost of sacrificing the realization of substantial citizenship. In fact, a comprehensive approach to multiculturalism is clearly lacking not only in the development and announcement of new policies and programs, but in almost all discussions around the integration of new immigrants in Canada. In the next few pages, after providing a summary of changes in characteristics and functions of the main players, I will explain how these changes have altered both the approach and commitment of these players to the success of multiculturalism. 
To begin with the immigrants, the advancement of communication technologies on the one hand and the globalization of economy, politics and human affairs on the other hand has made individual immigrants less committed to the success of the integration process. In comparison to their predecessors who generally lost their economic, social and cultural connections with their country of origin in a short period of time, new immigrants keep their links with the old society at least for a generation or more. Advancement in telecommunication technologies, as well as the lower costs of international connectedness and travel makes these linkages possible and more affordable than ever. Research shows that holding on to old connections and commitments has negative effects on the development of a new identity and commitment to multiculturalism. For example, Dick Field (2003) argues that some types of inter-group and intra-group conflicts in Canada are directly related to immigrants' transnationalist affiliations and legacies of conflict which they bring with them from their countries of origin.

With respect to globalization, as noted in chapter 3, a large majority of new immigrants have a higher level of skills and expertise than their earlier counterparts. In the global competition for the best and the brightest, this high level of skill easily opens the door to other nation states seeking highly skilled potential immigrants. Therefore, one should expect that some of these new immigrants will come across other available opportunities and take a risk of another migration, especially when they have a dull vision of their future in Canada. Indeed, considering the lower than expected levels of economic outcomes of immigrants during the last few years, particularly those with high 
levels of education and skills, it should not be a surprise that sometimes they commit less to the success of the integration process than their predecessors.

In addition to technological advancements and globalization, the individual characteristics of new immigrants have contributed to limiting the success of the integration process. As argued in chapters 3 and 5, a major shift in the origin of immigrants has been the most significant factor. To avoid repetition, suffice it to say that ethnic and religious differences of new immigrants made them more prone to isolation and marginalization from the larger society than earlier immigrants who came from Europe or the United States. As a result of divergence between the cultural values of new immigrants (which are mainly rooted in non-Christian religions and traditions) and those of larger society, we have been witness to an increasing number of disagreements and conflicts between these groups in the last few years. Hotly debated disagreements about "Sharia Law" in Ontario and the "Reasonable Accommodation" in Quebec are a couple of fresh examples of conflicts that originated from differences in religious and cultural backgrounds. In fact, the majority of scholars agree that religious diversity lies at the core of many of the current debates about multiculturalism.

The lack of language skills is another characteristic of some new immigrants that has been associated with a slower than expected integration process. Language skills have significant impacts on the lifestyle and relationships of immigrants with other members of society. In addition to lower levels of political integration, those with limited knowledge of English or French are more likely to be in low income brackets or even to be unemployed. 
Clear shifts in the destination of new immigrants and their increasing concentration in large metropolitan areas has been another issue highlighted in my review of new immigrants' characteristics. As noted in chapters 3 and 5, this concentration of immigrants in CMAs increases the possibility of segregation of ethnic communities and their relative isolation from the majority. Isolation of immigrants usually means being less exposed to an English or French environment, as well as fewer employment opportunities and lower levels of income. More importantly, it means a reduced level of a sense of belonging and less commitment to the integration process.

Changes in the demographic characteristics of immigrants have also had some negative impacts on the integration process of immigrants. As noted in chapter 3 , today the average age of immigrants arriving in Canada is at least 5 years older than that of immigrants arriving in the 1970 s (30 compared to 25 ). Research shows that, due to a higher possibility of success in the labour market, as well as a better ability to learn a new language and to get trained, younger immigrants integrate in a new society at a much quicker rate than older ones. Furthermore, younger people are more open to change and acceptance of other cultures. Therefore, they have fewer problems in developing relationships with others who belong to a different culture and have a different lifestyle. The increasing proportion of women immigrants has been also affecting the integration process of new immigrants. Research shows that in comparison to their male counterparts, female immigrants have lower levels of economic outcomes and poorer knowledge of English or French. In short, recent changes in the dynamics of immigration and the characteristics of immigrants have had significant impacts on their relationships with the rest of society and the state. As discussed throughout this thesis, these changes 
had negative effects on immigrants' sense of belonging and level of trust. One of the major outcomes of this situation has been immigrants' lower level of commitment to the success of integration policies and multiculturalism.

Not only do immigrants' demographic and gender status play an important role, but their perception of an ideal society does as well. For example, the immigrants' conception of justice was one of the main issues discussed in chapters 2 and 3. In my argument around this issue, I reviewed the links between economic outcomes of immigrants and their perception of justice. I argued that the deterioration of new immigrants' economic status during the last three decades not only affected their economic integration, but had significant impacts on their sense of identity, self-worth and emotional well being. Borrowing from Harrison Trice (1993), I argued that immigrants' economic integration not only provides them with financial support, but also insures their access to the resources of the new society and hence a sense of belonging and identity. I concluded that the failure of the economic integration process can result in a feeling of exclusion and disconnect from all other aspects of social life.

Chapter 4 revealed that the transformation of the liberal state in the last three decades has been one of the main reasons for this deterioration of immigrants' economic outcome. My conclusion was that the welfare state has been replaced with what is called a "workfare state." As noted, the re-alignment of social and cultural policies and significant cuts in social programs have had significant negative effects on the economic integration of middle and low income immigrants. The negative effect of the state transformation on the immigrant integration process is not merely limited to the economic success or failure of immigrants. It is also affected by their social and cultural 
integration. According to an article published in the Globe and Mail (Freeze, 2008), in the last 15 years, successive governments have cut funding for general multicultural programs to less than a dollar a year for each Canadian. This estimate is in line with numbers provided to the Parliamentary Standing Committee on Canadian Heritage in November 2004, by the then Minister of State on Multiculturalism, Raymond Chan (Standing Committee on Canadian Heritage meeting minutes 2004). According to him, funding for multiculturalism had been decreasing since the 1995 program review and had not returned to the pre-1995-96 norm since. At the same time, a growing population had been increasing the demand for multicultural programs.

Aside from major changes in social policies and programs, another key implication of the transformation of the welfare state to a workfare state has been the alteration of immigration policies. As explained in chapter 4 , as a result of the gradual dominance of economic priorities over social, demographic, and cultural considerations, the main goal of immigration has changed from nation building to securing a consistent flow of new immigrants into the labour force. These changes in approach not only significantly modified the rules governing the selection process of immigration, it also dramatically altered programs and policies aimed at the successful settlement and integration of immigrants. The signs are clear that during the last three decades, state agencies have been more concerned with efficiency and the "bottom line" rather than nation building and insuring the realization of substantial citizenship of new comers.

Therefore, although Canada can rightfully claim to have had a multicultural policy since 1971, confronted by issues of the day, this policy has changed in terms of focus, reference point, and mandate during the last three decades. As the priorities of the 
Canadian government have changed, so has the implementation of the multiculturalism principles. While the preamble of the Multiculturalism Act clearly insisted on both cultural rights and social and economic justice ${ }^{10}$, the focus of policy makers gradually shifted toward only cultural recognition and all other egalitarian aspects of the Act have been ignored. A review of speeches, discussions and programs shows a clear concentration on anti-racism or preservation of immigrants' cultural heritage, without any reference to other challenges immigrants are facing in their daily lives, particularly economic justice. In fact, the department responsible for implementation of the Multiculturalism Act (Canadian Heritage, until 2009) left the responsibility for economic and social integration of immigrants to other departments including Human Resources Development (HRDC) (Standing Committee on Canadian Heritage meeting minutes 2004). Not surprisingly, a current panel of immigration experts concluded that

\footnotetext{
${ }^{10}$ Passages from official Multiculturalism Policy of Canada (Noted directly in the Multiculturalism Act (Justice Canada, 1988: http://laws.justice.gc.ca/en/C-18.7/text.html):
}

\section{(1) It is hereby declared to be the policy of the Government of Canada to}

(a) recognize and promote the understanding that multiculturalism reflects the cultural and racial diversity of Canadian society and acknowledges the freedom of all members of Canadian society to preserve, enhance and share their cultural heritage;

(b) recognize and promote the understanding that multiculturalism is a fundamental characteristic of the Canadian heritage and identity and that it provides an invaluable resource in the shaping of Canada's future;

(c) promote the full and equitable participation of individuals and communities of all origins in the continuing evolution and shaping of all aspects of Canadian society and assist them in the elimination of any barrier to that participation;

(d) recognize the existence of communities whose members share a common origin and their historic contribution to Canadian society, and enhance their development;

(e) ensure that all individuals receive equal treatment and equal protection under the law, while respecting and valuing their diversity;

$(f)$ encourage and assist the social, cultural, economic and political institutions of Canada to be both respectful and inclusive of Canada's multicultural character;

(g) promote the understanding and creativity that arise from the interaction between individuals and communities of different origins;

(h) foster the recognition and appreciation of the diverse cultures of Canadian society and promote the reflection and the evolving expressions of those cultures;

(i) preserve and enhance the use of languages other than English and French, while strengthening the status and use of the official languages of Canada; and

(j) advance multiculturalism throughout Canada in harmony with the national commitment to the official languages of Canada. 
multiculturalism policies can work only if they are in sync with other domestic and foreign policies, such as those on employment, immigration, health, and international trade. The participants on the panel felt that government departments operated in isolation in their respective silos and there was little dialogue across different levels of government, different sectors and different organizations involved in immigrants' integration process (Kunz and Sykes 2007, 4).

In addition, panel participants expressed consternation about the disconnect between the policy of multiculturalism and the reality of multiculturalism on the ground. One of the main objectives of the Multiculturalism Act is to promote interaction between different groups and better understanding and recognition of other cultural and social views. However, it seems that overemphasizing the cultural differences have kept cultural communities from interacting with one another. While ethnic and cultural diversity has been the main focus of multicultural policies since the 1970 s, many agree that religious diversity lies at the core of most of the current debates about multiculturalism. Clearly, religious understanding, or lack of it, requires more attention. A review of reports on general reflections on the "Sharia Law" debate in Ontario and "Reasonable Accommodation" debate in Quebec shows how little the public knows or has been informed with regard to the religious principles of minority groups and the ways in which they might interact with public policy issues.

Furthermore, while much of the debate on integration of new comers centres on accommodating their religious principles, the general public and decision-makers are often not comfortable with tackling these challenges. Instead, much effort is devoted to particular concerns, such as religious radicalism and terrorism that might threaten 
security and order. Undoubtedly, the last decade has been characterized by considerable change in both public policies, and people's perception of terrorism and terrorists. There are plenty of cases, in the media or in public forums, where immigrants with specific religious backgrounds or regional roots have moved from being portrayed as potential Canadian citizens, voters and contributors to Canada to being portrayed as potential security threats to the Canadian political community. Therefore, it is no surprise that new discourses on the integration of immigrants in Canada and multiculturalism tend to be framed more in terms of security and tightened criteria for formal citizenship ${ }^{11}$, rather than assuring substantial citizenship and fostering inclusion, equality and justice, which cannot be ignored for the long term success of the immigrant integration process.

Even though Canadians have not been victims of any terrorist attacks, a poll conducted by the Strategic Council in 2006 (Strategic Council, 2006) found that more than 70 percent of Canadians believed that an act of terrorism would likely take place in Canada within the next few years. The same poll also showed that more than 40 percent of Canadians supported severely restricting the number of immigrants allowed into Canada from Muslim countries. Furthermore, a more recent poll by the same group found that close to half of Canadians (45\%) feel that new comers hold on to their customs and traditions for too long when they come to Canada (Strategic Council, 2008). A review of public opinion polls and media coverage of issues related to the integration of immigrants reveals no clear and consistent position, but rather portrays a puzzled view on this issue. No doubt, political events often influence public interpretations and attitudes and most of

\footnotetext{
11 - See for example the text of a speech by Jason Kenney, Minister of Citizenship, Immigration and Multiculturalism, at the Global Forum for Combating Anti-Semitism in Jerusalem on December 16, 2009. Toronto Star. Wednesday December 30, 2009. http://www.thestar.com/news/article/743930--text-of-jasonkenney-speech
} 
the time they fluctuate due to emphasis within the political spectrum. That is to say, this lack of consistent support for multicultural policies is not simply a by-product of a single factor. As discussed in chapter 5, in addition to immigrants themselves and a state that has been negligent in supporting a positive public attitude toward immigration and multiculturalism, the decline of civil society has also had a negative impact on this process. Similar to these two players, the public sphere and the mediating institutions that lie between them have undergone profound changes over the past few decades. Consequently, establishing the needed social settings for successful integration of new immigrants is getting harder than before.

In chapter 5, I insisted that civil society's distance from the dominant ideologies and its ability to foster a pluralistic atmosphere for overlapping identities has made it an important player in the integration process of immigrants. However, as we have seen, key social centres like churches, community clubs and neighbourhood associations that historically played a bridging role between the native-born and immigrants are losing their ground and no longer play the influential role they used to have in the integration process of immigrants. As noted, an increasing number of immigrants live and work in major metropolitan areas, in neighbourhoods populated by other immigrants, and as a result they have less contact with native-born Canadians. Regarding participation in social networks, new immigrants tend to engage mostly in networks and social settings surrounded by their ethnic or religious counterparts and detach themselves from larger social organizations. The lack of outreach programs and policies designed to increase immigrant participation exacerbates the problem and lowers the degree and extent of engagement. 
Based on the arguments presented above, it is safe to say that changes in the characteristics of immigrants, and the transformation of the state and civil society in the last 30 years are making the integration process of immigrants more complicated than before. These changes have made the main players more ontologically insecure and existentially uncertain. Each player doubts the commitment of the other player toward their mutual goals, as well as their fairness. This in turn has reshaped the dynamic of their interactions, making the integration process of new immigrants more complicated than before.

For some immigrants, the main response to such uncertainty has been to seek more self identification with the culture of the country of origin as a way to reduce existential anxiety. This, in turn, has extended their transitional trajectory period, widened their distance from the majority and amplified the liminal position of new immigrants in Canadian society.

On the other side of the spectrum, the state's main response to this uncertain situation has been the development of policies and guidelines that ask for more commitment from immigrants. By tightening access to formal citizenship, as well as focusing on the responsibilities of new immigrants, not just their rights, most Western states hope to solve the problematic of immigrants' integration. For example, in his speech during the unveiling ceremony of the new citizenship guide for all new immigrants who apply to become Canadian citizens, Jason Kenney, the Minister of Citizenship and Immigration, highlighted the language of the new document, which according to him centered on the responsibilities of citizenship. He said "When you become a citizen, you're not just getting a travel document into Hotel Canada. You are 
inheriting a set of responsibilities, of obligations as a citizen" (Stone 2009). Even though the new document covers some aspects of multiculturalism, the egalitarian facet of the Multiculturalism Act is generally ignored in both the document and the public announcements and discussions around introducing it.

In fact, the lack of a comprehensive approach to multiculturalism is not only limited to the development and announcement of this new policy, but is evident in the common actions of all major players. Often, immigrants or the state simply exploit multiculturalism to achieve some short term and limited results, with no attention to the long term consequences of their actions. For instance, some immigrants justify their self intended isolation from the rest of society with multiculturalism. In fact, they view multiculturalism as a means to defend their excessive relationship with their country of origin, as well as their restricted interaction with only those of the same ethnic or religious backgrounds and no one else. For this group of immigrants, multiculturalism is a type of right, which provides them the opportunity to recreate the social and cultural environment of their country of origin and resist conversion of their identity in the new society. As I have noted before, this kind of behavior negatively effects immigrants' participation in the social, cultural and political life of the new society and extends their process of integration. In short, for these immigrants, multiculturalism is reduced to a tool or a license for social and cultural isolation. No one can imagine that abusing multiculturalism to justify isolation was the intention of the architectures of the Multiculturalism Act.

Other players' approach to multiculturalism is equally limited. A review of policies, programs and discussions around multiculturalism in the last couple of decades shows 
that the state also has a clearly minimalist approach to multiculturalism. In public announcements, the federal government encourages new immigrants to participate fully in society by enhancing their level of economic, social, cultural and political participation. However, in practice and, as I noted before, during the last couple of decades the focus of government integration policies and programs has gradually concentrated on cultural recognition, and all other egalitarian aspects of the Multiculturalism Act have been shifted to the other federal departments, levels of government, or the market. Although the federal government still insists on its commitment to reach out to newcomers and develop a lasting relationship with them (Citizenship and Immigration Canada Multiculturalism Program), today multiculturalism is nothing more than a reason or a license to simply celebrate diversity and show that the government is active in the immigrant integration process.

The lack of a comprehensive approach to multiculturalism is not just limited to the players' action, but is also widespread in common discussions around issues related to the integration of new immigrants. In fact, a review of literature reveals a universal confusion in illustration and understanding of the term "multiculturalism." Recent studies on this subject show that while this term looks simple in its public appeal, it has a much more complex personal meaning for different people. For example, a review of literature in Canada confirms that the term "multiculturalism" has been used to refer to several different, but related phenomena. While a large majority simply interprets multiculturalism from a descriptive point of view and based on the demographic reality of cultural and ethnic diversity of Canadians, some others look at it as a social ideal or a value that accepts cultural pluralism as a positive and distinctive feature of Canadian 
society. From another point of view, the concept is seen as a policy initiative designed to recognize, support, and manage cultural and ethnic pluralism at federal, provincial, and municipal levels of government (Parliamentary Research Branch 2006, 7).

In this study, however, I look at multiculturalism from a different perspective. In contrast to the other debates about multiculturalism, which often have offered a simplistic and one dimensional approach to this complex phenomenon, I propose a process-based and multidimensional approach. I understand multiculturalism as a process where different players negotiate their positions and relationships to achieve particular goals and aspirations. In this process, the new immigrant competes to obtain support from the state and civil society for the achievement of specific goals related to recognition and justice. These goals may cover a wide range of issues, including recognition of cultural and religious differences, equal access to economic resources, and political representation. The state, on the other hand, considers multiculturalism as a means for assuming bigger roles and responsibilities and encourages citizens' participation in all areas of society. From this point of view, multiculturalism can no longer be seen as some end-point or an end result, but rather a dynamic process of interaction between the main players.

Alternatively, unlike other arguments that just focus on one side of this interaction and blame or praise the behaviour of that side as the main cause of failure or success of the multiculturalism, the process-based perspective is multidimensional and takes into account the characteristics and behaviour of all players. A review of multiculturalism literature shows that critics of multiculturalism build their arguments mainly on changes in the characteristics of immigrants and blame multicultural policies for a range of negative outcomes, varying from racial and ethnocultural segregation to hindering 
progressive policies in achieving the equitable distribution of economic and social benefits (Garcea 2008, 142). Conversely, defenders of multiculturalism report a success story based on the development of multicultural policies by the state. In a nutshell, most of these debates simply fail to recognize the multidimensional nature of multiculturalism.

Understanding multiculturalism as a multidimensional process has another advantage, which is closely in line with my analytical approach to the integration process of new immigrants in Canadian society. Here, the debate on multiculturalism and group rights does not primarily revolve around whether or not multiculturalism is, in itself, a good or a bad thing. Rather, it focuses mainly on the normative conditions of the process and invites the main players to commit to the success of the process and recognize the other side's rights and concerns.

I maintain that, in order to achieve substantial citizenship, we should redefine multiculturalism as a process map or a framework, where all players negotiate their positions and relationships. Based on three interconnected principles of commitment, recognition and inclusion, this process map will help the new immigrants and the state to reach out to the other side and develop a long lasting relationship, a relationship that enables both sides to achieve their long term objectives. Multiculturalism as a process demands that citizens define and understand their role in terms of commitment to the principles of a modern and plural state. It requires that state officials realize that the role and function of the state extends beyond providing official status. It is validation and acknowledgement of the specific distinctness of each citizen, thus the notion of recognition. Finally, there is both the thinking and practicing of inclusion. Multiculturalism requires both sides to exercise this by feeling and wanting inclusion of 
themselves in others and of others in themselves. Together these three principles, point to ways of thinking and ways of doing, not just official declaration.

The commitment of new immigrants to become responsible and active citizens in the new society is the first principle to be followed in this process. Here, multiculturalism should not be seen as a tool to justify the isolation and rigid continuation of an old way of life, but a framework or a process map to merge cultural values with a new way of life, which is based on active participation and interaction with the other members of the new society and the state.

Recognition is the second principle that should be followed and encouraged by the state. Here, multiculturalism ensures the recognition of new immigrants' fundamental social, cultural, economic and political rights. However, based on the experience of the last twenty years, one should insist that the state should not be satisfied with mere recognition of rights, but move a step further and become actively involved in the integration process. This could mean that state should support and encourage new immigrants to become active members of the society, on the one hand, and persuade the communities to open their doors to new immigrants, on the other.

This brings us to the third principle. Here, multiculturalism serves as a mode of inclusion, where it ensures the incorporation of new immigrants in different communities. As an inclusive vision, multiculturalism rejects the narrow approaches to Canadianism based on race, language and religion and opens the door to everyone who is a formal Canadian citizen. From this point of view, multiculturalism persuades both the native 
born and immigrants to recognize new comers as equal Canadians, regardless of their religion, language or ethnic background.

To construct these three interconnected pillars of commitment, recognition and inclusion, the question now is to answer is, "what policy solutions should be designed and implemented?" Based on the findings of this work, I would raise two separate but equally important points. The first point relates to the main purpose of policy making in issues related to new comers' integration in Canadian society. The second point deals with the approach and the methods used to design and implement these policies.

This study shows that as long as the process of immigrants' integration in Canadian society does not lead to the realization of substantial citizenship for the majority of immigrants, claims of wide-ranging accomplishment of multiculturalism will be erroneous. Therefore, policy in this area should be concentrated on the realization of substantial citizenship as the long term goal of the integration process. From this standpoint, all programs and activities of responsible governmental and nongovernmental organizations should be directed toward the achievement of this goal, and the state should make sure that short term priorities do not reroute these main strategies.

My second proposition is a reflection of my position on multiculturalism. As argued, to succeed in realizing substantial citizenship, the approach to multiculturalism should be multidimensional and process-based. The multidimensional approach will ensure that all angles of the integration process are covered by the government in a harmonized and efficient way. As discussed, in recent years there has been a confusion and misunderstanding of roles and responsibilities between different levels of 
government, as well as between different departments of the federal government. I suggest creating a board of cabinet ministers that lead organizations involved in the integration process (similar to Treasury Board) to coordinate immigration related issues, particularly immigrants' settlement and integration. This board can also play a central role in the harmonization of immigration related policies and programs between different levels of government. In the mean time, the Department of Citizenship and Immigration Canada (CIC) could play a more active role in coordination and management of these activities.

A process-based approach will make sure that government agencies are actively involved and supporting immigrants throughout the integration process. Government involvement in this process starts from the day the new immigrant starts considering options for emigrating from his/her home country and continues long after they are settled and active in Canada. Throughout this process, government support would not be limited to language training and economic integration, but would also include civic education and social integration. In addition, to ensure effectiveness and efficiency of government policies and programs, a performance measurement system should be developed that assures the progress in key integration areas. Based on the ongoing feedback of this system, integration strategies could be modified to ensure long term success.

The ultimate outcome of this approach would be the realization of substantial citizenship for new comers in Canada - a goal, that at the national level, ensures the 
continuation of Canada's tradition of successful immigrant integration and, at the global level, guarantees that the Canadian nation state stays powerful and competitive. 


\section{Bibliography:}

Abbott, Michael G. and Charles M. Beach. 1993. Immigrant earnings differentials and birthyear- effects for men in Canada: post-war-1972. Canadian Journal of Economics. 25: 505-524.

Abella, Irving and Troper, Harold. 2000. None Is Too Many: Canada and the Jews of Europe 1933-1948. Toronto; Key Porter Books.

Abu-Laban, Yasmeen. 1998. Welcome/stay out: the contradiction of Canadian integration and immigration policies at the millennium. Canadian Ethnic Studies. Vol. 30, Iss. 3; pg. 190

Ackerman, Bruce. 1980. Social justice in the liberal state. New Haven: Yale University Press.

Aizelwood Amanda and Ravi Pendakur. 2005. Ethnicity and Social Capital in Canada, Canadian Ethnic Studies, XXXVII, No. 2.

Albanesi, Cinzia, Elvira, Cicognani and Bruna, Zani. 2007. Sense of community, civic engagement and social well-being in Italian adolescents. Journal of community \& applied social psychology. Vol. 17, no 5, pp. 387-406.

Alesina, Alberto, Edward Glaeser and Bruce Sacerdote. 2001. Why doesn't the United States have a European-style Welfare State? Brookings Papers on Economic Activity, 2:2001.

Alesina, Alberto, Reza Baquir and William Easterly. 1997. Public goods and ethnic divisions, NBER Working Paper 6009. 
Andersen, Robert, James Curtis and Edward Grabb. 2006. Trends in Civic Association Activity in Four Democracies: The Special Case of Women in the United States. American Sociological Review, Vol. 71, No. 3, pp. 376-400

Anderson, Christopher and Jerome Black. 2008. The Political Integration of Newcomers, Minorities, and the Canadian-Born Perspectives on Naturalization, Participation, and Representation. In Immigration and Integration in Canada in the Twenty-first Century, ed. John Biles, Meyer Burstein and James Frideres, 45 - 76. Queen's Policy Studies Series.

Annamie Paul. 2005. Under-representation in Canadian Public Institutions: Canada's Challenge. Canadian Issues, Summer 2005, pp. 18-21.

Arendt, Hannah. 1951. The Origins of Totalitarianism. New York: Schocken Books, 2004.

Aydemir, Abdurrahman and Chris Robinson. 2006. Return and Onward Migration among Working Age. Ottawa: Statistics Canada, Family and Labour Studies Division. Catalogue no. 11F0019MIE - No. 273

Aydemir, Abdurrahman, Wen-Ho Chen and Miles Corak. 2005. Intergenerational Earnings Mobility Among the Children of Canadian Immigrants. Ottawa: Statistics Canada, Catalogue no. 11F0019MIE - No. 267. Ottawa. Analytical Studies Branch Research Paper Series, no. 267, 44 p.

Banting, K., Sharpe, A. and St-Hilaire, F. 2001. The longest decade: introduction and overview. In The Review of Economic Performance and Social Progress-The 
Longest Decade: Canada in the 1990s, editors. K. Banting, A. Sharpe and F. StHilaire, Montreal: Institute for Research on Public Policy, 1-20.

Banting, Keith, Thomas Courchene and F. Leslie Seidle. 2007. Diversity, Belonging and Shared Citizenship. In Belonging? Diversity, Recognition and Shared Citizenship in Canada. Eds Keith Banting, Thomas Courchene and F. Leslie Seidle. 646-687. Montreal: Institute for Research on Public Policy.

Banting, Keith. 2005. North American Narratives. Social policy; Vol . 39, No. 2, 98115.

Battle, Ken. 1998. Transformation: Canadian Social Policy Since 1985. Social Policy \& Administration. Vol. 32, No. 4, pp. 321-340

Baubock, Rainer. 2003. Towards a Political Theory of Migrant Transnationalism. International Migration Review. Volume 37 Number 3, 700-72.

Baudar, Harald, 2008. The Economic Case for Immigration: Neo-Liberal and Regulatory Paradigms in Canada's Press. Studies in Political Economy. Vol 82 Autumn issue.

Beaujot, Roderick. 2003. Effect of Immigration on the Canadian Population: Replacement Migration. Paper presented at the meeting of the Canadian Population Society. Halifax. June 2003. http://www.ssc.uwo.ca/sociology/popstudies/dp/dp0303.pdf

Bellamy, Castiglione \& Santoro. 2004. Lineages of European Citizenship Basingstoke: Palgrave Macmillan.

Bernard, André. 2008. Immigrants in the hinterlands. Perspectives. January 2008. Statistics Canada. Catalogue no. 75-001-X. 
Berry, John. 2001. A Psychology of Immigration. Journal of Social Issues, Vol. 57, No. 3, 2001, pp. 615-631.

Berry, John, Rudy Kalin, \& D. Taylor. 1977. Attitudes à l'égard du multiculturalisme et des groupes ethniques au Canada. Ottawa: Approvisionnements et Services Canada.

Berscheid E, Reis HT. 1998. Attraction and Close Relationships. In The Handbook of Social Psychology, ed. DT Gilbert, ST Fiske, G Lindzey, pp. 193-281. New York: McGraw-Hill. 4th ed.

Bilodeau, Antoine and Kanji Mebs. 2006. Political Engagement Among Immigrants in Four Anglo-Democracies. Electoral Insight. December 2006. 43-49.

Bilodeau, Anyoine. 2004. Learning Democracy: the political socialization of immigrants from authoritarian regimes in Canada. Ph.D Diss., University of Toronto.

Birch, Anthony 1964. Representative and responsible Government. Toronto: University of Toronto Press..

Bird, Karen. 2005. Guess Who's Running for Office? Visible Minority Representation in the 2004 Canadian Election. Canadian Issues / Thèmes Canadien. Summer 2005. $80-83$.

Blais, André. 2005. Accounting for the Electoral Success of the Liberal Party in Canada. Canadian Journal of Political Science. 38, no. 4: 821-840.

Bloemraad, Irene. 2005. The Limits of de Tocqueville: How Government Facilitates Organisational Capacity in Newcomer Communities. Journal of Ethnic and Migration Studies, vol. 31, no. 5, 865-887. 
Bloom, David, G. Grenier and M. Guderson 1995. The Changing Labour Market Position of Immigrants. Canadian Journal of Economics 28 (4b): 987-1005.

Bloom, David E. and Morley Gunderson. 1991. An analysis of the earnings of Canadian immigrants. In John M. Abowd and Richard B. Freeman (eds.), Immigration, Trade and the Labour Market. Chicago: The University of Chicago Press.

Bosniak, Lynda. 2000. Citizenship denationalized. Indiana Journal of Global Legal Studies, 447, pp. 1-67, http://ijgls.indiana.edu/archive/07/02/bosniak.shtml.

Bourdieu, P. 1986. The Forms of Capital. In Handbook of Theory and Research for the Sociology of Education. Edited by Richardson, J.G. New York: Greenwood Press, 241-258.

Bourne, Larry. 2000. "Convergence or divergence? Migration and immigration in the Canadian urban system." In Ioan Ianos, Denise Pumain and Jean Bernard Racine (eds.), Integrated Urban Systems and Sustainability of Urban Life. Bucuresti: Editura Technica.

Boyd, Monica and Vickers, Michael. 2000. 100 Years of Immigration. Canadian Social Trends. Autumn 2000, No 58.

British Columbia Stats. 2004. Special Feature: Welfare Benefits and Recent B.C. Immigrants. IMDB Series: Immigration Highlights, issue 00-4. http://www.bcstats.gov.bc.ca/pubs/immig/imm004sf.pdf

Bumsted, J.M. 2003. Canada's Diverse Peoples: a reference sourcebook. Oxford: ABCCLIO. 
Caldiera and Holston. 1999. Democracy, Law, and Violence: Disjunctions of Brazilian Citizenship. Comparative Studies in Society and History, Vol. 41, Issue 4, p. 717.

Calgary Herald. 2007. Poll shows different attitudes toward immigrants in Canada. Calgary Herald, October 20, News Section.

Calhoun, Craig.2003. Belonging in the Cosmopolitan Imaginary. Ethnicities, 3; 531

Canadian Race Relations Foundation. 2000. Unequal Access: A Canadian profile of Racial Differences in Education, Employment and Income. $\underline{\text { http://atwork.settlement.org/downloads/Unequal_Access.pdf }}$

Carens, Joseph. 2000. Culture, Citizenship and Community. Oxford: Oxford University Press.

Castles, Stephen and Alastair, Davidson. 2000. Citizenship and migration: globalization and the politics of belonging. London: Macmillan Press Ltd.

Castles, Stephen and Mark Miller. 2003. The Age of Migration. $3^{\text {rd }}$ Edition, Basingstoke and New York: Palgrave Macmillan.

Cerny, Philip. 1997. Paradoxes of the Competition State: The Dynamics of Political Globalisation. Government and Opposition, Volume 32, Issue 2, Pages251 - 274.

Chiswick, Barry R. 1978. The effect of Americanization on the earnings of foreign-born men. Journal of Political Economy. 86: 897-921.

Chiswick, Barry R. and Paul. Miller. 1995. The Endogeneity Between Language and Earnings: International Analyses. Journal of Labor Economics. 13, 2: 246-288. 
Chiswick, Barry R. and Paul. Miller. 2000. Do Enclaves Matter in Immigrant Adjustment?. Paper presented at the conference on the magnet societies. Loccum, Germany, June 2000.

Chui, Tina W.L., James Curtis and Ronald D. Lambert. 1991. Immigrant background and political participation: examining generational patterns," Canadian Journal of Sociology 16(4): 375-397.

Clark, Warren. 2002. Time alone. Canadian Social Trends. No. 66. Statistics Catalogue no. 11-008 XIE.

Clark, Warren and Grant Schellenberg. 2006. Who's Religious? Canadian Social Trends. Statistics Canada. Catalogue No. 11-008.

Clark, Warren. 2006. Interreligious unions in Canada. Canadian Social Trends. October. 2006 Statistics Canada. Catalogue No. 11-008.

Coleman, J.S., 1988. Social capital in the creation of human capital. American Journal of Sociology, 94, 95-121.

Cowan, James. 2006. Why Toronto is Liberal Bedrock. National Post, January 18, News Section.

Curley, Jami, Fred M. Sewamala, Micheal Sherraden. 2005. Institutions and Savings in Low-Income Households. Washington University: Centre for Social Development, Working Paper No. 05-13.

De Jong, Gordon F. and Anna B. Madamba. 2001. A double disadvantage? Minority group, immigrant status, and underemployment in the United States. Social Science Quarterly 82, no. 1 (March): 117-130. 
Delanty, Gerard. 2000. Citizenship in a Global Age. Buckingham: Open University Press.

Delhey, Jan and Kenneth Newton. 2005. Predicting Cross-National Levels of Social Trust: Global Pattern or Nordic Exceptionalism? European Sociological Review 21(4): $311-27$.

Denton, Frank, Christine Feaver \& Byron Spencer. 1997. Immigration, Labour Force, and the Age Structure of the Population. Independence and Economic Security of the Older Population Research Papers 24, McMaster University. http://ideas.repec.org/p/mcm/iesopp/24.html

Department of Citizenship \& Immigration. 2003. News release: Census release confirms immigration's important role in Canada's future. http://cicnet.ci.gc.ca/english/press/03/0301-pre.htm

Department of Citizenship \& Immigration. 2006. Annual Report to Parliament on Immigration. Ottawa: Government of Canada.

Department of Citizenship and Immigration Canada. 2006. Facts and Figures, 2006. Ottawa: CIC, 2006.

Department of Citizenship and Immigration Canada. 2007. Facts and Figures, 2007. Ottawa: CIC, 2007. P27.

Department of Citizenship and Immigration Canada. Multiculturalism Program. http://www.cic.gc.ca/ENGLISH/multiculturalism/index.asp.

Department of Employment \& Immigration.1985. Report to Parliament on the Review of Future Directions for Immigration Levels. Ottawa: Government of Canada. 
Department of Immigration and Citizenship. 2008. Annual Report to Parliament on Immigration, 2008. www.cic.gc.ca.

Department of Justice. Immigration and Refugee Protection Act ( 2001, c. 27). Objectives and Applications. http://laws.justice.gc.ca/en/I-2.5

Department of Manpower and Immigration, 1972. Immigration Statistics, 1972. http://epe.lac-bac.gc.ca/100/202/301/immigration_statistics-ef/mp22-1 1972.pdf

Dustman, C and A. Glitz. 2006. Immigration, Jobs and Wages: Theory, Evidence And Opinion. London: Center for Economic Policy Research.

Dustmann, Christian and Francesca Fabri. 2003. Language Proficiency and Labour Market Performance of Immigrants in the UK. Economic Journal. 113, July 2003: $695-717$.

Favell, A., 2003. Games Without Frontiers? Questioning the National Social Power of Migrants in Europe. Archives Europe Ennes de Sociologie, 44(3), 106-136.

Fennema, M. and Tillie, J. 1999. Political Participation and Political Trust in Amsterdam: civic communities and ethnic networks, Journal of Ethnic and Migration Studies, 25(4): 703-26.

Fennema, M. and Tillie, J. 2001. Civic Community, Political Participation and Political Trust of Ethnic Groups. Connections, 24(1): 26-41.

Ferrer, Ana and Craig Riddell. 2004. Education, Credentials and Immigrant Earnings. Department of Economics, University of British Columbia. 35 p. http://www.econ.ubc.ca/ine/papers/wp020.pdf 
Foley, Michael and Dean Hoge, 2007. Religion and the New Immigrants: How Faith Communities Form our Newest Citizens. New York: Oxford University Press, 288 pp

Foner, Nancy and Richard Alba. 2008. Immigrant Religion in the U.S. and Western Europe: Bridge or Barrier to Inclusion? International Migration Review, Vol. 42 No $2,360-392$

Fong Eric and Emi Ooka. 2006. Patterns of Participation in Informal Social Activities among Chinese Immigrants in Toronto. International Migration Review. 40:2, 348372.

Fortin, Jessica and Peter Loeven. 2004. Prejudice and Asymmetrical Opinion Structures: Public opinion toward immigration in Canada. Paper presented at the Annual Meeting of the Canadian Political Science Association, June 3-5 2004, University of Winnipeg, Winnipeg, Manitoba

Foster, Lorne. 2008. Foreign credentials in Canada's multicultural society. In. Daily Struggles: The deepening racialization and feminization of poverty in Canada, ed. Maria A Wallice and Siu-ming Kwok. 129-142. Toronto: Canadian Scholar's Press. 2008.

Fraser, Nancy and Axel, Honneth. 2003. Redistribution or Recognition? A PoliticalPhilosophical Exchange. London: Verso.

Fraser, Nancy and Linda Gordon. 1994. Dependency Demystified: inscription of power in a keyword of the welfare state. Social Politics: International Studies in Gender, State and Society, 1 (1), 4-32. 
Fraser, Nancy. 1997. Justice Interruptus: critical reflections on "postsocialist". London: Routledge.

Fraser, Nancy. 2000. Recognition without Ethics? In The Turn to Ethics. Marjorie Garber, Beatrice Hanssen and Rebecca L. Walkowitz (eds) New York: Routledge. pp. 95-126.

Freeman, Gary and D. Hill. 2006. Dis-Aggregating Immigration Policy: The Politics of Skilled Labor Recruitment in the USA. In The Human Face of Global Mobility. Ed. P. M. Smith and A. Favell. Transaction Publishers.

Freeman, Gary. 1995. Modes of Immigration Politics in Liberal Democratic States. International Migration Review 24(4):881-902.

Freeze, Colin. 2008. Heritage department takes aim at religious radicals, Multiculturalism plan under scrutiny. The Globe and Mail, Monday, September 01. Articles.

Frenette, Marc and René Morissette. 2003. Will they ever converge? Earnings of immigrant and Canadian-born workers over the last two decades. Ottawa: Statistics Canada. Catalogue No. 11F0019MIE2003215.

Frey, William. 2002. "A history of recent urban development in the United States." In H. S. Geyer (ed.) International Handbook of Urban Systems, Pp. 365-390. London: Edward Elgar Publisher.

Galabuzi, Grace Edward. 2008. Social exclusion: socio-economic and political implications of the racialized gap. In. Daily Struggles: The deepening racialization and feminization of poverty in Canada, ed. Maria A Wallice and Siu-ming Kwok. 81-93. Toronto: Canadian Scholar's Press. 2008. 
Galarneau, Diane and René Morissette. 2004. Immigrants: Settling for less? Perspectives. Ottawa: Statistics Canada. Catalogue no. 75-001-XIE

Galarneau, Diane and René Morissette. 2008. Immigrants' education and required job skills. Perspectives on Labour and Income. Ottawa: Statistics Canada, Catalogue no. 75-001-X.

Garcea, Joseph. 2008. Postulations on the Fragmentary Effects of Multiculturalism in Canada. Canadian Ethnic Studies. 40. 1. 141-160.

Gayer, Laurent. 2007. The Volatility of the 'Other': Identity Formation and Social Interaction in Diasporic Environments. South Asian Multidisciplinary Academic Journal (Online), Fall 2007, Migration and Constructions of the Other, URL : http://samaj.revues.org/document36.html.

Gerber, Linda. 2006. The Visible Minority, Immigrant, and Bilingual Composition of Ridings and Party Support in the Canadian Federal Election of 2004. Canadian Ethnic Studies. 38, 1. 65-83.

Giddens, A. 1994. Beyond Left and Right. Cambridge: Polity Press.

Giddens, A. 1998. The Third Way. Cambridge: Polity Press.

Gidengil, E., A. Blais, N. Nevitte, and R. Nadeau, 2004. Citizens. Vancouver: UBC Press.

Gilbert, N. 2002. Transformation of the Welfare State: The silent surrender of public responsibility. Oxford: Oxford University Press.

Ginieniewicz, Jorge. 2007. The Scope of Political Participation. International Migration \& Integration. 8:327-345. 
Gould, S. and John Palmer. 1988. Outcomes, Interpretations and Policy. In The Vulnerable. Editors John Palmer, Tim Smeeding and B. Torrey. Washington: The Urban Institute Press.

Green, David A. and Christopher Worswick. 2004. Immigrant Earnings Profiles in the Presence of Human Capital Investment; Measuring Cohort and Macro Effects. University of British Columbia and Carleton University. http://www.econ.ubc.ca/green/chrcoh9.pdf

Griego, Manuel Garcia. 1994. Canada: Flexibility and Control in Immigration and Refugee Policy, in Controlling Immigration: A Global Perspective, ed Wayne Al. Cornelius, et al. Stanford CA: Stanford University Press.

Grubel, Herbert. 2005. Immigration and the Welfare State in Canada: Growing Conflicts, Constructive Solutions. The Fraser Institute: Public Policy sources, No 84.

Guest, D. 1997. The Emergence of Social Security in Canada ( $3^{\text {rd }}$ edition), Vancouver: University of British Columbia Press.

Guillemette, Yvan and William Robson. 2006. No Elixir of Youth: Immigration Cannot Keep Canada Young. C.D. Howe Institute Backgrounder. No. 96, September 2006

Haan, Michael. 2005. The Decline of the Immigrant Home-ownership Advantage: Lifecycle, Declining Fortunes and Changing Housing Careers in Montreal, Toronto and Vancouver, 1981-2001. Urban Studies, Vol. 42, No. 12, 2191-2212, November 2005. 
Haan, Michael. 2007. The Homeownership Hierarchies of Canada and the United States: The Housing Patterns of White and Non-White Immigrants of the Past Thirty Years. International Migration Review, Vol. 41, No. 2, pp. 433-465.

Harvey, Jane. 2001. Access for Foreign-Trained IT Professionals: An Exploration of Systemic Barriers to Employment. March, pp. 1-40. http://www.ftpd.maytree.com/cats_re s.phtml

Held, David. 1995. Democracy and the Global Order-From the Modern State to Cosmopolitan Governance. London: Polity Press.

Held, David. 1999. The Transformation of Political Community: Rethinking Democracy in the Context of Gloabalization. In Democracy's Edges. eds Ian Shapiro and Casiano Hacker-Cordon (eds.), Cambridge University Press, Cambridge. 84 -111.

Held, David. 2006. Reframing Global Governance: Apocalypse Soon or Reform!. New Political Economy, Vol. 11, No. 2.

Held, David and Anthony McGrew. 2007. Globalization Theory, Approaches and Controversies. Cambridge: Polity Press.

Hero, Rodney. 2003. Social Capital and Racial Inequality in America. Perspectives on Politics, 1: 113-22.

Herrick, John and Stuart, Paul, 2005. Encyclopaedia of social welfare history in North America. SAGE Publications.

Hollifield, James. 2000. The Politics of International Migration: How Can We 'Bring the State Back In'?. In Migration Theory: Talking Across Disciplines. Ed. C. B. Brettel and J. F. Hollifield. New York and London: Routledge. Pp. 137-85. 
Hou, Feng and Garnett Picot, 2004. Visible minority neighbourhoods in Toronto, Montréal, and Vancouver. Canadian Social Trends. Spring 2004. Statistics Canada. Catalogue No. 11-008. 8-13.

Houston, Christopher. 1998. Alternative Modernities, Islamism, and Secularism on Charles Taylor. Critique of Anthropology 18(2): 234-240.

Hum, Derek and Wayne Simpson. 1999. Wage Opportunities for Visible Minorities in Canada. Canadian Public Policy / Analyse de Politiques, Vol. 25, No. 3. (Sep., 1999), pp. 379-394.

Hum, Derek and Wayne Simpson. 2004. Economic Integration of Immigrants to Canada: A Short Survey. Canadian Journal of Urban Research. June. Vol. 13. Institute of Urban Studies, University of Winnipeg.

Hung Richard Chi-Kan, 2007. Immigrant Nonprofit Organizations in U.S. Metropolitan Areas. Nonprofit and Voluntary Sector Quarterly. No. 36.

Ignatieff, Michael. 2001. Human Rights as Politics and Idolatry. Princeton, NJ: Princeton University Press.

Inglehart, Ronald and Wayne Baker, 2000. Modernization, Cultural Change, and the Persistence of Traditional Values. American Sociological Review, 65, 19-51.

Iris Marion Young. 1990. Justice and the Politics of Difference. Princeton, NJ: Princeton University Press.

Iris Marion Young. 2000. Inclusion and Democracy. Oxford: Oxford University Press.

Isin, Engin and Bryan, Turner. 2007. Investigating Citizenship: An Agenda for Citizenship Studies. Citizenship Studies, Vol. 11, No. 1, 5-17. 
Jackson, A. and Robinson, D. 2000. Falling Behind: The State of Working Canada, 2000. Ottawa: Canadian Centre for Policy Alternatives.

Jedwab, Jack. 2006. The "Roots" of Immigrant and Ethnic Voter Participation in Canada. Electoral Insight. December 2006. 3-9.

Jessop, Bob. 1993. Towards a Schumeterian Workfare State? Preliminary Remarks on Post-Fordist Political Economy. Studies in Political Economy, pp. 7-39.

Jessop, Bob. 1999. Narrating the future of the national economy and the national state? Remarks on remapping regulation and reinventing governance. Available online at: http:// www.comp.lancs.ac.uk/sociology/soc014rj.html.

Jessop, Bob. 2003. The Future of the State in an Era of Globalization. Internationale Politik und Gesellschaft, no. 3, pp. 30-46.

Jiménez, Marina. 2008. Marina Jiménez on the Shift in the Immigrant Vote. The Globe and Mail. September 18. Politics Section.

Jimenez, Marina. 2007. Do Ethnic Enclaves Impede Integration? The Globe \& Mail. February 8. News Section.

Johnston, R., \& Soroka, S. 1999. Social Capital in a Multicultural Society: The Case of Canada. Paper prepared for delivery at the annual meeting of the Canadian Political Science Association, Sherbrooke, Quebec, June 1999. http://www2.arts.ubc.ca/cresp/papers.htm.

Joppke, Christian. 1999. Immigration Challenges the Nation-State. In Challenge to the Nation-State: Immigration in Western Europe and the United States. Ed. C. Joppke. Oxford and New York: Oxford University Press. Pp. 5-46. 
Joppke, Christian. 2005. Exclusion in the Liberal State: The Case of Immigration and Citizenship Policy. European Journal of Social Theory. 8(1): 43-61.

Joppke, Christian. 2007. Transformation of Citizenship: Status, Rights, Identity. Citizenship Studies, Vol. 11, No. 1, 37-48.

Junankar, Raja, David Pope and Glenn Withers 1998. Immigration and the Australian Macroeconomy: Perspective and Prospective. The Australian Economic Review, vol. 31 , no. 4 , pp. $435-44$.

Kalin, Rudy, and J. W. Berry. 1994. Ethnic and multicultural attitudes. In Ethnicity and culture in Canada: The research landscape. Eds. J.W. Berry \& J. Laponce (Eds.), 293-321. Toronto: University of Toronto Press.

Kelley, Ninette and Trebilcock, Michael. 1998. The Making of the Mosaic: A History of Canadian Immigration Policy. Toronto: University of Toronto Press.

Keung, Nicholas. 2005. Immigrants Better Trained, Worse Off. The Toronto Star, February 1.

Keung, Nicholas. 2009. Ontario Accuses Ottawa of Waffling on Immigration funds. Toronto Star. July 9. http://www.thestar.com/news/ontario/article/663436

King, Karen. 2009. The Geography of Immigration in Canada: Settlement, Education, Labour Activity and Occupation Profiles. University of Toronto: Rotman School of Management. Working Paper Series: Ontario in the Creative Age. March 2009.

Kingsley, Jean Pierre, Chief Electoral Officer of Canada. 2002. Bringing Worlds Together. Paper presented at Metropolis Conference, March 22, in Ottawa, Ontario. 
http://www.elections.ca/content.asp?section $=$ med\&document $=$ mar $2202 \& \operatorname{dir}=$ spe $\& 1$ $\underline{\text { ang }=e \& \text { textonly }=\text { false }}$

Kniss, Fred and Paul Numrich, 2007. Sacred Assemblies and Civic Engagement: How Religion Matters for America's Newest Immigrants. New York: Rutgers University Press.

Kritz, Mary and June Marie Nogle. 1994. Nativity concentration and internal migration among the foreign-born. Demography. 31, 3: 509-524.

Kunz, Jean, Anne Milan, and Sylvain Schetagne. 2002. Unequal Access: A Canadian Profile of Racial Differences in Education, Employment and Income. Toronto: Canadian Race Relations Foundation.

Kunz, Jean. 2003. Social Capital: A Key Dimension of Immigrant Integration. Canadian Issues. April 2003.

Kunz, Jean and Stuart Sykes. 2007. From Mosaic to Harmony: Multicultural Canada in the $21^{\text {st }}$ Century: Results of Regional Roundtables. Policy Research Initiative. Ottawa.

Kymlicka, Will. 1995. Multicultural Citizenship a Liberal Theory of Minority Rights. Oxford: Clarendon Press.

Kymlicka, Will. 2001. Politics in the Vernacular: Nationalism, Multiculturalism, and Citizenship. Oxford : Oxford University Press.

Labelle, Micheline and Levy, Joseph. 1995. Ethnicite et Enjeux Sociaux: le Quebec vu par les leaders sociaux. Montreal, Liober. 
Laghi, Brian. 2008. Majority believes Canada coddles minorities: Poll reveals deeply divided attitudes toward immigration. The Globe and Mail. April 17, News Section.

Leca, Jean. 1992. Questions on Citizenship. In Dimensions of democracy, ed Mouffe. London: Verso.

Lehning, Percy. 1998. Towards a Multicultural Civil Society: The Role of Social Capital and Democratic Citizenship. Government and Opposition. Volume 33, Issue 2, Pages: 221-242.

Letki, Natalia. 2008. Does Diversity Erode Social Cohesion? Social Capital and Race in British Neighbourhoods, Political Studies, Vol 56, 99-126.

Ley, David and Judith Tutchener. 1999. Immigration and Metropolitan House Prices in Canada. Vancouver: Vancouver Centre of Excellence. Working paper No.99-09.

Li, Chris, Ginette Gervais and Aurélie Duval. 2006. The Dynamics of Overqualification: Canada's Underemployed University Graduates. Ottawa: Statistics Canada, Income Statistics Division. Catalogue no. 11-621-MIE - No. 039.

Li, Peter S. 2001.The market worth of immigrants' educational credentials. Canadian Public Policy 27, no. 1 (March): 23-38.

Li, Peter. 2003. Deconstructing Canada's discourse of immigrant integration. Journal of International Migration and Integration. Volume 4, Number 3, 315-333.

Li, Peter. 2003. Destination Canada: Immigration debates and issues. Oxford University Press. 
Lindsay, Colin. 2008. Canadians attend weekly religious services less than 20 years ago. The General Social Survey, Mater of Fact, No 3. Ottawa: Statistics Canada Catalogue no. 89-630-X.

Lister, R., Williams, F., Anttonen, A., Bussemaker, J., Gerhard, U., Heinen, J., Johansson, S., Leira, A. \& Siim, B. 2007. Gendering Citizenship in Western Europe. Bristol: Policy Press.

Lister, Ruth. 1997. Citizenship: Towards a Feminist Synthesis. Feminist Review. No 57. $28-48$.

Little Margaret and Lynne Marks. 2006. A Closer Look at the Neo-Liberal Petri Dish: Welfare Reform in British Columbia and Ontario. Canadian Review of Social Policy. Issue 57; 16-46.

Logan, John, Richard Alba and Wenquan Zhang. 2002. Immigrant enclaves and ethnic communities in New York and Los Angeles. American Sociological Review 67:299-322.

Lowndes, Vivien and David Wilson, 2001. Social Capital and Local Governance: Exploring the Institutional Design Variable, Political Studies, vol. 49, no. 4, 629647.

Manpower Inc. 2008. Talent Shortage Survey 2008 Global Results. http://www.manpower.com/research/research.cfm?chooseyear=2008\&categoryid=2

Marr, William L. and Pierre L. Siklos. 1994. The Link Between Immigration and Unemployment in Canada. Journal of Policy Modeling 16 (No. 1, 1994) pp. 1-25. 
Marshall, T.H. 1950. Citizenship and Social Class. In Citizenship and Social Class, editors T.H. Marshall and T. Bottomore. London: Pluto Press.

Marshall, Thomas. 1950. Citizenship and Social Class and Other Essays. Cambridge: Cambridge University Press.

Marshall, Thomas. 2006. Citizenship and Social Class. In The Welfare State Reader. Eds Pierson Christopher and Frnacis Castles. Cambridge: polity Press.

Martin, Susan. 2007. Women, Migration and Development. Washington: Institute for the $\begin{array}{llll}\text { Study } & \text { of } & \text { International }\end{array}$ $\underline{\text { http://isim.georgetown.edu/Publications/GMF\%20Materials/Martin.pdf }}$

Martiniello, Marco. 2003. The State, the Market and Cultural Diversity. Immigrants and Minorities. Vol.22, Nos.2\&3, July/November, 127-140.

Massey, Douglas. 1990. The Social and Economic Origins of Immigration. Annals, AAPSS, 510, July 1990.

McDonald, James. 2003. "Location choice of new immigrants to Canada: the role of ethnic networks." In Canadian Immigration Policy for the 21st Century. ed. Charles Beach, Alan Green, and Jeffery Reitz (eds.). Montréal: McGill-Queen's University Press. 163-195.

McLaughlin, Terry. 1992. Citizenship, Diversity and Education. Journal of Moral Education. 21/3: 235-50.

Meng, Ronald. 1987. The earnings of Canadian immigrant and native-born males. Applied Economics. 19: 1107-1119.

Miller, David. 1995. On Nationality. Oxford: Oxford University Press. 
Morissette, Rene, Xuelin Zhang and Marie Drolet. 2002. The Evolution of Wealth Inequality in Canada, 1984-1999. Working Paper Series, no. 187. Ottawa: Statistics Canada, Catalogue no. 11F0019 No. 187.

Moya, Jose, 2005. Immigrants and Associations: A Global and Historical Perspective., Journal of Ethnic and Migration Studies, vol. 31, no. 5, pp. 833-864.

Myrdal, Gunnar. 1944. An American Dilemma: The Negro Problem and Modern Democracy. New York: Harper and Row.

Myrdal, Gunnar. 1957. Economic Theory and Underdeveloped Regions, London: Gerald Duckworth.

Nakhaie, Reza. 2007. Ethnoracial Origins, Social Capital, and Earnings. Journal of International Migration and Integration, vol. 8, no. 3, pp. 307-325.

Newbold, Bruce. 1999. Spatial distribution and redistribution of immigrants in the metropolitan United States, 1980 and 1990. Economic Geography. 75, 3: 254-271.

Newland, Kathleen, Hiroyuki Tanak and Laura Barker, 2007. Bridging Divides: The role of Ethnic Community-Based Organizations in Refugee Integration. Migration Policy Institute and International Rescue Committee. 72 pp. www.theirc.org/resources/Bridging-Divides.pdf

Newton, K. And J. Delhey, 2005. Predicting Cross-national Levels of Social Trust: Global Pattern or Nordic Exceptionalism? European Sociological Rreview, 21. 311327.

Nussbaum, Martha. 1997. Cultivating Humanity. Cambridge, MA: Harvard University Press. 
Nussbaum, Martha. 2002. Patriotism and Cosmopolitanism. In For Love of Country, ed Nussbaum, M., pp. 1-17. Boston, MA: Beacon.

O'Hara, Kathy. 1998. Securing the Social Union. Ottawa: CPRN 02.

Oliver Eric and Janelle Wong. 2003. Intergroup prejudice in multiethnic settings. American Journal of Political Science, Vol. 47, No. 4, 567-582.

Ontario Council of Agencies Serving Immigrants (OCASI). 2009. Canada - Ontario Immigration Agreement (COIA): Crafting the Vision for the Sector. OCASI Discussion Paper. http://www.ocasi.org/index.php?qid=1005)

Ontario Legislative Assembly. 1995. Official Reports of Debates (Hansard), 1st Session, 36th Legislature. September 28.

Oreopoulos Philip. 2009. Why Do Skilled Immigrants Struggle in the Labour Market? A Field Experiment with Six Thousand Résumés. Metropolis British Columbia. Working Paper Series. No. 09 -03.

Organisation for Economic Co-operation and Development. 2007. International Migration Outlook. Sopemi 2007 Edition. Paris: OECD.

Organisation for Economic Co-operation and Development. 2007. The Unemployment Impact of Immigration in OECD Countries. Paris: OECD Economics Department, Working paper No. 563.

Orwin, Clifford. 2009. Canadian values boil down to liberal democracy. The Globe and Mail, May 9, Articles.

Palameta, Boris. 2004. Low income among immigrants and visible minorities. Perspectives. Statistics Canada: Catalogue no. 75-001-XIE. April 2004. 
Pammett, Jon and Lawrence LeDuc. 2003. Explaining the Turnout Decline in Canadian Federal Elections: A New Survey of Non-voters. Ottawa: Elections Canada. (Cross tabulation using provided http://www.elections.ca/content.asp?section=loi\&document=index\&dir=tur/tud\&la $\mathrm{ng}=\mathrm{e} \&$ textonly $=$ false

Papademetriou, Demetrious. 1988. “International Migration in North America and Western Europe: Trends and Consequences". In International Migration Today, Vol. 1, Trends and Prospects, 311-380. ed. Reginald Appleyard. Paris: UNESCO.

Parliament of Canada, Parliamentary Research Branch. 2006. Canadian Multiculturalism. Current Issue Review. 93-6E. Revised 16 March.

Parliament of Canada, Standing Committee on Canadian Heritage. 2004. Evidence. CHPC, Number 006, 1st Session, 38th Parliament. November 22.

Parliament of Canada, Standing Committee on Citizenship and Immigration. 2006. Evidence Contents. 39th Parliament, 1st Session: Tuesday, September 2006. http://www2.parl.gc.ca/HousePublications/Publication.aspx?DocId=2354547\&Lan guage $=$ E $\&$ Mode $=1 \&$ Parl $=39 \&$ Ses $=1$

Pateman, Carol. 1988. The Sexual Contract. Cambridge: Polity Press.

Paxton, Pamela. 1999. Is Social Capital Declining in the United States? A MultipleIndicator Assessment. American Journal of Sociology. 105, 88-127. 
Pendakur, Krishna and Ravi Pendakur. 2002. Language as both human capital and ethnicity. International Migration Review. Volume 36 Number 1 (Spring 2002):147-177.

Per Marchildon, Gregory, 1995. Fin de Siècle Canada: The Federal Government in Retreat, in Disintegration or Transformation, The crisis of the State in advanced industrial societies. Editors Patrick McCarthy and Erik Jones, Palgrave Macmillan.

Pettigrew, Thomas F. and Linda R. Tropp. 2006. A Meta-Analytic Test of Intergroup Contact Theory. Journal of Personality and Social Psychology, 2006, Vol. 90, No. $5,751-783$.

Picot Garnett and Arthur Sweetman. 2005. The Deteriorating Economic Welfare of Immigrants and Possible Causes: Update 2005. Ottawa: Statistics Canada. Business and Labour Market Analysis Division. Catalogue no: 11F0019MIE No. 262.

Picot, Garnette, Feng Hou and Simon Coulombe. 2007. Chronic Low Income and Lowincome Dynamics among Recent Immigrants. Ottawa: Statistics Canada, Business and Labour Market Analysis Division. Catalogue no. 11F0019MIE - No. 294.

Pikkov, Deanna. 2006. Political Integration of Immigrants in North America: Integrating Qualitative and Quantitative Research. Paper presented at the annual meeting of the American Sociological Association, Montreal, Canada, Aug 10, 2006

Polanyi, Karl. 1957. The Great Transformation. Boston: Beacon Hill.

Portes, A., 1998. Social capital: its origins and applications in modern sociology. Annual Review of Sociology, 24: 1-24. 
Power, Sally and S. Gewirtz. 2001. Reading Education Action Zones. Journal of Education Policy. 16,1:

Putnam, Robert. 1993. Making Democracy Work: Civic Traditions in Modern Italy. Princeton, NJ: Princeton University Press.

Putnam, Robert. 1995. Bowling Alone: America's Declining Social Capital. Journal of Democracy, 6:1, 65-78.

Putnam, Robert, 1995. Turning in, Turning Out: the strange disappearance of social capital in America. Political Science and Politics, Vol. 28, No. 4.

Putnam, Robert, 2000. Bowling Alone: The Collapse and Revival of American Community. New York: Simon \& Schuster. 384 pp.

Putnam, Robert, 2007. E Pluribus Unum: Diversity and Community in the Twenty-first Century The 2006 Johan Skytte Prize Lecture. Scandinavian Political Studies, Vol. 30, No. 2 .

Rawls, John. 1985. Justice as Fairness: Political not Metaphysical. Philosophy and Public Affairs, Vol. 14, No. 3, pp. 223-251

Rawls, John. 1993. Political Liberalism. New York: Columbia University Press.

Raz, Joseph . 1990. Facing diversity: the case of epistemic abstinence. Philosophy and Public Affairs, Vol. 19, No. 1. 3-46.

Raz, Joseph. 1994. Ethics in Public Domain: Essays in the Morality of law and Politics. London: Oxford University Press. 
Reitz, Jeffrey and Raymond Breton. 1994. The Illusion of Difference: Realities of Ethnicity in Canada and the United States. Toronto: C.D. Howe Institute.

Reitz, Jeffrey and Rupa Banerjee. 2007. Racial Inequality, Social Cohesion and Policy Issues in Canada. In Belonging? Diversity, Recognition and Shared Citizenship in Canada. Eds Keith Banting, Thomas Courchene and F. Leslie Seidle. 489-545. Montreal: Institute for Research on Public Policy.

Reva Joshee and Tracey Fanning. 2005. The Unmaking of Citizenship Education for Adult Immigrants in Canada. Journal of International Migration and Integration. Vol. 6, Number 1. P 61-80.

Riesman, David, Nathan Glazer, Reuel Denny. 2001. The Lonely Crowd: A Study of the Changing American Character. Yale University Press.

Roberts, Lance, Rodney Clifton and Barry Ferguson. 2005. Recent Social Trends in Canada, 1960-2000. Montreal: McGill-Queen's University Press.

Rosanvallon, Pierre. 2000. The New Social Question. Princeton, NJ: Princeton University Press

Rosenblum, Nancy. 1998. Membership and Morals: The Personal Use of Pluralism in America. Princeton, N.J.: Princeton University Press.

Ruiter, Stijn; de Graaf, Nan Dirk. 2006. National Context, Religiosity, and Volunteering: results from 53 Countries. American Sociological Review, 71: 191-210

Sabbatier, Colette \& John Berry. 1994. Immigration et acculturation. In Stéréotypes, discrimination et relations intergroupes, Eds Richard Bourhis \& J. P. Leyens, 261291. Liège: Mardaga. 
Sassen, Saskia. 1996. Losing Control: Sovereignty in an Age of Globalization. New York. Columbia University Press.

Schellenberg, Grant and Yuri Ostrovsky. 2008. The Retirement Plans and Expectations of Older Workers. Canadian Social Trends. Statistics Canada - Catalogue no. 11008. September 9,2008

Seligman, Adam, 1992. The Idea of Civil Society. Toronto: Maxwell Macmillan Canada.

Shamsuddin, Abul F. M. and Don J. DeVoretz. 1997. Wealth Accumulation of Canadian and Foreign-Born Households in Canada. Vancouver Centre of Excellence for Research on Immigration and Integration in the Metropolis (RIIM) Working Paper Series, No. 97-03.

Shields, John. 2004. No Safe Haven: Markets, Welfare and Migrants. In Immigrants, Welfare Reform and the Poverty of Policy, eds Philip Kretsendemas and Ana Aparacio. 35-60. New York: Praeger.

Siim, Birte. 2000. Gender and Citizenship, Cambridge: Cambridge University Press.

Simard, Carolle. 2000. Ethnic Minority Political Representation in Montreal. Paper presented at the Fourth National Metropolis Conference, March 2000, in Toronto, Ontario.

Simich, L. 2000. Towards a Greater Toronto Charter: Implications for Immigrant Settlement. Toronto: Maytree Foundation.

Simmons, A.B., and K. Keohane.1992. Canadian immigration policy: state strategies and the quest for legitimacy. Canadian Review of Sociology and Anthropology, Vol. 29, No. 4, pp. 421-452. 
Simon, Rita and Keri W. Sikich. 2007. Public Attitudes toward Immigrants and Immigration Policies across Seven Nations. International Migration Review. Volume 41 Number 4: 956-962.

Skocpol, Theda, Rachael V. Cobb, Casey Andrew Klofstad, 2005. Disconnection and Reorganization: The Transformation of Civic Life in Late-Twentieth-Century America. Studies in American Political Development, 19, 137-156.

Soroka, Stuart, Richard Johnston and Keith Banting. 2002. Ethnicity, Trust, and the Welfare State. Paper presented at the conference on Social Cohesion and the Policy Agenda: Canada in International Perspective". at Queen's University, Kingston, Ontario, August 19th-21st 2002.

Soroka, Stuart, Keith Banting, and Richard Johnston. 2006. Immigration and Redistribution in the Global Era. In Globalization and Social Redistribution, edited by Michael Wallerstein, Pranab Bardhan, and Samuel Bowles. Princeton and New York: Princeton University Press, Russell Sage Foundation.

Soroka, Stuart; Richard Johnston \& Keith Banting. 2007. Ties That Bind? Social Cohesion and Diversity in Canada in Belonging? In Diversity, Recognition and Shared Citizenship in Canada Edited by Keith Banting, Thomas J. Courchene and F. Leslie Seidle. Montréal : Institute for Research on Public Policy. 561-600.

Soysal, Yasemin. 1994. Limits of Citizenship: migrants and post-national membership in Europe. Chicago : University of Chicago Press. 
Speech of Louis Gareau at the launch of Les rendez-vous de la Francophonie 2005 in the Public Service of Canada. French Presence in Western Canada. http://www.psagency-agencefp.gc.ca/ollo/even/Franco2005/lg_e.asp

Statistics Canada 2000. Societal Indicators 2000: Social participation and inclusion. Ottawa: Statistics Canada. http://www.statcan.gc.ca/pub/89f0123x/00002/4064624$\underline{\text { eng.htm }}$

Statistics Canada. 2003a. Ethnic Diversity Survey: portrait of a multicultural society. Ottawa: Statistics Canada, Housing, Family and Social Statistics Division. Catalogue no. 89-593-XIE

Statistics Canada. 2003b. Longitudinal Survey of Immigrants to Canada: Process, progress and prospects. Ottawa: Statistics Canada, Catalogue no 89-611-XIE.

Statistics Canada: 2003c. Canada's ethnocultural portrait: The changing mosaic. 2001 Census: analysis series. Ottawa: Statistics Canada, Catalogue no 96F0030XIE2001008.

Statistics Canada. 2003d. 2001 Census Analysis Series: Religions in Canada. Ottawa: Statistics Canada, Catalogue no. 96F0030XIE2001015. 
Statistics Canada. 2003e. Visible Minority Groups and Immigrant Status and Period of Immigration for Population, for Canada, Provinces, Territories, Census Metropolitan Areas and Census Agglomerations, 2001 Census - 20\% Sample Data. Catalogue No. 97F0010XCB2001003. http://www.statcan.gc.ca/bsolc/olc-cel/olccel?lang=eng\&catno $=97 \mathrm{~F} 0010 \times 2001003$.

Statistics Canada. 2003f. Education in Canada: Raising the Standard, 2001 Census. Ottawa: Statistics Canada. Catalogue no 96F0030XIE. http://www12.statcan.gc.ca/english/census01/products/analytic/companion/educ/ca nada.cfm

Statistics Canada. 2003g. Canada's Ethno-cultural Portrait: The Changing Mosaic, 2001 Census. Ottawa: Statistics Canada, Catalogue no. 96F0030XIE2001008.

Statistics Canada. 2004a. Immigrants in Canada's Census Metropolitan Areas. Ottawa: Statistics Canada, Business and Labour Market Analysis Division. Catalogue No. 89-613-MIE, No. 003

Statistics Canada. 2004b. 2003 General Social Survey on Social Engagement, cycle 17: an overview of findings. Ottawa: Catalogue no. 89-598-XIE.

Statistics Canada. 2004c. Immigrant Source Country Educational Quality and Canadian Labour Market Outcomes. Ottawa: Statistics Canada, Catalogue no. 11F0019MIE - No. 234

Statistics Canada. 2004d. Recent immigration and the formation of visible minority neighbourhoods in Canada's large cities. Ottawa: Statistics Canada, Catalogue no. 11F0019MIE - No. 221 
Statistics Canada. 2005a Your Community, Your Health: Findings from the Canadian Community Health Survey (CCHS). Catalogue No: 82-621XWE2005001.

Statistics Canada. 2005b. Longitudinal Survey of Immigrants to Canada: Progress and Challenges of New Immigrants in the Workforce 2003. Ottawa: Statistics Canada, Catalogue no. 89-615-XIE

Statistics Canada. 2005c. Population Projections for Canada, Provinces and Territories 2005-2031. Ottawa: Statistics Canada, Catalogue no. 91-520-XIE.

Statistics Canada. 2005d. Longitudinal Survey of Immigrants to Canada: A Portrait of Early Settlement. Ottawa: Statistics Canada, Catalogue no. 89-614-XIE.

Statistics Canada. 2005e. Knowledge of Official Languages Among New Immigrants: How Important Is It in the Labour Market? Ottawa: Statistics Canada, Catalogue no. 89-624-XIE

Statistics Canada. 2006a. Fertility among visible minority women. Daily. June 30, 2006. http://www.statcan.gc.ca/daily-quotidien/060630/dq060630b-eng.htm

Statistics Canada. 2006b. Return and Onward Migration among Working Age Ottawa: Statistics Canada, Catalogue no. 11F0019MIE - No. 273

Statistics Canada. 2007a. 2006 Census: Immigration, Citizenship, Language, Mobility and Migration. Daily. December 4.

Statistics Canada. 2007b. Impact of immigration on labour markets in Canada, Mexico and the United States. Daily. May 25. 
Statistics Canada. 2007c. The Canadian Immigrant Labour Market in 2006: First Results from Canada's Labour Force Survey. Ottawa: Statistics Canada, Catalogue no. 71606-XIE

Statistics Canada. 2007d. Canada's immigrant labour market, 2006. Daily. September 10, 2007.

Statistics Canada. 2008a. 2006 Census: Ethnic origin, visible minorities, place of work and mode of transportation. Daily. April 2, 2008.

Statistics Canada. 2008b. The Canadian Immigrant Labour Market in 2007: Analysis by Region of Postsecondary Education. Ottawa: Statistics Canada, Catalogue no. 71$606-\mathrm{X}$

Statistics Canada. 2008c. Immigrants' education and required job skills. Daily. December 22,2008

Statistics Canada. 2008d. Canada's Changing Labour Force, 2006 Census. Ottawa: Statistics Canada. Catalogue no. 97-559-X.

Statistics Canada. 2009. Caring Canadians, Involved Canadians: Highlights from the 2007 Canada Survey of Giving, Volunteering and Participating. Ottawa: Statistics Canada, Catalogue no. 71-542-XPE

Stein, Janice. 2003. "The Global Context of Immigration". In Canadian Immigration Policy for the 21st Century, ed. Charles Beach, Alan Green and Jeffrey Reitz, 2733. McGill-Queen's University Press. 
Svendsen, G.L. and Svendsen, G.T. 2004. The Creation and Destruction of Social Capital: Entrepreneurship, Co-operative Movements and Institutions. Cheltenham: Edward Elgar.

Tarrow, Sidney. 2005. The New Transnational Activism. Cambridge, UK: Cambridge University Press.

Taylor Charles. 1985. Philosophy and the Human Sciences: Philosophical Papers 2. Cambridge: Cambridge University Press.

Taylor, Charles. 1992. The Ethics of Authenticity. Cambridge: Harvard University Press.

Taylor, Charles. 1993. Reconciling the Solitudes. Montreal and Kingston: McGillQueen's University Press.

Taylor, Charles. 1997. Nationalism and Modernity. In The Morality of Nationalism. Eds McMahan, and McKim. New York: Oxford University Press.

Taylor, David. 1989. Citizenship and social policy. Critical Social Policy No. 26: 19-31.

Teelucksingh, Cheryl, and Grace- Edward Galabuzi. 2005. Working Precariously: The Impact of Race and Immigrant Status on Employment Opportunities and Outcome in Canada. The Canadian Race Relations Foundation, May, pp. 1-38. http://www.amillionreasons.ca/WorkingPrecariously.pdf

Telford, Hamish and Harvey Lazar. 2002. Canada: The State of Federation 2001. Canadian Political Culture(s) in Transition. Montreal and Kingston, McGill Queen's University Press.

Than Ha, tu. 2007. Quebec town defends conduct code for minorities. The Globe and Mail, October 25 
Thomas, Derrick. 2009a. Immigrants in Canada who work in a language other than English or French. Canadian Social Trends. January 20, 2009.

Thomas, Derrick. 2009b. The impact of working in a non-official language on the occupations and earnings of immigrants in Canada. Canadian Social Trends. January 20, 2009.

Thomson, Irene taviss. 2005. The Theory That Won't Die: From Mass Society to the Decline of Social Capital. Sociological Forum, Vol. 20, No. 3, 421-448.

Torfing, J. 1999. Towards a Schumpeterian workfare post-national regime: Path-shaping and path-dependency in Danish welfare state reform. Economy and Society 28(3): $369-402$.

Tossutti, Livianna S. and Tom P. Najem. 2002. Minority Representation in the Fourth Party System: macro and micro constraints and opportunities. Canadian Ethnic Studies/études ethniques au Canada 34(1): 85-111.

Tossutti, Livianna, 2003. Does Volunteerism Increase the Political Engagement of Young Newcomers? Assessing the Potential of Individual and Group-Based Forms of Unpaid Service. Canadian Ethnic Studies/Etudes Ethniques au Canada, vol. 35, no. $3,70-84$.

Tran, Kelly, Jennifer Kaddatz and Paul Allard. 2005. South Asians in Canada: Unity through diversity. Canadian Social Trends. Autumn 2005 Statistics Canada Catalogue No. 11-008.

Trice, Harrison M. 1993. Occupational Subcultures in the Workplace. Ithaca: ILR Press. 
Turcotte, Martin. 2007. Time Spent with Family During a Typical Workday, 1986 to 2005. Canadian Social Trends. No. 83. Statistics Catalogue no. 11-008 XIE.

Turner, Bryan. 1986. Citizenship and Capitalism. The debate over reformism. London: Allen \& Unwin.

Turner, Bryan. 1993. Contemporary problems in the theory of citizenship', In Turner, Bryan. (ed.) Citizenship and Social Theory, London: Sage, pp.1-18

Turner, Bryan. 1997. Citizenship Studies: a general theory. Citizenship Studies, Vol. 1, No.1.

UN Population Division. 2005. Trends in Total Migrant Stock: The 2005 Revision. New York: UN Population Division.

United Nations High Commissioner for Refugees. 1999. UNHCR Global Appeal 1999 Refugee Women. Geneva. Available at http://www.unhcr.org/publ/PUBL/3eaff442e.html

United Nations Population Division. 2000. Replacement Migration: Is It a Solution to Declining and Ageing Populations?. United Nations Department of Economics and Social Affairs Population Division, http://www.un.org/esa/population/publications/migration/migration.htm

Uslaner, Eric and Richard Conley, 2003. Civic Engagement and Particularized Trust: the ties that bind people to their ethnic communities. American Politics Research; 31; 331. 
Verba, Sidney, Kay Lehman Schlozman and Henry E. Brady. 1995. Voice and Equality: Civic Voluntarism in American Politics. Cambridge, Massachusetts: Harvard University Press.

Veugelers, John. 2000. State-Society Relations in the Making of Canadian Immigration Policy during the Mulroney Era. Canadian Review of Sociology and Anthropology; Volume 37, Number 1, pp. 95-110.

Vivekanandan B, 2002. Welfare State System in Canada: Emerging Challenges. International Studies. 39, 1. 45-63.

Walby, Sylvia. 1994. Is citizenship gendered? Sociology. Vol. 28, No 2. 379-395.

Warner Parker, A. 1924. The Quota Provisions of the Immigration Act of 1924. American Journal of International Law 18(4): 737-54.

Warren, Mark. 1992. Democratic Theory and Self-Transformation. American Political Science Review 86: 8-23

Werbner \& Yuval-Davis. 1999. Introduction: women and the new discourse of citizenship. In Women, Citizenship and Difference. Eds Werbner, P. and N. YuvalDavis. London and New York: Zed Books.

Wilkes, Rima, Neil Guppy and Lily Farris. 2008. "No Thanks, We're Full”: Individual Characteristics, National Context, and Changing Attitudes Toward Immigration. International Migration Review. Volume 42 Number 2. 302-329.

Woolcock, M. 2003. Diversity as Opportunity and Challenge: The Role of Social Capital Theory, Evidence and Policy. Paper presented to the Policy Research Initiative Conference, November 24-25, in Montréal. 
Woolcock, M. and Narayan, D. 2000. Social Capital: Implications for Development Theory, Research, and Policy, World Bank Research Observer 15(2): 225-49.

World Bank. 2009. Trade Protection: Incipient but Worrisome Trends. Trade Notes. March 2, 2009. Number 37.

Zhou, M. and C. Bankston, 1994. Social capital and the adaptation of the second generation: the case of Vietnamese youth in New Orleans. International Migration Review, 28(4): 821_45.

Zietsma, Danielle. 2007. The Canadian Immigrant Labour Market in 2006: First Results from Canada's Labour Force Survey. Statistics Canada: Catalogue no. 71-606XIE2007001. 